\title{
Advanced Nanofibrous Scaffolds to Influence Endothelial Cell Activity
}

Citation for published version (APA):

Yao, T. (2020). Advanced Nanofibrous Scaffolds to Influence Endothelial Cell Activity: Towards Improved Strategies for Vascularized Tissue Regeneration. [Doctoral Thesis, Maastricht University]. Maastricht University. https://doi.org/10.26481/dis.20200508ty

Document status and date:

Published: 01/01/2020

DOI:

10.26481/dis.20200508ty

Document Version:

Publisher's PDF, also known as Version of record

\section{Please check the document version of this publication:}

- A submitted manuscript is the version of the article upon submission and before peer-review. There can be important differences between the submitted version and the official published version of record.

People interested in the research are advised to contact the author for the final version of the publication, or visit the DOI to the publisher's website.

- The final author version and the galley proof are versions of the publication after peer review.

- The final published version features the final layout of the paper including the volume, issue and page numbers.

Link to publication

\footnotetext{
General rights rights.

- You may freely distribute the URL identifying the publication in the public portal. please follow below link for the End User Agreement:

www.umlib.nl/taverne-license

Take down policy

If you believe that this document breaches copyright please contact us at:

repository@maastrichtuniversity.nl

providing details and we will investigate your claim.
}

Copyright and moral rights for the publications made accessible in the public portal are retained by the authors and/or other copyright owners and it is a condition of accessing publications that users recognise and abide by the legal requirements associated with these

- Users may download and print one copy of any publication from the public portal for the purpose of private study or research.

- You may not further distribute the material or use it for any profit-making activity or commercial gain

If the publication is distributed under the terms of Article $25 \mathrm{fa}$ of the Dutch Copyright Act, indicated by the "Taverne" license above, 
Advanced Nanofibrous Scaffolds to Influence
Endothelial Cell Activity: Towards Improved
Strategies for Vascularized Tissue Regeneration

Tianyu Yao 
Copyright 2020 ( ) Tianyu Yao, Maastricht

Advanced Nanofibrous Scaffolds to Influence Endothelial Cell Activity: Towards Improved Strategies for Vascularized Tissue Regeneration

PhD Thesis, Maastricht University, Maastricht, the Netherlands

ISBN: 978-94-6402-235-3

Cover design: Tianyu Yao

Printed by: Gildeprint, Enschede

All rights are reserved. For articles published, the copyright has been transferred to the respective publisher. No parts of this thesis may be reproduced, stored in a retrieval system or transmitted in any form or by any means, without prior permission from the author 


\title{
Advanced Nanofibrous Scaffolds to Influence Endothelial Cell Activity: Towards Improved Strategies for Vascularized Tissue Regeneration
}

\author{
DISSERTATION
}

To obtain the degree of Doctor at the Maastricht University, on the authority of the Rector Magnificus,

Prof.dr. Rianne M. Letschert

in accordance with the decision of the Board of Deans, to be defended in public on Friday, $8^{\text {th }}$ of May 2020 at $14: 00$

by 


\section{Supervisor:}

Prof. dr. L. Moroni

\section{Co-supervisor:}

Dr. Matthew B. Baker

\section{Assessment Committee:}

Prof. dr. T. M. Hackeng(Chairman)

Prof. dr. M. Post

Prof. dr. L. Schurgers

Prof. dr. C. V. C. Bouten (Eindhoven University of Technology)

Dr. F. Yang (Radboud University)

The research described in this thesis was conducted at MERLN Institute for Technology-Inspired Regenerative Medicine in Maastricht University. The work in this thesis was financially supported by the Dutch Province of Limburg and China Scholarship Council ((CSC, File No. 201508610081)). 


\section{Contents}

Chapter 1 General Introduction and Aims

Chapter 2 Effects of Fiber Alignment and Coculture with 45 Endothelial Cells on Osteogenic Differentiation of Mesenchymal Stromal Cells

Chapter 3 Self-assembly of Electrospun Nanofibers into Gradient Honeycomb structures

73

Chapter 4 Fabrication of a Self-assembled Honeycomb Nanofibrous Scaffold to Guide Endothelial Morphogenesis

95

Chapter 5 Electrospun Fibrous Scaffolds Functionalized with Hydrogen Sulfide Donor Stimulate Angiogenesis

123

Chapter 6 Thiol-ene Click Conjugation of VEGF Peptide to 153 Electrospun Scaffolds as Potential Application for Angiogenesis

Chapter 7 General Discussion

Valorisation

Summary

203

Acknowledgements 207

Scientific output

Curriculum vitae 



\section{Chapter 1}

General Introduction and Aims 


\section{Abstract}

There is an expanding interest for the fabrication of biomimetic scaffolds for tissue engineering. Nanofibrous scaffolds can mimic the mechanical and structural properties of the natural extracellular matrix (ECM), and have shown high potential in tissue engineering and regenerative medicine. Electrospinning is a popular, effective and controllable technique for the production of scaffolds in nano/micro scale. This review presents a general overview on nanofiber fabrication, with a specific focus on the design and application of nanofibrous scaffolds for vascular regeneration. The main nanofiber fabrication approaches, including self-assembly, thermally induced phase separation and electrospinning are described. We also address nanofibrous scaffolds design, including nanofiber structure design and surface functionalization, to improve scaffolds properties, with a particular focus on electrospun scaffolds as these have found more and more applications in tissue engineering and regenerative medicine. Scaffolds for vascular regeneration with enhanced functional properties by providing cells with structural cues or bioactive components are discussed. In vivo evaluation with these nanofibrous scaffolds is highly required before their potential application in clinical vascular tissue engineering can be further assessed.

Keywords: nanofibers; scaffolds; vascularization 


\section{Introduction}

Tissue engineering, which combines the principles and methods of the life sciences with those of engineering to create tissue replacements to direct tissue regeneration, has attracted the interest of many researchers with the hope to regenerate patient's own tissues and organs without tissue/organ transplantation [1, 2]. The most classical tissue engineering approach consists of cell seeding on a scaffold, followed by cell proliferation, eventually differentiation if the starting cells are stem cells, and tissue growth (through extracellular matrix synthesis by the cells) in an orderly manner. The resulting biological construct is typically matured in vitro to become a functional new tissue that can be implanted back in the host environment [3]. The field of regenerative medicine has achieved many progress in the past decade (Figure 1) [4]. A few examples comprise: 1) the generation of induced pluripotent stem (iPS) cells from adult somatic cells, which showed the possibility for personalized regenerative medicine [5-7]; 2) the development of scaffolds with tailored stiffness and topography that could regulate stem cell differentiation, providing an approach to control cell phenotype using physical and mechanical cues [8-10]; 3) a more fundamental understanding of the role of immune cells in presence of a regenerative medicine treatment (e.g. at the interface with biomaterials, or triggered by cell therapy application) [11-13]. Some successful products to aid in tissue regeneration are already available in the clinic, such as poly(vinyl alcohol) sheets developed for vessel coverage during anterior vertebral surgery [14], collagen sponges with $\beta$-tricalcium phosphate ( $\beta$-TCP) commonly used as void fillers for bone regeneration [15], and the use of limbal stem cells for cornea injury repair [16]. However, there are still challenges that discourage the clinical use of tissue engineering approaches at a larger scale than what is happening today. Several important aspects should be considered to reach successful regeneration, such as, (i) scaffolds with desired mechanical, chemical and biological properties that better mimic the native microenvironment of a targeted tissue and by doing so 
can better support cell activity; (ii) maintenance and regulation of growth factors to steer cellular behavior; and (iii) large vascular networks that can easily integrate the engineered tissues into the host system for fully functional regeneration $[17,18]$.

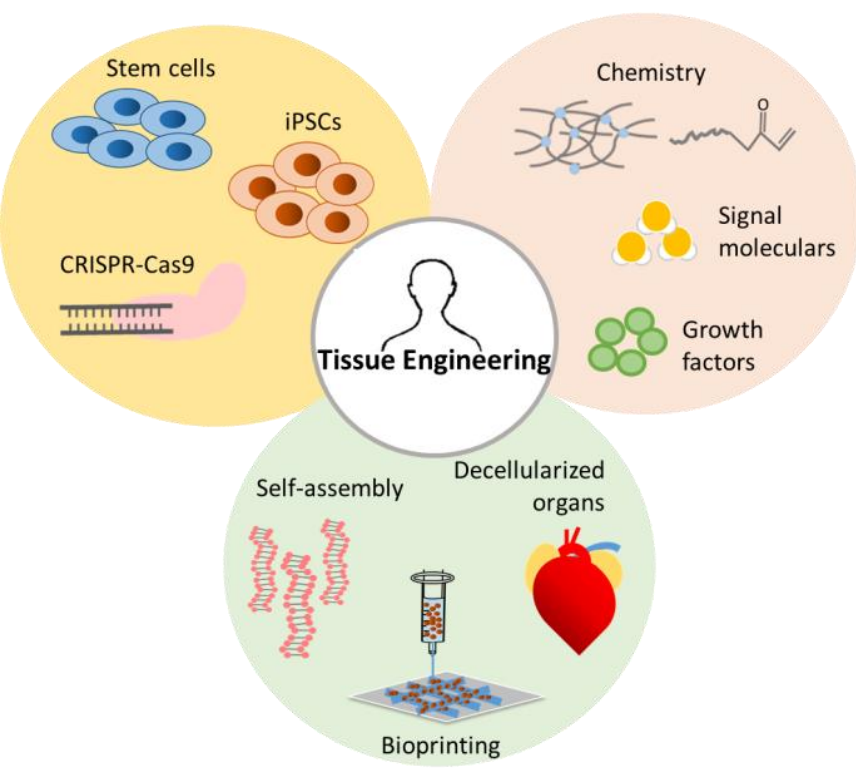

Figure 1: Summary of tissue engineering progress.

Tissue engineering approaches typically start with scaffold design. An engineered scaffold should provide favorable biochemical (e.g. surface chemistry [19]) and biophysical cues (e.g. fibrous structure [20], hydrophilicity [21] and stiffness [22]) to mimic the native extracellular matrix (ECM) for cells. Biochemical and biophysical properties from ECM are important to support cell growth and affect cell functions [23]. For example, scaffolds mimicking key features of the ECM can regulate cell behavior including attachment, migration, proliferation and differentiation in tissue regeneration [24-26]. The creation of scaffolds that can better mimic the native ECM and provide native structures have become a common goal for tissue engineering [27]. In native tissues, the 
diameter of structural ECM proteins is smaller than the cells, approximately 50-500 nm [28]. ECM normally affords structural support and biological factors to guide cell maturation and integration to form tissues [29-31]. To mimic the nanofibrous structure of ECM, three fabrication techniques have been widely investigated: molecular self-assembly [32-35], phase separation $[36,37]$, and electrospinning [38-40]. These three methods are briefly introduced in the following section.

\section{Nanofibrous fabrication techniques \\ Self-assembly}

Self-assembly is a method by which simple molecular and macromolecular building blocks are engineered to organize themselves into nanofibers through non-covalent forces such as hydrogen bonding, hydrophobic forces, and electrostatic interactions $[41,42]$. The molecules and the intermolecular forces are critical for the self-assembly of nanofibous scaffolds. Self-assembly of biomolecules to form nanostructures is widely used in natural systems, as can be seen in many of the superstructures of the cell or the ECM [43]. Likewise synthetically created self-assembling systems and materials are widely used in tissue engineering for a variety of functions [44-46]. A well-established approach to creating molecularly self-assembled biomaterials is to engineer amphiphilic peptide sequences [47-49]. The self-assembly of these peptide amphiphiles are controlled by both hydrophobic interactions and hydrogen bonding[50]. These peptide amphiphiles (PA) consists of a hydrophobic tail group and a hydrophilic head group (Figure 2) [51, 52]. During the selfassembly process, the hydrophobic tail of PA will be driven away from water and towards each other, and smaller nanofibers around 5-25 nm can be successfully archived based on the peptide design [53]. Peptide amphiphiles remain one of the most prolific platforms for molecularly self-assembled fibrous scaffolds and have found success in applications ranging from spinal cord regeneration to vascularization $[54,55]$. 
Moreover, supramolecular nanofibers can also be created by other selfassembling motifs. Early examples of supramolecular polymers to form nanofibers are Ureido-Pyrimidone (Upy). Sijbesma and coworkers prepared the self-assembled UPy nanofibers through self-complementary four hydrogen bonding between self-complimentary Upy moieties [56]. The fibrous Upy based materials have been widely used for drug delivery and tissue engineering [57, 58], with early success in regenerative heart valves [58]. Other examples of nanofibrous self-assembling materials include bsenzene1,3,5-Tricarboxamide (BTA) [59,60], polyelectrolytes [61], and squaramide derivatives [62], to name a few. The nanofibers produced by molecular selfassembly usually are much smaller than those produced by electrospinning, clearly due to the molecular design character of self-assembly [32]. While fascinating helical nanofibers can be particularly well-formed by the selfassembly method, full and rational control of the self-assembling of peptides or supramolecular polymers at the nanoscale is still a challenge. For example, it is hard to control nanofibers assembling in a direct way (e.g. guiding nanofibers deposition like electrospinning). Another challenge is the scaling of self-assembled nanofibers in comparison to polymer processing techniques. The study to investigate how to control and produce self-assembled scaffolds at large scales will be beneficial for the further application of this technique in tissue engineering [63].
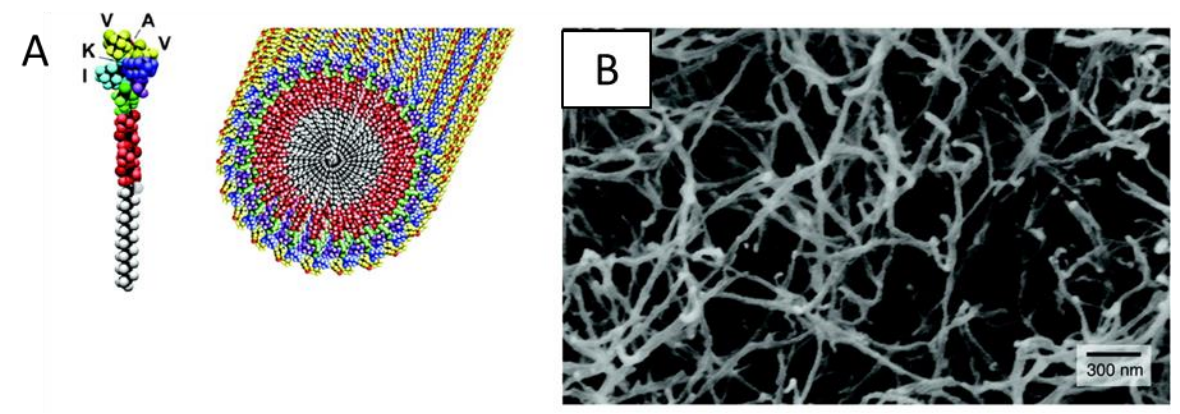

Figure 2. (A) Molecular model of a peptide amphiphiles (IKVAV) and (B) SEM images of a selfassembling peptide-amphiphile nanofiber network. Reproduced with permission from [64]. Copyright 2004, AAAS. 


\section{Thermally Induced Phase separation}

Thermally Induced Phase Separation (TIPS) has been used to produce threedimensional (3D) porous scaffolds from many years ago. Nanofibrous materials have also been achieved by this technique [37]. When phase separation occurs, two different phases, a polymer-rich phase and a polymerpoor phase are divided in polymer mixtures. The polymer-rich phase dries during solvent evaporation and then forms $3 \mathrm{D}$ porous structures at a certain concentration. If polymer concentration is too low, polymer beads will be formed after phase separation. High concentration will only lead to form small pores without interconnection in polymer scaffolds. Hence, the polymer concentration for a specific polymer-solvent system, with which TIPS is performed, is an important parameter to be optimized. This process involves four steps: (a) dissolution of a polymer in a targeted solvent to form a homogeneous polymer solution, (b) separation of two phases, (c) solvent evaporation and polymer solidification, and (d) freeze-drying of the final product (Figure. 3) $[65,66]$. One of the advantages of TIPS is that adjusting temperature and polymer concentration could change the pore size and fiber diameter of scaffolds [67]. Ma and his team have fabricated poly (I-lactic acid) (PLLA) nanofibrous matrix by using TIPS with a low polymer concentration from $1 \%$ to $7.5 \%$ in Tetrahydrofuran [37]. The diameter of PLLA nanofibers are $50-500 \mathrm{~nm}$ and the porosity of matrix are quite high, reaching to $98.5 \%$. Normally using low concentration of polymer solution could produce smaller fibers and high porous structure of scaffolds. The porous nanofiber scaffolds formed by phase separation, which was reported to mimic the structure of collagen type I fibers in ECM, are useful for tissue engineering applications [68]. For example, Yang et al. fabricated PLLA fibrous scaffolds via phase separation method for nerve regeneration study. In vitro results proved that nanofibrous scaffolds could support neural stem cell (NSC) growth and differentiation, which is considered to be promising in nerve tissue engineering [69]. However, there are still limitations in TIPS. First, the fibers created by TIPS are randomly oriented and the diameters are in wide range. Next, phase 
separation to produce fibrous scaffolds are only limited to the laboratory scale. The potential methods to control and upscale TIPS fibrous scaffolds are highly required for tissue engineering.
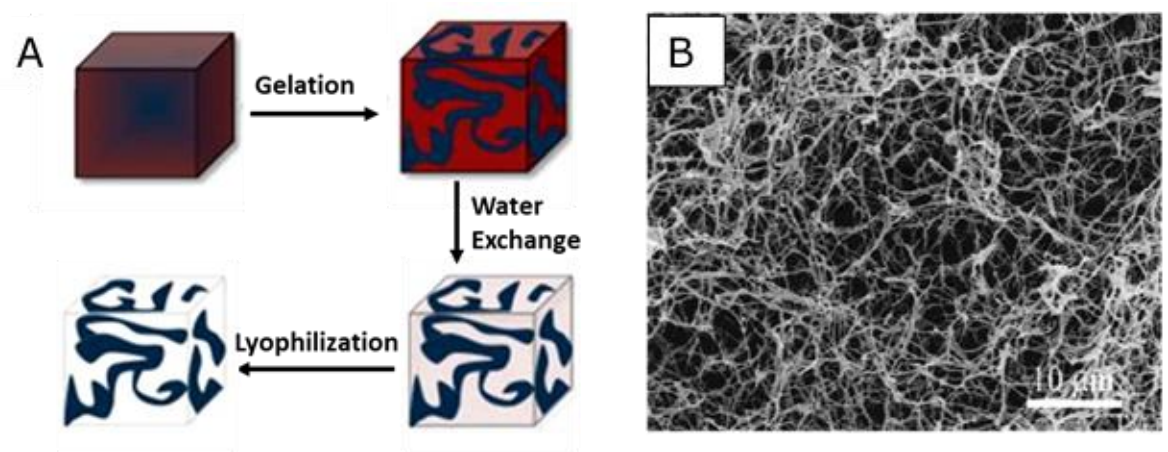

Figure 3. A schematic (A) of nanofiber formation by phase separation, and an SEM image (B) of nanofibrous structure fabricated by this technique. A is reproduced with permission from [66]. Copyright 2012, Elsevier Ltd. SEM image is reproduced with permission from [37]. Copyright 1999, John Wiley \& Sons.

\section{Electrospinning}

Electrospinning is a common and cost-effective fabrication technique to generate nano/micro fiber scaffolds [70]. The fiber formation process is driven by the electrostatic force on polymer solution [38]. When electrostatic forces are higher than the surface tension of polymer solution, the polymer droplet is stretched to form a Taylor's cone, as a charged jet. After the charged polymers solution is sprayed out, the solvent evaporates quickly and polymer fibers solidify. Then sprayed fibers are deposited to a grounded collector. A broad variety of nature and synthetic polymers have been reported to produce nanofibers via electrospinning. Due to less restrictions in materials choice, this technique has gained high relevance for applications in tissue regeneration [71]. The major advantage of electrospun scaffolds is the high porosity and small structure in scaffolds which can be used as ideal scaffolds in tissue engineering [72].

By controlling the processing parameter of electrospinning (including polymer content, high voltage, flow rate and collecting distance), the structure, 
diameter and pore size of nanofibers can be successfully controlled [38, 73]. Many researchers highlighted that the micro- and nano fibrous structure in electrospun scaffolds imitate the morphological features of the ECM, and offer a viable environment to help cells attach to, proliferate and migrate on the scaffolds [74, 75]. Therefore, a considerable number of electrospun scaffolds have been studied in tissue engineering application, such as soft tissue regeneration like skin [76], blood vessels [77], cartilage [78], and nerve [79], and hard tissue regeneration like bone [80-82].
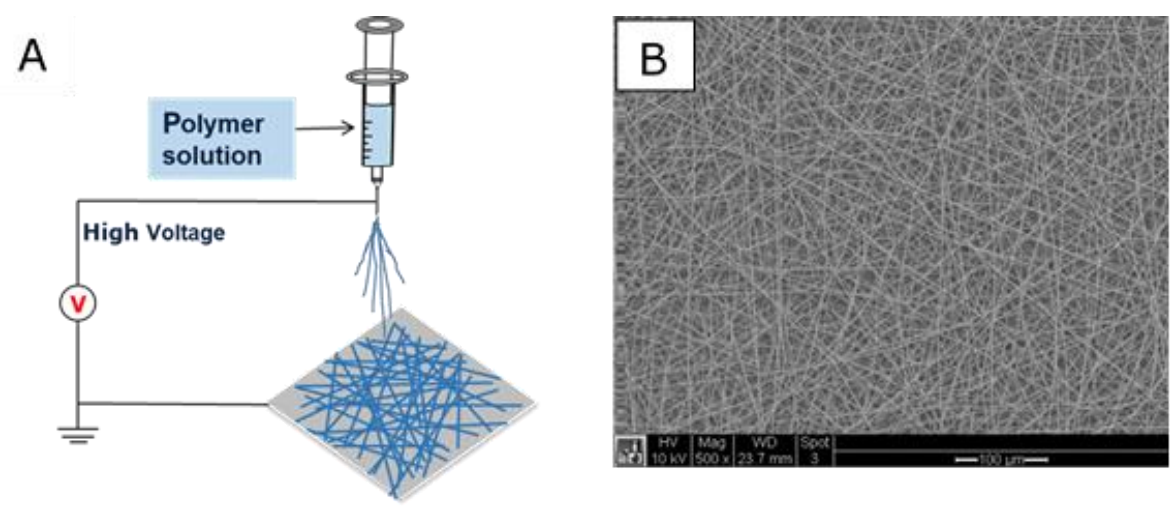

Figure 4. Schematic (A) of a typical electrospinning system, and SEM image (B) of electrospun nanofibrous structure.

\section{Nanofiber structure design}

Although there are three main approaches used for nanofiber fabrication as mentioned above, electrospinning is still the most common and effective method for generating nanofibers for tissue engineering applications. Traditional electrospun nanofibrous scaffolds are randomly oriented due to the jet instability during electrospinning. In past years, researchers have attempted to make nanofibrous scaffolds with highly ordered structure by changing the parameters of electrospinning or using additional setups. Although the beads structure in electrospun scaffolds has often been considered as a defect structure in fibers, some researchers proposed the use of a uniform beaded nanofibrous scaffold structure for drug delivery 
applications [83]. Examples comprise using lower concentration (5\%) of poly(ethylene oxide) (PEO) solution, which could result in a more beaded structure compared with electrospinning 6\% PEO [84]. Highly aligned PLLA fibers have been produced by using a rotating disk as a collector [85]. The tunability of nanofiber structure provides more possibilities for the application of electrospun scaffolds in tissue engineering applications. In this section, some achievements to control fiber architectures, including fabricating beaded, aligned, honeycomb, web, and wavy fibers and nanotubes, will be described.

\section{Porous Microsphere/Nanofiber Composites}

It is well known that the lotus leaves are dry and exhibit self-cleaning effects from the mud. The hierarchical micro/nanostructure of lotus-leaf leads to a specific surface roughness, which is highly related to its super hydrophobicity [86]. Inspired by the lotus-leaf, many researchers have been investigating its surface structure and tried to mimic its super hydrophobic surface for biomedical applications. Super hydrophobic surfaces were reported to restrict protein adsorption and cell adhesion [87]. Some researchers showed the potential of creating a super hydrophobic micropattern or a tunable hydrophobic surface to control cell behavior [88, 89]. Moreover, super hydrophobic materials could be applied in drug delivery, to slow down drug release. Kaplan and his colleagues fabricated polycaprolactone (PCL) and poly(glycerol monostearate-co-caprolactone) (PGC) electrospun nanofiber mesh, which showed super hydrophobic surface [90]. The non-wetting properties made them successful as a drug delivery system to sustain the release of cisplatin over 90 days. Electrospinning is an effective method to prepare super hydrophobic surfaces by fabricating a composite hierarchical structure, which contains microspheres and micro/nanofibers inside. Jiang et al. created electrospun polystyrene (PS) porous microspheres and nanofiber composites in order to obtain super hydrophobicity. The contact angle of fabricated PS films was higher than $150^{\circ}$, confirming super hydrophobic properties (Figure 5A) [91]. 
The shape and morphology of beads/fibers can be controlled by adjusting electrospinning parameters. For example, Lee et al. illustrated that changing polymer concentration during electrospinning could result in different bead dimensions and morphology. Bead structures were largely produced when electrospun with a PS solution below $15 \%$, while only fibers were formed after increased concentration above 15\% [92]. As PS is not biodegradable, translating these findings to biodegradable polymers for a hybrid fiber-beaded scaffold fabrication could find better use for tissue engineering studies. Hence, electrospinning polymer solutions with lower concentration to produce beads or beaded fibers were also verified with several other polymers [93-95]. Microor nanostructured electrospun meshes are known to be more hydrophobic, which is mainly ascribed to the underlying beads or fibrous structures producing air pockets between the mesh surface and water droplets when measuring the contact angle [96-98]. Yet, most of cell studies in tissue engineering were performed on uniform electrospun micro/nano fibers and only few of them worked on electrospun beads containing mesh.

\section{Aligned nanofibers}

Aligned nanofibers provide specific physical cues to affect activities, especially it could guide cell distribution and elongation in the direction of the fibers [99]. There are several aligned electrospun fibers, which have been used in tissue regeneration. For example, Deepthi et al. fabricated electrospun aligned PLLA nanofibers and covered them with a chitosan-collagen hydrogel in order to mimic the fibrous ECM for tendon regeneration [100]. In the bone matrix, collagen fibers are preferentially oriented (parallel to the long axis of bone), and their structural features are important to provide strength in tension and resistance in bone bending [101-103]. Many researchers attempted to mimic this unique structure of bone by using aligned electrospun fibers [104, 105]. The effects of fiber alignment on osteogenic differentiation have been widely investigated [82, 106, 107]. It was reported that the alignment of fibers induced osteogenic differentiation and upregulated the expression of osteogenic marker genes, including osteocalcin, runx2, osteopontin and osteonectin, 
compared to that on random fiber [104]. Aligned electrospun fibers provide specific geometrical cues, which guide the structure and function of human mesenchymal stromal cells (hMSCs) for bone regeneration [104, 108]. Calcium content on aligned fibers was significantly higher compared to that of random fibers [82]. These aligned fibrous meshes showed positive effect for bone regeneration. Moreover, aligned topography of fibers also showed a positive effect on vascular regeneration. Zhu et al. fabricated PCL aligned fibers by using a rotating mandrel to collect fibers [109]. Human umbilical artery smooth muscle cells (huSMC) and human umbilical vein endothelial cells (HUVECs) were seeded on aligned PCL fibers, showing that the alignment of fibers guided cell distribution and elongation, which is important for tube formation. In another study, 3D PCL fibrous tubular scaffolds were produced [110]. Cell studies proved that the 3D aligned tubular scaffolds effectively restricted the endothelial cells distribution. The alignment of fibers could be, therefore, used to create functional vascular grafts to achieve mechanical compliance.

The most common and effective way to fabricate aligned electrospun nanofibers is the use of a rotating collector. Our lab also fabricated PCL aligned nanofibers by using this approach (Figure 5B). We found, like many other researchers in the field, that the degree of alignment and the diameter of the nanofibers could be controlled by controlling the rotating speed of the collector. High rotating speed of the mandrel results in enhanced stretching of the fibers, which gives higher fiber alignment and smaller fibers. Co-cultured hMSCs with HUVECs on aligned and random PCL fibrous scaffolds was investigated to study how fiber alignment modulate osteogenic differentiation of hMSCs. The result demonstrated that aligned PCL fibers strongly influenced the morphology and orientation of hMSCs and HUVECs. Aligned fibers could be introduced to regenerate bone tissues with oriented topography without significant deleterious effects on hMSCs differentiation [111]. 


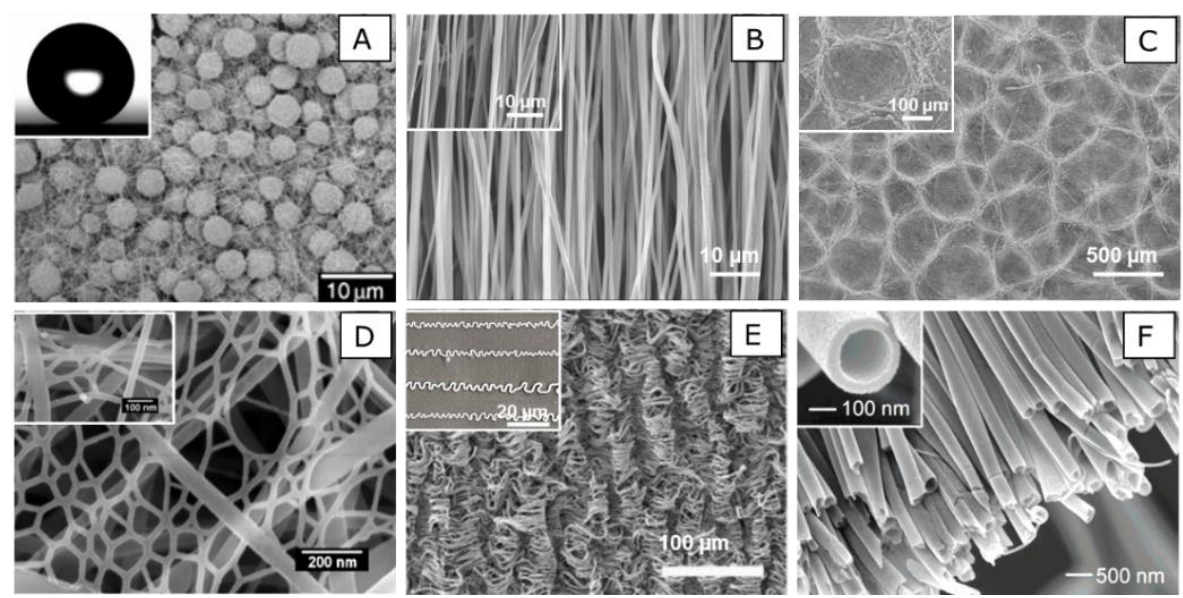

Figure 5. Different nanofibrous structures fabricated by electrospinning approach. SEM images of (A) porous microsphere/nanofiber composite, (B) aligned nanofiber, (C) honeycomb nanofiber, (D) spider web-like nanofiber, (E) curly nanofiber and (F) nanotube. Porous microsphere/nanofiber composite: reproduced with permission from [91]. Copyright 2004, WILEY-VCH. Spider web-like nanofiber: reproduced with permission from [112]. Copyright 2011. Elsevier B.V. Curly nanofiber: reproduced with permission from [113]. Copyright 2019, Royal Society of Chemistry. Nanotube: reproduced with permission from [114]. Copyright 2004, American Chemical Society.

\section{Honeycomb nanofibers}

A honeycomb is composed of hexagonal wax cells constructed by honeybees in their nests[115]. Natural honeycombs structure showed good features for cell culture, including large surface area, well stability and permeability [116]. In recent years, many researchers showed interests in making ordered honeycomb scaffolds, which mimics nature honeycombs' structure. Garcia et al created a PCL and hydroxyapatite (HA) honeycomb scaffolds, which could facilitate osteocompatibility in vitro and osteoinduction in vivo [117]. To fabricate honeycomb patterns by electrospinning, two methods have proven successful: 1) self-assembly [118] and 2) a collector equipped with hexagonal micropatterns [117]. The self-assemble approach is an easy, fast, and effective way to obtain honeycomb patterns. Honeycomb nanofibrous scaffolds have been successfully fabricated in our lab by self-assembly (Figure 5C). By changing the electrospinning parameters, such as the polymer concentration, high voltage and collecting distance, we could produce 
honeycomb nanofibrous scaffolds with different diameter [119]. We also cultured HUVECs on honeycomb scaffolds as a biocompatible template to induce and regulate the formation of vascular network. Results showed that the honeycomb patterned nanofibrous scaffolds could support endothelial cells adhesion, proliferation and migration into the scaffolds. Moreover, HUVECs cultured on the honeycomb scaffolds reorganized their cell bodies into tube-like structures, suggesting that HUVECs morphogenesis can be regulated by geometrical cues.

In addition to honeycomb patterns, other studies reported to achieve fiber patterns through directed fiber deposition, such as in the case of the direct writing approach $[120,121]$. Lee and his colleagues made concentric circles and lattice patterned PCL electrospun fibrous mesh by using this approach [121]. The direct writing approach 1) requires a side-wall electrode which is placed around the electrospinning jet to focus the fiber deposition, and 2) need a $X-Y$ stage to control the pattern during writing. The patterned nanofibrous mesh could be used for cell patterning in tissue engineering. Our group developed complex 3D poly(ethylene oxide terephthalate)/poly-(butylene terephthalate) (PEOT/PBT) fibrous scaffolds with articular cartilage mimetic structure by the direct writing method [122]. The effect of mimetic pattern on chondrogenic differentiation was also studied, demonstrating that patterned scaffolds guided fibril matrix organization and promoted the expression of chondrogenic markers (Sox9 and ACAN). As human tissues always exhibit unique anisotropical structures, these results showed the great potential of using patterned fibrous structures (like in the case of honeycomb and direct writing methods here discussed) to generate complex tissue mimetic patterns, which could be used for inducing tissue regeneration.

\section{Spider webs}

A conventional electrospun membrane only produce one type of (micro or nano) fibers. One big improvement of recent electrospinning is creating complex electrospun scaffolds with both micro and nano fibers at same time. 
Electrospun fibers in the nano scale could mimic native ECM fibers (a diameter in the range of 10-50 nm), while microfibers could keep high porosity of scaffolds which benefit cell infiltration and migration. The fabrication of electrospun scaffolds that contain spider-web-like nano-nets with two types of (micro or nano) fibers could enhance scaffolds properties for tissue engineering applications [123]. The addition of nano-webs structure could improve the mechanical properties of scaffolds. Nylon- 6 and poly (acrylic acid) nano-nets were first reported, which were fabricated by tuning electrospun parameter and polymer solutions [124]. Four years later, Pant et al. reported another spider-web like nanofibers, which contain thin Methoxy Poly(ethylene glycol) (MPEG) nanofibers and thick nylon-6 nanofibers. Those composite nanofibrous mats could increase mechanical strength and hydrophilicity compared with neat nylon-6 nanofibers (Figure 5D) [125]. 1 wt\% MPEG nanofibers showed higher mechanical strength because of the interconnected MPEG web-nanofiber with nylon-6 thick nanofibers. Tiwari and their colleagues fabricated a PCL-human serum albumin (PCL-HSA) membrane with a spider-web-like nano-nets by electrospinning the blend solution of $\mathrm{PCL}$ and HAS [126]. The phase separation during electrospinning led to the formation of two type of fibers with different diameters. They also evaluated cell behavior on PCL-HSA scaffolds and proved that the membrane containing HSA nano-nets have better support for cellular activities compared to PCL scaffolds. Another study developed a polycaprolactone/polyethylene glycol (PCL/PEG) electrospun fibrous mesh with nano-nets embedded into it [127]. The stress-strain curves showed that the addition of PEG nano-nets could increase the tensile stress of PCL fibers, from 13.40 $\pm 0.9 \mathrm{MPa}$ to $27.20 \pm 1.4$ $\mathrm{MPa}$. Higher mechanical strength of PCL/PEG nanofibrous mesh benefits cell attachment and growth. Other studies have also shown spider-web-like structures in different electrospun polymeric membranes can better mimic the ECM and displayed enhanced mechanical properties like in the cases here discussed, which could be especially beneficial for cell attachment and migration in comparison to membranes without nano-webs [127-129]. 


\section{Curly fiber}

Inspired by the structure of proteins in different tissues of our body, nanofibers with curved morphology display many specific features, including large porosity, elasticity, and toughness, which make it attractive in biomedical tissue engineering. Three techniques has been reported to produce waved nanofibers: 1) self-assembly [130, 131], 2) chemical vapor deposition [132] and 3) electrospinning [133-135]. Wang et al. reported that two synthesized $\beta$-sheet dipeptides with long alkyl chains derived from I- and d-threonine (Thr) and sodium hydroxide $(\mathrm{NaOH})$ could self-assemble into helical nanofibers [136]. It has been reported that peptides amphiphiles with longer peptide sequences could form helical nanofibers, due to the hydrogen bonding interactions between side chains, induced the formation of twisted nanofibers. Chemical vapor deposition was considered to be another technique generating helical fibers. It is widely reported that straight nanowires have been grown by the mechanism of vapor-liquid-solid (V-L-S). The adsorption of a gas phase deposit on to a solid surface leads to the growth of crystal from bottom to top, thus creating the nanofibrillar structures. Zhang and his team produced helical $\mathrm{SiO}_{2}$ nanofibers by using this technique, with diameters of the fabricated nanofibers from 80 to $140 \mathrm{~nm}$ [132]. Although, the addition of $\mathrm{CH}_{4}$ flow in the carrier gas resulted in a helical structure of the formed nanofibers, the actual mechanism with which a helical structure was formed, was not reported. It was only hypothesized that $\mathrm{CH}_{4}$ helped moderating the highly oxidizing environment and kept the activity of Iron catalytic particles.

Electrospinning has been regarded as the most common and efficient technique to fabricate helical nanofibers. Researchers produced helical nanofibers by electrospinning and studied the potential factors that could guide the fibers to be helical and curly. Zhou et al. created wavy nanofiber through an airflow-electrospinning process [137]. Airflow could drive electrospun nanofibers to deposit into a hybrid yarn, then form wavy structures. Another study demonstrated that using auxiliary electrodes in near-field electrospinning could regulate the deposited fibers to form wavy pattern [138]. 
They found that the frequency of the wavy fibers was the same as the current power frequency. Our lab investigated the use of a thermally shrinking film to guide electrospun fibers in the formation of curly and wavy patterns (Figure $5 E)$ [113]. In vitro studies showed that wavy patterns could enhance cellular infiltration and induce transforming growth factor-beta (TGF- $\beta$ ) expression. These hierarchically structured nanofibers could be used to mimicking epithelial tissue buckling morphogenesis for tissue formation. The wavy pattern could afford unique physical properties to regulate cell behavior, which showed possibility for application in tissue engineering.

\section{Nanotubes}

Tubular nanostructures are widely used in tissue engineering, especially for drug delivery [139]. Many approaches have been studied to produce nanotubes for drug delivery systems. For instance, nanotube structures could be developed from organic building blocks by self-assembly approach [140142]. Yan et al. demonstrated that cationic dipeptides $\left(\mathrm{H}-\mathrm{Phe}-\mathrm{Phe}-\mathrm{NH}_{2} \cdot \mathrm{HCl}\right)$ could form nanotubes at physiological $\mathrm{pH}$ via self-assembly methods. To test the delivery of these cationic dipeptide nanotubes in cells, fluorescein labeled single-stranded DNA (ssDNA) was bound to the nanotubes by electrostatic interactions. After incubation with HeLa cells, the fluorescence showed that these nanotubes could enter cells and accumulate in the cytoplasm. It might have a possibility to exploit the nanotubes for potential applications of gene and drug delivery. However, low yield is a significant limitation to produce nanotubes in a large scale. The template-directed approach have also been used to build nanotubes, since it is more direct and controllable compared to self-assembly approach [143, 144]. Hou et al. produced poly(p-xylylene) nanotubes by this approach [144]. The average inner tube diameter was in the range of about $10 \mathrm{~nm}$. The template approach works well for producing short tubes. It is hard to fabricate continuous nanotubes by this approach. Compared with self-assembly and template-directed approaches, coaxial electrospinning was proved to be the optimal approach for creating continuous 
nanotubes with a controllable condition and large-scale production. In coelectrospinning, a coaxial nozzle is the key device that is comprised of a central tube and a concentric circular corona. This coaxial nozzle allows two different solutions to produce a core-shell composite structure [145, 146]. In order to fabricate hollow nanofibers, it was shown that different oil-soluble materials could be directly spun into the core of the fiber [114, 147]. After removal of the oil phase from the core of the scaffolds, hollow nanofibers were obtained (Figure 5F) [114]. Srouji et al. developed electrospun core-shell fiber scaffolds to load bone morphogenetic protein-2 (BMP-2) in the core of the fibers. After BMP-2 slow release from the scaffolds, both in vitro and vivo studies showed that slow-releasing scaffolds have significant increase in alkaline phosphatase activity and bone regeneration compared to fast BMP-2 releasing scaffolds. This core-shell scaffolds serve as an ideal approach for drug releasing system and could be also used in other tissue regeneration applications. Moreover, Zhao et al. successfully developed multi-channel tubes with variable diameter and channel number. The channel number of nanotubes was controlled by a powerful multifluidic compound-jet during electrospinning [148]. Multi-channel tubes could be used to load different bioactive components without interaction in drug release.

\section{Nanofiber functionalization}

To explore more applications of nanofibrous scaffolds in tissue engineering, researchers investigated the functionalization of nanofibrous scaffolds by many different approaches, such as, physical blends, core-shell electrospinning, and post functionalization.

\section{Physical Blends}

Polymer blends is an easy and direct method to introduce bioactive components into nanofibrous scaffolds for tissue-engineering applications. Nanostructure polymer blends could result in the production of low-cost nanoscaffolds with specific functionality. Biopolymers can be blended into a synthetic polymer for electrospinning to obtain better mechanical properties, 
good biodegradability and biocompatibility of nanofibers. For example, to improve the biodegradability and biocompatibility, gelatin was mixed in PCL electrospun solution and then incorporated into PCL nanofibrous scaffolds during electrospinning [149]. The obtained PCL/gelatin nanofibrous scaffolds showed positive influence on cell proliferation and nerve differentiation compared with pure PCL scaffolds. A lot of natural polymers have been used extensively to blend with synthetic polymers for electrospinning, such as collagen [150-152], gelatin [153-155], elastin [156-158], fibrinogen [159], silk fibroin [160], alginate [161, 162], chitosan [163, 164], dextran [165, 166], and heparin [167]. These results highlight the essential role of both natural and synthetic polymers in tissue engineering applications. The combination of natural and synthetic polymers could effectively improve the mechanical properties and biocompatibility of nanofibrous scaffolds, which could support cell growth and favor tissue regeneration. More importantly, the simple physical blending process for the introduction of functional components to polymeric nanofibers usually resulted in converting the nanofibers into highly effective delivery systems. Many biofunctional components (such as, growth factors [168, 169], peptides [170, 171], enzymes [172, 173], drugs [174, 175], DNA [176, 177]) have been incorporated into nanofibers for biomedical research. After incorporating bioactive components into polymer nanofibers, the composite scaffolds could serve as a carrier to provide continued or controlled release of the bioactive components for tissue regeneration. Selecting polymers (such as, biodegradable and non-degradable) as a carrier could offer the possibility to control the speed of drug release. By selecting different polymers with a variety of biofunctional components, nanofibrous scaffolds afford high possibility for different applications.

\section{Core-Shell electrospinning}

Electrospinning is an effective technique to incorporate biomolecules into nanofibrous scaffolds. However, physical blends cannot be effective for long time and often provide bioactive molecules with a fast release. The burst release often results in a short lifetime of the bioactive scaffolds and reduced 
therapeutic efficiency of bioactive molecules. To overcome these restrictions, coaxial electrospinning have been designed to produce core-shell nanofibers, which facilitate the biomolecules encapsulation into the core of nanofibers. This specific coaxial structure is essential to avoid burst release, slow down the release rate, and maintain the mechanical and biological properties of scaffolds. For example, Zhang et al. encapsulated vascular endothelial growth factor (VEGF) and platelet-derived growth factor-bb (PDGF) into fibrous films via coaxial electrospinning technique. VEGF was loaded in a chitosan hydrogel/poly(ethylene glycol)-b-poly(l-lactide-co-caprolactone) (PELCL) electrospun membrane as the inner layer and PDGF was loaded in an emulsion/PELCL electrospun membrane as the outer layer. Results demonstrated that the release of those two growth factors at same time could promote vascular endothelial cells (VECs) proliferation and facilitate revascularization [178]. Mickova and his colleagues designed polyvinyl alcohol/PCL as core/shell nanofibers with embedded liposomes in the core. Results showed that the enzymatic activity of encapsulated horseradish peroxidase was still maintained in the scaffolds, which could be used in drug delivery system [179].

Researchers compared the loading efficiency and releasing properties of two methods (physical blends and coaxial electrospinning). They fabricated two different Basic fibroblast growth factor (bFGF) embedded poly(lactic-coglycolic acid) (PLGA) nanofibers by using physical blends and coaxial electrospinning. Although both PLGA nanofibers showed growth factors encapsulation and achieved continued release, the release profiles were quite different. Co-electrospinning scaffolds could prolong the bFGF release one week more compared to physical blends scaffolds. Therefore, coelectrospinning technique are more effective to load the growth factors and achieve continued release. Except growth factors and liposomes, controlled release of other bioactive components, such as peptides, proteins and even DNA, is also accomplished with core-shell electrospinning approaches [180]. 
A

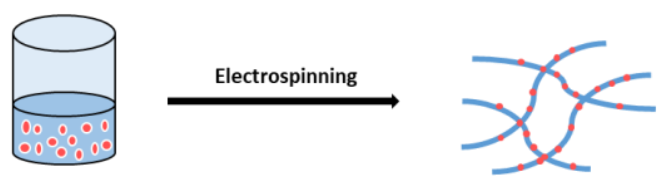

B

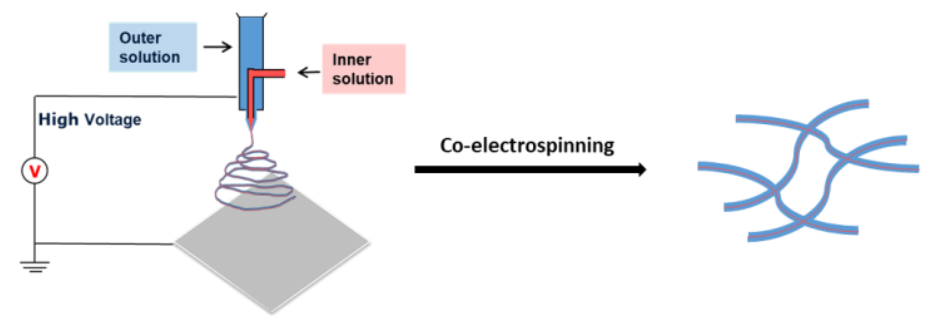

C
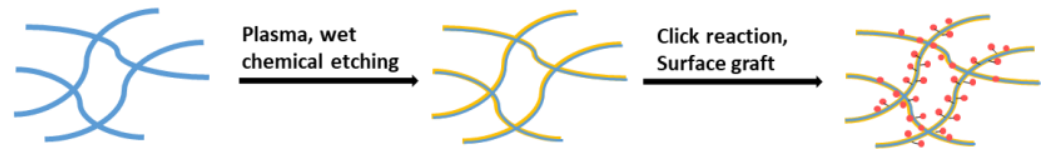

Figure 6. Functionalization approaches of electrospun nanofibers. (A) Physical blends, (B) coreshell electrospinning and $(\mathrm{C})$ post functionalization.

\section{Post functionalization}

Plasma treatments

The simple plasma treatment is the most widely used method to improve nanofibers biocompatibility. Different gases such as $\mathrm{Ar}, \mathrm{N}_{2}, \mathrm{O}_{2}$ and $\mathrm{NH}_{3}$ were utilized during plasma treatment to change the chemical composition or introduce functional groups on the surface of scaffolds for further applications. For example, polymer nanofibers were exposed with oxygen plasma in order to obtain carboxyl groups on the surface of nanofibers [181]. Plasma treatments with ammonia can generate amine active sites on the surface of nanofibers [182]. After generating desired functional groups (e.g., $-\mathrm{NH}_{2},-\mathrm{OH}$, $-\mathrm{COOH}$ ) at the surface of nanofibers, these surfaces could be largely used as substrates for biomolecule immobilization.

A study demonstrated that the functionalization of PLLA nanofibers with RGD (Arg-Gly-Asp) peptides by plasma treatments and covalent coupling. The 
plasma treatment of PLLA nanofibers is a key step to produce carboxyl groups for RGD coupling. RGD peptides could immobilize on the functionalized nanofibers by EDC/sulfo-NHS chemistry. In vitro results showed that RGD functionalized scaffolds promoted the proliferation and osteogenic differentiation of hMSCs[183]. Another study functionalized PLLA nanofibers with cationized gelatin (CG) to increase the biocompatibility of PLLA scaffolds [181]. Oxygen plasma was used to modify PLLA nanofibers with carboxyl groups. After the introduction of carboxyl groups on the surface of nanofiber, gelatin could covalently bind to the PLLA nanofibers. Apart from growth factors and gelatin, other bioactive components (calcium phosphate [184], collagen [185], and laminin [186]) were also reported to bind onto nanofibers after plasma treatment. Plasma treatment was regarded as a simple approach to generate functional groups on the surface, which provide an opportunity for the further immobilization of bioactive components onto scaffolds.

\section{Wet chemical etching}

Except plasma treatments, the surface modification of nanofibrous scaffolds could also be achieved by wet chemical treatments. Wet chemical approaches, such as hydrolysis, soaking in $\mathrm{NaOH}$ or $\mathrm{KOH}$ often leads to the degradation of nanofiber properties and morphology. Chen et al. reported that PCL nanofibrous membranes treated with $\mathrm{NaOH}$ etching led to enhanced roughness and surface area [187]. 3Т3 fibroblast cells exhibited a better adhesion on the surface modified PCL membranes and well spread out morphology. Other chemical etching approaches, like aminolysis, could introduce amino groups onto the nanofiber surface. Amino modified nanofibers could be used as a substrate to bond other bioactive molecules by a covalent bond with the $-\mathrm{COOH}$ group. Fibronectin (Fn), for example, was grafted onto nanofibrous scaffolds via polyester aminolysis and then coupling via glutaraldehyde [188]. Cell studies demonstrated that the Fn coupling onto polymer nanofiber scaffolds significantly promoted epithelium regeneration. The introduction of active groups by using wet chemical etching afford an easy route for preparing functional nanofibrous materials in tissue engineering. A 
variety of bioactive components such as growth factors, peptides, gelatin or chitosan, can be functionalized into scaffolds afterwards. Therefore, this functionalization approach showed high potential for tissue regeneration applications.

\section{Click chemistry}

Click chemistry is an attractive alternative for facile immobilization of bioactive components onto electrospun nanofiber surface, because of its simple reaction conditions, high reaction rate, high yields and functional group tolerance [189-192]. Several "click" methods including radical thiol-ene[193], copper-catalyzed azide alkyne cycloaddition (CuAAC) [194, 195], strainpromoted azide-alkyne cycloaddition (SPAAC)[196, 197], Diels-Alder addition [198] and Michael additions [199] have been employed for nanofiber functionalization [200]. Modification of nanofibers surface with bioactive components by click chemistry could be used to improve the bio-functional properties of nanofibrous scaffolds for tissue regeneration applications. For example, Lancuški et al. developed a clickable nanofibrous scaffolds by electrospinning a mixture of PCL-80K with PCL-2K azide. The surface of PCL$2 \mathrm{~K}$ azide presented clickable sites for CuAAc reaction. This approach provide high efficiency to produce clickable nanofibrous scaffolds [194]. Then, functionalized nanofibers could easily click to a desired biomolecules (peptides, growth factor, drugs etc.). Another study showed a breast cancer sensitive protease (TSP50) was successfully coupled onto P(LA90-co-MPC10) electronspun fibers by CuAAc click reaction [195]. The TSP50 fibers could be applied for detection, separation, and purification of anti-TSP50. This method verifies the possibility of click reaction to couple proteins on electrospun fibers. Photo-initiated thiol-ene click chemistry is also widely used to bind bioactive molecules. For example, a cysteine contained CAG-peptide was functionalized onto scaffolds via thiol-ene click chemistry [201]. These peptide-functionalized surfaces exhibited enhanced cell adhesion, growth and proliferation. Compared to previous chemical functionalization of nanofibers, such as plasma treatment and wet chemical method, click reactions are 
unique and offers many benefits (stoichiometric control, orthogonal chemistry and mild water-tolerant conditions), which could effectively attach biomolecules to the surface of nanofibers without damaging a fibrous structure. As the benefits of click chemistry keeps increasing, clickable nanofibers have shown great promise to bond various biomolecules with different approaches for tissue engineering applications.

\section{Surface graft}

Surface graft approach has been also developed to introduce functional groups on scaffolds for the subsequent coupling of bioactive components. Plasma treatment is usually required to introduce free radicals for polymerization during graft polymerization. For example, the surface of poly(vinylidene) fluoride nanofibers was successfully grafted with Poly(methyl methacrylate) by plasma-induced graft copolymerization [202]. By processing with graft polymerization, the pore size of electrospun nanofibrous meshes was significantly decreased, from 3.58 to $0.88 \mu \mathrm{m}$. The grafted electrospun membranes could be used as a microfiltration membrane. Ma et al. modified electrospun PCL nanofibers with gelatin by surface grafting [203]. Gelatin modified PCL nanofibrous scaffolds effectively helped endothelial cells (ECs) adhesion and promoted proliferation compared with the unmodified PCL scaffolds. However, the grafting approach can only modify the top surface of nanofibers and could not penetrate beyond the first few fiber layers.

\section{Electrospun fibrous scaffolds in vascular regeneration}

Vascular regeneration is one of most challenging issues in tissue engineering [204, 205]. During formation of new tissue, blood vessels are required to supply oxygen and nutrition for cells as well as to remove waste products [206208]. Lack of efficient vascularization limits the size of tissue-engineered constructs [209, 210]. Implantation of tissue constructs in a poorly vascularized site often leads to lack of tissue integration and cell death [211, 212]. As a result, many tissue-engineered constructs have been reported to fail in vivo due to lack of vascular formantion [209, 213, 214]. Therefore, 
vascular regeneration is critical for the successful regeneration of tissues where vascularization is necessary $[215,216]$. Electrospinning is a commonused technique to produce fibers in micro/nano scale, which could mimic the mechanical properties of native ECM. The potential in vivo use of implantable electrospun tubular scaffolds for vascular graft was widely reported [217-219]. Especially, tubular electrospun scaffolds collected on a rotating mandrel showed advantages to mimic the scale and architecture of vessels.

\section{Effects of electrospun scaffold architecture on vascular regeneration}

Nanotopography has been noted as an important factor to affect cell growth and differentiation. ECs could interact with their physical environments and guided by scaffolds topography. $\mathrm{Xu}$ et al. reported that the alignment of nanofibers plays a positive role in the regulation of endothelial cellular behavior [220]. Cell elongation and migration are indispensable processes in angiogenesis. This study proved that the alignment of nanofibers could guide cell distribution, affect cell morphology and even control migration velocity [221]. When HUVECs were cultured on PLGA aligned nanofibrous scaffolds, the morphology of migrating cell was highly ordered. Therefore, the topographic features and scaffold guidance should be evaluated when designing a tissue-engineered scaffold for vascular regeneration. Few other studies showed that EC morphogenesis into capillary-like structures was regulated by micropatterned stripe substrates [216, 222]. Dike et al. showed that ECs cultured on substrates micropatterned with $10 \mu \mathrm{m}$-wide lines of fibronectin formed capillary tube-like structures containing a central lumen; cells cultured on wider $(30 \mu \mathrm{m})$ lines did not form tubes [222]. Moon et al. micropatterned poly (ethylene glycol) diacrylate hydrogels with RGDS in different geometries [216]. As a result, ECs cultured on RGDS patterns reorganized their cell bodies into tube-like structures on $50-\mu \mathrm{m}$-wide stripes, but not on wider stripes. These result suggested that ECs morphogenesis could be regulated by topography cues. Development of a well-designed 
topography, in which capillary tubes consistently form, is an important step toward the fabrication of engineered tissues.

\section{Effects of controlled release of biochemicals from electrospun scaffolds on vascular regeneration}

\section{Growth factors}

Many researchers have reported that the controlled release of angiogenic factors could promote vascular formation in vivo and in vitro. Electrospun nanofibrous scaffolds showed high potential to incorporate or functionalize bioactive component into the nanofibrous scaffolds, and nanofibers considered as a transport carrier could achieved a controlled degree of drug release. VEGF is the most important growth factor to stimulate early vascular formation and promote angiogenesis. Jia and his colleagues loaded VEGF into the inner of core/shell fibrous scaffold by coaxial electrospinning with PLGA as the shell [223]. VEGF release could sustain for more than 28 days and cell studies showed that VEGF encapsulated scaffolds effectively enhanced cell proliferation and benefited cell distribution. Another study demonstrated VEGF functionalized heparin-conjugated PCL fibrous scaffolds able to release the growth factor for 15 days [224]. This resulted in new blood vessel formation with minimum immunological rejection. Other growth factors, such as bFGF [225] and PDGF [178] were also reported to be released from nanofibrous scaffolds for vascular regeneration. Montero et al. prepared bFGF-loaded gelatin fibrous scaffolds by physical adsorption after electrospinning [226]. HUVECs were seeded on these scaffolds. Results showed that the releasing of bFGF from the scaffolds significantly promoted cell proliferation and helped capillary formation. Moreover, combing two or more growth factors and controlling their spatio-temporal release could be another option to improve the functionality of scaffolds.

\section{VEGF-mimetic Peptides}

Except growth factors, many studies have also reported the immobilization of VEGF-mimetic peptides on scaffolds as potential application for vascular 
regeneration. D'Andrea et al. designed a VEGF-mimetic peptide, QK (domain: KLTWQELYQLKYKGI), and showed the ability to activate VEGF receptors and similar bioactivity to VEGF[227]. QK peptides provided many advantages including smaller molecular weight, low immunogenic potential, and costeffectiveness by synthesis [227-231]. Leslie-Barbick et al. reported that QK peptides are easier to conjugate or immobilize into scaffolds than VEGF because it could diffuse into scaffolds faster and more completely [231] Another study loaded QK peptide into poly(ethylene glycol)-b-poly(L-lactideco-e-caprolactone) (PELCL) nanofibers by emulsion or suspension electrospinning [232]. It was found that QK loaded PELCL electrospun scaffolds could significantly accelerate the proliferation of ECs compared with pure PELCL scaffolds in 9 days. Zhou et al. functionalized the surface of the PELCL scaffolds with QK peptides via EDC/NHS chemistry [230]. In vitro studies demonstrated that the QK peptide-functionalized PELCL scaffolds could significantly promote the proliferation of ECs compared with unfunctionalized PELCL scaffolds. QK peptide-functionalized electrospun scaffolds showed their ability of fast endothelialization, which could have potential use in vascular regeneration.

Apart from VEGF-memetic peptide, RGD peptide was aslo reported to immobilize into electrospun scaffolds for vascular tissue engineering. For example, Kim et al electrospun a mixture of PLGA and PLGA-b-PEG-NH $\mathrm{N}_{2}$ to generate electrospun scaffolds with active amino group [233]. RGD was covalently grafted with on PLGA fibrous scaffolds. In vitro study showed that the immobilization of RGD significantly promote cell adhesion and proliferation. These results suggest RGD functionalized fibrous scaffolds could be a promising for vascular regeneration.

\section{Hydrogen Sulfide}

Hydrogen sulfide $\left(\mathrm{H}_{2} \mathrm{~S}\right)$, a unique gasotransmitter, has been recognized as an important physiological and pathological signaling molecule, which can mediate and promote the effects on angiogenesis $[234,235]$. The 
phenomenon that $\mathrm{H}_{2} \mathrm{~S}$ promotes $\mathrm{EC}$ proliferation and migration has been reported by different groups [236, 237]. $\mathrm{H}_{2} \mathrm{~S}$ has been reported to simulate angiogenesis in vitro and in vivo $[236,238]$. Since $\mathrm{H}_{2} \mathrm{~S}$ has been recognized to be beneficial for angiogenesis, researchers started to focus on the development of $\mathrm{H}_{2} \mathrm{~S}$ releasing scaffolds for vascular regeneration [239, 240]. Feng et al. electrospun $\mathrm{N}$-(benzoylthio)benzamide (NSHD1), an $\mathrm{H}_{2} \mathrm{~S}$ donor, with PCL solution to form $\mathrm{H}_{2} \mathrm{~S}$ release fibrous scaffolds [241]. The $\mathrm{H}_{2} \mathrm{~S}$ fibrous scaffolds could facilitate (H9c2 and 3T3) cells proliferation. Moreover, these scaffolds were also reported to increase the expression of collagen type I and collagen type III, and wound healing related genes. Kang and his colleagues synthesized a $\mathrm{pH}$-controlled $\mathrm{H}_{2} \mathrm{~S}$ donor (JK-1) from phenylphosphonothioic dichloride [242]. Wu et al., instead, mixed JK-1 with PCL to prepare $\mathrm{H}_{2} \mathrm{~S}$ releasing electrospun nanofibers [243]. The fabricated fibrous scaffolds showed that lower $\mathrm{pH}$ induced greater and faster $\mathrm{H}_{2} \mathrm{~S}$ release. JK1 doped PCL fibers were nontoxic to fibroblasts and in vivo experiments proved that PCLJK1 could significantly improve wound healing. Although previous studies showed promising results in vitro and in vivo, many aspects still need to be improved for the fabrication of $\mathrm{H}_{2} \mathrm{~S}$ releasing nanofibrous scaffolds: 1) slow $\mathrm{H}_{2} \mathrm{~S}$ releasing donor need to be included; 2) except physical doping, other surface functionalization approach should be considered.

\section{Studying angiogenesis in vivo}

Chick chorioallantoic membrane (CAM) assay, rabbit or rat cornea are the most widely used animal models for studying the process of angiogenesis in vivo. CAM is an extraembryonic membrane mediating gas and nutrient exchanges until hatching [244]. Since this membrane could form blood vessels network after incubation, it has been widely performed as an in vivo model to screen angiogenesis stimulators and inhibitors in response to biomaterials. Rabbit cornea and mouse model has been reported to be other in vivo angiogenesis models. However, CAM is believed to be simpler and cost-effective with lower ethical concerns than other animal models. 
A

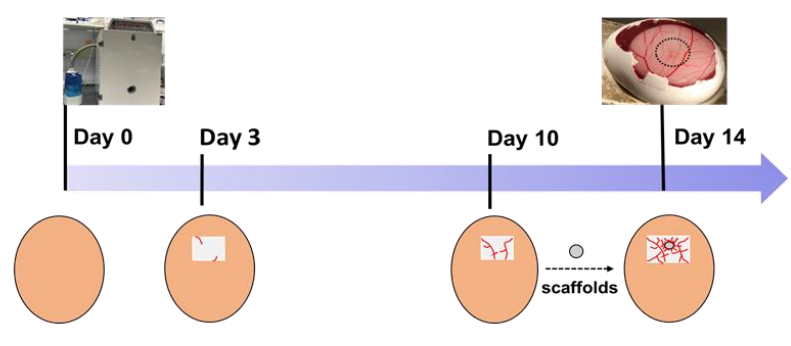

B

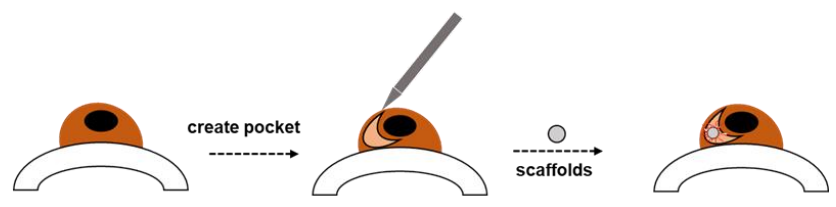

C

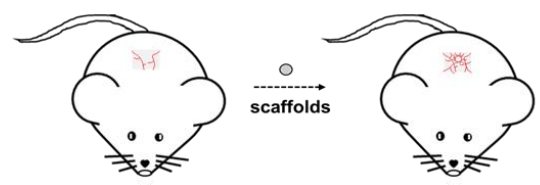

Figure 7. (A) Chick chorioallantoic membrane (CAM), (B) rabbit cornea and (C) mouse model to evaluate the angiogenic ability of implanted scaffolds.

CAM assay has been used by many researchers as an in vivo model in vascular tissue engineering for more than 40 years. A number of studies have evaluated electrospun nanofibrous scaffolds on the CAM to examine their angiogenic response and biocompatibility. The general procedure of CAM assay is shown in Figure 7A. By implanting nanofibrous scaffolds onto the CAM, the potential angiogenic activity of scaffolds can be analyzed through changes in the vascular density of the surrounding environment. Test components could be growth factors, peptides, drugs and other biomolecules, which are immobilized or incorporated to nanofibrous scaffolds. For example, in order to evaluate the angiogenic ability of VEGF loaded collagen-PCL scaffolds in vivo, a CAM assay was carried out showing that VEGF-loaded PCL scaffolds could significantly increase the vessel area on the scaffolds[245] Their result proved that the VEGF releasing from VEGF-loaded scaffolds could promote early blood vessel formation in vivo. Augustine et al. developed zinc oxide ( $\mathrm{ZnO})$ nanoparticle-loaded electrospun PCL scaffolds [246]. CAM 
assay was used to assess the angiogenic potential of these scaffolds. A $1 \mathrm{wt} \%$ $\mathrm{ZnO}$ nanoparticle incorporated PCL scaffolds were pro-angiogenic, which showed to be statistically higher in the number of branching points compared with PCL scaffolds. Diaz-Gomez et al. performed a CAM assay to evaluate the angiogenesis response of platelet-rich plasma (PRP) coated PCL scaffolds [247]. PRP-PCL scaffolds were integrated with the CAM and formed many capillary blood vessels around the PRP-PCL scaffolds compared to the PCL scaffolds. These few selected studies are just to exemplify the potential of the CAM assay as a simple validation tool for newly designed scaffolds for vascular tissue regeneration, after an initial assessment in vitro. For a more thorough review on the several angiogenesis available assays, the reader is referred elsewhere [248].

\section{Aims and outline of thesis}

The aims of this thesis are: 1) to explore different fabrication approaches to create instructive structure of nanofibrous scaffolds; 2) to develop different chemistry strategies to functionalize nanobibrous scaffolds with bioactive components; 3) and finally to use these enhanced functional nanofibrous scaffolds for vascular tissue engineering. Different approaches to achieve these goals are described in 6 chapters in this thesis.

In chapter 1, a general overview is presented on nanofiber fabrication, the design of nanofibrous scaffolds and the application of nanofibrous scaffolds in vascular regeneration. Based on this review, it can be inferred that nanofibrous scaffolds that include well-designed physical or chemical modifications, structure design and biomolecules functionalization, have greater chance of success in tissue engineering than pristine polymeric scaffolds with a random structural architecture. The theme of chapter 2, 3 and 4 is to introduce structure modifications of nanofibrous scaffolds to create different physical constraints for cells. Chapter 2 introduces two factors (alignment of nanofibers and coculture with ECs) to take into consideration when using MSCs for osteogenic differentiation. In particular, the optimized 
coculture conditions for enhanced osteogenic differentiation on electrospun fibrous scaffolds were demonstrated. Chapter 3 shows a simple, versatile and effective approach to generate gradient honeycomb patterns in nanofibrous meshes and investigates the effect of electrospinning parameters on the honeycomb formation. The size of honeycomb patterns and evenly gradient honeycomb could be controlled by adjusting the processing parameters. In chapter 4, the influence of honeycomb nanofibrous scaffolds on ECs behavior was investigated in terms of cell proliferation and tube formation.

Compared to conventional chemical modifications of nanofiber surface, click chemistry is an attractive alternative for facile immobilization of bioactive components onto the surface of electrospun nanofibers, because of many advantages, including simple reaction conditions, high reaction rate, high yields and functional group tolerance. Chapter $\mathbf{5}$ and $\mathbf{6}$ describe two surface functionalization approaches as a strategy to immobilize bioactive components on nanofibrous scaffolds. In chapter 5, PCL-N $\mathrm{N}_{3}$ clickable scaffolds were prepared by electrospinning blended PCL-N $\mathrm{N}_{3}$ and PCL solution. $\mathrm{H}_{2} \mathrm{~S}$ donor (alkyne-NTA) was immobilized on PCL-N $\mathrm{N}_{3}$ fibrous scaffolds by azide-alkyne click conjugation. The effects of $\mathrm{H}_{2} \mathrm{~S}$-release nanofibrous scaffolds on ECs behavior, such as cell viability, proliferation and angiogenesis were investigated. However, it is impossible to localize the vessel growth by this approach. In order to archive spatial control of vessel pattern, Chapter 6 presents a photopatterning strategy based on the advantage of using the photochemically promoted radical thiol-ene click chemistry. A proof of concept study using a thiol dye demonstrates the ability to use photomasks to create any desired pattern (e.g. circles, squares) on nanofibrous scaffolds. A VEGF-mimicking peptide terminated with a thiol group was immobilized on PCL-diacrylate (PCL-DA) nanofibrous scaffolds by this approach, showing enhanced ECs survival in nutrient starvation conditions. 
Finally, a general discussion of the results obtained in chapter 2-6 and future perspectives are provided in chapter 7 . The valorization potential along with future applications of this research will be described in chapter 8 . 


\section{Reference}

[1] H. Shin, S. Jo, A.G. Mikos, Biomimetic materials for tissue engineering, Biomaterials 24(24) (2003) 4353-4364.

[2] J.P. Vacanti, R. Langer, Tissue engineering: the design and fabrication of living replacement devices for surgical reconstruction and transplantation, The lancet 354 (1999) S32-S34.

[3] I. Jun, H.-S. Han, J. Edwards, H. Jeon, Electrospun fibrous scaffolds for tissue engineering: Viewpoints on architecture and fabrication, International journal of molecular sciences 19(3) (2018) 745.

[4] A. Khademhosseini, R. Langer, A decade of progress in tissue engineering, Nature protocols 11(10) (2016) 1775 .

[5] R. Samuel, L. Daheron, S. Liao, T. Vardam, W.S. Kamoun, A. Batista, C. Buecker, R. Schafer, X. Han, P. Au, D.T. Scadden, D.G. Duda, D. Fukumura, R.K. Jain, Generation of functionally competent and durable engineered blood vessels from human induced pluripotent stem cells, Proceedings of the National Academy of Sciences of the United States of America 110(31) (2013) 12774-9.

[6] T. Stoddard-Bennett, R. Reijo Pera, Treatment of Parkinson's Disease through Personalized Medicine and Induced Pluripotent Stem Cells, Cells 8(1) (2019).

[7] D.T. Paik, M. Chandy, J.C. Wu, Patient and Disease-Specific Induced Pluripotent Stem Cells for Discovery of Personalized Cardiovascular Drugs and Therapeutics, Pharmacol Rev 72(1) (2020) 320-342.

[8] A. Nandakumar, R. Truckenmuller, M. Ahmed, F. Damanik, D.R. Santos, N. Auffermann, J. de Boer, P. Habibovic, C. van Blitterswijk, L. Moroni, A Fast Process for Imprinting Micro and Nano Patterns on Electrospun Fiber Meshes at Physiological Temperatures, Small (2013).

[9] S.C. Neves, C. Mota, A. Longoni, C.C. Barrias, P.L. Granja, L. Moroni, Additive manufactured polymeric 3D scaffolds with tailored surface topography influence mesenchymal stromal cells activity, Biofabrication 8(2) (2016) 025012.

[10] A. Di Luca, A. Longoni, G. Criscenti, I. Lorenzo-Moldero, M. Klein-Gunnewiek, J. Vancso, C. van Blitterswijk, C. Mota, L. Moroni, Surface energy and stiffness discrete gradients in additive manufactured scaffolds for osteochondral regeneration, Biofabrication 8(1) (2016) 015014.

[11] L. Chung, D.R. Maestas, Jr., F. Housseau, J.H. Elisseeff, Key players in the immune response to biomaterial scaffolds for regenerative medicine, Adv Drug Deliv Rev 114 (2017) 184-192.

[12] K. Sadtler, M.T. Wolf, S. Ganguly, C.A. Moad, L. Chung, S. Majumdar, F. Housseau, D.M. Pardoll, J.H. Elisseeff, Divergent immune responses to synthetic and biological scaffolds, Biomaterials 192 (2019) 405-415.

[13] E.M. Sussman, M.C. Halpin, J. Muster, R.T. Moon, B.D. Ratner, Porous implants modulate healing and induce shifts in local macrophage polarization in the foreign body reaction, Ann Biomed Eng 42(7) (2014) 1508-16.

[14] E.T. Pashuck, M.M. Stevens, Designing regenerative biomaterial therapies for the clinic, Science translational medicine 4(160) (2012) 160sr4-160sr4.

[15] E.S. Place, N.D. Evans, M.M. Stevens, Complexity in biomaterials for tissue engineering, Nature materials 8(6) (2009) 457-470.

[16] G. Pellegrini, D. Ardigo, G. Milazzo, G. Iotti, P. Guatelli, D. Pelosi, M. De Luca, Navigating Market Authorization: The Path Holoclar Took to Become the First Stem Cell Product Approved in the European Union, Stem Cells Transl Med 7(1) (2018) 146-154.

[17] C.A. Heath, Cells for tissue engineering, Trends in biotechnology 18(1) (2000) 17-19.

[18] A.J. Putnam, D.J. Mooney, Tissue engineering using synthetic extracellular matrices, Nature Publishing Group, 1996.

[19] D. Grafahrend, K.-H. Heffels, M.V. Beer, P. Gasteier, M. Möller, G. Boehm, P.D. Dalton, J. Groll, Degradable polyester scaffolds with controlled surface chemistry combining minimal protein adsorption with specific bioactivation, Nature materials 10(1) (2011) 67.

[20] Z. Meng, Y. Wang, C. Ma, W. Zheng, L. Li, Y. Zheng, Electrospinning of PLGA/gelatin randomly-oriented and aligned nanofibers as potential scaffold in tissue engineering, Materials Science and Engineering: C 30(8) (2010) 1204-1210.

[21] R.B. Diego, M.P. Olmedilla, Á.S. Aroca, J.G. Ribelles, M.M. Pradas, G.G. Ferrer, M.S. Sánchez, Acrylic scaffolds with interconnected spherical pores and controlled hydrophilicity for tissue engineering, Journal of materials science 40(18) (2005) 4881-4887.

[22] N.J. Amoroso, A. D’Amore, Y. Hong, C.P. Rivera, M.S. Sacks, W.R. Wagner, Microstructural manipulation of electrospun scaffolds for specific bending stiffness for heart valve tissue engineering, Acta biomaterialia 8(12) (2012) 4268-4277. 
[23] E.M. Christenson, K.S. Anseth, J.J. van den Beucken, C.K. Chan, B. Ercan, J.A. Jansen, C.T. Laurencin, W.J. Li, R. Murugan, L.S. Nair, Nanobiomaterial applications in orthopedics, Journal of Orthopaedic Research 25(1) (2007) 11-22.

[24] A.D. Doyle, N. Carvajal, A. Jin, K. Matsumoto, K.M. Yamada, Local 3D matrix microenvironment regulates cell migration through spatiotemporal dynamics of contractilitydependent adhesions, Nature communications 6 (2015) 8720.

[25] G. Jin, R. He, B. Sha, W. Li, H. Qing, R. Teng, F. Xu, Electrospun three-dimensional aligned nanofibrous scaffolds for tissue engineering, Materials Science and Engineering: C (2018).

[26] Y. Yan, L.M. Martin, D.B. Bosco, J.L. Bundy, R.S. Nowakowski, Q.-X.A. Sang, Y. Li, Differential effects of acellular embryonic matrices on pluripotent stem cell expansion and neural differentiation, Biomaterials 73 (2015) 231-242.

[27] C.M. Kelleher, J.P. Vacanti, Engineering extracellular matrix through nanotechnology, Journal of the Royal Society Interface 7(suppl_6) (2010) S717-S729.

[28] C.P. Barnes, S.A. Sell, E.D. Boland, D.G. Simpson, G.L. Bowlin, Nanofiber technology: designing the next generation of tissue engineering scaffolds, Advanced drug delivery reviews 59(14) (2007) 1413-1433.

[29] S.F. Badylak, The extracellular matrix as a scaffold for tissue reconstruction, Seminars in cell \& developmental biology, Elsevier, 2002, pp. 377-383.

[30] S.F. Badylak, D.O. Freytes, T.W. Gilbert, Extracellular matrix as a biological scaffold material: structure and function, Acta biomaterialia 5(1) (2009) 1-13.

[31] R.O. Hynes, The extracellular matrix: not just pretty fibrils, Science 326(5957) (2009) 1216 1219.

[32] J.D. Hartgerink, E. Beniash, S.I. Stupp, Self-assembly and mineralization of peptideamphiphile nanofibers, Science 294(5547) (2001) 1684-1688.

[33] J.D. Hartgerink, E. Beniash, S.I. Stupp, Peptide-amphiphile nanofibers: a versatile scaffold for the preparation of self-assembling materials, Proceedings of the National Academy of Sciences 99(8) (2002) 5133-5138.

[34] O.J. Goor, S.I. Hendrikse, P.Y. Dankers, E. Meijer, From supramolecular polymers to multicomponent biomaterials, Chemical Society Reviews 46(21) (2017) 6621-6637.

[35] M.J. Webber, E.A. Appel, E. Meijer, R. Langer, Supramolecular biomaterials, Nature materials 15(1) (2016) 13.

[36] V.J. Chen, P.X. Ma, Nano-fibrous poly (L-lactic acid) scaffolds with interconnected spherical macropores, Biomaterials 25(11) (2004) 2065-2073.

[37] P.X. Ma, R. Zhang, Synthetic nano-scale fibrous extracellular matrix, Journal of Biomedical Materials Research: An Official Journal of The Society for Biomaterials, The Japanese Society for Biomaterials, and The Australian Society for Biomaterials 46(1) (1999) 60-72.

[38] Z.-M. Huang, Y.-Z. Zhang, M. Kotaki, S. Ramakrishna, A review on polymer nanofibers by electrospinning and their applications in nanocomposites, Composites science and technology 63(15) (2003) 2223-2253.

[39] D. Li, Y. Xia, Electrospinning of nanofibers: reinventing the wheel?, Advanced materials 16(14) (2004) 1151-1170.

[40] D.H. Reneker, I. Chun, Nanometre diameter fibres of polymer, produced by electrospinning, Nanotechnology 7(3) (1996) 216.

[41] D. Philp, J.F. Stoddart, Self-assembly in natural and unnatural systems, Angewandte Chemie International Edition in English 35(11) (1996) 1154-1196.

[42] L.A. Smith, X. Liu, P.X. Ma, Tissue engineering with nano-fibrous scaffolds, Soft Matter 4(11) (2008) 2144-2149.

[43] J.K. Mouw, G. Ou, V.M. Weaver, Extracellular matrix assembly: a multiscale deconstruction, Nature reviews Molecular cell biology 15(12) (2014) 771-785.

[44] R.H. Fang, A.V. Kroll, W. Gao, L. Zhang, Cell membrane coating nanotechnology, Advanced Materials 30(23) (2018) 1706759.

[45] M.J. Webber, Engineering responsive supramolecular biomaterials: Toward smart therapeutics, Bioengineering \& translational medicine 1(3) (2016) 252-266.

[46] M.J. Webber, E.A. Appel, E. Meijer, R. Langer, Supramolecular biomaterials, Nature materials 15(1) (2016) 13-26.

[47] C.J. Edwards-Gayle, I.W. Hamley, Self-assembly of bioactive peptides, peptide conjugates, and peptide mimetic materials, Organic \& biomolecular chemistry 15(28) (2017) 5867-5876.

[48] S. Fleming, R.V. Ulijn, Design of nanostructures based on aromatic peptide amphiphiles, Chemical Society Reviews 43(23) (2014) 8150-8177.

[49] J.B. Matson, S.I. Stupp, Self-assembling peptide scaffolds for regenerative medicine, Chemical communications 48(1) (2012) 26-33. 
[50] S. Han, S. Cao, Y. Wang, J. Wang, D. Xia, H. Xu, X. Zhao, J.R. Lu, Self-assembly of short peptide amphiphiles: the cooperative effect of hydrophobic interaction and hydrogen bonding, Chemistry-A European Journal 17(46) (2011) 13095-13102.

[51] L. Sun, C. Zheng, T.J. Webster, Self-assembled peptide nanomaterials for biomedical applications: promises and pitfalls, International journal of nanomedicine 12 (2017) 73.

[52] H. Cui, M.J. Webber, S.I. Stupp, Self-assembly of peptide amphiphiles: From molecules to nanostructures to biomaterials, Peptide Science: Original Research on Biomolecules 94(1) (2010) $1-18$.

[53] S. Zhang, Fabrication of novel biomaterials through molecular self-assembly, Nature biotechnology 21(10) (2003) 1171.

[54] S. Ghanaati, M.J. Webber, R.E. Unger, C. Orth, J.F. Hulvat, S.E. Kiehna, M. Barbeck, A. Rasic, S.I. Stupp, C.J. Kirkpatrick, Dynamic in vivo biocompatibility of angiogenic peptide amphiphile nanofibers, Biomaterials 30(31) (2009) 6202-6212.

[55] V.M. Tysseling-Mattiace, V. Sahni, K.L. Niece, D. Birch, C. Czeisler, M.G. Fehlings, S.I. Stupp, J.A. Kessler, Self-assembling nanofibers inhibit glial scar formation and promote axon elongation after spinal cord injury, Journal of Neuroscience 28(14) (2008) 3814-3823.

[56] R.P. Sijbesma, F.H. Beijer, L. Brunsveld, B.J. Folmer, J.K. Hirschberg, R.F. Lange, J.K. Lowe, E. Meijer, Reversible polymers formed from self-complementary monomers using quadruple hydrogen bonding, Science 278(5343) (1997) 1601-1604.

[57] P.Y. Dankers, M.C. Harmsen, L.A. Brouwer, M.J. Van Luyn, E. Meijer, A modular and supramolecular approach to bioactive scaffolds for tissue engineering, Nature materials $4(7)$ (2005) 568-574.

[58] D.E. Muylaert, G.C. van Almen, H. Talacua, J.O. Fledderus, J. Kluin, S.I. Hendrikse, J.L. van Dongen, E. Sijbesma, A.W. Bosman, T. Mes, Early in-situ cellularization of a supramolecular vascular graft is modified by synthetic stromal cell-derived factor-1a derived peptides, Biomaterials 76 (2016) 187-195.

[59] P.P. Bose, M.G. Drew, A.K. Das, A. Banerjee, Formation of triple helical nanofibers using self-assembling chiral benzene-1, 3, 5-tricarboxamides and reversal of the nanostructure's handedness using mirror image building blocks, Chemical Communications (30) (2006) 31963198.

[60] C.M. Leenders, L. Albertazzi, T. Mes, M.M. Koenigs, A.R. Palmans, E. Meijer, Supramolecular polymerization in water harnessing both hydrophobic effects and hydrogen bond formation, Chemical Communications 49(19) (2013) 1963-1965.

[61] H. Zhao, J. Xu, K. Peng, X. Fu, E. Zhang, F. Lv, L. Liu, N. Zhang, Y. Wang, S. Wang, Supramolecular Nanofibers for Encapsulation and In Situ Differentiation of Neural Stem Cells, Advanced healthcare materials 9(1) (2020) 1901295.

[62] C. Tong, T. Liu, V. Saez Talens, W.E. Noteborn, T.H. Sharp, M.M. Hendrix, I.K. Voets, C.L. Mummery, V.V. Orlova, R.E. Kieltyka, Squaramide-based supramolecular materials for threedimensional cell culture of human induced pluripotent stem cells and their derivatives, Biomacromolecules 19(4) (2018) 1091-1099.

[63] C.C. Lee, C. Grenier, E. Meijer, A.P. Schenning, Preparation and characterization of helical self-assembled nanofibers, Chemical Society Reviews 38(3) (2009) 671-683.

[64] G.A. Silva, C. Czeisler, K.L. Niece, E. Beniash, D.A. Harrington, J.A. Kessler, S.I. Stupp, Selective differentiation of neural progenitor cells by high-epitope density nanofibers, Science 303(5662) (2004) 1352-1355.

[65] L. Smith, P. Ma, Nano-fibrous scaffolds for tissue engineering, Colloids and surfaces B: biointerfaces 39(3) (2004) 125-131.

[66] R.J. Wade, J.A. Burdick, Engineering ECM signals into biomaterials, Materials Today 15(10) (2012) 454-459.

[67] G. Wei, P.X. Ma, Structure and properties of nano-hydroxyapatite/polymer composite scaffolds for bone tissue engineering, Biomaterials 25(19) (2004) 4749-4757.

[68] R. Zhang, P. Ma, Processing of polymer scaffolds: phase separation, Methods of tissue engineering (2001) 715-724.

[69] F. Yang, R. Murugan, S. Ramakrishna, X. Wang, Y.-X. Ma, S. Wang, Fabrication of nanostructured porous PLLA scaffold intended for nerve tissue engineering, Biomaterials 25(10) (2004) 1891-1900.

[70] S. Ramakrishna, K. Fujihara, W.-E. Teo, T. Yong, Z. Ma, R. Ramaseshan, Electrospun nanofibers: solving global issues, Materials today 9(3) (2006) 40-50.

[71] W.J. Li, C.T. Laurencin, E.J. Caterson, R.S. Tuan, F.K. Ko, Electrospun nanofibrous structure: a novel scaffold for tissue engineering, Journal of Biomedical Materials Research: An Official Journal of The Society for Biomaterials, The Japanese Society for Biomaterials, and The Australian Society for Biomaterials and the Korean Society for Biomaterials 60(4) (2002) 613-621. 
[72] J. Kucinska-Lipka, I. Gubanska, H. Janik, M. Sienkiewicz, Fabrication of polyurethane and polyurethane based composite fibres by the electrospinning technique for soft tissue engineering of cardiovascular system, Materials Science and Engineering: C 46 (2015) 166-176.

[73] N. Bhardwaj, S.C. Kundu, Electrospinning: a fascinating fiber fabrication technique, Biotechnology advances 28(3) (2010) 325-347.

[74] R. Murugan, S. Ramakrishna, Nano-featured scaffolds for tissue engineering: a review of spinning methodologies, Tissue engineering 12(3) (2006) 435-447.

[75] Q.P. Pham, U. Sharma, A.G. Mikos, Electrospinning of polymeric nanofibers for tissue engineering applications: a review, Tissue engineering 12(5) (2006) 1197-1211.

[76] P.P. Bonvallet, M.J. Schultz, E.H. Mitchell, J.L. Bain, B.K. Culpepper, S.J. Thomas, S.L. Bellis, Microporous dermal-mimetic electrospun scaffolds pre-seeded with fibroblasts promote tissue regeneration in full-thickness skin wounds, PLoS One 10(3) (2015) e0122359.

[77] E. Vatankhah, M.P. Prabhakaran, D. Semnani, S. Razavi, M. Morshed, S. Ramakrishna, Electrospun tecophilic/gelatin nanofibers with potential for small diameter blood vessel tissue engineering, Biopolymers 101(12) (2014) 1165-1180.

[78] J. Steele, S. McCullen, A. Callanan, H. Autefage, M. Accardi, D. Dini, M. Stevens, Combinatorial scaffold morphologies for zonal articular cartilage engineering, Acta biomaterialia 10(5) (2014) 2065-2075.

[79] P.M. Jenkins, M.R. Laughter, D.J. Lee, Y.M. Lee, C.R. Freed, D. Park, A nerve guidance conduit with topographical and biochemical cues: potential application using human neural stem cells, Nanoscale research letters 10(1) (2015) 264.

[80] G. Cadafalch Gazquez, H. Chen, S.A. Veldhuis, A. Solmaz, C. Mota, B.A. Boukamp, C.A. van Blitterswijk, J.E. ten Elshof, L. Moroni, Flexible yttrium-stabilized zirconia nanofibers offer bioactive cues for osteogenic differentiation of human mesenchymal stromal cells, ACS nano 10(6) (2016) 5789-5799.

[81] J.H. Lee, J.-H. Park, A. El-Fiqi, J.-H. Kim, Y.-R. Yun, J.-H. Jang, C.-M. Han, E.-J. Lee, H.-W. Kim, Biointerface control of electrospun fiber scaffolds for bone regeneration: engineered protein link to mineralized surface, Acta biomaterialia 10(6) (2014) 2750-2761.

[82] J. Ma, X. He, E. Jabbari, Osteogenic differentiation of marrow stromal cells on random and aligned electrospun poly (L-lactide) nanofibers, Annals of biomedical engineering 39(1) (2011) 14-25.

[83] A.K. Gaharwar, S.M. Mihaila, A.A. Kulkarni, A. Patel, A. Di Luca, R.L. Reis, M.E. Gomes, C. van Blitterswijk, L. Moroni, A. Khademhosseini, Amphiphilic beads as depots for sustained drug release integrated into fibrillar scaffolds, Journal of controlled release 187 (2014) 66-73.

[84] V. Jacobs, R.D. Anandjiwala, M. Maaza, The influence of electrospinning parameters on the structural morphology and diameter of electrospun nanofibers, Journal of applied polymer science 115(5) (2010) 3130-3136.

[85] F. Yang, R. Murugan, S. Wang, S. Ramakrishna, Electrospinning of nano/micro scale poly (L-lactic acid) aligned fibers and their potential in neural tissue engineering, Biomaterials 26(15) (2005) 2603-2610.

[86] L. Feng, Y. Song, J. Zhai, B. Liu, J. Xu, L. Jiang, D. Zhu, Creation of a superhydrophobic surface from an amphiphilic polymer, Angewandte Chemie International Edition 42(7) (2003) 800-802.

[87] N.M. Alves, J. Shi, E. Oramas, J.L. Santos, H. Tom á S, J.F. Mano, Bioinspired superhydrophobic poly (L-lactic acid) surfaces control bone marrow derived cells adhesion and proliferation, Journal of Biomedical Materials Research Part A: An Official Journal of The Society for Biomaterials, The Japanese Society for Biomaterials, and The Australian Society for Biomaterials and the Korean Society for Biomaterials 91(2) (2009) 480-488.

[88] F.L. Geyer, E. Ueda, U. Liebel, N. Grau, P.A. Levkin, Superhydrophobic-superhydrophilic micropatterning: towards genome-on-a-chip cell microarrays, Angewandte Chemie International Edition 50(36) (2011) 8424-8427.

[89] R.B. Pernites, C.M. Santos, M. Maldonado, R.R. Ponnapati, D.F. Rodrigues, R.C. Advincula, Tunable protein and bacterial cell adsorption on colloidally templated superhydrophobic polythiophene films, Chemistry of Materials 24(5) (2011) 870-880.

[90] J.A. Kaplan, R. Liu, J.D. Freedman, R. Padera, J. Schwartz, Y.L. Colson, M.W. Grinstaff, Prevention of lung cancer recurrence using cisplatin-loaded superhydrophobic nanofiber meshes, Biomaterials 76 (2016) 273-281.

[91] L. Jiang, Y. Zhao, J. Zhai, A lotus - leaf-like superhydrophobic surface: a porous microsphere/nanofiber composite film prepared by electrohydrodynamics, Angewandte Chemie International Edition 43(33) (2004) 4338-4341.

[92] K. Lee, H. Kim, H. Bang, Y. Jung, S. Lee, The change of bead morphology formed on electrospun polystyrene fibers, Polymer 44(14) (2003) 4029-4034. 
[93] Y. Liu, J.H. He, J.y. Yu, H.m. Zeng, Controlling numbers and sizes of beads in electrospun nanofibers, Polymer International 57(4) (2008) 632-636.

[94] C. Zhang, X. Yuan, L. Wu, Y. Han, J. Sheng, Study on morphology of electrospun poly (vinyl alcohol) mats, European polymer journal 41(3) (2005) 423-432.

[95] X. Zong, K. Kim, D. Fang, S. Ran, B.S. Hsiao, B. Chu, Structure and process relationship of electrospun bioabsorbable nanofiber membranes, Polymer 43(16) (2002) 4403-4412.

[96] B. Ding, C. Li, Y. Hotta, J. Kim, O. Kuwaki, S. Shiratori, Conversion of an electrospun nanofibrous cellulose acetate mat from a super-hydrophilic to super-hydrophobic surface, Nanotechnology 17(17) (2006) 4332.

[97] S. Huan, G. Liu, G. Han, W. Cheng, Z. Fu, Q. Wu, Q. Wang, Effect of experimental parameters on morphological, mechanical and hydrophobic properties of electrospun polystyrene fibers, Materials 8(5) (2015) 2718-2734.

[98] Y. Miyauchi, B. Ding, S. Shiratori, Fabrication of a silver-ragwort-leaf-like super-hydrophobic micro/nanoporous fibrous mat surface by electrospinning, Nanotechnology 17(20) (2006) 5151. [99] V. Chaurey, F. Block, Y.-H. Su, P.-C. Chiang, E. Botchwey, C.-F. Chou, N.S. Swami, Nanofiber size-dependent sensitivity of fibroblast directionality to the methodology for scaffold alignment, Acta biomaterialia 8(11) (2012) 3982-3990.

[100] S. Deepthi, M.N. Sundaram, J.D. Kadavan, R. Jayakumar, Layered chitosan-collagen hydrogel/aligned PLLA nanofiber construct for flexor tendon regeneration, Carbohydrate polymers 153 (2016) 492-500.

[101] G.E. Fantner, H. Birkedal, J.H. Kindt, T. Hassenkam, J.C. Weaver, J.A. Cutroni, B.L. Bosma, L. Bawazer, M.M. Finch, G.A. Cidade, Influence of the degradation of the organic matrix on the microscopic fracture behavior of trabecular bone, Bone 35(5) (2004) 1013-1022.

[102] J. Ramasamy, O. Akkus, Local variations in the micromechanical properties of mouse femur: the involvement of collagen fiber orientation and mineralization, Journal of biomechanics $40(4)$ (2007) 910-918.

[103] M.C. Summitt, K.D. Reisinger, Characterization of the mechanical properties of demineralized bone, Journal of Biomedical Materials Research Part A: An Official Journal of The Society for Biomaterials, The Japanese Society for Biomaterials, and The Australian Society for Biomaterials and the Korean Society for Biomaterials 67(3) (2003) 742-750.

[104] Z. Guo, J. Xu, S. Ding, H. Li, C. Zhou, L. Li, In vitro evaluation of random and aligned polycaprolactone/gelatin fibers via electrospinning for bone tissue engineering, Journal of Biomaterials Science, Polymer Edition 26(15) (2015) 989-1001.

[105] J. Xie, X. Li, J. Lipner, C.N. Manning, A.G. Schwartz, S. Thomopoulos, Y. Xia, "Aligned-torandom" nanofiber scaffolds for mimicking the structure of the tendon-to-bone insertion site, Nanoscale 2(6) (2010) 923-926.

[106] Y. Xu, Z. Wu, X. Dong, H. Li, Combined biomaterial signals stimulate communications between bone marrow stromal cell and endothelial cell, Rsc Advances 7(9) (2017) 5306-5314.

[107] Y.M. Kolambkar, M. Bajin, A. Wojtowicz, D.W. Hutmacher, A.J. García, R.E. Guldberg, Nanofiber orientation and surface functionalization modulate human mesenchymal stem cell behavior in vitro, Tissue Engineering Part A 20(1-2) (2013) 398-409.

[108] S.K. Madhurakkat Perikamana, J. Lee, T. Ahmad, Y. Jeong, D.-G. Kim, K. Kim, H. Shin, Effects of immobilized BMP-2 and nanofiber morphology on in vitro osteogenic differentiation of hMSCs and in vivo collagen assembly of regenerated bone, ACS applied materials \& interfaces 7(16) (2015) 8798-8808.

[109] Y. Zhu, Y. Cao, J. Pan, Y. Liu, Macro-alignment of electrospun fibers for vascular tissue engineering, Journal of Biomedical Materials Research Part B: Applied Biomaterials: An Official Journal of The Society for Biomaterials, The Japanese Society for Biomaterials, and The Australian Society for Biomaterials and the Korean Society for Biomaterials 92(2) (2010) 508-516.

[110] H. Wu, J. Fan, C.-C. Chu, J. Wu, Electrospinning of small diameter 3-D nanofibrous tubular scaffolds with controllable nanofiber orientations for vascular grafts, Journal of Materials Science: Materials in Medicine 21(12) (2010) 3207-3215.

[111] T. Yao, H. Chen, M.B. Baker, L. Moroni, Effects of Fiber Alignment and Coculture with Endothelial Cells on Osteogenic Differentiation of Mesenchymal Stromal Cells, Tissue engineering. Part C, Methods 26(1) (2020) 11-22.

[112] X. Wang, B. Ding, J. Yu, J. Yang, Large-scale fabrication of two-dimensional spider-weblike gelatin nano-nets via electro-netting, Colloids and Surfaces B: Biointerfaces 86(2) (2011) 345-352.

[113] H. Chen, D. Baptista, G. Criscenti, J. Crispim, H. Fernandes, C. van Blitterswijk, R. Truckenmuller, L. Moroni, From fiber curls to mesh waves: A platform for fabrication of hierarchically structured nanofibers mimicking natural tissue formation, Nanoscale (2019).

[114] D. Li, Y. Xia, Direct fabrication of composite and ceramic hollow nanofibers by electrospinning, Nano letters 4(5) (2004) 933-938. 
[115] W.J. Roberts, Honeycomb Geometry: Applied Mathematics in Nature, Mathematics Teacher 77(3) (1984) 188-90.

[116] L. Heng, X. Meng, B. Wang, L. Jiang, Bioinspired design of honeycomb structure interfaces with controllable water adhesion, Langmuir 29(30) (2013) 9491-9498.

[117] A. Garcia Garcia, A. Hébraud, J.-L. Duval, C.R. Wittmer, L. Gaut, D. Duprez, C. Egles, F. Bedoui, G. Schlatter, C. Legallais, Poly ( $\varepsilon$-caprolactone)/Hydroxyapatite 3D Honeycomb Scaffolds for a Cellular Microenvironment Adapted to Maxillofacial Bone Reconstruction, ACS Biomaterials Science \& Engineering 4(9) (2018) 3317-3326.

[118] G. Yan, J. Yu, Y. Qiu, X. Yi, J. Lu, X. Zhou, X. Bai, Self-assembly of electrospun polymer nanofibers: A general phenomenon generating honeycomb-patterned nanofibrous structures, Langmuir 27(8) (2011) 4285-4289.

[119] T. Yao, H. Chen, P. Samal, S. Giselbrecht, M.B. Baker, L. Moroni, Self-assembly of electrospun nanofibers into gradient honeycomb structures, Materials \& Design 168 (2019) 107614.

[120] J. Lee, J. Jang, H. Oh, Y.H. Jeong, D.-W. Cho, Fabrication of a three-dimensional nanofibrous scaffold with lattice pores using direct-write electrospinning, Materials Letters 93 (2013) 397-400.

[121] J. Lee, S.Y. Lee, J. Jang, Y.H. Jeong, D.-W. Cho, Fabrication of patterned nanofibrous mats using direct-write electrospinning, Langmuir 28(18) (2012) 7267-7275.

[122] H. Chen, A.d.B.F.B. Malheiro, C. van Blitterswijk, C. Mota, P.A. Wieringa, L. Moroni, Direct writing electrospinning of scaffolds with multidimensional fiber architecture for hierarchical tissue engineering, ACS applied materials \& interfaces 9(44) (2017) 38187-38200.

[123] H.R. Pant, H.J. Kim, M.K. Joshi, B. Pant, C.H. Park, J.I. Kim, K. Hui, C.S. Kim, One-step fabrication of multifunctional composite polyurethane spider-web-like nanofibrous membrane for water purification, Journal of hazardous materials 264 (2014) 25-33.

[124] B. Ding, C. Li, Y. Miyauchi, O. Kuwaki, S. Shiratori, Formation of novel 2D polymer nanowebs via electrospinning, Nanotechnology 17(15) (2006) 3685.

[125] H.R. Pant, M.P. Bajgai, K.T. Nam, K.H. Chu, S.-J. Park, H.Y. Kim, Formation of electrospun nylon-6/methoxy poly (ethylene glycol) oligomer spider-wave nanofibers, Materials letters 64(19) (2010) 2087-2090.

[126] A.P. Tiwari, M.K. Joshi, J.I. Kim, A.R. Unnithan, J. Lee, C.H. Park, C.S. Kim, Bimodal fibrous structures for tissue engineering: Fabrication, characterization and in vitro biocompatibility, Journal of colloid and interface science 476 (2016) 29-34.

[127] A.P. Tiwari, M.K. Joshi, J. Lee, B. Maharjan, S.W. Ko, C.H. Park, C.S. Kim, Heterogeneous electrospun polycaprolactone/polyethylene glycol membranes with improved wettability, biocompatibility, and mineralization, Colloids and Surfaces A: Physicochemical and Engineering Aspects 520 (2017) 105-113.

[128] N. Li, G. Chen, J. Liu, Y. Xia, H. Chen, H. Tang, F. Zhang, N. Gu, Effect of surface topography and bioactive properties on early adhesion and growth behavior of mouse preosteoblast MC3T3E1 cells, ACS applied materials \& interfaces 6(19) (2014) 17134-17143.

[129] R. Nirmala, R. Navamathavan, H.-S. Kang, M.H. El-Newehy, H.Y. Kim, Preparation of polyamide-6/chitosan composite nanofibers by a single solvent system via electrospinning for biomedical applications, Colloids and Surfaces B: Biointerfaces 83(1) (2011) 173-178.

[130] C. Wang, Y. Guo, Y. Wang, H. Xu, R. Wang, X. Zhang, Supramolecular Amphiphiles Based on a Water-Soluble Charge-Transfer Complex: Fabrication of Ultralong Nanofibers with Tunable Straightness, Angewandte Chemie International Edition 48(47) (2009) 8962-8965.

[131] H. Wang, W. You, P. Jiang, L. Yu, H.H. Wang, Supramolecular Self-Assembly of Conjugated Diblock Copolymers, Chemistry-A European Journal 10(4) (2004) 986-993.

[132] H.-F. Zhang, C.-M. Wang, E.C. Buck, L.-S. Wang, Synthesis, characterization, and manipulation of helical SiO2 nanosprings, Nano Letters 3(5) (2003) 577-580.

[133] T. Han, D.H. Reneker, A.L. Yarin, Buckling of jets in electrospinning, Polymer 48(20) (2007) 6064-6076.

[134] T. Lin, H. Wang, X. Wang, Self-crimping bicomponent nanofibers electrospun from polyacrylonitrile and elastomeric polyurethane, Advanced Materials 17(22) (2005) 2699-2703.

[135] M.K. Shin, S.I. Kim, S.J. Kim, Controlled assembly of polymer nanofibers: From helical springs to fully extended, Applied physics letters 88(22) (2006) 223109.

[136] H. Zhang, X. Xin, J. Sun, L. Zhao, J. Shen, Z. Song, S. Yuan, Self-assembled chiral helical nanofibers by amphiphilic dipeptide derived from d-or I-threonine and application as a template for the synthesis of Au and Ag nanoparticles, Journal of colloid and interface science 484 (2016) 97-106. 
[137] Y. Zhou, H. Wang, J. He, K. Qi, B. Ding, Highly stretchable nanofiber-coated hybrid yarn with wavy structure fabricated by novel airflow-electrospinning method, Materials Letters 239 (2019) 1-4.

[138] Z. Zhu, X. Chen, Z. Du, S. Huang, D. Peng, J. Zheng, H. Wang, Fabricated wavy micro/nanofiber via auxiliary electrodes in near-field electrospinning, Materials and Manufacturing Processes 31(6) (2016) 707-712.

[139] R.H. Baughman, A.A. Zakhidov, W.A. De Heer, Carbon nanotubes--the route toward applications, science 297(5582) (2002) 787-792.

[140] D.T. Bong, T.D. Clark, J.R. Granja, M.R. Ghadiri, Self-assembling organic nanotubes, Angewandte Chemie International Edition 40(6) (2001) 988-1011.

[141] R. Tenne, Inorganic Nanotubes and Fullerene-Like Materials, Chemistry-A European Journal 8(23) (2002) 5296-5304.

[142] N.M. Matsumoto, R.P. Lafleur, X. Lou, K.-C. Shih, S.P. Wijnands, C. Guibert, J.W. van Rosendaal, I.K. Voets, A.R. Palmans, Y. Lin, Polymorphism in benzene-1, 3, 5-tricarboxamide supramolecular assemblies in water: a subtle trade-off between structure and dynamics, Journal of the American Chemical Society 140(41) (2018) 13308-13316.

[143] M. Bognitzki, H. Hou, M. Ishaque, T. Frese, M. Hellwig, C. Schwarte, A. Schaper, J.H. Wendorff, A. Greiner, Polymer, metal, and hybrid nano-and mesotubes by coating degradable polymer template fibers (TUFT process), Advanced Materials 12(9) (2000) 637-640.

[144] H. Hou, Z. Jun, A. Reuning, A. Schaper, J.H. Wendorff, A. Greiner, Poly (p-xylylene) nanotubes by coating and removal of ultrathin polymer template fibers, Macromolecules 35 (7) (2002) 2429-2431.

[145] D. Han, A.J. Steckl, Superhydrophobic and oleophobic fibers by coaxial electrospinning, Langmuir 25(16) (2009) 9454-9462.

[146] A. Yarin, Coaxial electrospinning and emulsion electrospinning of core-shell fibers, Polymers for Advanced Technologies 22(3) (2011) 310-317.

[147] J.T. McCann, D. Li, Y. Xia, Electrospinning of nanofibers with core-sheath, hollow, or porous structures, Journal of Materials Chemistry 15(7) (2005) 735-738.

[148] Y. Zhao, X. Cao, L. Jiang, Bio-mimic multichannel microtubes by a facile method, Journal of the American Chemical Society 129(4) (2007) 764-765.

[149] L. Ghasemi-Mobarakeh, M.P. Prabhakaran, M. Morshed, M.-H. Nasr-Esfahani, S. Ramakrishna, Electrospun poly ( $\varepsilon$-caprolactone)/gelatin nanofibrous scaffolds for nerve tissue engineering, Biomaterials 29(34) (2008) 4532-4539.

[150] W. He, T. Yong, W.E. Teo, Z. Ma, S. Ramakrishna, Fabrication and endothelialization of collagen-blended biodegradable polymer nanofibers: potential vascular graft for blood vessel tissue engineering, Tissue engineering 11(9-10) (2005) 1574-1588.

[151] I.K. Kwon, T. Matsuda, Co-electrospun nanofiber fabrics of poly (L-lactide-co- $\varepsilon$ caprolactone) with type I collagen or heparin, Biomacromolecules 6(4) (2005) 2096-2105.

[152] J.D. Stitzel, K.J. Pawlowski, G.E. Wnek, D.G. Simpson, G.L. Bowlin, Arterial smooth muscle cell proliferation on a novel biomimicking, biodegradable vascular graft scaffold, Journal of biomaterials applications 16(1) (2001) 22-33.

[153] S. Heydarkhan-Hagvall, K. Schenke-Layland, A.P. Dhanasopon, F. Rofail, H. Smith, B.M. Wu, R. Shemin, R.E. Beygui, W.R. MacLellan, Three-dimensional electrospun ECM-based hybrid scaffolds for cardiovascular tissue engineering, Biomaterials 29(19) (2008) 2907-2914.

[154] S. Zhang, Y. Huang, X. Yang, F. Mei, Q. Ma, G. Chen, S. Ryu, X. Deng, Gelatin nanofibrous membrane fabricated by electrospinning of aqueous gelatin solution for guided tissue regeneration, Journal of Biomedical Materials Research Part A: An Official Journal of The Society for Biomaterials, The Japanese Society for Biomaterials, and The Australian Society for Biomaterials and the Korean Society for Biomaterials 90(3) (2009) 671-679.

[155] Y. Zhang, H. Ouyang, C.T. Lim, S. Ramakrishna, Z.M. Huang, Electrospinning of gelatin fibers and gelatin/PCL composite fibrous scaffolds, Journal of Biomedical Materials Research Part B: Applied Biomaterials: An Official Journal of The Society for Biomaterials, The Japanese Society for Biomaterials, and The Australian Society for Biomaterials and the Korean Society for Biomaterials 72(1) (2005) 156-165.

[156] M.J. McClure, S.A. Sell, C.P. Barnes, W.C. Bowen, G.L. Bowlin, Cross-linking electrospun polydioxanone-soluble elastin blends: material characterization, Journal of Engineered Fibers and Fabrics 3(1) (2008) 155892500800300101.

[157] S. Sell, M.J. McClure, C.P. Barnes, D.C. Knapp, B.H. Walpoth, D.G. Simpson, G.L. Bowlin, Electrospun polydioxanone-elastin blends: potential for bioresorbable vascular grafts, Biomedical materials 1(2) (2006) 72 . 
[158] M.J. Smith, M.J. McClure, S.A. Sell, C.P. Barnes, B.H. Walpoth, D.G. Simpson, G.L. Bowlin, Suture-reinforced electrospun polydioxanone-elastin small-diameter tubes for use in vascular tissue engineering: a feasibility study, Acta Biomaterialia 4(1) (2008) 58-66.

[159] M.C. McManus, S.A. Sell, W.C. Bowen, H.P. Koo, D.G. Simpson, G.L. Bowlin, Electrospun fibrinogen-polydioxanone composite matrix: Potential for in situ urologic tissue engineering, Journal of Engineered Fibers and Fabrics 3(2) (2008) 155892500800300204.

[160] H.-J. Jin, J. Chen, V. Karageorgiou, G.H. Altman, D.L. Kaplan, Human bone marrow stromal cell responses on electrospun silk fibroin mats, Biomaterials 25(6) (2004) 1039-1047.

[161] M.S. Kim, G. Kim, Three-dimensional electrospun polycaprolactone (PCL)/alginate hybrid composite scaffolds, Carbohydrate polymers 114 (2014) 213-221.

[162] Y.B. Kim, G.H. Kim, PCL/alginate composite scaffolds for hard tissue engineering: fabrication, characterization, and cellular activities, ACS combinatorial science 17(2) (2015) 87 99.

[163] A. Cooper, N. Bhattarai, M. Zhang, Fabrication and cellular compatibility of aligned chitosan-PCL fibers for nerve tissue regeneration, Carbohydrate Polymers 85(1) (2011) 149-156. [164] U. Sajeev, K.A. Anand, D. Menon, S. Nair, Control of nanostructures in PVA, PVA/chitosan blends and PCL through electrospinning, Bulletin of Materials Science 31(3) (2008) 343-351.

[165] J.-f. Pan, N.-h. Liu, H. Sun, F. Xu, Preparation and characterization of electrospun $\mathrm{PLCL} /$ poloxamer nanofibers and dextran/gelatin hydrogels for skin tissue engineering, PLoS One 9(11) (2014) e112885.

[166] A.R. Unnithan, N.A. Barakat, P.T. Pichiah, G. Gnanasekaran, R. Nirmala, Y.-S. Cha, C.-H. Jung, M. El-Newehy, H.Y. Kim, Wound-dressing materials with antibacterial activity from electrospun polyurethane-dextran nanofiber mats containing ciprofloxacin $\mathrm{HCl}$, Carbohydrate polymers 90(4) (2012) 1786-1793.

[167] Y. Su, X. Li, Y. Liu, Q. Su, M.L.W. Qiang, X. Mo, Encapsulation and controlled release of heparin from electrospun poly (I-lactide-co- $\varepsilon$-caprolactone) nanofibers, Journal of Biomaterials Science, Polymer Edition 22(1-3) (2011) 165-177.

[168] S. Sahoo, L.T. Ang, J.C.H. Goh, S.L. Toh, Growth factor delivery through electrospun nanofibers in scaffolds for tissue engineering applications, Journal of Biomedical Materials Research Part A: An Official Journal of The Society for Biomaterials, The Japanese Society for Biomaterials, and The Australian Society for Biomaterials and the Korean Society for Biomaterials 93(4) (2010) 1539-1550.

[169] A. Schneider, X. Wang, D. Kaplan, J. Garlick, C. Egles, Biofunctionalized electrospun silk mats as a topical bioactive dressing for accelerated wound healing, Acta Biomaterialia 5(7) (2009) 2570-2578.

[170] M. Nune, U.M. Krishnan, S. Sethuraman, PLGA nanofibers blended with designer selfassembling peptides for peripheral neural regeneration, Materials Science and Engineering: C 62 (2016) 329-337.

[171] Y.C. Shin, J.H. Lee, M.J. Kim, S.W. Hong, B. Kim, J.K. Hyun, Y.S. Choi, J.-C. Park, D.-W. Han, Stimulating effect of graphene oxide on myogenesis of $\mathrm{C} 2 \mathrm{C} 12$ myoblasts on RGD peptidedecorated PLGA nanofiber matrices, Journal of biological engineering 9(1) (2015) 22.

[172] Y. Wang, Y.-L. Hsieh, Immobilization of lipase enzyme in polyvinyl alcohol (PVA) nanofibrous membranes, Journal of Membrane Science 309(1-2) (2008) 73-81.

[173] J. Xie, Y.-L. Hsieh, Ultra-high surface fibrous membranes from electrospinning of natural proteins: casein and lipase enzyme, Journal of Materials Science 38(10) (2003) 2125-2133.

[174] C.L. He, Z.M. Huang, X.J. Han, Fabrication of drug-loaded electrospun aligned fibrous threads for suture applications, Journal of Biomedical Materials Research Part A: An Official Journal of The Society for Biomaterials, The Japanese Society for Biomaterials, and The Australian Society for Biomaterials and the Korean Society for Biomaterials 89(1) (2009) 80-95.

[175] E.-R. Kenawy, F.I. Abdel-Hay, M.H. El-Newehy, G.E. Wnek, Processing of polymer nanofibers through electrospinning as drug delivery systems, Nanomaterials: Risks and Benefits, Springer2009, pp. 247-263.

[176] Y. Liu, J. Chen, N.T. Anh, C.O. Too, V. Misoska, G.G. Wallace, Nanofiber mats from DNA, SWNTs, and poly (ethylene oxide) and their application in glucose biosensors, Journal of The Electrochemical Society 155(5) (2008) K100-K103.

[177] Y. Liu, J. Chen, V. Misoska, G.G. Wallace, Preparation of novel ultrafine fibers based on DNA and poly (ethylene oxide) by electrospinning from aqueous solutions, Reactive and Functional Polymers 67(5) (2007) 461-467.

[178] H. Zhang, X. Jia, F. Han, J. Zhao, Y. Zhao, Y. Fan, X. Yuan, Dual-delivery of VEGF and PDGF by double-layered electrospun membranes for blood vessel regeneration, Biomaterials 34(9) (2013) 2202-2212. 
[179] A. Mickova, M. Buzgo, O. Benada, M. Rampichova, Z. Fisar, E. Filova, M. Tesarova, D. Lukas, E. Amler, Core/shell nanofibers with embedded liposomes as a drug delivery system, Biomacromolecules 13(4) (2012) 952-962.

[180] S.K. Tiwari, R. Tzezana, E. Zussman, S.S. Venkatraman, Optimizing partition-controlled drug release from electrospun core-shell fibers, International journal of pharmaceutics 392(1-2) (2010) 209-217.

[181] J.-P. Chen, C.-H. Su, Surface modification of electrospun PLLA nanofibers by plasma treatment and cationized gelatin immobilization for cartilage tissue engineering, Acta biomaterialia 7(1) (2011) 234-243.

[182] A. Manakhov, E. Kedroňová, J. Medalová, P. Černochová, A. Obrusnik, M. Michlíček, D.V. Shtansky, L. Zajičcková, Carboxyl-anhydride and amine plasma coating of PCL nanofibers to improve their bioactivity, Materials \& Design 132 (2017) 257-265.

[183] J.R.J. Paletta, S. Bockelmann, A. Walz, C. Theisen, J.H. Wendorff, A. Greiner, S. FuchsWinkelmann, M.D. Schofer, RGD-functionalisation of PLLA nanofibers by surface coupling using plasma treatment: influence on stem cell differentiation, Journal of Materials Science: Materials in Medicine 21(4) (2010) 1363-1369.

[184] F. Yang, J. Wolke, J. Jansen, Biomimetic calcium phosphate coating on electrospun poly $(\varepsilon-$ caprolactone) scaffolds for bone tissue engineering, Chemical Engineering Journal 137(1) (2008) 154-161.

[185] W. He, Z. Ma, T. Yong, W.E. Teo, S. Ramakrishna, Fabrication of collagen-coated biodegradable polymer nanofiber mesh and its potential for endothelial cells growth, Biomaterials 26(36) (2005) 7606-7615.

[186] H. Koh, T. Yong, C. Chan, S. Ramakrishna, Enhancement of neurite outgrowth using nanostructured scaffolds coupled with laminin, Biomaterials 29(26) (2008) 3574-3582.

[187] F. Chen, C. Lee, S. Teoh, Nanofibrous modification on ultra-thin poly (e-caprolactone) membrane via electrospinning, Materials Science and Engineering: C 27(2) (2007) 325-332.

[188] Y. Zhu, M.F. Leong, W.F. Ong, M.B. Chan-Park, K.S. Chian, Esophageal epithelium regeneration on fibronectin grafted poly (L-lactide-co-caprolactone)(PLLC) nanofiber scaffold, Biomaterials 28(5) (2007) 861-868.

[189] W.H. Binder, R. Sachsenhofer, 'Click'chemistry in polymer and materials science, Macromolecular Rapid Communications 28(1) (2007) 15-54.

[190] A. Celebioglu, S. Demirci, T. Uyar, Cyclodextrin-grafted electrospun cellulose acetate nanofibers via "Click" reaction for removal of phenanthrene, Applied Surface Science 305 (2014) 581-588.

[191] J.E. Moses, A.D. Moorhouse, The growing applications of click chemistry, Chemical Society Reviews 36(8) (2007) 1249-1262.

[192] H.C. Kolb, M. Finn, K.B. Sharpless, Click chemistry: diverse chemical function from a few good reactions, Angewandte Chemie International Edition 40(11) (2001) 2004-2021.

[193] A.R. Davis, J.A. Maegerlein, K.R. Carter, Electroluminescent networks via photo "click" chemistry, Journal of the American Chemical Society 133(50) (2011) 20546-20551.

[194] A. Lancuški, S.b. Fort, F.d.r. Bossard, Electrospun azido-PCL nanofibers for enhanced surface functionalization by click chemistry, ACS applied materials \& interfaces 4(12) (2012) 6499-6504.

[195] Q. Shi, X. Chen, T. Lu, X. Jing, The immobilization of proteins on biodegradable polymer fibers via click chemistry, Biomaterials 29(8) (2008) 1118-1126.

[196] L.A.S. Callahan, S. Xie, I.A. Barker, J. Zheng, D.H. Reneker, A.P. Dove, M.L. Becker, Directed differentiation and neurite extension of mouse embryonic stem cell on aligned poly (lactide) nanofibers functionalized with YIGSR peptide, Biomaterials 34(36) (2013) 9089-9095.

[197] J. Zheng, K. Liu, D.H. Reneker, M.L. Becker, Post-assembly derivatization of electrospun nanofibers via strain-promoted azide alkyne cycloaddition, Journal of the American Chemical Society 134(41) (2012) 17274-17277.

[198] O.I. Kalaoglu-Altan, R. Sanyal, A. Sanyal, "Clickable" Polymeric Nanofibers through Hydrophilic-Hydrophobic Balance: Fabrication of Robust Biomolecular Immobilization Platforms, Biomacromolecules 16(5) (2015) 1590-1597.

[199] H. Yang, Q. Zhang, B. Lin, G. Fu, X. Zhang, L. Guo, Thermo-sensitive electrospun fibers prepared by a sequential thiol-ene click chemistry approach, Journal of Polymer Science Part A: Polymer Chemistry 50(20) (2012) 4182-4190.

[200] O.I. Kalaoglu-Altan, R. Sanyal, A. Sanyal, Reactive and 'clickable'electrospun polymeric nanofibers, Polymer Chemistry 6(18) (2015) 3372-3381.

[201] M. Khan, J. Yang, C. Shi, J. Lv, Y. Feng, W. Zhang, Surface tailoring for selective endothelialization and platelet inhibition via a combination of SI-ATRP and click chemistry using Cys-Ala-Gly-peptide, Acta biomaterialia 20 (2015) 69-81. 
[202] S. Kaur, Z. Ma, R. Gopal, G. Singh, S. Ramakrishna, T. Matsuura, Plasma-induced graft copolymerization of poly (methacrylic acid) on electrospun poly (vinylidene fluoride) nanofiber membrane, Langmuir 23(26) (2007) 13085-13092.

[203] Z. Ma, W. He, T. Yong, S. Ramakrishna, Grafting of gelatin on electrospun poly (caprolactone) nanofibers to improve endothelial cell spreading and proliferation and to control cell orientation, Tissue engineering 11(7-8) (2005) 1149-1158.

[204] X. Guo, C.G. Elliott, Z. Li, Y. Xu, D.W. Hamilton, J. Guan, Creating 3D angiogenic growth factor gradients in fibrous constructs to guide fast angiogenesis, Biomacromolecules $13(10)$ (2012) 3262-3271.

[205] S.T. Nillesen, P.J. Geutjes, R. Wismans, J. Schalkwijk, W.F. Daamen, T.H. van Kuppevelt, Increased angiogenesis and blood vessel maturation in acellular collagen-heparin scaffolds containing both FGF2 and VEGF, Biomaterials 28(6) (2007) 1123-1131.

[206] A. Hadjizadeh, F. Ghasemkhah, N. Ghasemzaie, Polymeric scaffold based gene delivery strategies to improve angiogenesis in tissue engineering: a review, Polymer Reviews 57(3) (2017) 505-556.

[207] J. Rouwkema, A. Khademhosseini, Vascularization and angiogenesis in tissue engineering: beyond creating static networks, Trends in biotechnology 34(9) (2016) 733-745.

[208] J. Rouwkema, N.C. Rivron, C.A. van Blitterswijk, Vascularization in tissue engineering, Trends in biotechnology 26(8) (2008) 434-441.

[209] S. Chakraborty, T. Ponrasu, S. Chandel, M. Dixit, V. Muthuvijayan, Reduced graphene oxide-loaded nanocomposite scaffolds for enhancing angiogenesis in tissue engineering applications, Royal Society open science 5(5) (2018) 172017.

[210] M. Lovett, K. Lee, A. Edwards, D.L. Kaplan, Vascularization strategies for tissue engineering, Tissue Engineering Part B: Reviews 15(3) (2009) 353-370.

[211] C.K. Griffith, C. Miller, R.C. Sainson, J.W. Calvert, N.L. Jeon, C.C. Hughes, S.C. George, Diffusion limits of an in vitro thick prevascularized tissue, Tissue engineering 11(1-2) (2005) 257 266.

[212] S. Singh, B.M. Wu, J.C. Dunn, The enhancement of VEGF-mediated angiogenesis by polycaprolactone scaffolds with surface cross-linked heparin, Biomaterials 32(8) (2011) 20592069.

[213] H. Bae, A.S. Puranik, R. Gauvin, F. Edalat, B. Carrillo-Conde, N.A. Peppas, A. Khademhosseini, Building vascular networks, Science translational medicine 4(160) (2012) 160ps23-160ps23.

[214] E. Hunziker, M. Spector, J. Libera, A. Gertzman, S.L.-Y. Woo, A. Ratcliffe, M. Lysaght, A. Coury, D. Kaplan, G. Vunjak-Novakovic, Translation from research to applications, Tissue engineering 12(12) (2006) 3341-3364.

[215] M.W. Laschke, Y. Harder, M. Amon, I. Martin, J. Farhadi, A. Ring, N. Torio-Padron, R. Schramm, M. Rücker, D. Junker, Angiogenesis in tissue engineering: breathing life into constructed tissue substitutes, Tissue engineering 12(8) (2006) 2093-2104.

[216] J.J. Moon, M.S. Hahn, I. Kim, B.A. Nsiah, J.L. West, Micropatterning of poly (ethylene glycol) diacrylate hydrogels with biomolecules to regulate and guide endothelial morphogenesis, Tissue Engineering Part A 15(3) (2008) 579-585.

[217] N. Detta, C. Errico, D. Dinucci, D. Puppi, D.A. Clarke, G.C. Reilly, F. Chiellini, Novel electrospun polyurethane/gelatin composite meshes for vascular grafts, Journal of Materials Science: Materials in Medicine 21(5) (2010) 1761-1769.

[218] A. Hasan, A. Memic, N. Annabi, M. Hossain, A. Paul, M.R. Dokmeci, F. Dehghani, A. Khademhosseini, Electrospun scaffolds for tissue engineering of vascular grafts, Acta biomaterialia 10(1) (2014) 11-25.

[219] K.A. Rocco, M.W. Maxfield, C.A. Best, E.W. Dean, C.K. Breuer, In vivo applications of electrospun tissue-engineered vascular grafts: a review, Tissue Engineering Part B: Reviews 20(6) (2014) 628-640.

[220] C. Xu, R. Inai, M. Kotaki, S. Ramakrishna, Aligned biodegradable nanofibrous structure: a potential scaffold for blood vessel engineering, Biomaterials 25(5) (2004) 877-886.

[221] M. Ahmed, T. Ramos, P. Wieringa, C. van Blitterswijk, J. de Boer, L. Moroni, Geometric constraints of endothelial cell migration on electrospun fibres, Scientific reports 8(1) (2018) 6386. [222] L.E. Dike, C.S. Chen, M. Mrksich, J. Tien, G.M. Whitesides, D.E. Ingber, Geometric control of switching between growth, apoptosis, and differentiation during angiogenesis using micropatterned substrates, In Vitro Cellular \& Developmental Biology-Animal 35(8) (1999) 441448.

[223] X. Jia, C. Zhao, P. Li, H. Zhang, Y. Huang, H. Li, J. Fan, W. Feng, X. Yuan, Y. Fan, Sustained release of VEGF by coaxial electrospun dextran/PLGA fibrous membranes in vascular tissue engineering, Journal of Biomaterials Science, Polymer Edition 22(13) (2011) 1811-1827. 
[224] Z. Wang, B. Sun, M. Zhang, L. Ou, Y. Che, J. Zhang, D. Kong, Functionalization of electrospun poly ( $\varepsilon$-caprolactone) scaffold with heparin and vascular endothelial growth factors for potential application as vascular grafts, Journal of Bioactive and Compatible Polymers 28(2) (2013) 154-166.

[225] S. He, T. Xia, H. Wang, L. Wei, X. Luo, X. Li, Multiple release of polyplexes of plasmids VEGF and bFGF from electrospun fibrous scaffolds towards regeneration of mature blood vessels, Acta biomaterialia 8(7) (2012) 2659-2669.

[226] R.B. Montero, X. Vial, D.T. Nguyen, S. Farhand, M. Reardon, S.M. Pham, G. Tsechpenakis, F.M. Andreopoulos, bFGF-containing electrospun gelatin scaffolds with controlled nanoarchitectural features for directed angiogenesis, Acta biomaterialia 8(5) (2012) 1778-1791.

[227] L.D. D'Andrea, G. Iaccarino, R. Fattorusso, D. Sorriento, C. Carannante, D. Capasso, B. Trimarco, C. Pedone, Targeting angiogenesis: structural characterization and biological properties of a de novo engineered VEGF mimicking peptide, Proceedings of the National Academy of Sciences 102(40) (2005) 14215-14220.

[228] T.R. Chan, P.J. Stahl, S.M. Yu, Matrix-bound vegf mimetic peptides: design and endothelialcell activation in collagen scaffolds, Advanced functional materials 21(22) (2011) 4252-4262. [229] F. Finetti, A. Basile, D. Capasso, S. Di Gaetano, R. Di Stasi, M. Pascale, C.M. Turco, M. Ziche, L. Morbidelli, L.D. D'Andrea, Functional and pharmacological characterization of a VEGF mimetic peptide on reparative angiogenesis, Biochemical pharmacology 84(3) (2012) 303-311. [230] F. Zhou, X. Jia, Y. Yang, Q. Yang, C. Gao, Y. Zhao, Y. Fan, X. Yuan, Peptide-modified PELCL electrospun membranes for regulation of vascular endothelial cells, Materials Science and Engineering: C 68 (2016) 623-631.

[231] J.E. Leslie-Barbick, J.E. Saik, D.J. Gould, M.E. Dickinson, J.L. West, The promotion of microvasculature formation in poly (ethylene glycol) diacrylate hydrogels by an immobilized VEGF-mimetic peptide, Biomaterials 32(25) (2011) 5782-5789.

[232] Y. Yang, Q. Yang, F. Zhou, Y. Zhao, X. Jia, X. Yuan, Y. Fan, Electrospun PELCL membranes loaded with QK peptide for enhancement of vascular endothelial cell growth, Journal of Materials Science: Materials in Medicine 27(6) (2016) 106.

[233] T.G. Kim, T.G. Park, Biomimicking extracellular matrix: cell adhesive RGD peptide modified electrospun poly (D, L-lactic-co-glycolic acid) nanofiber mesh, Tissue engineering 12(2) (2006) 221-233.

[234] N.L. Kanagy, C. Szabo, A. Papapetropoulos, Vascular biology of hydrogen sulfide, American Journal of Physiology-Cell Physiology 312(5) (2017) C537-C549.

[235] C. Szabó, A. Papapetropoulos, Hydrogen sulphide and angiogenesis: mechanisms and applications, British journal of pharmacology 164(3) (2011) 853-865.

[236] A. Papapetropoulos, A. Pyriochou, Z. Altaany, G. Yang, A. Marazioti, Z. Zhou, M.G. Jeschke, L.K. Branski, D.N. Herndon, R. Wang, Hydrogen sulfide is an endogenous stimulator of angiogenesis, Proceedings of the National Academy of Sciences 106(51) (2009) 21972-21977.

[237] W.-J. Cai, M.-J. Wang, P.K. Moore, H.-M. Jin, T. Yao, Y.-C. Zhu, The novel proangiogenic effect of hydrogen sulfide is dependent on Akt phosphorylation, Cardiovascular research 76(1) (2007) 29-40.

[238] M.-J. Wang, W.-J. Cai, N. Li, Y.-J. Ding, Y. Chen, Y.-C. Zhu, The hydrogen sulfide donor $\mathrm{NaHS}$ promotes angiogenesis in a rat model of hind limb ischemia, Antioxidants \& redox signaling 12(9) (2010) 1065-1077.

[239] C.R. Powell, K.M. Dillon, J.B. Matson, A review of hydrogen sulfide (H2S) donors: Chemistry and potential therapeutic applications, Biochemical pharmacology 149 (2018) 110-123.

[240] Z.J. Song, M.Y. Ng, Z.-W. Lee, W. Dai, T. Hagen, P.K. Moore, D. Huang, L.-W. Deng, C.-H. Tan, Hydrogen sulfide donors in research and drug development, MedChemComm 5(5) (2014) 557-570.

[241] S. Feng, Y. Zhao, M. Xian, Q. Wang, Biological thiols-triggered hydrogen sulfide releasing microfibers for tissue engineering applications, Acta biomaterialia 27 (2015) 205-213.

[242] J. Kang, Z. Li, C.L. Organ, C.-M. Park, C.-t. Yang, A. Pacheco, D. Wang, D.J. Lefer, M. Xian, $\mathrm{pH}$-controlled hydrogen sulfide release for myocardial ischemia-reperfusion injury, Journal of the American Chemical Society 138(20) (2016) 6336-6339.

[243] J. Wu, Y. Li, C. He, J. Kang, J. Ye, Z. Xiao, J. Zhu, A. Chen, S. Feng, X. Li, Novel H2S releasing nanofibrous coating for in vivo dermal wound regeneration, ACS applied materials \& interfaces 8(41) (2016) 27474-27481.

[244] D. Ribatti, Chick embryo chorioallantoic membrane as a useful tool to study angiogenesis, International review of cell and molecular biology 270 (2008) 181-224.

[245] S. Singh, B.M. Wu, J.C. Dunn, Delivery of VEGF using collagen-coated polycaprolactone scaffolds stimulates angiogenesis, Journal of Biomedical Materials Research Part A 100(3) (2012) 720-727. 
[246] R. Augustine, E.A. Dominic, I. Reju, B. Kaimal, N. Kalarikkal, S. Thomas, Investigation of angiogenesis and its mechanism using zinc oxide nanoparticle-loaded electrospun tissue engineering scaffolds, RSC Advances 4(93) (2014) 51528-51536.

[247] L. Diaz-Gomez, C. Alvarez-Lorenzo, A. Concheiro, M. Silva, F. Dominguez, F.A. Sheikh, T. Cantu, R. Desai, V.L. Garcia, J. Macossay, Biodegradable electrospun nanofibers coated with platelet-rich plasma for cell adhesion and proliferation, Materials Science and Engineering: C 40 (2014) 180-188.

[248] P. Nowak-Sliwinska, K. Alitalo, E. Allen, A. Anisimov, A.C. Aplin, R. Auerbach, H.G. Augustin, D.O. Bates, J.R. van Beijnum, R.H.F. Bender, Consensus guidelines for the use and interpretation of angiogenesis assays, Angiogenesis 21(3) (2018) 425-532. 


\section{Chapter 2}

\section{Effects of Fiber Alignment and Coculture with Endothelial Cells on Osteogenic Differentiation of Mesenchymal Stromal Cells}

Tianyu Yao ${ }^{1}$, Honglin Chen², Matthew B Baker ${ }^{1}$, Lorenzo Moroni ${ }^{1}$

1. Complex Tissue Regeneration Department, MERLN Institute for Technology Inspired Regenerative Medicine Maastricht University, Maastricht, 6229 ER, the Netherlands

2. Institute for Life Science, School of Medicine, South China University of Technology, Guangzhou, 510640, China 


\section{Abstract}

Vascularization is a critical process during bone regeneration. The lack of vascular networks leads to insufficient oxygen and nutrients supply, which compromises the survival of regenerated bone. One strategy for improving the survival and osteogenesis of tissue-engineered bone grafts involves the coculture of endothelial cells (ECs) with mesenchymal stromal cells (MSCs). Moreover, bone regeneration is especially challenging due to its unique structural properties with aligned topographical cues, with which stem cells can interact. Inspired by the aligned fibrillar nanostructures in human cancellous bone, we fabricated polycaprolactone ( $P C L)$ electrospun fibers with aligned and random morphology, co-cultured human MSCs with human umbilical ECs (HUVECs), and finally investigated how these two factors modulate osteogenic differentiation of hMSCs. After optimizing cell ratio, a hMSCs/HUVECs ratio (90:10) was considered to be the best combination for osteogenic differentiation. Co-culture results showed that hMSCs and HUVECs adhered to and proliferated well on both scaffolds. The aligned structure of PCL fibers strongly influenced the morphology and orientation of hMSCs and HUVECs; however, fiber alignment was observed to not affect alkaline phosphate activity (ALP) or mineralization of hMSCs compared to random scaffolds. More importantly, co-cultured cells on both random and aligned scaffolds had significantly higher ALP activities than monoculture groups, which indicated co-culture with HUVECs provided a larger relative contribution to the osteogenesis of hMSCs compared to fiber alignment. Taken together, we conclude that co-cultured with endothelial cells is an effective strategy to promote osteogenesis on electrospun scaffolds, and aligned fibers could be introduced to regenerate bone tissues with oriented topography without significant deleterious effects on hMSCs differentiation. This study shows the ability to grow oriented tissue engineered co-cultures with significant increases in osteogenesis over monoculture conditions. 
Keywords: electrospun, co-culture, alignment, bone regeneration, vascularization

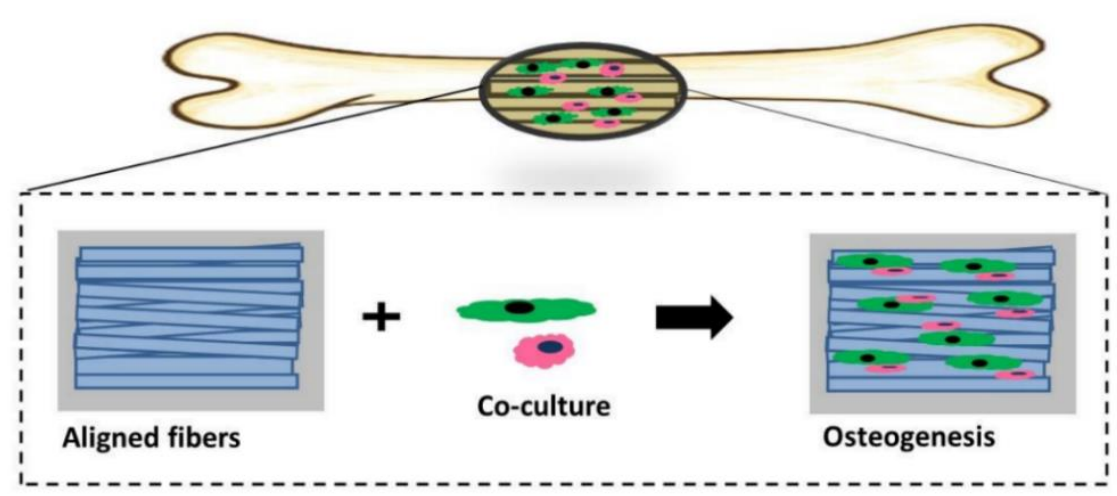




\section{Introduction}

Bone is a highly vascularized tissue which contains multiple cell types, including osteogenic and endothelial cells [1, 2]. Blood vessels can provide oxygen, nutrition and metal ions for osteogenic cells during bone regeneration $[3,4]$. Lack of efficient vascularization limits the size of new bone formation and even leads to cell death in bone graft [5-8]. Therefore, vascularization is a great challenge in bone tissue engineering $[9,10]$. In an attempt to solve this problem, co-culture techniques have been widely used for vascularized bone tissue engineering [11]. Several studies have highlighted the interaction between osteogenic cells and endothelial cells (ECs) using co-culture systems as tools for mimicking the communication between these cells in living tissue [12-14]. For example, the co-culture of human mesenchymal stem cells (hMSCs) and human umbilical vein endothelial cells (HUVECs) spheroid by seeding $2 \%$ or fewer HUVECs were used to create perivascular networks in vitro, and finally induced osteogenic differentiation of hMSCs [15]. The cocultured groups had higher ALP activity compared with monocultures, showing that endothelial cells promoted osteogenic differentiation of hMSCs $[16,17]$. In another study, a cell sheet model on PVDF membrane combining bone marrow stem cells with endothelial cells was proven to be a useful strategy for the pre-vascularization of tissue regeneration. This cell sheetbased constructs improved the survival of bone implantation by promoting the formation and stabilization of vascular units [18]. Therefore, co-cultures of hMSCs with ECs could be an effective strategy for vascularized bone formation.

The surface topography of biomaterials is considered to be one of the crucial parameters in determining cell activity [19-21]. In particular, the effect of surface topography on stem cell differentiation has been extensively investigated [22-24]. Previous reports indicated that different nanopatterns, mechanical properties and geometrical cues of scaffolds showed a significant effect on regulating stem cells behavior [25]. There are several kinds of 
nanopatterns which have been previously studied, such as grooves [26, 27], nanopillars [28, 29], nanopits [30] and aligned fibers [31, 32]. In the bone matrix, collagen fibers are preferentially oriented (parallel to the long axis of bone), and their structural features are important to provide strength in tension and resistance in bending of bone [33-35]. Since native bone tissue is composed of highly aligned collagen fibers [36], researchers attempted to mimic this unique structure by using aligned electrospun fibers [31, 37]. The effects of fiber alignment on osteogenic differentiation have been already investigated [38-40]. It was reported that the alignment of fibers induced osteogenic differentiation and upregulated the expression of osteogenic marker genes [31]. Aligned electrospun fibers provide specific geometrical cues which guide the structure and function of hMSCs for bone regeneration $[31,41]$. Calcium content on aligned fibers was significantly higher compared to that of random fibers[38]. These aligned fibrous meshes showed positive effect for bone regeneration. However, the lack of vascularization in biomaterials scaffold is still a primary challenge to support long-term functions of the regenerated bone [42, 43].

Combining the design of aligned nanofibrous scaffolds and co-cultures with ECs has been considered to be a highly promising strategy for bone regeneration research [39]. Only one study reported the combination effects of these two factors on the osteogenic differentiation of hMSCs. Xu and his collaborators combined structural signals of aligned electrospun scaffolds and chemical signals of bioglass ionic products, and investigated the effects of combined biomaterials signals on communications between hBMSCs and HUVECs [39]. This study only showed the effect of aligned electrospun scaffolds on osteogenesis, but did not investigate if fiber alignment of the electrospun scaffolds contributed to the enhanced osteogenic differentiation. Moreover, studies on the optimization of co-culture conditions on electrospun scaffolds are lacking, and more specific conditions including co-culture medium and cell ratio should be taken into consideration when co-culture studies are performed. Many studies reported that a co-culture ratio of 1:1 
( $\mathrm{hMSCs/ECs)} \mathrm{is} \mathrm{the} \mathrm{best} \mathrm{combination} \mathrm{to} \mathrm{obtain} \mathrm{osteogenic} \mathrm{differentiation} \mathrm{[44,}$ 45]. This ratio is also the most commonly used in literature for co-culture experiments of HMSCs/ECs [10, 46-48]. Some researchers presumed that lower ratio of ECs could be beneficial for the vessels formation and they used 98:2-98:5 for co-culture studies [1, 15, 49]. Guided by these considerations, 1) we optimized cell ratio of hMSCs and HUVECs (98:2-50:50) on random electrospun scaffolds and finally chose the optimal ratio on cell differentiation and mineralization for osteogenesis; 2) we developed biomimetic aligned fibrous scaffolds using a rotating mandrel as a collector, then co-cultured hMSCs and HUVECs on the scaffolds. The influence of aligned topography on the behavior of co-cultured HUVECs and hMSCs was studied. We hypothesized that hMSCs/HUVECs co-cultures may behave differently on the random and aligned fibrous scaffolds as illustrated in Scheme 1. The aligned fibers may guide the structural assembly of collagen with an alignment that is closer to native bone environment for regeneration. Subsequently, we focus on an in vitro assessment of the osteogenic differentiation potential of hMSCs by quantifying ALP activity and calcium content in cell-scaffolds. We were interested in investigating the effect of two combined factors (tissue-mimetic nanotopography and co-culture with ECs) on hMSCs differentiation and subsequent mineralization.

\section{Materials and methods}

\section{Fabrication of random and different aligned fibers}

Poly(caprolactone) (PCL; Mn $=70-90 k$ ) was produced by Sigma-Aldrich. PCL was dissolved in chloroform-dimethylformamide (4:1) mixture to prepare final concentrations of $15 \%(\mathrm{w} / \mathrm{v})$ for random and aligned fibers. Homogeneous solutions were prepared with gentle stirring overnight. A homemade electrospinning setup applied in our study was reported before [50]. It made up of a plastic syringe, the syringe pump (Harvard 2000), a stainless-steel blunt-end needle (inner diameter $=0.8 \mathrm{~mm}$ ), an aluminum plate and a high-voltage power supply. The random fibers were randomly deposited 
on the aluminum plate. For aligned fibrous mesh, a high-speed rotational mandrel was used as collector. In order to get highly alignment, the speed of rotating mandrel was set from 1000 to $4600 \mathrm{rpm}$.

\section{Characterization of random and different aligned fibers}

The morphology of the random and aligned fibers was imaged by a scanning electron microscopy (Philips XL-30 ESEM). Briefly, electrospun samples were coated with gold (Cressington Sputter Coater 108 auto) for $100 \mathrm{~s}$ at $30 \mathrm{~mA}$ and then observed by SEM at an accelerating voltage of $10 \mathrm{kV}$. All images were applied to quantitatively measure the diameter and coherency of fibers by using the Fiji software. The coherency coefficient of fibers was measured using the Orientation $\mathrm{J}$ plug-in of Fiji. The value of coherency usually ranges from 0 to 1 , the value is close to 1 indicating a strongly coherent orientation and greater alignment.

\section{Cell culture}

hMSCs (D8011L) were provided by Institute of Regenerative Medicine (Texas A\&M University, Temple, Texas). Cells were first cultured in a basic medium including a-MEM (Gibco) with 10\% FBS (Sigma), $0.2 \mathrm{mM}$ ascorbic acid (Sigma), $100 \mathrm{U} / \mathrm{ml}$ penicillin and $100 \mathrm{mg} / \mathrm{ml}$ streptomycin (Gibco) for proliferation. In order to study osteogenesis and mineralization of cells, hMSCs were then cultured in osteogenic medium which consists of a basic medium plus $10 \mathrm{nM}$ dexamethasone and $0.01 \mathrm{M}$ b-glycerol phosphate. HUVECs were ordered from Lonza and then cultured in endothelial growth medium (EGM-2; Lonza). Cells at passages 3-6 were used for all the experiments. The culture medium was refreshed after 48 hours. Monocultures and co-cultures of cells were treated with different medium in 2D wellplate as explained in Table S1. Optical microscopic images of both co-cultures and monocultures in mix medium showed normal cell morphology and clear cell proliferation after 7 days (Figure S1). Only HUVECs cultured with OM were dead after 7 days. Therefore, mix medium was applied for co-culture study. 


\section{Optimization of cell ratio}

The optimization studies of cell ratios were carried on random fibrous scaffolds. The diameter of each electrospun sample for cell culture is $15 \mathrm{~mm}$. hMSCs and HUVECs were trypsinized separately and then co-cultured on electrospun scaffolds. The influence of cell ratio on hMSCs osteogenic differentiation was tested using the following groups: 98:2 (hMSCs:HUVECs), 90:10, 70:30 and 50:50. Monocultures of hMSCs and HUVECs were also performed as controls. Both monocultures and co-cultures of cells were seeded on scaffolds at the same total density of $2 \times 10^{4}$ cells $/ \mathrm{cm}^{2}$.

\section{Cell morphology and orientation}

After 7 days culture, co-cultured cells were stained with F-actin and nuclei to quantitatively analyze the morphology of cells on random and aligned scaffolds. Cell-scaffolds were fixed with $4 \% \mathrm{w} / \mathrm{v}$ formaldehyde for 30 minutes at room temperature. After the permeabilization with $0.1 \% \mathrm{v} / \mathrm{v}$ TritonX-100, cells were stained for F-actin using Alexa Fluor 488 phalloidin diluted in PBS (1:200; Fisher Scientific) for 1 hour. For nuclei staining, cells were stained using DAPI diluted PBS solution (1:200; Sigma-Aldrich) for 5 minutes. Finally, images were taken by a fluorescence microscopy (Nikon Eclipse Ti-S). The orientation of nuclear and cellular orientation was analyzed using CellProfiler 3.1.5. The cells cultured on electrospun scaffolds after 7 days were also observed by SEM. After fixation, the samples were dehydrated for $15 \mathrm{~min}$ in different gradient concentrations of ethanol (30\%, 50\%, 70\%, 80\%, 90\%, 96\% and $100 \%$ ). Cell-scaffolds were then immersed with hexamethyldisilazane (HMDS, Sigma-Aldrich) for 15 min twice and dried in flow hood overnight. Dehydrated samples were gold sputtered and imaged under the scanning electron microscopy.

\section{Live/dead assay and Dil-Ac-LDL staining}

The cytotoxicity of hMSCs/HUVECs co-cultured on the scaffolds was examined by live/dead staining (Fisher Scientific). Cells were rinsed with warm 
PBS after 1 day of culture, then stained for 30 min with $200 \mu$ of $1 \mu \mathrm{M}$ Calcein$\mathrm{AM}$ and $6 \mu \mathrm{M}$ ethidium homodimer-1 (EthD-1) diluted in PBS. The samples were washed with $200 \mu \mathrm{l}$ PBS for 3 times before imaging. Uptake of Dilacetylated low-density lipoprotein (Dil-Ac-LDL) was applied to identify HUVECs in our co-culture system. Cell-scaffolds were incubated with $200 \mu \mathrm{l}$ Dil-Ac-LDL (10 $\mu \mathrm{g} / \mathrm{ml}$; Bioquote) in mix medium for 4 hours. After incubation, scaffolds were rinsed in PBS for 3 times before imaging under the fluorescent microscope (Nikon Eclipse Ti-S).

\section{Cell viability}

Cell viability was measured at day 7 and 21 using the PrestoBlue ${ }^{\mathrm{TM}}$ reagent (Fisher Scientific). After wash with PBS, cell-scaffolds were put in incubator for $30 \mathrm{~min}$ with culture medium supplemented with PrestoBlue ${ }^{\mathrm{TM}}$ reagent diluted 1:9. $100 \mu \mathrm{L}$ of solution were transferred to a black 96 -well plate with clear bottom and fluorescence was measured on a microplate reader (CLARIOstar, BMG Labtech) at 590nm.

\section{Quantification of DNA}

The proliferation of cells on the random and aligned nanofibrous scaffolds was quantified by the CyQUANT ${ }^{\mathrm{TM}}$ Cell Proliferation Assay (Fisher Scientific). Briefly, cell-seeded scaffolds were washed with PBS for three times, and lysated with Tris/EDTA solution containing Proteinase $\mathrm{K}$ overnight at $56^{\circ} \mathrm{C}$. Then, following the manufacturer's manual, RNAse buffer and Gr-dye solution were added. The fluorescence of the solution was measured on the microplate reader with excitation at $480 \mathrm{~nm}$ and emission detection at $520 \mathrm{~nm}$.

\section{ALP activity}

Cells were incubated after 14 days in mix medium, and alkaline phosphatase (ALP) activity was quantified by using CDP-Star kit form Roche. Cell lysates

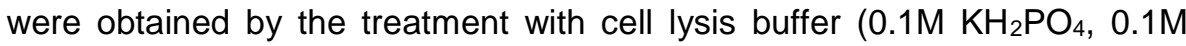
$\mathrm{K}_{2} \mathrm{HPO}_{4}$ and $0.1 \%$ Triton $\mathrm{X}-100$ ) for $1 \mathrm{~h}$, and then immersed with CDP-Star reagent for $15 \mathrm{~min}$. The absorbance was detected at $466 \mathrm{~nm}$ by the microplate 
reader, then results were normalized to DNA content.

\section{Immunostaining}

Cells were washed twice in PBS and then fixed by $4 \% \mathrm{w} / \mathrm{v}$ formaldehyde for $30 \mathrm{~min}$. After fixation, the cells were permeabilized with $0.1 \%$ Triton $\mathrm{X}-100$ for $15 \mathrm{~min}$ and followed by blocking with block buffer which include $1 \%$ bovine serum albumin (BSA, VWR), 0.05\% Tween20 (VWR) and 5\% goat serum (Sigma-Aldrich) in PBS. The primary antibodies used to target interested proteins were VE-cadherin and OPN (1:200 dilute in block buffer). Secondary antibodies (including Goat anti-Mouse Alexa Fluor 488 and Goat anti-Rabbit Alexa Fluor 568) were 1:200 diluted with $0.05 \%$ Tween20 and 1\% BSA in PBS. After incubated with primary antibodies overnight, secondary antibodies was added to scaffolds and soaked for $1 \mathrm{~h}$. The samples were then washed with PBS for 3 times. Fluorescence images were captured by a fluorescence microscopy (Nikon Eclipse Ti-S).

\section{Alizarin red S staining}

To observe the calcium deposits produced by cells differentiated into osteoblasts, Alizarin red $S$ staining was performed at day 28. After fixation steps as mentioned above, scaffolds were rinsed twice in distilled water and incubated with $2 \%$ Alizarin Red $\mathrm{S}(\mathrm{VWR})$ solution $(\mathrm{pH}=4.2)$ at room temperature for $2 \mathrm{~min}$. Scaffolds were rinsed in distilled water for five times in order to wash off the excess dye. For quantitative analysis of Alizarin red $\mathrm{S}$ staining, stained samples were transferred to a micro centrifuge tube and dissolve in $30 \%$ acetic acid solution. After heating at $85^{\circ} \mathrm{C}$ for $10 \mathrm{~min}$, samples were put on ice for $5 \mathrm{~min}$ until fully cooled. Sample solutions were centrifuged for $15 \mathrm{~min}$ at $20,000 \mathrm{rcf}$ and the supernatant was collected to a new micro tube. $30 \%$ ammonium hydroxide was added into tube to neutralize the $\mathrm{pH}$ between 4.1 and 4.5. Finally, sample solution was transferred in a 96-wellplate with transparent bottom and measured by a microplate spectrophotometer (CLARIOstar, BMG Labtech) at 405nm. 


\section{Statistical analysis}

All data were shown as mean \pm standard deviation. Statistical analysis was performed by using GraphPad Prism 8. One-way ANOVA analysis with Tukey's multiple comparisons test was carried out to assess statistical differences between different groups. In all cases, significance was shown as ${ }^{*} p<0.05,{ }^{* *} p<0.01,{ }^{* * *} p<0.001$ and ${ }^{* * * *} p<0.0001$.

\section{Results and discussion}

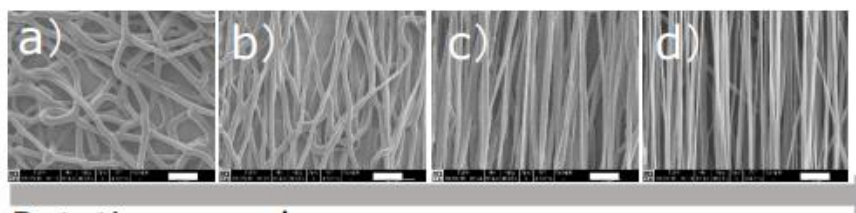

\section{Rotating speed}

e)

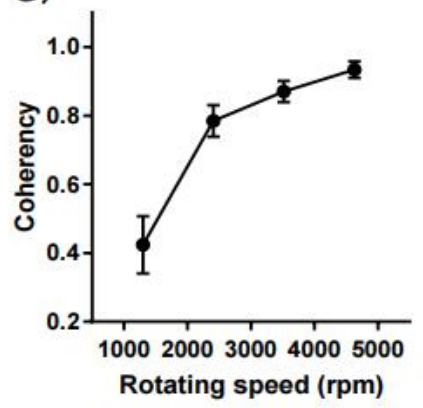

f)

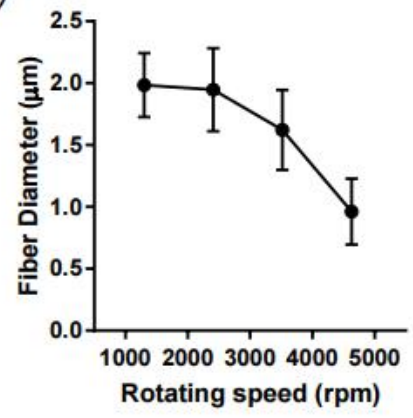

Figure 1. SEM images (a-d) showing the morphology of aligned electrospun fibers produced from different rotating speed of mandrel (scale bar: $10 \mu \mathrm{m}$ ). (e) The effects of rotating speed on the coherency of the aligned PCL elecrospun fibers. (f) The diameter of different aligned PCL elecrospun fibers.

\section{Morphology and coherency of different PCL aligned fiber}

Figure 1 showed the SEM images of different aligned electrospun PCL fibers, along with their coherency distribution and fiber diameter. As it can be seen from Figure 1a-d, by increasing the rotating speed of the collecting mandrel, 
more oriented and aligned fibers can be obtained. The level of alignment was also proved by the coherency coefficients (Figure 1e). The value of coherency is close to 1 representing a highly coherent orientation and greater alignment[51]. It can be observed that the high speed rotation of mandrel led to a high coherency value of fibers and high alignment of fibers. Moreover, as the rotating speed increased to $4600 \mathrm{rpm}$, there was a decreasing trend for the diameter of PCL aligned fibers (Figure 1f). We found that the rotating speed of the mandrel was negatively correlated with fiber diameter. In the production of aligned nanofibers using different rotating speed, the polymer solution was continuously extruded from the tip of the needle while stretching the polymer fibers towards the rotating collector. A higher rotating speed of the mandrel lead to the stretch of fibers more towards to the mandrel, which gave higher fiber alignment and smaller fibers. This result was consistent with previous studies [41, 52-54]. A rotating speed of 4600rpm was found to be the best condition for the production of aligned nanofibers in our study.
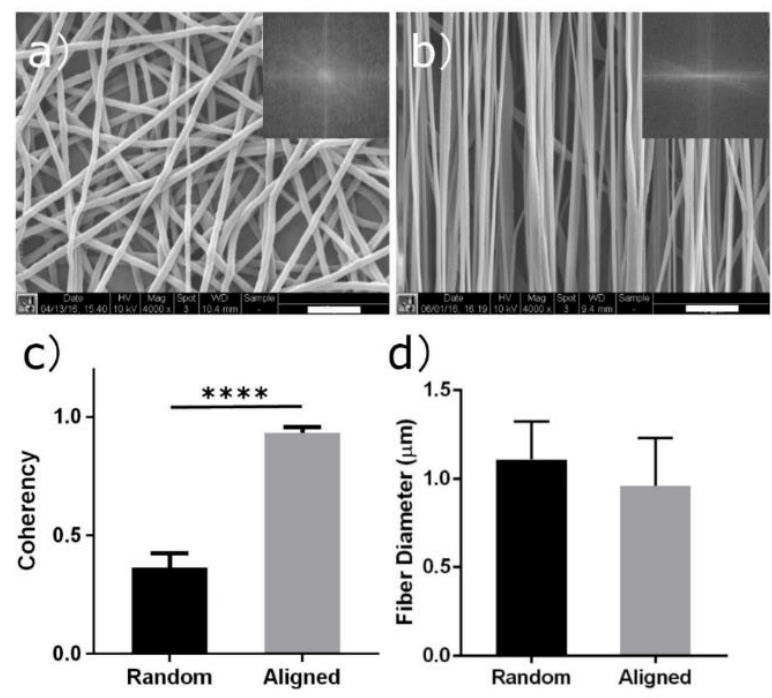

d)

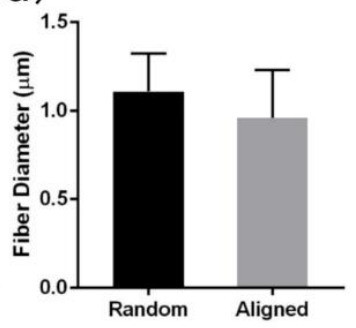

Figure 2. SEM images (a and b), alignment coherence (c) and average diameters (d) of random and aligned PCL electrospun fibers (scale bar: $10 \mu \mathrm{m}$ ). Inset in SEM images (a and b) are FFT output images of random and aligned fibers. 


\section{Characterization of electrospun PCL random and aligned fibers}

Random PCL fibrous scaffolds were fabricated by electrospinning a PCL solution onto a flat collector, while the aligned fibrous scaffolds were collected on a high rotating speed of the mandrel. SEM images showed a significant difference in the surface morphology of PCL random and aligned fibrous scaffolds (Figure 2a-b). The majority of the fibers in the random scaffolds had an irregular arrangement and generated a FFT output image containing pixels distributed in a symmetrical, circular shape. In contrast, the aligned fibrous scaffold generated an output image containing pixels distributed in a nonrandom, elliptical distribution. This distribution occurred because the pixel intensities were preferentially distributed with a specific orientation in aligned SEM images, whereas the frequency at which specific pixel intensities occurred in the random SEM image was theoretically identical in any direction[55]. Analysis of the SEM images showed that the coherency factor of aligned PCL fibers was statistically higher $(P<0.0001)$ than that of the randomly oriented $\mathrm{PCL}$ fibers (Figure $2 \mathrm{c}$ ). Both random and aligned fibrous scaffolds showed uniform fibers with similar fiber diameters of $1.11 \pm 0.22 \mu \mathrm{m}$ and $0.96 \pm 0.27 \mu \mathrm{m}$ (Figure 2d).

\section{Optimization of cell ratio}

Co-culture of MSCs and ECs was considered to be an excellent prevascularization approach for bone regeneration. To find out the best combinations of co-culture, HUVECs and hMSCs were co-cultured at different ratios (98:2-50:50) on random electrospun scaffolds. hMSCs osteogenic differentiation with different cell ratio were evaluated by measuring ALP activity. As it is shown in Figure 3a, significantly higher ALP activity was found in 90:10 co-culture on day 14 compared with 98:2, 70:30, 50:50, hMSCs and HUVECs monocultures $(P<0.001)$. For both $90: 10$ and 98:2 groups, the ALP activity was higher than hMSCs monoculture. Results indicated that the presence of lower amount of HUVECs significantly promoted osteogenic differentiation of hMSCs. Previous reports also observed higher ALP activity 
when hMSCs were co-cultured with a lower ratio of HUVECs [15, 49]. These studies suggested that the crosstalk between the hMSCs and HUVECs might be able to secrete cytokines, such as bone morphogenetic proteins (BMPs), which could enhance the osteogenesis of hMSCs [56]. Our results correlated well with those of previous reports, revealing that co-culture ratios had a significant effect on the ALP activity and especially a lower ratio of HUVECs to hMSCs was considered to benefit osteogenic differentiation.
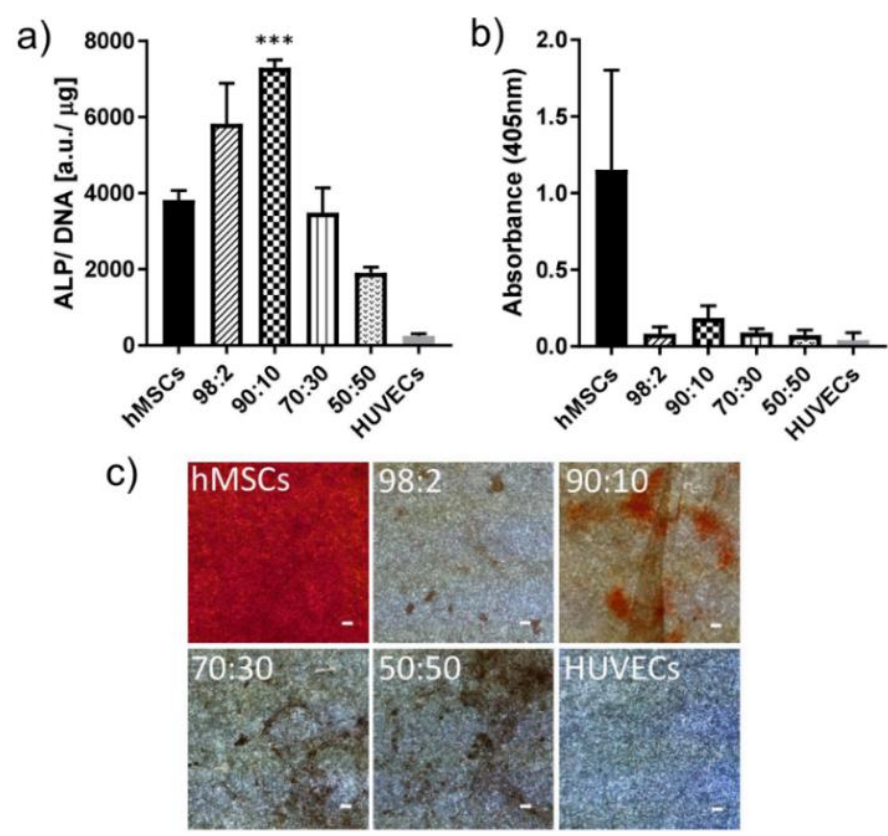

Figure 3. (a) ALP activity expression in hMSCs and HUVECs on the PCL random scaffolds in monocultures and cocultures after 14 days of incubation. (b) Quantification of the degree of mineralization as measured by Alizarin red S staining. Representative images (c) of Alizarin red $S$ staining cells cultured on the random electrospun sacffolds in mono- and coculture systems for 4 weeks (scale bar: $100 \mu \mathrm{m})\left({ }^{\star \star *} p<0.001\right)$. ALP, alkaline phosphate; HUVECs, human umbilical vein endothelial cells.

Calcium deposition is commonly used as a late marker for osteogenic differentiation[44]. Alizarin Red S staining was used to visualize and quantify the total volume of mineralization. Representative Alizarin Red S staining images after 4 weeks of cell culture were shown in Figure 3c. The staining images showed that the mineralization in hMSCs monoculture was much 
higher than that in other groups, since this group was set as positive control and only cultured in osteogenic medium. The ratio of 90:10 co-culture was the one resulting in the higher Alizarin Red S staining compared to other coculture groups. These results were also supported by staining intensity quantification (Figure $3 b$ ). Based on the present results of ALP activity and Alizarin Red S staining, 90:10 of hMSCs/HUVECs co-cultured on random scaffolds is regarded as the optimal ratio for osteogenic differentiation in vitro.

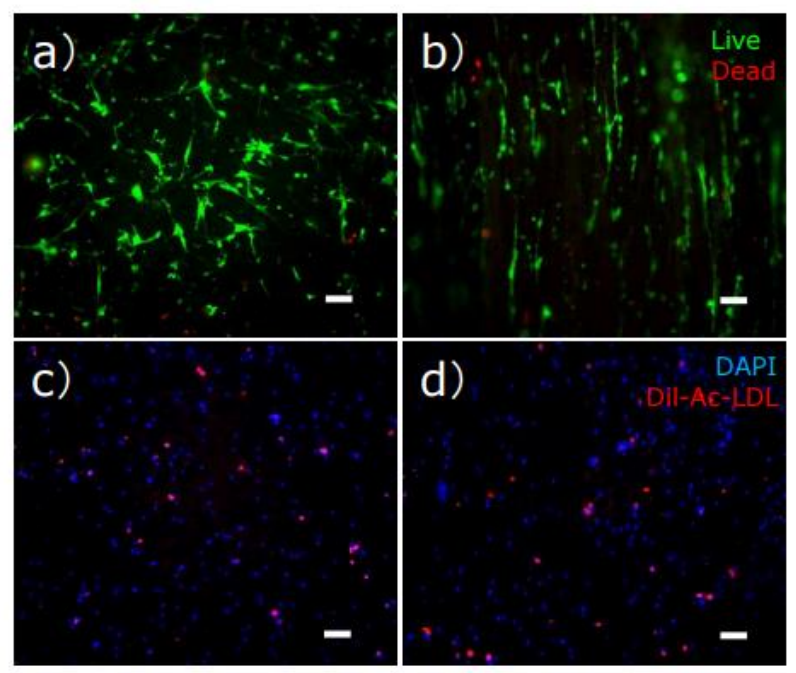

Figure 4. Live (stained green) and dead (stained red) staining of hMSCs-HUVECs co-culture system cultured for 1 day on random (a) and aligned (b) electrospun PCL fibers. hMSCs-HUVECs cultured on random (c) and aligned (d) PCL fibrous scaffolds after day1 were stained by Dil-acLDL (red) and DAPI (blue). Only HUVECs showed positive for Dil-ac-LDL staining (scale bar: 100 $\mu \mathrm{m})$.

\section{Live/dead staining and Dil-Ac-LDL uptake in hMSCs/ HUVECs coculture}

Live/dead staining was used to assess cytotoxicity of hMSCs/HUVECs cocultured on PCL fibrous scaffolds after $24 \mathrm{~h}$ seeding. Figure $4 \mathrm{a}-\mathrm{b}$ showed representative images of live/dead assay staining on random and aligned electrospun scaffolds. Green color indicates the viable cells, while dead cells are red. Most of the cells were stained green, very few red cells were found in 
the images. It means the majority of the cells were alive on both scaffolds after 24h culture. Both hMSCs and HUVECs cultured on scaffolds were attached and grew well. The live ratios on random and aligned scaffolds were determined to be $92 \pm 4 \%$ and $93 \% \pm 2 \%$, respectively. Live/dead assay showed that there was no cytotoxicity of hMSCs and HUVECs on PCL random and aligned scaffolds in our system. PCL fibrous scaffolds offered good support for hMSCs and HUVECs growth.

To prove that the system contained ECs in the co-culture system, Dil-Ac-LDL was used to only stain HUVECs after culturing for 1 day. Both hMSCs and HUVECs showed DAPI staining in Figure 4c-d, whereas the red fluorescence of Dil-Ac-LDL was only detected in HUVECs. The red staining clearly shown in the images indicated that the constructs contained HUVECs on cell-seeded random and aligned scaffolds.

\section{Cell morphology and orientation on random and aligned scaffolds}

Significant differences were observed in cell spreading and morphology among different scaffolds after 7 days of culture (Figure 5a-b). Generally, the cells on the random scaffolds had disorganized actin filaments without particular orientation, while cells on the aligned scaffolds showed a large number of actin filaments parallel to the orientation of PCL fibers and exhibited a polarized morphology. Both the nuclei and cell bodies were significantly more elongated when cultured on aligned scaffolds compared to those on random scaffolds. The nuclear and cellular orientation degree of cells was measured to quantify cell alignment (Figure $5 \mathrm{c}-\mathrm{d}$ ). The distribution of nuclear and cellular orientation had a similar trend. In the aligned scaffolds, $\sim 80 \%$ of the cells had an orientation between $65^{\circ}$ and $90^{\circ}$, which suggests cells seeded on aligned scaffolds were elongated and stretched along the preferred fiber direction. On the random scaffolds, a random distribution of cell orientation from $1^{\circ}$ to $90^{\circ}$ was presented. The SEM images were consistent with the immunostaining observations (Figure 5e-f). 

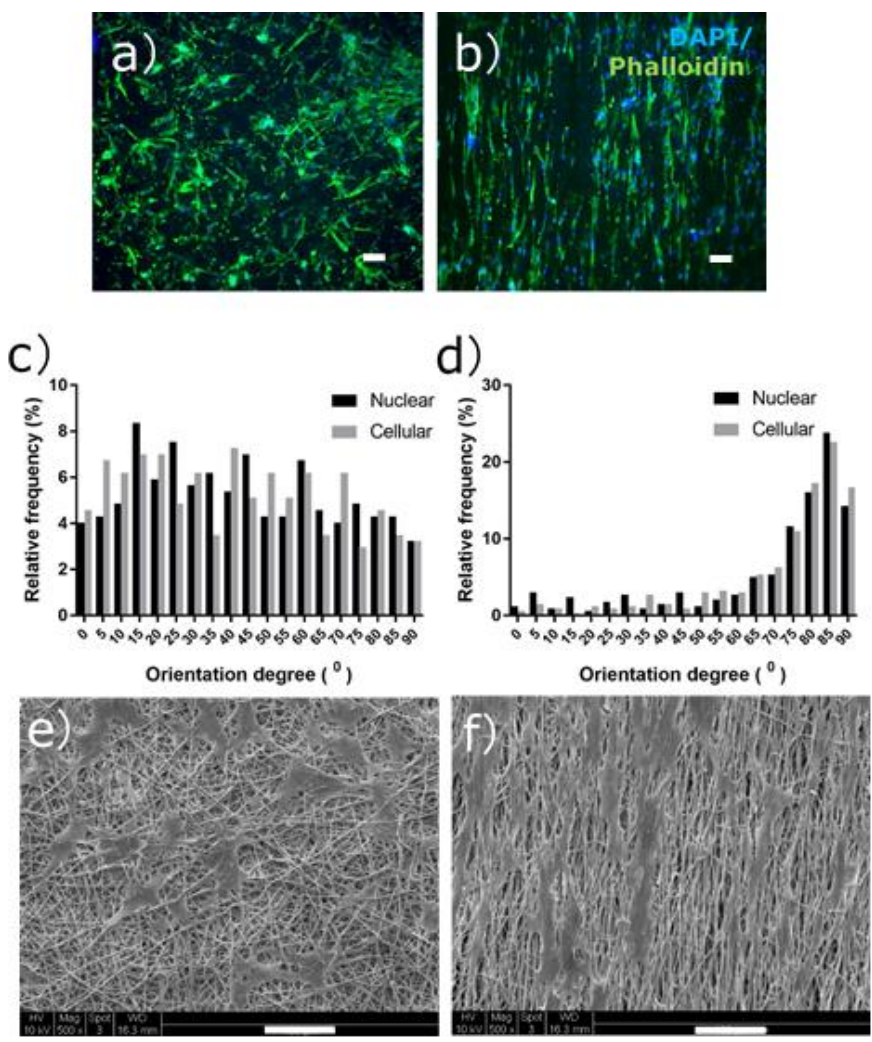

Figure 5. Fluorescence images stained for F-actin (phalloidin: green) and nuclei (DAPI: blue) of hMSCs-HUVECs on random (a) and aligned (b) PCL electrospun scaffolds after 7 days of coculture (scale bar: $100 \mu \mathrm{m}$ ). The nuclear and cellular orientation degree of cells cultured on random (c) and aligned (d) electrospun fibers. SEM images of hMSCs-HUVECs on random (e) and aligned (f) PCL fibers after 7 days culture (scale bar: $100 \mu \mathrm{m}$ ).

\section{Prestoblue and DNA assay}

The metabolic activity of cells after co-culturing 7 and 21 days was assessed with Prestoblue assay. As observed in Figure 6a, the metabolic activity rate of hMSCs/HUVECs co-cultured on random fibers was similar to that on aligned fibers $(P>0.05)$. Cells co-cultured on both fibrous scaffolds after day 21 showed statistically significant increase of the metabolic activity compared to cells cultured for 7 days $(P<0.0001)$. The increase in metabolic activity rate after 21 days could be ascribed to the proliferation of cells. The DNA quantification of hMSCs/HUVECs co-culture indicated a similar trend as the 
metabolic activity assay, which presented a significant increase of proliferation at day 21 compared to day 7 (Figure 6b). The DNA content on random scaffolds changed from $0.1 \pm 0.01$ to $0.35 \pm 0.11 \mu \mathrm{g} / \mathrm{ml}$ after 7 and 21 days culture, while that of aligned scaffolds increased from $0.20 \pm 0.06$ to $0.43 \pm 0.03$ $\mu \mathrm{g} / \mathrm{ml}$. DNA results indicated both random and aligned scaffolds could support cell proliferation. However, there was still no statistical differences in DNA content between random and aligned groups $(P>0.05)$. It can be concluded that the cell proliferation on random and aligned scaffolds may not be significantly different. This result is consistent with previous results reporting that the fiber orientation did not alter cell proliferation[38].
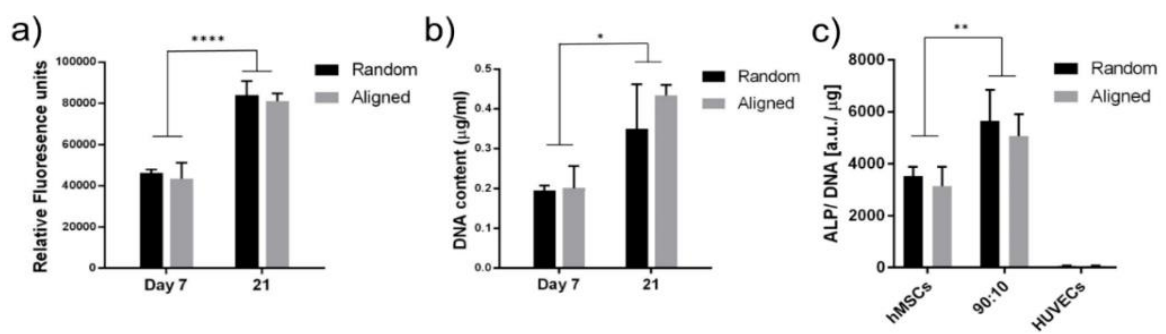

Figure 6. Metabolic activity (a) and proliferation (b) of hMSCs-HUVECs cultured for 7 and 21 days on PCL electrospun fibers. (c) ALP activity expression in hMSCs-HUVECs on the PCL random and aligned scaffolds after 14 days of culture $\left({ }^{*} p<0.05,{ }^{* *} p<0.01\right.$, and $\left.{ }^{* * * *} p<0.0001\right)$.

\section{ALP activity}

ALP activity was used to examine the early osteogenic differentiation of hMSCs. The ALP activity of different cells on fibrous scaffolds at day 14 was measured and shown in Figure 6c. For both random and aligned scaffolds, the ALP activity was significantly higher in co-culture than that in monoculture $(p<0.01)$, indicating that HUVECs supported osteogenesis of hMSCs. We also compared the ALP activity between cells cultured on random and aligned scaffolds. However, there were no statistical differences between hMSCs cultured on different scaffolds $(P>0.05)$. Our study demonstrated that fiber 
alignment did not have much effect on ALP activity of hMSCs. Similar trend were also found in the co-culture group. These results clearly indicated that fiber alignment did not play an important role in osteogenic differentiation, while co-culture with hUVECs actively induced early osteogenic differentiation of hMSCs.

Previous studies on whether random and aligned topography of nanofibers affect MSCs osteogenic differentiation is still controversial. Some studies showed that fiber alignment enhanced osteogenic differentiation: for example, MSCs cultured on the aligned $\mathrm{PHBHHx}$ microfibers showed relatively higher expression of osteogenic genes, including osteocalcin, runx2, osteopontin and osteonectin, compared to that on random fiber [57]. Another study however demonstrated that MSCs grew on randomly PLLA fibrous scaffolds presented enhanced ALP staining and osteogenic maker genes compared with cells on aligned PLLA fibrous scaffolds [58]. Quite few studies also reported that fiber alignment guided the orientation of adherent cells, but did not influence osteogenic differentiation [38, 41]. In the presence of HUVECs, our results are consistent with observations where the aligned fibers provide oriented tissue, but do not significantly influence osteogenic differentiation [38, 41].

\section{Immunostaining}

After 21 days, the formation of vascularized bone tissue on different scaffolds was evaluated by the immunofluorescence staining of an osteogenic differentiation marker osteopontin (OPN, red) and an angiogenic specific marker VE-Cadherin (green), respectively. OPN is a key marker of osteogenesis and biomineralization[59]. Immunostaining for OPN showed a robust expression in cells cultured on random and aligned scaffolds (Figure $7 a-b)$. 


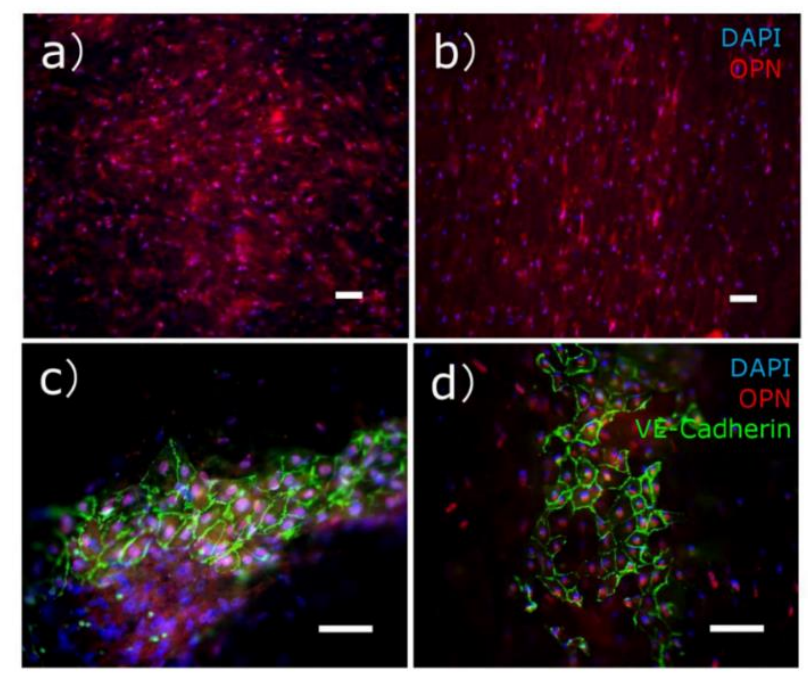

Figure 7. OPN (osteogenesis marker; red) immunostaining of hMSCs cultured on the random (a) and aligned (b) PCL electrospun fibers in coculture with HUVECs for 21 days. Graphs(c-d) showing expression of endothelial marker, VE-Cadherin (green), by HUVECs in coculture with hMSCs at day 21 on random and aligned scaffolds (scale bar: $100 \mu \mathrm{m}$ ).

Moreover, immunofluorescent staining for VE-cadherin (Figure 7c-d) revealed the formation of an interconnected endothelial cell layer in co-culture conditions. The localization of these proteins at the cell-cell borders is consistent with their functions as endothelial cells adhesion molecules [60]. Both random and aligned scaffolds showed the expression of VE-cadherin at endothelial cell junctions in hMSCs-HUVECs co-culture. Nuclear staining with DAPI was used to detect all cells, including hMSCs which did not express VEcadherin. The localization of hMSCs was adjacent to the endothelial network formed by HUVECs, suggesting that hMSCs could be acting as pericytes to stabilize the networks [61-63]. Our study did not show much vascular network due to the low amount of HUVECs in co-culture, however cells on both scaffolds showed relatively expression of VE-Cadherin. Taken together, these results indicate that co-culture of hMSCs and HUVECs on both random and aligned scaffolds exhibited a positive result on osteogenesis and the ability of generating intercellular junctions. 


\section{Alizarin Red S staining}

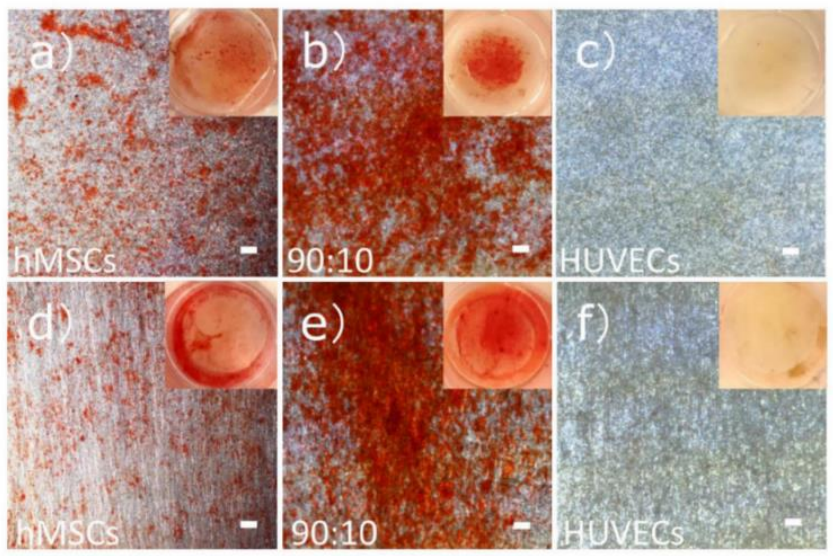

g)

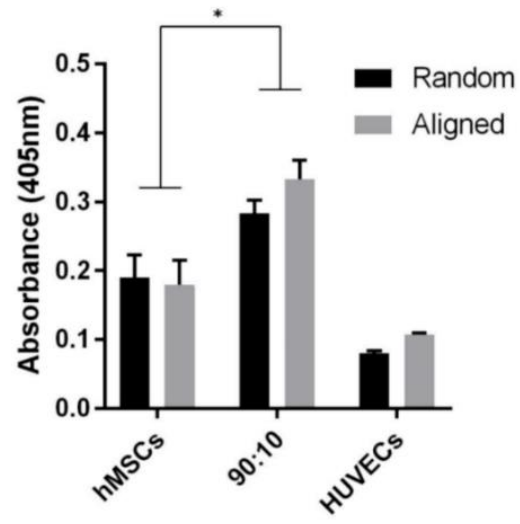

Figure 8. Representative images of Alizarin Red S staining cells cultured on the random and aligned electrospun sacffolds in mono and co-culture systems for 4 weeks (scale bar: $100 \mu \mathrm{m}$ ). (b) Quantification of the degree of mineralization as measured by Alizarin Red $S$ staining $\left({ }^{*} p<0.05\right)$.

The osteogenic differentiation of hMSCs on the scaffolds was further analyzed via staining calcium deposits with Alizarin Red (Figure 8). This mineralization assay demonstrated positive Alizarin Red staining from hMSCs monoculture and co-culture group in comparison to HUVECs monoculture. Significant higher staining of calcium deposits was shown in hMSCs/HUVECs co-culture than hMSCs monoculture $(P<0.05)$. This results are consistent with other 
literature which demonstrated co-culture of hMSCs with ECs result in an increased osteogenic differentiation [47]. However, no significant difference was found between hMSCs monoculture and co-culture on random and aligned fibrous scaffolds ( $P>0.05)$. Hence, fiber alignment did not influence hMSCs mineralization. This finding suggests that the co-culture with endothelial cells strongly promoted the osteogenesis of hMSCs, while fiber alignment did not.

\section{Conclusion}

In summary, we fabricated random and aligned PCL fibrous scaffolds to evaluate the combinatorial influence of fiber orientation and co-culture with endothelial cells on hMSCs osteogenic differentiation. The optimization of coculture results indicated that the 90:10 of hMSCs/HUVECs cultured on random fibrous scaffolds appeared to be the optimal ratio for osteogenisis of hMSCs. Fiber alignment strongly influenced cell morphology and orientation, but did not show an important impact on hMSCs osteogenic differentiation. Moreover, the addition of endothelial cells to hMSCs enhanced their osteogenic differentiation, as shown by ALP activity and mineralization of hMSCs. The microcapillary-like structures organized by ECs were apparent when co-cultured with hMSCs on scaffolds. These results indicated that cocultures with endothelial cells have more influence on bone regeneration than fiber alignment; in addition, structural properties of scaffolds (such as, fiber alignment) can control orientation and distribution of cells, which may be used to engineer bone tissue with defined direction. 


\section{Reference}

[1] Y. Kang, S. Kim, M. Fahrenholtz, A. Khademhosseini, Y. Yang, Osteogenic and angiogenic potentials of monocultured and co-cultured human-bone-marrow-derived mesenchymal stem cells and human-umbilical-vein endothelial cells on three-dimensional porous beta-tricalcium phosphate scaffold, Acta biomaterialia 9(1) (2013) 4906-4915.

[2] M. Grellier, L. Bordenave, J. Amedee, Cell-to-cell communication between osteogenic and endothelial lineages: implications for tissue engineering, Trends in biotechnology 27(10) (2009) 562-571.

[3] S. Stegen, N. van Gastel, G. Carmeliet, Bringing new life to damaged bone: the importance of angiogenesis in bone repair and regeneration, Bone 70 (2015) 19-27.

[4] H. Yu, P.J. VandeVord, L. Mao, H.W. Matthew, P.H. Wooley, S.-Y. Yang, Improved tissueengineered bone regeneration by endothelial cell mediated vascularization, Biomaterials $30(4)$ (2009) 508-517.

[5] J.R. García, A.J. García, Biomaterial-mediated strategies targeting vascularization for bone repair, Drug delivery and translational research 6(2) (2016) 77-95.

[6] X. He, R. Dziak, X. Yuan, K. Mao, R. Genco, M. Swihart, D. Sarkar, C. Li, C. Wang, L. Lu, BMP2 genetically engineered MSCs and EPCs promote vascularized bone regeneration in rat critical-sized calvarial bone defects, PLoS One 8(4) (2013) e60473.

[7] D. Logeart-Avramoglou, F. Anagnostou, R. Bizios, H. Petite, Engineering bone: challenges and obstacles, Journal of cellular and molecular medicine 9(1) (2005) 72-84.

[8] M.I. Santos, R.L. Reis, Vascularization in bone tissue engineering: physiology, current strategies, major hurdles and future challenges, Macromolecular bioscience 10(1) (2010) 12-27. [9] H. Park, D.-J. Lim, M. Sung, S.-H. Lee, D. Na, H. Park, Microengineered platforms for cocultured mesenchymal stem cells towards vascularized bone tissue engineering, Tissue engineering and regenerative medicine 13(5) (2016) 465-474.

[10] M. Stoppato, H. Stevens, E. Carletti, C. Migliaresi, A. Motta, R. Guldberg, Influence of scaffold properties on the inter-relationship between human bone marrow derived stromal cells and endothelial cells in pro-osteogenic conditions, Acta biomaterialia 25 (2015) 16-23.

[11] G.-Z. Jin, C.-M. Han, H.-W. Kim, In vitro co-culture strategies to prevascularization for bone regeneration: a brief update, Tissue Engineering and Regenerative Medicine 12(2) (2015) 69-79. [12] R.E. Unger, S. Ghanaati, C. Orth, A. Sartoris, M. Barbeck, S. Halstenberg, A. Motta, C. Migliaresi, C.J. Kirkpatrick, The rapid anastomosis between prevascularized networks on silk fibroin scaffolds generated in vitro with cocultures of human microvascular endothelial and osteoblast cells and the host vasculature, Biomaterials 31(27) (2010) 6959-6967.

[13] R.E. Unger, E. Dohle, C.J. Kirkpatrick, Improving vascularization of engineered bone through the generation of pro-angiogenic effects in co-culture systems, Advanced drug delivery reviews 94 (2015) 116-125.

[14] A. Wenger, A. Stahl, H. Weber, G. Finkenzeller, H. Augustin, G. Stark, U. Kneser, Modulation of in vitro angiogenesis in a three-dimensional spheroidal coculture model for bone tissue engineering, Tissue engineering 10(9-10) (2004) 1536-1547.

[15] J. Rouwkema, J.D. Boer, C.A.V. Blitterswijk, Endothelial cells assemble into a 3-dimensional prevascular network in a bone tissue engineering construct, Tissue engineering 12(9) (2006) 2685-2693.

[16] W.-L. Fu, Z. Xiang, F.-G. Huang, Z.-P. Gu, X.-X. Yu, S.-Q. Cen, G. Zhong, X. Duan, M. Liu, Coculture of peripheral blood-derived mesenchymal stem cells and endothelial progenitor cells on strontium-doped calcium polyphosphate scaffolds to generate vascularized engineered bone, Tissue Engineering Part A 21(5-6) (2014) 948-959.

[17] F. Saleh, M. Whyte, P. Genever, Effects of endothelial cells on human mesenchymal stem cell activity in a three-dimensional in vitro model, Eur Cell Mater 22(242) (2011) e57.

[18] L.F. Mendes, R.P. Pirraco, W. Szymczyk, A.M. Frias, T.C. Santos, R.L. Reis, A.P. Marques, Perivascular-like cells contribute to the stability of the vascular network of osteogenic tissue formed from cell sheet-based constructs, PLoS One 7(7) (2012) e41051.

[19] D. Brunette, The effects of implant surface topography on the behavior of cells, International Journal of Oral \& Maxillofacial Implants 3(4) (1988).

[20] D. Brunette, B. Chehroudi, The effects of the surface topography of micromachined titanium substrata on cell behavior in vitro and in vivo, Journal of biomechanical engineering 121(1) (1999) 49-57.

[21] R. Flemming, C.J. Murphy, G. Abrams, S. Goodman, P. Nealey, Effects of synthetic microand nano-structured surfaces on cell behavior, Biomaterials 20(6) (1999) 573-588. 
[22] G. Abagnale, A. Sechi, M. Steger, Q. Zhou, C.-C. Kuo, G. Aydin, C. Schalla, G. Müller-Newen, M. Zenke, I.G. Costa, Surface topography guides morphology and spatial patterning of induced pluripotent stem cell colonies, Stem cell reports 9(2) (2017) 654-666.

[23] M.J. Dalby, N. Gadegaard, R. Tare, A. Andar, M.O. Riehle, P. Herzyk, C.D. Wilkinson, R.O. Oreffo, The control of human mesenchymal cell differentiation using nanoscale symmetry and disorder, Nature materials 6(12) (2007) 997.

[24] D. Discher, Matrix elasticity directs stem cell lineage specification, APS March Meeting Abstracts, 2010.

[25] T. Ozdemir, A. M Higgins, J. L Brown, Osteoinductive biomaterial geometries for bone regenerative engineering, Current pharmaceutical design 19(19) (2013) 3446-3455.

[26] H. Li, F. Wen, H. Chen, M. Pal, Y. Lai, A.Z. Zhao, L.P. Tan, Micropatterning extracellular matrix proteins on electrospun fibrous substrate promote human mesenchymal stem cell differentiation toward neurogenic lineage, ACS applied materials \& interfaces 8(1) (2015) 563573.

[27] A. Rajnicek, S. Britland, C. McCaig, Contact guidance of CNS neurites on grooved quartz: influence of groove dimensions, neuronal age and cell type, Journal of cell science 110(23) (1997) 2905-2913.

[28] M.A. Kafi, W.A. El-Said, T.-H. Kim, J.-W. Choi, Cell adhesion, spreading, and proliferation on surface functionalized with RGD nanopillar arrays, Biomaterials 33(3) (2012) 731-739.

[29] K.S. Park, K.J. Cha, I.B. Han, D.A. Shin, D.W. Cho, S.H. Lee, D.S. Kim, Mass-producible Nano-featured Polystyrene Surfaces for Regulating the Differentiation of Human Adipose-derived Stem Cells, Macromolecular bioscience 12(11) (2012) 1480-1489.

[30] R.J. McMurray, N. Gadegaard, P.M. Tsimbouri, K.V. Burgess, L.E. McNamara, R. Tare, K. Murawski, E. Kingham, R.O. Oreffo, M.J. Dalby, Nanoscale surfaces for the long-term maintenance of mesenchymal stem cell phenotype and multipotency, Nature materials $10(8)$ (2011) 637.

[31] Z. Guo, J. Xu, S. Ding, H. Li, C. Zhou, L. Li, In vitro evaluation of random and aligned polycaprolactone/gelatin fibers via electrospinning for bone tissue engineering, Journal of Biomaterials Science, Polymer Edition 26(15) (2015) 989-1001.

[32] H. Jahani, S. Kaviani, M. Hassanpour-Ezatti, M. Soleimani, Z. Kaviani, Z. Zonoubi, The effect of aligned and random electrospun fibrous scaffolds on rat mesenchymal stem cell proliferation, Cell Journal (Yakhteh) 14(1) (2012) 31.

[33] G.E. Fantner, H. Birkedal, J.H. Kindt, T. Hassenkam, J.C. Weaver, J.A. Cutroni, B.L. Bosma, L. Bawazer, M.M. Finch, G.A. Cidade, Influence of the degradation of the organic matrix on the microscopic fracture behavior of trabecular bone, Bone 35(5) (2004) 1013-1022.

[34] J. Ramasamy, O. Akkus, Local variations in the micromechanical properties of mouse femur: the involvement of collagen fiber orientation and mineralization, Journal of biomechanics $40(4)$ (2007) 910-918.

[35] M.C. Summitt, K.D. Reisinger, Characterization of the mechanical properties of demineralized bone, Journal of Biomedical Materials Research Part A: An Official Journal of The Society for Biomaterials, The Japanese Society for Biomaterials, and The Australian Society for Biomaterials and the Korean Society for Biomaterials 67(3) (2003) 742-750.

[36] H.N. Kim, A. Jiao, N.S. Hwang, M.S. Kim, D.-H. Kim, K.-Y. Suh, Nanotopography-guided tissue engineering and regenerative medicine, Advanced drug delivery reviews 65(4) (2013) 536558.

[37] J. Xie, X. Li, J. Lipner, C.N. Manning, A.G. Schwartz, S. Thomopoulos, Y. Xia, "Aligned-torandom" nanofiber scaffolds for mimicking the structure of the tendon-to-bone insertion site, Nanoscale 2(6) (2010) 923-926.

[38] J. Ma, X. He, E. Jabbari, Osteogenic differentiation of marrow stromal cells on random and aligned electrospun poly (L-lactide) nanofibers, Annals of biomedical engineering 39(1) (2011) 14-25.

[39] Y. Xu, Z. Wu, X. Dong, H. Li, Combined biomaterial signals stimulate communications between bone marrow stromal cell and endothelial cell, Rsc Advances 7(9) (2017) 5306-5314.

[40] Y.M. Kolambkar, M. Bajin, A. Wojtowicz, D.W. Hutmacher, A.J. García, R.E. Guldberg, Nanofiber orientation and surface functionalization modulate human mesenchymal stem cell behavior in vitro, Tissue Engineering Part A 20(1-2) (2013) 398-409.

[41] S.K. Madhurakkat Perikamana, J. Lee, T. Ahmad, Y. Jeong, D.-G. Kim, K. Kim, H. Shin, Effects of immobilized BMP-2 and nanofiber morphology on in vitro osteogenic differentiation of hMSCs and in vivo collagen assembly of regenerated bone, ACS applied materials \& interfaces 7(16) (2015) 8798-8808.

[42] Y. Naito, T. Shinoka, D. Duncan, N. Hibino, D. Solomon, M. Cleary, A. Rathore, C. Fein, S. Church, C. Breuer, Vascular tissue engineering: towards the next generation vascular grafts, Advanced drug delivery reviews 63(4-5) (2011) 312-323. 
[43] Y. Liu, J.K. Chan, S.H. Teoh, Review of vascularised bone tissue-engineering strategies with a focus on co-culture systems, Journal of tissue engineering and regenerative medicine $9(2)$ (2015) 85-105.

[44] J. Ma, J.J. van den Beucken, F. Yang, S.K. Both, F.-Z. Cui, J. Pan, J.A. Jansen, Coculture of osteoblasts and endothelial cells: optimization of culture medium and cell ratio, Tissue Engineering Part C: Methods 17(3) (2010) 349-357.

[45] J. Zhou, H. Lin, T. Fang, X. Li, W. Dai, T. Uemura, J. Dong, The repair of large segmental bone defects in the rabbit with vascularized tissue engineered bone, Biomaterials 31(6) (2010) 1171-1179.

[46] D. Henrich, C. Seebach, C. Kaehling, A. Scherzed, K. Wilhelm, R. Tewksbury, M. Powerski, I. Marzi, Simultaneous Cultivation of Human Endothelial-like Differentiated Precursor Cells and Human Marrow Stromal Cells on $\beta$-Tricalcium Phosphate, Tissue Engineering Part C: Methods 15(4) (2009) 551-560.

[47] M. Kazemzadeh-Narbat, J. Rouwkema, N. Annabi, H. Cheng, M. Ghaderi, B.H. Cha, M. Aparnathi, A. Khalilpour, B. Byambaa, E. Jabbari, Engineering photocrosslinkable bicomponent hydrogel constructs for creating 3D vascularized bone, Advanced healthcare materials $6(10)$ (2017) 1601122.

[48] R. Mishra, B.M. Roux, M. Posukonis, E. Bodamer, E.M. Brey, J.P. Fisher, D. Dean, Effect of prevascularization on in vivo vascularization of poly (propylene fumarate)/fibrin scaffolds, Biomaterials 77 (2016) 255-266.

[49] J.-I. Sasaki, M. Hashimoto, S. Yamaguchi, Y. Itoh, I. Yoshimoto, T. Matsumoto, S. Imazato, Fabrication of biomimetic bone tissue using mesenchymal stem cell-derived three-dimensional constructs incorporating endothelial cells, PLoS One 10(6) (2015) e0129266.

[50] T. Yao, H. Chen, P. Samal, S. Giselbrecht, M.B. Baker, L. Moroni, Self-assembly of electrospun nanofibers into gradient honeycomb structures, Materials \& Design 168 (2019) 107614.

[51] M. Kobayashi, N.Y. Lei, Q. Wang, B.M. Wu, J.C. Dunn, Orthogonally oriented scaffolds with aligned fibers for engineering intestinal smooth muscle, Biomaterials 61 (2015) 75-84.

[52] V. Thomas, M.V. Jose, S. Chowdhury, J.F. Sullivan, D.R. Dean, Y.K. Vohra, Mechanomorphological studies of aligned nanofibrous scaffolds of polycaprolactone fabricated by electrospinning, Journal of Biomaterials Science, Polymer Edition 17(9) (2006) 969-984.

[53] S. Haider, Y. Al-Zeghayer, F.A.A. Ali, A. Haider, A. Mahmood, W.A. Al-Masry, M. Imran, M.O. Aijaz, Highly aligned narrow diameter chitosan electrospun nanofibers, Journal of Polymer Research 20(4) (2013) 105.

[54] N. Zander, M. Gillan, D. Sweetser, Composite fibers from recycled plastics using melt centrifugal spinning, Materials 10(9) (2017) 1044.

[55] C. Ayres, G.L. Bowlin, S.C. Henderson, L. Taylor, J. Shultz, J. Alexander, T.A. Telemeco, D.G. Simpson, Modulation of anisotropy in electrospun tissue-engineering scaffolds: Analysis of fiber alignment by the fast Fourier transform, Biomaterials 27(32) (2006) 5524-5534.

[56] J. Kim, H.N. Kim, K.-T. Lim, Y. Kim, S. Pandey, P. Garg, Y.-H. Choung, P.-H. Choung, K.-Y. Suh, J.H. Chung, Synergistic effects of nanotopography and co-culture with endothelial cells on osteogenesis of mesenchymal stem cells, Biomaterials 34(30) (2013) 7257-7268.

[57] Y. Wang, R. Gao, P.-P. Wang, J. Jian, X.-L. Jiang, C. Yan, X. Lin, L. Wu, G.-Q. Chen, Q. Wu, The differential effects of aligned electrospun $\mathrm{PHBHHx}$ fibers on adipogenic and osteogenic potential of MSCs through the regulation of PPARy signaling, Biomaterials 33(2) (2012) 485-493. [58] Z. Yin, X. Chen, H.-x. Song, J.-j. Hu, Q.-m. Tang, T. Zhu, W.-I. Shen, J.-I. Chen, H. Liu, B.C. Heng, Electrospun scaffolds for multiple tissues regeneration in vivo through topography dependent induction of lineage specific differentiation, Biomaterials 44 (2015) 173-185.

[59] C. Li, J.P.K. Armstrong, I.J. Pence, W. Kit-Anan, J.L. Puetzer, S. Correia Carreira, A.C. Moore, M.M. Stevens, Glycosylated superparamagnetic nanoparticle gradients for osteochondral tissue engineering, Biomaterials 176 (2018) 24-33.

[60] X. Wu, E. Rabkin-Aikawa, K.J. Guleserian, T.E. Perry, Y. Masuda, F.W.H. Sutherland, F.J. Schoen, J. John E. Mayer, J. Bischoff, Tissue-engineered microvessels on three-dimensional biodegradable scaffolds using human endothelial progenitor cells, American Journal of Physiology-Heart and Circulatory Physiology 287(2) (2004) H480-H487.

[61] Y. Pang, O. Tsigkou, J.A. Spencer, C.P. Lin, C. Neville, B. Grottkau, Analyzing Structure and Function of Vascularization in Engineered Bone Tissue by Video-Rate Intravital Microscopy and 3D Image Processing, Tissue Engineering Part C: Methods 21(10) (2015) 1025-1031.

[62] T. Takebe, N. Koike, K. Sekine, M. Enomura, Y. Chiba, Y. Ueno, Y.W. Zheng, H. Taniguchi, Generation of Functional Human Vascular Network, Transplantation Proceedings 44(4) (2012) 1130-1133.

[63] X. Wu, E. Rabkin-Aikawa, K.J. Guleserian, T.E. Perry, Y. Masuda, F.W.H. Sutherland, F.J. Schoen, J.E. Mayer, J. Bischoff, Tissue-engineered microvessels on three-dimensional 
Effects of Fiber Alignment and Coculture with Endothelial Cells on Osteogenic Differentiation of Mesenchymal Stromal Cells

biodegradable scaffolds using human endothelial progenitor cells, American Journal of Physiology-Heart and Circulatory Physiology 287(2) (2004) H480-H487. 


\section{Supporting Information}

Table S1. Optimization of culture medium used in the experiments

\begin{tabular}{l|l|l|l|l|l|l}
\hline Cells & HUVECs & HUVECs & HUVECs & hMSCs & hMSCs & hMSCs:HUVECs \\
\hline $\begin{array}{l}\text { Culture } \\
\text { medium }\end{array}$ & OM & EGM & $\begin{array}{l}\text { Mix medium } \\
(\text { OM:EGM=1:1) }\end{array}$ & OM & $\begin{array}{l}\text { Mix medium } \\
(\text { OM:EGM=1:1) }\end{array}$ & $\begin{array}{l}\text { Mix medium } \\
(\text { OM:EGM=1:1) }\end{array}$ \\
\hline
\end{tabular}

$\mathrm{OM}$, Osteogenic differentiation medium. EGM, endothelial growth medium. Mix medium, 1:1 mixture of OM and EGM.

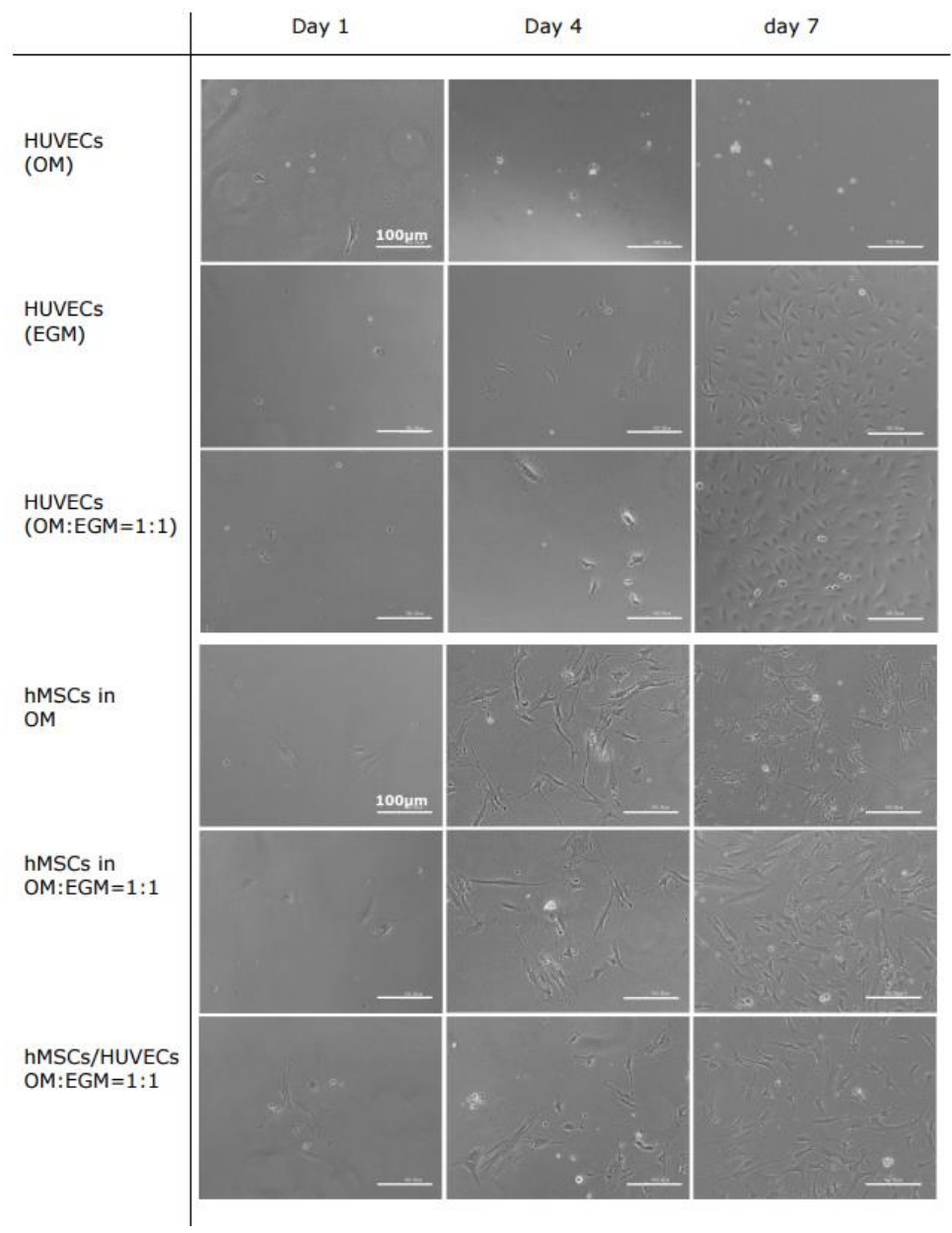

Figure S1. Bright filed images showing the proliferation of HUVECs and hMSCs in different medium. Scale bars are $100 \mu \mathrm{m}$. 
Effects of Fiber Alignment and Coculture with Endothelial Cells on Osteogenic Differentiation of Mesenchymal Stromal Cells 


\section{Chapter 3}

\section{Self-assembly of Electrospun Nanofibers into Gradient Honeycomb Structures}

Tianyu Yao ${ }^{1}$, Honglin Chen ${ }^{1}$, Pinak Samal ${ }^{1}$, Stefan Giselbrecht ${ }^{1}$, Matthew B Baker $^{1}$, Lorenzo Moroni ${ }^{1}$

1. Complex Tissue Regeneration Department, MERLN Institute for Technology Inspired Regenerative Medicine Maastricht University, Maastricht, 6229 ER, the Netherlands 


\section{Abstract}

The self-assemble approach is a technically simple, rapid, and direct way to realize selective deposition of electrospun nanofibers. In the present study, we aimed to fabricate gradient polycaprolactone (PCL) honeycomb meshes by electrospinning. We demonstrated for the first time the ability to effectively fabricate a self-assembled gradient honeycomb pattern in electrospun meshes. Different honeycomb patterns were successfully fabricated by controlling the electrospinning conditions. The working distance was found to be the most important factor for the formation of gradient honeycomb structures. At a smaller working distance of $12 \mathrm{~cm}$, gradients honeycomb patterns were successfully fabricated. The pore diameter of the obtained gradient honeycomb structures spanned a range from $800 \mu \mathrm{m}$ to $300 \mu \mathrm{m}$. The average depth of gradient honeycomb was $123 \pm 56 \mu \mathrm{m}$. These findings are interesting and particularly useful for us to optimize the design of gradients honeycomb scaffolds for interface tissue regeneration.

Key words: electrospun; self-assembly; gradient honeycomb

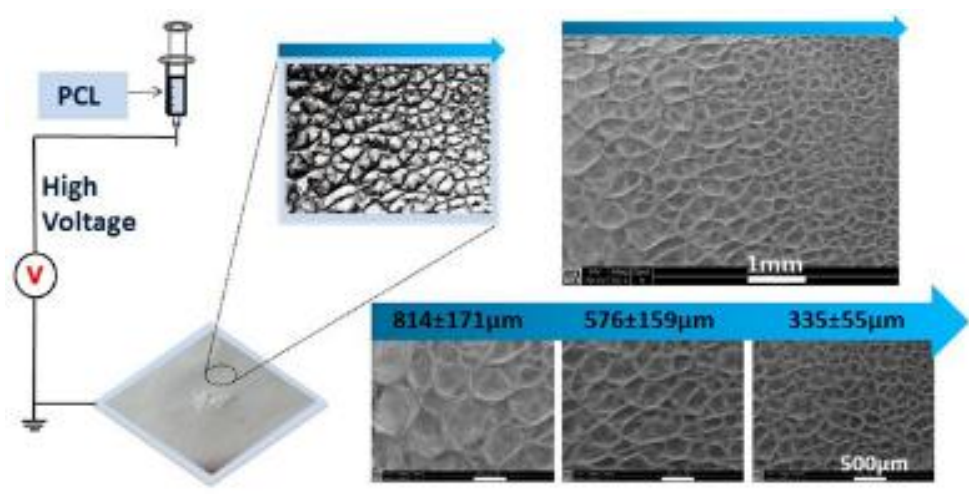




\section{Introduction}

Electrospinning is a simple and versatile technique that can produce continuous nanofibers with high efficiency [1, 2]. Electrospinning has been applied to successfully fabricate nanofibers with different diameters, from micrometer down to tens of nanometers [3]. These electrospun nanofibers have several advantages, such as fibers with diameters in the range of fibrillary extracellular matrix (ECM), large surface area, and high porosity[4], which render this technology very attractive for many applications, e.g. tissue engineering [5-7], drug delivery [8, 9], catalyst supports [10], textiles[11], and sensing applications [12-14].

Biomimetic nanofibrous scaffolds that mimic the ECM of living tissues are widely used in tissue engineering, which provides a promising strategy to restore the functions of tissue or promote the natural healing process [15]. By adjusting electrospinning parameters [16, 17], several fascinating bioinspired nanofibrous structures have been successfully fabricated such as the lotus leaf [18], silver ragwort leaf [19], feather [20], plant tendril [21], spider web [22], polar bear hair [23], and honeycomb [24]. Inspired from natural honeycombs with hexagonal structure, researchers used electrospinning to produce honeycomb-patterned nanofibrous structures [24]. The electrospun nanofibers could self-assemble into honeycomb-patterned nanofibers driven by the competitive actions of surface tension and electrostatic repulsion. Biomimetic honeycombs pattern have the properties of large surface area, high structural stability and good permeability, which have shown to be excellent for proliferation and differentiation of osteoblasts [25]. These honeycomb structures can also promote uniform cell distribution and provide a stimulating environment for tissue regeneration.

Electrospun nanofibrous meshes with different patterns are usually fabricated by designing special collectors to generate selective deposition. Most of the collectors are electroconductive templates [26-29]. For example, Zhang et al. [29] fabricated electrospun mats with controllable architectures and patterns 
by using electroconductive templates. Another study demonstrated that the self-organization of nanofibers into honeycomb like structures could be readily prepared by using a honeycomb collector [28]. Whereas the collectors above used are electroconductive substrates, worked with insulating collectors to obtain patterned nanofibers [30-32]. Zhao et al. [32] proved that the generation of nanofibrous patterns by direct deposition of electrospun nanofibers onto a variety of insulating substrates can be achieved. Both methods used for selective deposition required well-designed collectors with different surface patterns. Yet, it may still be of interest to study self-assembling of nanofibers without special collectors to enable the generation of nanofibrous patterns, just like a patterned collector does. This self-assemble approach is appealing since it is a technically simple, rapid, and direct way to realize selective deposition of nanofibers.

Human tissues display unique gradients in organization [33]. Especially interface tissues in the body consists of complex structures and properties, which gradually vary from one tissue to another [34]. Structural gradients can be found mainly in interface tissues $[35,36]$, such as bone-cartilage interfaces [37], dentino-enamel junctions [38], tendon-bone [39] and ligament-bone tissues [40]. The concept of gradient scaffolds has been applied in different studies to mimic complex gradients found in native tissues [41, 42]. Gradient scaffolds could provide cues similar to the native environment and may guide stem cells to migrate [43] or differentiate toward the targeted tissue to be regenerated [35, 39, 44]. Most of the conventional scaffolds reported in tissue engineering have uniform composition and pore sizes, which lack the structural complexity to regenerate specific tissue [34]. Only a few studies have developed gradient scaffolds for tissue regeneration [45]. Moreover, gradient biomaterials are generally more difficult to fabricate than uniform or homogenous biomaterials [46]. Such as, the freeze drying and particulate leaching methods which is commonly used to fabricate scaffolds with controlled pore size $[47,48]$. However, it is not easy to design scaffolds with gradient pore size by those two methods [49]. Some studies have investigated 
the fabrication of uniform honeycomb fibrous meshes by electrospinning [24], honeycomb fibrous meshes with gradients in pore sizes have not been reported yet. In this work, we show the first report of simple gradient honeycomb structure fabrication by the self-assembly of electrospun PCL nanofibers. By adjusting the electrospinning conditions, including the polymer solution concentration, voltage, and working distance, we obtained wellorganized honeycomb structures with different diameters and evenly fabricated gradient honeycomb patterns.

\section{Experimental}

\section{Electrospinning process}

Poly(caprolactone) (PCL; $M n=40,000-50,000$ ) was provided by SigmaAldrich. This polymer was dissolved in chloroform-dimethylformamide $\left(\mathrm{CHCl}_{3}: \mathrm{DMF}=4: 1\right)$ to prepare different concentrations for electrospinning (Table 1). After mixing for at least $10 \mathrm{~h}$, the solution was loaded into a $5 \mathrm{~mL}$ BD plastic syringe equipped with a stainless steel blunt-ended needle. The polymer solution was delivered to the needle via a silicon feed line with a constant flow rate (FR) of $1 \mathrm{ml} / \mathrm{h}$ using a syringe pump (Harvard Apparatus PHD 2000). The working distance (WD) between the needle and conductive aluminum collector was from 12 to $20 \mathrm{~cm}$. The high-voltage power was set from $15 \mathrm{kV}$ to $18 \mathrm{kV}$. The environmental parameters were held constant and were similar for all of the experiments $\left(T=25^{\circ} \mathrm{C}, \mathrm{H}=35 \%\right)$.

Table 1. Electrospinning parameters used for optimization studies

\begin{tabular}{|c|c|c|c|c|c|c|c|}
\hline $\begin{array}{l}\text { Concentration } \\
\text { PCL (wt\%) }\end{array}$ & $\begin{array}{l}\text { Solvent } \\
\text { (DMF: } \mathrm{CHCl}_{3} \text { ) }\end{array}$ & $\begin{array}{l}\text { Flow rate } \\
(\mathrm{ml} / \mathrm{h})\end{array}$ & $\begin{array}{l}\text { Voltage } \\
\text { (kV) }\end{array}$ & $\begin{array}{l}\text { Working distance } \\
\text { (cm) }\end{array}$ & $\begin{array}{l}\text { Temperature } \\
\left({ }^{\circ} \mathrm{C}\right)\end{array}$ & $\begin{array}{l}\text { Humidity } \\
(\%)\end{array}$ & $\begin{array}{l}\text { Collection time } \\
\text { (min) }\end{array}$ \\
\hline 18 & $1: 4$ & 1 & 15 & $12 ; 15 ; 20$ & 25 & 35 & $1 ; 10 ; 30$ \\
\hline 20 & $1: 4$ & 1 & $15 ; 18$ & $12 ; 15 ; 20$ & 25 & 35 & 10 \\
\hline 22 & $1: 4$ & 1 & 15 & $12 ; 15 ; 20$ & 25 & 35 & 10 \\
\hline 26 & $1: 4$ & 1 & 15 & $12 ; 15 ; 20$ & 25 & 35 & 10 \\
\hline
\end{tabular}




\section{Characterization}

The morphology of the honeycomb nanofibers scaffolds was observed by scanning electron microscopy (Philips XL-30 ESEM, Philips, Netherlands). Following this, samples were gold-sputtered (Cressington Sputter Coater 108 auto) for $60 \mathrm{~s}$ at $30 \mathrm{~mA}$ and then imaged using a SEM at $\mathrm{V}=10 \mathrm{kV}$. For quantification of the diameter and area of honeycomb fibrous pattern, SEM images were analyzed by Image J. 3D optical-profiles and the depths of gradients honeycomb were measured by using a confocal laser scanning microscopy (Keyence).

\section{Contact angle measurements}

The wettability of honeycomb fibrous mesh was calculated by sessile drop technique contact angle goniometer (Drop shape Analyzer DSA25, Kruss, Germany) at room temperature. For this approach, the samples were fixed on a stage of the contact angle device. The water droplets (about $4 \mu \mathrm{L}$ ) were dropped onto the surface of meshes, and the value of contact angle (CA) was obtained after $30 \mathrm{~s}$. The average CA value of three measurements was performed at different positions on the same sample. The diameter of gradients honeycomb mesh are $2.5 \mathrm{~cm}$. Contact angle were measured from central to right in three region, from $0 \mathrm{~cm}$ to $1 \mathrm{~cm}$, then to $2 \mathrm{~cm}$.

\section{Statistics analysis}

Statistics analysis was performed using GraphPad Prism 5.01 (GraphPad software, San Diego, USA). Values were averaged and expressed as means \pm standard deviation (SD). Statistical differences were determined by the analysis of One-Way ANOVA with Bonferroni's multiple comparison tests. The differences were considered statistically significant at $p<0.05$, and the data were indicated with $\left({ }^{*}\right)$ for $p<0.05,\left({ }^{* *}\right)$ for $p<0.01$, and $\left({ }^{* *}\right)$ for $p<0.001$, respectively. 


\section{Results and discussion}

\section{Concentration of PCL}

Polymer concentration is one of the most important parameters in the electrospinning process because it is strongly related to the polymer viscosity and the degree of entanglement[50]. Figure 1 shows the SEM images of the honeycomb pattern from the PCL solutions with different concentration $(w / v)$. Electrospinning $18 \mathrm{wt} \% \mathrm{PCL}$ solutions led to the formation of a honeycomb pattern, but this polymer concentration also produced numerous beads inside the fibrous mesh (Figure 1a-c). In case of lower surface tension produced by lower concentration, the jet would be broken down into drops[50]. Therefore, lower surface tension tends to form more beads during the electrospinning process. The diameter of beads and fiber were $9.53 \pm 1.44 \mu \mathrm{m}$ and $130 \pm 50$ $\mathrm{nm}$, respectively (Figure S1). When the concentration of the PCL solution increased to $22 \mathrm{wt} \%$, a self-assembled honeycomb pattern emerged with less bead formation (Figure 1d-f). When the polymer concentration was increased, it induced an improvement in the surface tension, which finally led to formation of more smooth fibers. Moreover, higher surface tension could drive nanofibers to merge together, and then produced more fiber clusters for the self-organization of honeycomb. The average diameter of beads and fibers were $9.78 \pm 1.78 \mu \mathrm{m}$ and $150 \pm 30 \mathrm{~nm}$, respectively (Figure S1). This means that the polymer concentration between $18 \mathrm{wt} \%$ and $22 \mathrm{wt} \%$ did not have a significant influence on the diameter of beads and fibers. After increasing the concentration to 26 wt $\%$, fiber self-assembly could not be obtained and electrospun short fibers in the form of sticks were observed, randomly distributed, without big beads in the fabricated meshes (Figure 1g-i). Honeycomb self-assembly generally disappeared at higher solution concentration, which has been reported before $[24,51]$. This is because the nanosticks are drier and stronger when high concentrations are used. Less solvent remaining on the surface of the nanosticks can decrease surface tension, finally resulting in lack of fiber cluster formation. We hypothesize that 
no continuous nanofibers clusters were formed through electrospinning at this concentration, preventing self-assembly of honeycomb structures.

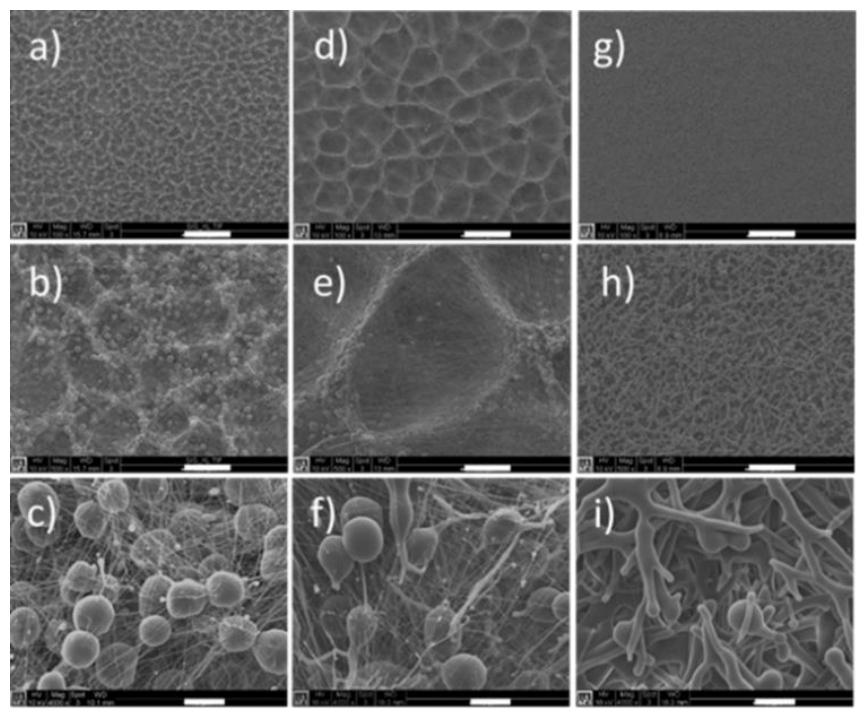

Figure 1. SEM images of the electrospun fibrous meshes with different concentration. The images were obtained after $10 \mathrm{~min}$ of electrospinning. (a-c) PCL at a concentration of $18 \mathrm{wt} \%$, (d-f) PCL at a concentration of $22 \mathrm{wt} \%$, (g-i) PCL at a concentration of $26 \mathrm{wt} \%$ with $\mathrm{V}=15 \mathrm{kV}, \mathrm{FR}=1 \mathrm{ml} / \mathrm{h}$ and $W D=15 \mathrm{~cm}$. Scale bars are $500 \mu \mathrm{m}(\mathrm{a}, \mathrm{d}$ and $\mathrm{g}), 100 \mu \mathrm{m}(\mathrm{b}, \mathrm{e}$ and $\mathrm{h})$ and $10 \mu \mathrm{m}(\mathrm{c}, \mathrm{f}$ and $\mathrm{i})$.

\section{Working distance}

The impact of the working distance on gradient honeycomb formation was investigated by varying from 12 to $20 \mathrm{~cm}$ during the electrospinning process. Figure 2 shows SEM images of the obtained honeycomb patterns with the working distance set to 20,15 and $12 \mathrm{~cm}$, with constant values for other parameters ( $15 \mathrm{kV}$ applied voltage, $1 \mathrm{ml} / \mathrm{L}$ flow rate, $18 \mathrm{wt} \%$ polymer solution). There was poor self-organization when the working distance was set at $20 \mathrm{~cm}$ (Figure $2 \mathrm{a}$ and $\mathrm{b}$ ). The fiber clusters were not well connected, and patterns could not be detected by Image J. However, after decreasing the working distance to $15 \mathrm{~cm}$ and $12 \mathrm{~cm}$, the self-assembly into honeycomb structures occurred (Figure $2 \mathrm{c}-\mathrm{f}$ ). As demonstrated in Figure $2 \mathrm{~g}$ and $2 \mathrm{~h}$, when a working distance of $15 \mathrm{~cm}$ and $12 \mathrm{~cm}$ was applied in forming honeycombs, the average pore diameters were $146 \pm 30 \mu \mathrm{m}$ and $308 \pm 49 \mu \mathrm{m}$, and the area of the 
honeycombs were $1.11 \pm 0.39 \times 10^{4} \mu \mathrm{m}^{2}$ and $4.93 \pm 1.69 \times 10^{4} \mu \mathrm{m}^{2}$, respectively. The diameter of honeycomb patterns increased with smaller working distance between 12 and $15 \mathrm{~cm}$ (Figure 2g). The area of the honeycomb structures showed similar results, increasing with decreasing the working distance (Figure $2 h$ ). This phenomenon was also reported by Yan et al., [24] who proposed that it is related to the increase of the electrical field strength at shorter distance and similar voltage. Larger electrical fields could produce more electrostatic repulsion between fiber clusters. This increase in electrostatic repulsion pushes clusters apart with more force, therefore forming larger honeycomb structures.
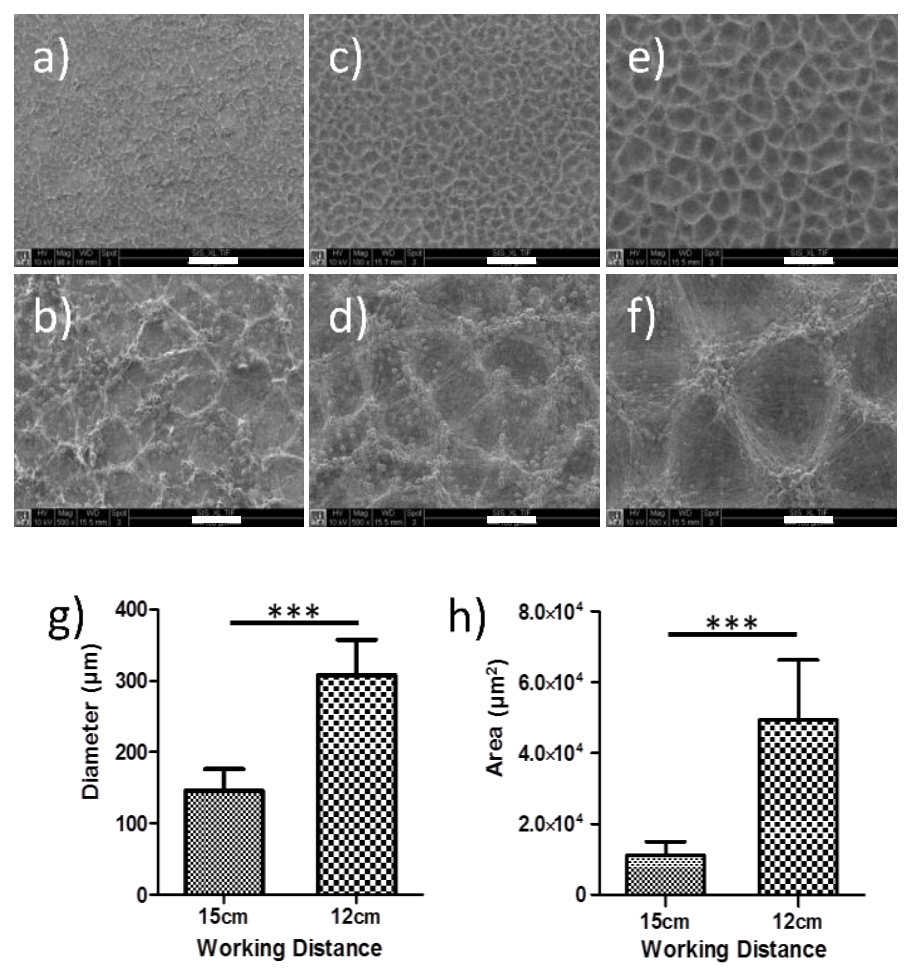

Figure 2. SEM images showing the morphologies of $\mathrm{PCL}$ electrospun fibrous meshes with different working distances. (a, b) WD=20cm; (c, d) WD=15cm; (e, f) WD=12cm. Scale bars are $500 \mu \mathrm{m}(\mathrm{a}, \mathrm{c}$ and $\mathrm{e})$ and $100 \mu \mathrm{m}(\mathrm{b}, \mathrm{d}$ and $\mathrm{f}) .(\mathrm{g}, \mathrm{h})$ The average diameters and area of selfassemble honeycomb structures from different working distance. ${ }^{* * *} \mathrm{P} \leq 0.0005$. 


\section{Collection time}

To study the effect of collection time on honeycomb formation, electrospinning was carried out with different deposition time from $1 \mathrm{~min}$ to $30 \mathrm{~min}$. The conditions consisted of a voltage of $15 \mathrm{kV}$ and a concentration of $18 \mathrm{wt} \%$, which were applied to ensure a stable, efficient deposition of fibers. The morphology and structure of self-assembly electrospun meshes with different deposition time were characterized by SEM (Figure. 3a-f). The morphology and pattern of PCL nanofibrous meshes were clearly demonstrated, confirming that the self-assemble of fiber clusters started from $1 \mathrm{~min}$ of electrospinning. As shown in Figure $3 a-b$, lots of nanofibrous clusters were randomly distributed in the electrospun mesh. Although the amount of fiber deposition was small, poor honeycomb formation was observed at this time point.

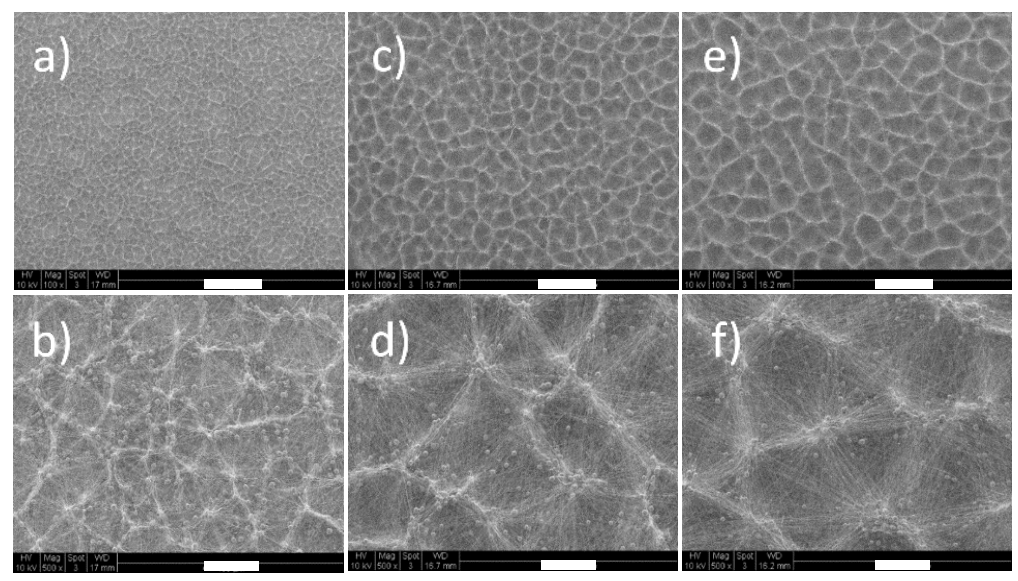

Figure 3. The self-assembly of electrospun fibers with different deposition time. SEM pictures obtained at (a-b) $t=1 \mathrm{~min},(\mathrm{c}-\mathrm{d}) \mathrm{t}=10 \mathrm{~min},(\mathrm{e}-\mathrm{f}) \mathrm{t}=30 \mathrm{~min}$. Scale bars are $500 \mu \mathrm{m} \mathrm{(a,c} \mathrm{and} \mathrm{e)} \mathrm{and}$ $100 \mu \mathrm{m}(\mathrm{b}, \mathrm{d}$ and $\mathrm{f})$. PCL was spun at a concentration of $18 \mathrm{wt} \%$ with $\mathrm{V}=15 \mathrm{kV}, \mathrm{FR}=1 \mathrm{ml} / \mathrm{h}$ and $\mathrm{WD}=15 \mathrm{~cm}$.

After increasing electrospinning time to $10 \mathrm{~min}$, the amount of nanofiber clusters increased and the pattern of honeycomb became clearer (Figure. 3cd). It was expected that deposition time of 10 min could be used as a higher efficient time due to the longer deposition of nanofiber clusters. When the 
deposition time was increased to $30 \mathrm{~min}$, the honeycomb pattern was still very clear on the mesh (Figure. 3e). However, the morphology of nanofiber clusters at higher magnification did not show too much difference compared to $10 \mathrm{~min}$ of spinning time. We also found that the size of the whole electrospun mesh continuously increased with increasing electrospinning time. From these results, it can be concluded that the collection time influenced honeycomb pattern formation and 10 min could be used as an efficient time for honeycomb formation.

\section{Self-assembly of gradient honeycomb patterns}

The working voltage of electrospinning was also varied to study its effect on the formation of the honeycomb structures. For this purpose, PCL solutions with a concentration of $20 \mathrm{wt} \%$ and $22 \mathrm{wt} \%$ were chosen. A good gradient honeycomb structure was formed in these two conditions by adjusting electrospinning parameters (working distance and voltage). We found that different concentrations of PCL solution each have their optimum voltage to form the most well-defined gradient honeycomb structures. The 20 wt $\%$ PCL solution started to form the gradient honeycomb structure when the working voltage was set to $18 \mathrm{kV}$ (Figure 4). However, the $22 \mathrm{wt} \% \mathrm{PCL}$ solution was able to generate a gradient structure at $15 \mathrm{kV}$ (Figure S2). Gradients honeycomb structures only consistently produced when working distance was set at $12 \mathrm{~cm}$.

Figure 4a showed the SEM images of a well-defined gradient honeycomb structure. Figure $4 \mathrm{~b}-\mathrm{g}$ shows additional SEM images of the left (Figure $4 \mathrm{~b}$ and c), middle (Figure $3 \mathrm{~d}$ and $\mathrm{e}$ ), and right (Figure $3 \mathrm{f}$ and $\mathrm{g}$ ) regions of the gradient honeycomb structure. In order to better investigate gradients in the honeycomb, the average area and diameter of the gradient honeycomb were measured (Figure 4). The diameter of honeycombs, which relates to region S1, S2 and S3, were $814 \pm 171 \mu \mathrm{m}, 576 \pm 159 \mu \mathrm{m}$ and $335 \pm 55 \mu \mathrm{m}$, respectively. The area of the honeycomb in the three gradients regions were $3.75 \pm 1.57 \times 10^{5} \mu \mathrm{m}^{2}, 1.87 \pm 0.86 \times 10^{5} \mu \mathrm{m}^{2}$ and $0.63 \pm 0.26 \times 10^{5} \mu \mathrm{m}^{2}$, 
respectively. The pore size of the honeycomb structures decreased from left to right which is believed to be due to the gradients electric field produced when lower working distance applied (Figure $4 b-g$ ). Three regions of different pore sizes were also confirmed by the average diameter and area of honeycomb pattern (Figure 5). Images at a high magnification also showed that honeycomb units were compactly stacked and well interconnected. Similar results were obtained with the $22 \mathrm{wt} \% \mathrm{PCL}$ solutions (shown in SI and Figures S2 and S3).

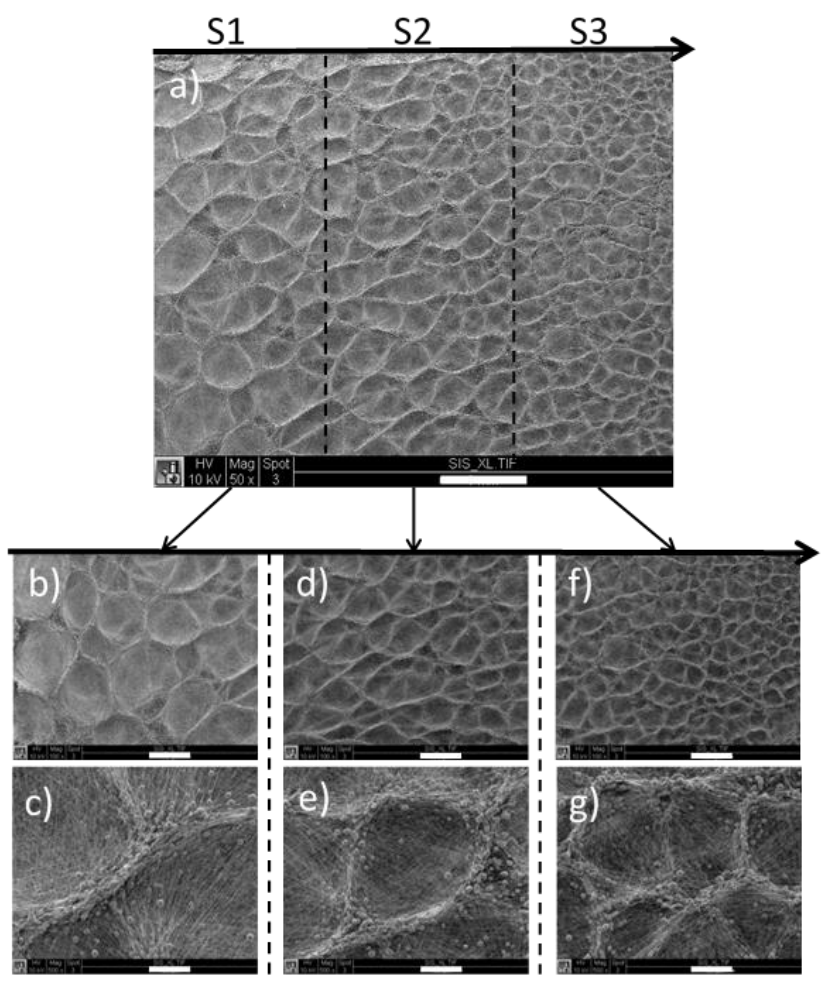

Figure 4. SEM images of the entire gradients honeycomb structures (a) and highly magnified images of the three different regions, took from left to right (S1-S3) having a different pore size. $(b, c)$ is the higher magnification of $\mathrm{S} 1 ;(\mathrm{d}, \mathrm{e})$ middle is the higher magnification of $\mathrm{S} 2 ;(\mathrm{f}, \mathrm{g})$ right is the higher magnification of S3. Scale bars are $1 \mathrm{~mm}(\mathrm{a}), 500 \mu \mathrm{m} \mathrm{(b,} \mathrm{d} \mathrm{and} \mathrm{f)} \mathrm{and} 100 \mu \mathrm{m} \mathrm{(c,e}$ and $g$ ). 
a)

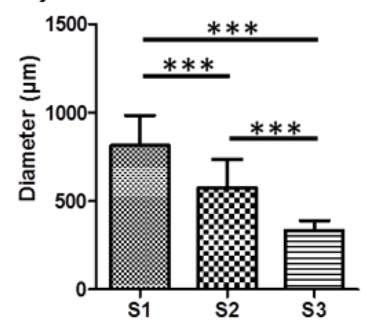

b)

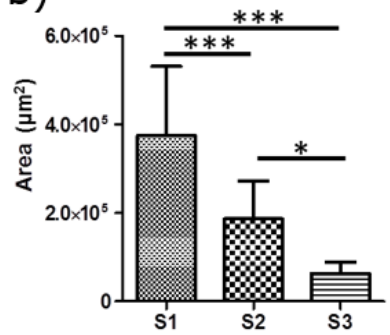

Figure 5. The average diameters (a) and area (b) of gradient honeycomb structures from the three different regions $(\mathrm{S} 1-\mathrm{S} 3)$. ${ }^{*} \mathrm{P} \leq 0.05,{ }^{* *} \mathrm{P} \leq 0.0005$.

As honeycomb size is related to the electric force (at a fixed working distance), in principle, the pore size can be changed by manipulating the electric filed[24]. Recently, Niazi et al [52] investigated the electric honeycomb and explored geometric attributes of the instability pattern, finally proving the role of charged ions as the key factor that drives the instability to form a honeycomb pattern when high voltage applied. They reported that in the tip-plane configuration the electric field is strongest right underneath the tip and reduces radially away from the tip. Correspondingly, the single needle of electrospinning geometry results in an inhomogeneous electric field with an extremely high-electric field concentrated on the surrounding area of the needle[53]. The electrospinning setup display gradients in the generated electric field from the central area of the needle to the side. This is the reason why changing working distance can influence the honeycomb size. After the gradient in electric field formed on the collecting plate, we found that the honeycomb size varied radially with the largest pores below the tip and the smaller pores at the boundary of the collected meshes. The higher electric field in the central part is presumed to have formed higher electric repulsion during the honeycomb formation. This electric repulsion resulted in pushing fiber clusters stronger close to each other, thus resulting in a larger honeycomb formed in the central area. Conversely, smaller honeycombs were obtained in the side parts because of the lower electric field compared the central part of the electrospun meshes. No self-organization occurred at the boundary, suggesting that this higher 
electric field is a necessary condition for self-organization. A SEM analysis at a higher magnification showed that the fibrous meshes at the boundary displayed more droplets instead of nanofibers (Figure S2g). This phenomenon also supports the hypothesis that the electric field at the edge is too low and cannot drive droplet to stretch into fibers.

\section{Wettability of honeycomb-patterned mesh}
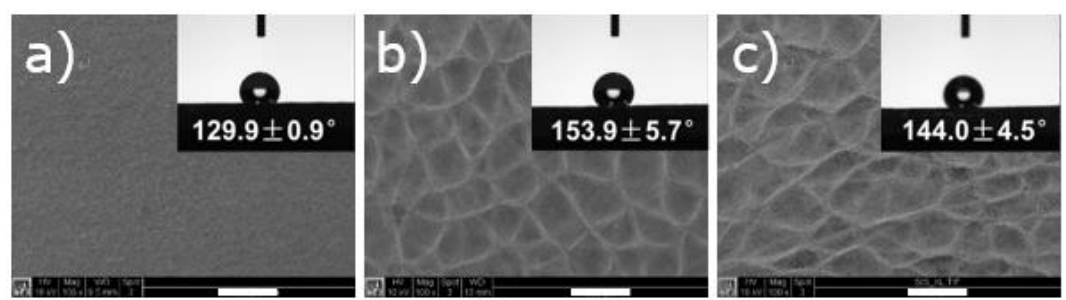

Figure 6. Microstructure and morphology of different electrospun meshes was visualized under SEM. (a) the PCL nanofibrous mesh, (b) honeycomb meshes and (c) gradient honeycomb meshes. The contact angle measurements of each mesh is showed in corresponding inset. Scale bars are $500 \mu \mathrm{m}$.

The wettability of polymer meshes can be influenced by surface topography[54]. Hence, we measured the contact angles (CA) of different PCL electrospun meshes. As demonstrated in Figure 6, the water contact angles were $129.9 \pm 0.9^{\circ}$ and $153.9 \pm 5.7^{\circ}$ on the normal fibrous meshes and honeycomb meshes. In order to test whether the size of honeycomb patterns can affect the wettability of honeycomb meshes, we compared the contact angle of gradients honeycomb meshes in different positions (the left, middle and right), which have different size of honeycomb patterns, from $800 \mu \mathrm{m}$ to $300 \mu \mathrm{m}$. The contact angle was $140.1 \pm 3.1^{\circ}, 146.6 \pm 3.3^{\circ}$ and $145.3 \pm 4.8^{\circ}$, moving from left to right respectively. The average contact angle of gradients honeycomb meshes was $144.0 \pm 4.5^{\circ}$. The size of honeycomb in gradient honeycomb meshes did not have much effect on the wettability of honeycomb meshes. The honeycomb structured meshes had a higher CA value than normal PCL fibrous meshes, thus indicating a higher hydrophobicity as the honeycomb structures are present. The reason for the increase of the 
hydrophobicity is mainly ascribed to air pockets between the substrate surface and water droplets when water droplets were much larger than the dimension of the pores[55]. The formed air pockets, which can prevent the intrusion of water into the pores, finally can result in the large contact angle of honeycomb meshes[56]. However, the CA value between honeycomb meshes and gradient honeycomb meshes were similar, which means the gradients structure did not have a strong influence on the mesh wettability.

\section{The depth of gradients honeycomb pattern}

The depth of gradients honeycomb fibrous mesh was investigated by optical profilometry. Figure 7a showed the 3D-profile of the honeycomb mesh as scanned by the optical profilometer. It can be seen that the wall of honeycomb has higher depth compared to the central area. This observation agreed very well with the result obtained from the SEM images (Figure 4e). The higher depth of the wall is mainly due to the deposition of wet fiber clusters on the wall during honeycomb formation. It has been demonstrated that wet fiber clusters that are in contact with the collector, which can induce the deposition of the fibers onto the walls in a self-sustained way, primarily form the walls of the honeycomb [51].

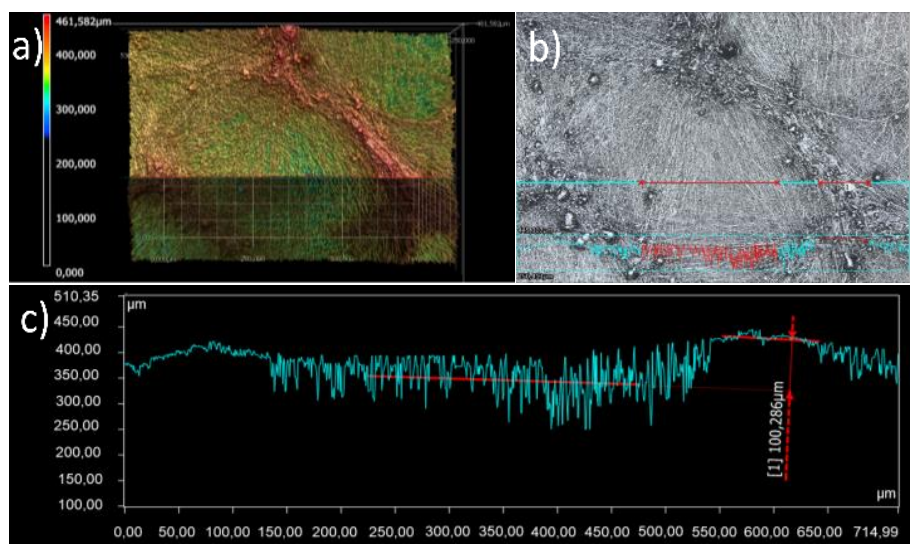

Figure 7. Optical profilometer scans of gradients honeycomb mesh (a and b); (c) Profile graph measuring the height of honeycomb structure in the fibrous mesh. 
The observed depth of this honeycomb is approximately $100 \mu \mathrm{m}$ (Figure 7c). Since it is a self-assemble process during the formation of honeycomb pattern, the depth of honeycomb is not completely uniform. The average depth value for gradients honeycomb was $123 \pm 56 \mu \mathrm{m}$. These results showed the possibility of fabricating electrospun nanofibrous mesh with higher depth compared normal electrospun mesh.

\section{Conclusion}

In summary, a new process to produce gradient honeycomb patterned meshes was first demonstrated by using a simple electrospinning setup. The self-assembly of the electrospun nanofibers into the honeycomb structure was successfully fabricated by optimizing the electrospinning parameters. The effects of the electrospinning parameters and the concentration of polymer solution on the morphology of self-assembled honeycomb structures have been investigated. The working distance of electrospinning was considered as a remarkable effect on the morphology of the honeycomb structures. By adjusting the working distance, it is possible to form honeycomb patterned meshes with different diameter and area, which also could control the formation of a gradient structures. The gradient honeycomb meshes present a pore size gradient from $800 \mu \mathrm{m}$ to $300 \mu \mathrm{m}$. The self-assembly of honeycomb gradients are mainly ascribed to the gradients in the applied electric field. Furthermore, honeycomb scaffold with controllable structure and diameter should be adaptable for tissue regeneration. Their gradient porosity and dimensions makes them particularly attractive for the regeneration of interface tissue, and future experiments will utilize these structures as tissue engineering substrates. 


\section{References}

[1] R. Ostermann, D. Li, Y. Yin, J.T. McCann, Y. Xia, V2O5 nanorods on TiO2 nanofibers: a new class of hierarchical nanostructures enabled by electrospinning and calcination, Nano letters $6(6)$ (2006) 1297-1302.

[2] D.H. Reneker, I. Chun, Nanometre diameter fibres of polymer, produced by electrospinning, Nanotechnology 7(3) (1996) 216.

[3] Z.-M. Huang, Y.Z. Zhang, M. Kotaki, S. Ramakrishna, A review on polymer nanofibers by electrospinning and their applications in nanocomposites, Composites Science and Technology 63(15) (2003) 2223-2253.

[4] S. Ramakrishna, K. Fujihara, W.-E. Teo, T. Yong, Z. Ma, R. Ramaseshan, Electrospun nanofibers: solving global issues, Materials today 9(3) (2006) 40-50.

[5] J. Venugopal, S. Ramakrishna, Biocompatible nanofiber matrices for the engineering of a dermal substitute for skin regeneration, Tissue engineering 11(5-6) (2005) 847-854.

[6] F. Yang, R. Murugan, S. Wang, S. Ramakrishna, Electrospinning of nano/micro scale poly (Llactic acid) aligned fibers and their potential in neural tissue engineering, Biomaterials 26(15) (2005) 2603-2610.

[7] W. He, T. Yong, W.E. Teo, Z. Ma, S. Ramakrishna, Fabrication and endothelialization of collagen-blended biodegradable polymer nanofibers: potential vascular graft for blood vessel tissue engineering, Tissue engineering 11(9-10) (2005) 1574-1588.

[8] N. Murthy, J. Campbell, N. Fausto, A.S. Hoffman, P.S. Stayton, Design and synthesis of pHresponsive polymeric carriers that target uptake and enhance the intracellular delivery of oligonucleotides, Journal of Controlled Release 89(3) (2003) 365-374.

[9] N. Murthy, J. Campbell, N. Fausto, A.S. Hoffman, P.S. Stayton, Bioinspired pH-responsive polymers for the intracellular delivery of biomolecular drugs, Bioconjugate chemistry 14(2) (2003) 412-419.

[10] A.C. Patel, S. Li, C. Wang, W. Zhang, Y. Wei, Electrospinning of porous silica nanofibers containing silver nanoparticles for catalytic applications, Chemistry of materials 19(6) (2007) 1231-1238.

[11] N. Bedford, A. Steckl, Photocatalytic self cleaning textile fibers by coaxial electrospinning, ACS applied materials \& interfaces 2(8) (2010) 2448-2455.

[12] P. Gouma, Nanostructured polymorphic oxides for advanced chemosensors, Rev. Adv. Mater. Sci 5(123) (2003) 122.

[13] K. Ramanathan, M.A. Bangar, M. Yun, W. Chen, N.V. Myung, A. Mulchandani, Bioaffinity sensing using biologically functionalized conducting-polymer nanowire, Journal of the American Chemical Society 127(2) (2005) 496-497.

[14] X. Wang, C. Drew, S.-H. Lee, K.J. Senecal, J. Kumar, L.A. Samuelson, Electrospun nanofibrous membranes for highly sensitive optical sensors, Nano letters 2(11) (2002) 12731275.

[15] P.X. Ma, Biomimetic materials for tissue engineering, Advanced drug delivery reviews 60(2) (2008) 184-98.

[16] J. Lin, X. Wang, B. Ding, J. Yu, G. Sun, M. Wang, Biomimicry via Electrospinning, Critical Reviews in Solid State and Materials Sciences 37(2) (2012) 94-114.

[17] X. Wang, B. Ding, B. Li, Biomimetic electrospun nanofibrous structures for tissue engineering, Materials today 16(6) (2013) 229-241.

[18] L. Jiang, Y. Zhao, J. Zhai, A lotus - leaf-like superhydrophobic surface: a porous microsphere/nanofiber composite film prepared by electrohydrodynamics, Angewandte Chemie 116(33) (2004) 4438-4441.

[19] Y. Miyauchi, B. Ding, S. Shiratori, Fabrication of a silver-ragwort-leaf-like super-hydrophobic micro/nanoporous fibrous mat surface by electrospinning, Nanotechnology 17(20) (2006) 5151. [20] E. Bormashenko, Y. Bormashenko, T. Stein, G. Whyman, E. Bormashenko, Why do pigeon feathers repel water? Hydrophobicity of pennae, Cassie-Baxter wetting hypothesis and CassieWenzel capillarity-induced wetting transition, Journal of colloid and interface science $311(1)$ (2007) 212-216.

[21] M. Godinho, J. Canejo, G. Feio, E. Terentjev, Self-winding of helices in plant tendrils and cellulose liquid crystal fibers, Soft Matter 6(23) (2010) 5965-5970.

[22] X. Wang, B. Ding, J. Yu, J. Yang, Large-scale fabrication of two-dimensional spider-web-like gelatin nano-nets via electro-netting, Colloids and Surfaces B: Biointerfaces 86(2) (2011) 345352.

[23] Y. Zhao, X. Cao, L. Jiang, Bio-mimic multichannel microtubes by a facile method, Journal of the American Chemical Society 129(4) (2007) 764-765. 
[24] G. Yan, J. Yu, Y. Qiu, X. Yi, J. Lu, X. Zhou, X. Bai, Self-assembly of electrospun polymer nanofibers: a general phenomenon generating honeycomb-patterned nanofibrous structures, Langmuir : the ACS journal of surfaces and colloids 27(8) (2011) 4285-9.

[25] A. Welle, M. Kröger, M. Döring, K. Niederer, E. Pindel, I.S. Chronakis, Electrospun aliphatic polycarbonates as tailored tissue scaffold materials, Biomaterials 28(13) (2007) 2211-2219.

[26] Z. Ding, A. Salim, B. Ziaie, Selective nanofiber deposition through field-enhanced electrospinning, Langmuir 25(17) (2009) 9648-9652.

[27] D. Li, G. Ouyang, J.T. McCann, Y. Xia, Collecting electrospun nanofibers with patterned electrodes, Nano letters 5(5) (2005) 913-916.

[28] S. Nedjari, S. Eap, A. Hébraud, C.R. Wittmer, N. Benkirane-Jessel, G. Schlatter, Electrospun honeycomb as nests for controlled osteoblast spatial organization, Macromolecular bioscience 14(11) (2014) 1580-1589.

[29] D. Zhang, J. Chang, Patterning of electrospun fibers using electroconductive templates, Advanced Materials 19(21) (2007) 3664-3667.

[30] S.J. Cho, B. Kim, T. An, G. Lim, Replicable multilayered nanofibrous patterns on a flexible film, Langmuir 26(18) (2010) 14395-14399.

[31] D.K. Dempsey, C.J. Schwartz, R.S. Ward, A.V. Iyer, J.P. Parakka, E.M. Cosgriff-Hernandez, Micropatterning of electrospun polyurethane fibers through control of surface topography, Macromolecular Materials and Engineering 295(11) (2010) 990-994.

[32] S. Zhao, Q. Zhou, Y.-Z. Long, G.-H. Sun, Y. Zhang, Nanofibrous patterns by direct electrospinning of nanofibers onto topographically structured non-conductive substrates, Nanoscale 5(11) (2013) 4993-5000.

[33] J. Guo, C. Li, S. Ling, W. Huang, Y. Chen, D.L. Kaplan, Multiscale design and synthesis of biomimetic gradient protein/biosilica composites for interfacial tissue engineering, Biomaterials 145 (2017) 44-55.

[34] A. Seidi, M. Ramalingam, I. Elloumi-Hannachi, S. Ostrovidov, A. Khademhosseini, Gradient biomaterials for soft-to-hard interface tissue engineering, Acta biomaterialia 7(4) (2011) 1441 1451.

[35] A. Di Luca, B. Ostrowska, I. Lorenzo-Moldero, A. Lepedda, W. Swieszkowski, C. Van Blitterswijk, L. Moroni, Gradients in pore size enhance the osteogenic differentiation of human mesenchymal stromal cells in three-dimensional scaffolds, Scientific reports 6 (2016) 22898.

[36] S. Sant, M.J. Hancock, J.P. Donnelly, D. Iyer, A. Khademhosseini, Biomimetic gradient hydrogels for tissue engineering, The Canadian journal of chemical engineering 88(6) (2010) 899-911.

[37] A. Miserez, T. Schneberk, C. Sun, F.W. Zok, J.H. Waite, The transition from stiff to compliant materials in squid beaks, Science 319(5871) (2008) 1816-1819.

[38] P.J. Yang, J.S. Temenoff, Engineering orthopedic tissue interfaces, Tissue Engineering Part B: Reviews 15(2) (2009) 127-141.

[39] R.I. Sharma, J.G. Snedeker, Biochemical and biomechanical gradients for directed bone marrow stromal cell differentiation toward tendon and bone, Biomaterials 31(30) (2010) 76957704.

[40] L. Lohmander, A. Östenberg, M. Englund, H. Roos, High prevalence of knee osteoarthritis, pain, and functional limitations in female soccer players twelve years after anterior cruciate ligament injury, Arthritis \& Rheumatism: Official Journal of the American College of Rheumatology 50(10) (2004) 3145-3152.

[41] H. Liu, L. Yang, E. Zhang, R. Zhang, D. Cai, S. Zhu, J. Ran, V. Bunpetch, Y. Cai, B.C. Heng, Biomimetic tendon extracellular matrix composite gradient scaffold enhances ligament-to-bone junction reconstruction, Acta biomaterialia 56 (2017) 129-140.

[42] L. Diaz-Gomez, B.T. Smith, P.D. Kontoyiannis, S.M. Bittner, A.J. Melchiorri, A.G. Mikos, Multimaterial segmented fiber printing for gradient tissue engineering, Tissue Engineering Part $\mathrm{C}$ : Methods (2018).

[43] J. Wu, Z. Mao, H. Tan, L. Han, T. Ren, C. Gao, Gradient biomaterials and their influences on cell migration, Interface focus 2(3) (2012) 337-355.

[44] P.Y. Wang, L.R. Clements, H. Thissen, A. Jane, W.B. Tsai, N.H. Voelcker, Screening mesenchymal stem cell attachment and differentiation on porous silicon gradients, Advanced Functional Materials 22(16) (2012) 3414-3423.

[45] C. Liu, Z. Han, J. Czernuszka, Gradient collagen/nanohydroxyapatite composite scaffold: development and characterization, Acta biomaterialia 5(2) (2009) 661-669.

[46] X. Miao, D. Sun, Graded/gradient porous biomaterials, Materials 3(1) (2009) 26-47.

[47] F.J. O'Brien, B. Harley, I.V. Yannas, L.J. Gibson, The effect of pore size on cell adhesion in collagen-GAG scaffolds, Biomaterials 26(4) (2005) 433-441.

[48] I. Schwartz, B.P. Robinson, J.O. Hollinger, E.H. Szachowicz, J. Brekke, Calvarial bone repair with porous D, L-polylactide, Otolaryngology-Head and Neck Surgery 112(6) (1995) 707-713. 
[49] S.H. Oh, I.K. Park, J.M. Kim, J.H. Lee, In vitro and in vivo characteristics of PCL scaffolds with pore size gradient fabricated by a centrifugation method, Biomaterials 28(9) (2007) 16641671 .

[50] Y. Liu, J.H. He, J.y. Yu, H.m. Zeng, Controlling numbers and sizes of beads in electrospun nanofibers, Polymer International 57(4) (2008) 632-636.

[51] D. Ahirwal, A. Hébraud, R. Kádár, M. Wilhelm, G. Schlatter, From self-assembly of electrospun nanofibers to 3D cm thick hierarchical foams, Soft Matter 9(11) (2013) 3164-3172. [52] M.S. Niazi, The Electric Honeycomb; an investigation of the Rose window instability, Royal Society open science 4(10) (2017) 170503.

[53] Y. Zheng, S. Xie, Y. Zeng, Electric field distribution and jet motion in electrospinning process: from needle to hole, Journal of materials science 48(19) (2013) 6647-6655.

[54] A. Cassie, Contact angles, Discussions of the Faraday Society 3 (1948) 11-16.

[55] T. Kawano, Y. Nakamichi, S. Fujinami, K. Nakajima, H. Yabu, M. Shimomura, Mechanical regulation of cellular adhesion onto honeycomb-patterned porous scaffolds by altering the elasticity of material surfaces, Biomacromolecules 14(4) (2013) 1208-13.

[56] X. Wu, S. Wang, Regulating MC3T3-E1 cells on deformable poly ( $\varepsilon$-caprolactone) honeycomb films prepared using a surfactant-free breath figure method in a water-miscible solvent, ACS applied materials \& interfaces 4(9) (2012) 4966-4975. 


\section{Supporting Information}

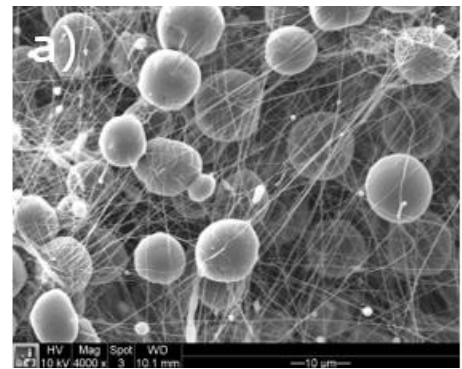

c)

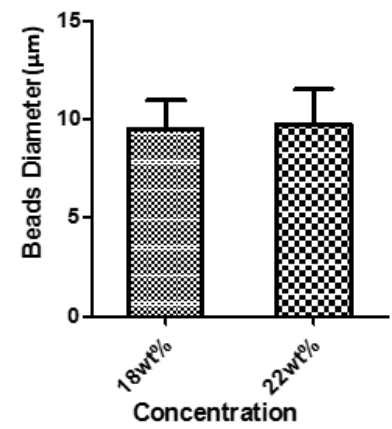

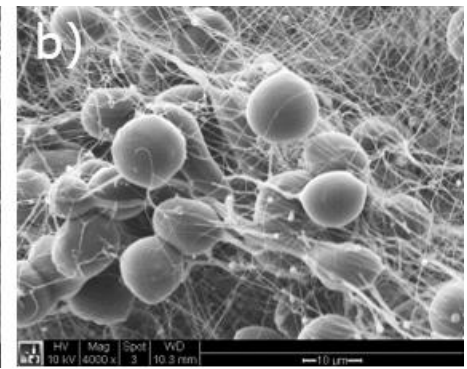

d)

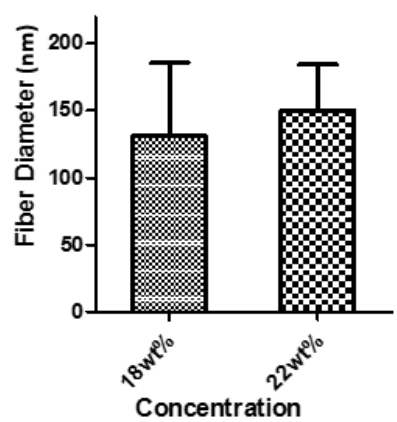

Figure S1. SEM images showing the PCL electrospun honeycomb fibers at the concentration of $18 \mathrm{wt} \%$ (a) and $22 \mathrm{wt} \%$ (b). The beads diameters (c) and fiber diameter (d) of electrospun honeycomb fiber from different PCL concentration. Scale bars are $10 \mu \mathrm{m}$ ( $a$ and $b$ ). 


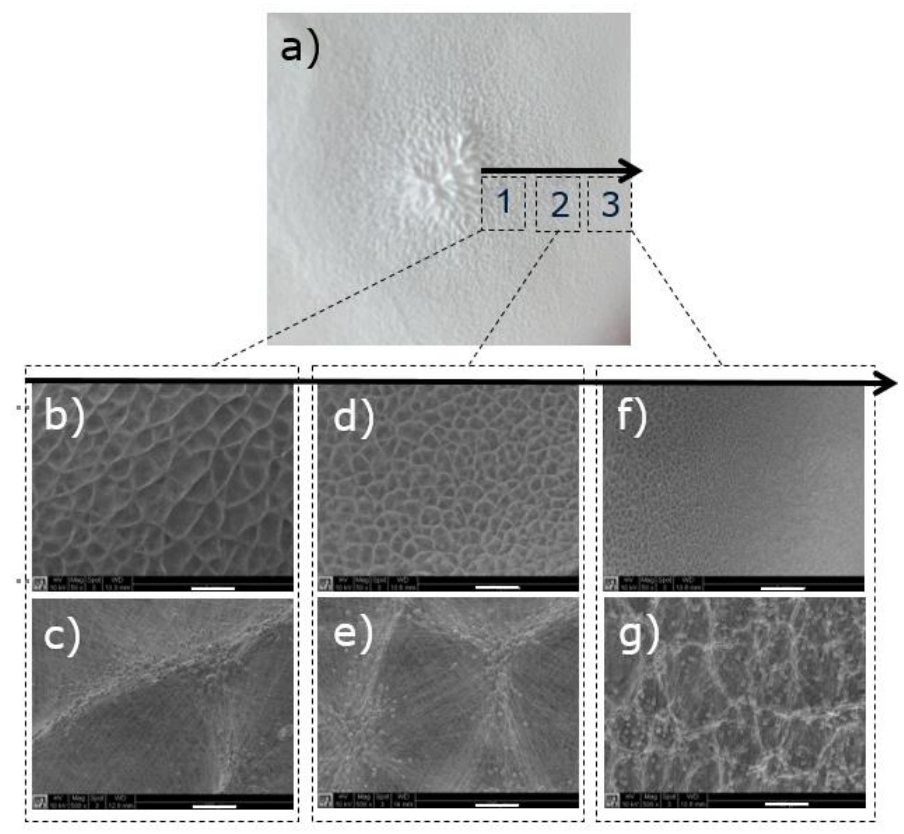

Figure S2. A photograph (a) of the entire electrospun fibrous mesh with gradient honeycomb structures. Higher magnified SEM images of the three different regions, took from the central to the boundary of fibrous mesh (1-3). Figure $(b, c)$ is the higher magnification in region 1 ; figure $(d$, e) and (f, g) are the higher magnification in region 2 and region 3 . Scale bars are $1 \mathrm{~mm}(\mathrm{~b}, \mathrm{~d}$ and f) and $100 \mu \mathrm{m}(\mathrm{c}, \mathrm{e}$ and $\mathrm{g})$.

a)

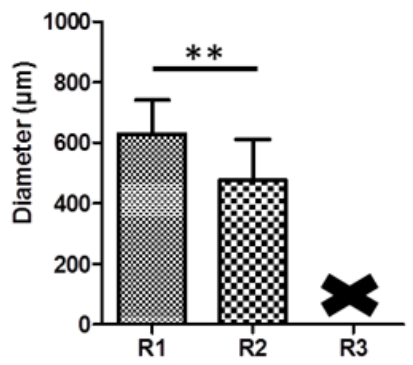

b)

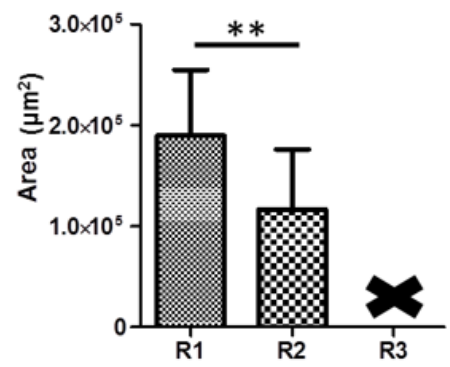

Figure S3.The average diameters (a) and area (b) of gradient honeycomb structures from the three different regions (R1-R3). 


\section{Chapter 4}

\section{Fabrication of a Self-assembled Honeycomb Nanofibrous Scaffold to Guide Endothelial Morphogenesis}

Tianyu Yao' ${ }^{1}$, Paul Andrew Wieringa ${ }^{1}$, Honglin Chen², Pinak Samal', Stefan Giselbrecht ${ }^{1}$, Matthew B Baker ${ }^{1}$, Lorenzo Moroni ${ }^{1}$

1. Complex Tissue Regeneration Department, MERLN Institute for Technology Inspired Regenerative Medicine Maastricht University, Maastricht, 6229 ER, the Netherlands

2. Institute for Life Science, School of Medicine, South China University of Technology, Guangzhou, 510640, China 


\section{Abstract}

Controlling angiogenesis within tissue engineered constructs remains a critical challenge, especially with regard to the guidance of pre-vascular network formation. In this work, we aimed to guide angiogenesis on a selfassembled honeycomb nanofibrous scaffold. Scaffolds with honeycombs patterns have several desirable properties for tissue engineering, including large surface area, high structural stability and good permeability. Furthermore, the honeycomb pattern resembles early vascular network formation. The self-assembly electrospinning approach to honeycomb scaffolds is a technically simple, rapid, and direct way to realize selective deposition of nanofibers. To evaluate cell compatibility, spreading, proliferation and tube formation, human umbilical vein endothelial cells (HUVECs) were cultured on honeycomb scaffolds, as well as on random scaffolds for comparison. The optimized honeycomb nanofibrous scaffolds were observed to better support cell proliferation and network formation, which can facilitate angiogenesis. Moreover, HUVECs cultured on the honeycomb scaffolds were observed to reorganize their cell bodies into tube-like structures containing a central lumen, while this was not observed on random scaffolds. This work has shown that the angiogenic response can be guided by honeycomb scaffolds, allowing improved early HUVECs organization. The guided organization via honeycomb scaffolds can be utilized for tissue engineering applications that require the formation of microvascular networks.

Key words: electrospun, honeycomb, nanofibrous, angiogenesis 


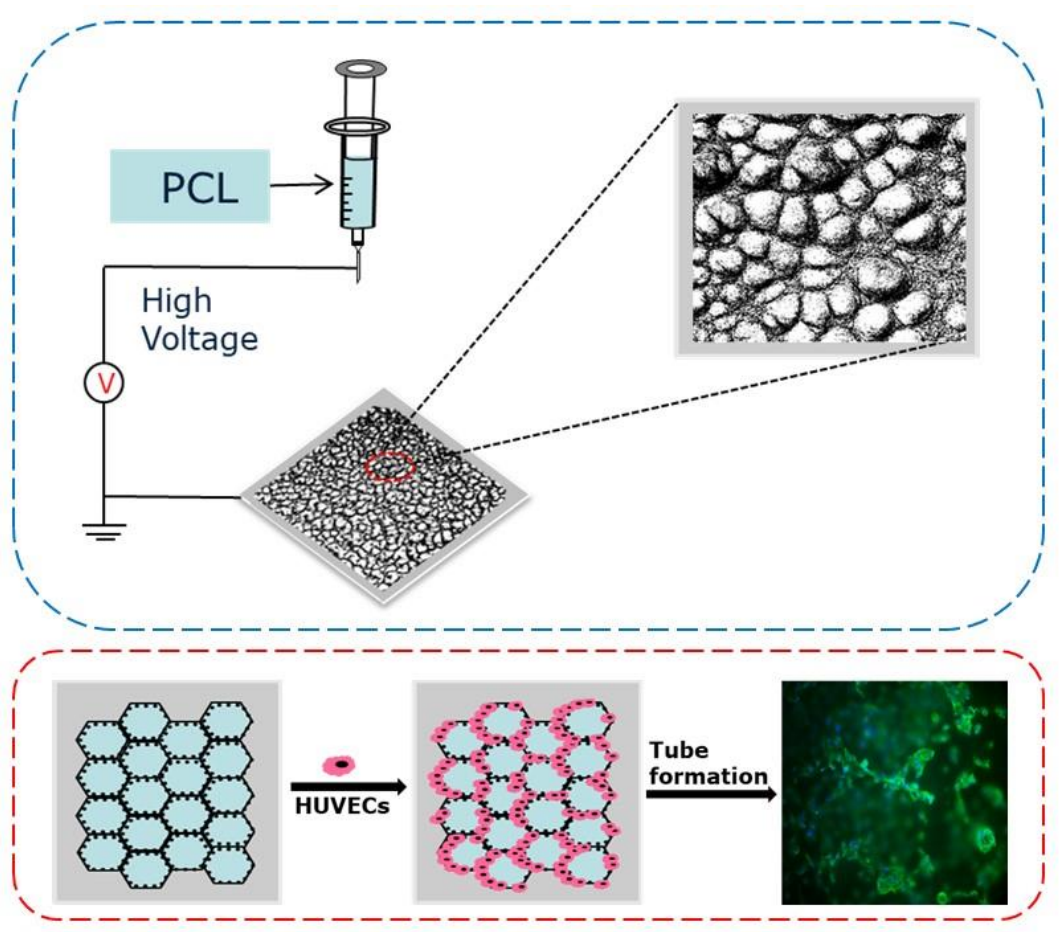




\section{Introduction}

With significant progress in tissue engineering over recent years, there comes a great promise to develop functional constructs resembling the structural organization of native tissues to repair or replace damaged tissues or organs $[1,2]$. Yet, angiogenesis remains one of the most challenging issues [3, 4]. During formation of new tissue, the vessels created by the natural angiogenic process is required to supply oxygen and nutrition for the regenerating tissues as well as to remove metabolic waste products [5-7]. Lack of efficient vascularization limits the size of tissue-engineered constructs $[1,8]$, and often is the reason for failure of translation. Implantation of tissue constructs in a poorly vascularized site often leads to lack of tissue integration and cell death $[9,10]$. As a result, many tissue-engineered constructs also fail in vivo $[1,11$, 12]. The angiogenesis process is critical for the successful regeneration of most tissues within the human body $[13,14]$.

Numerous studies have been conducted to improve angiogenesis in tissue engineering [6,7]. Recent strategies can be classified into three categories: 1) scaffold design [15-18], 2) growth factor delivery [19, 20] and 3) prevascularization [21-23]. Tissue-engineered scaffolds have been considered to be common and simple strategy to induce angiogenesis [7]. An engineered scaffold should typically provide well-defined biochemical (e.g. surface chemistry [24]) and biophysical cues (e.g. fibrous structure [25], hydrophilicity [26] and stiffness [27]) to mimic the environment of a cell's native extracellular matrix (ECM). Three techniques have proven successful to fabricate the biomimetic nanofibrous structure: molecular self-assembly [2831], phase separation [32, 33], and electrospinning [34-36]. Electrospinning is a simple and cost-effective processing technique widely used to produce nanofibers for tissue engineering applications [2]. Several fascinating bioinspired nanofibrous structures have been successfully fabricated by electrospinning such as a lotus leaf [37], a silver ragwort leaf [38], a feather [39], a plant tendril [40], a spider web [41], a polar bear hair [42], and a 
honeycomb [43]. The honeycomb-patterned nanofibrous structures have interesting mechanical properties for tissue-engineering, and can be fabricated by the self-assembly method of electrospinning [44-46]. By adjusting the electrospinning parameters, a well-organized honeycomb structure with different diameters of the honeycomb cells can be obtained [45, 46]. Previously, honeycomb-patterned 2D films fabricated by casting the polymer solution under a moist air was shown to be a suitable substrate to enhance cell adhesion and proliferation [47, 48]. Honeycomb 3D scaffolds display large surface area, high porosity and good mechanical performance, which provide them great potential as porous scaffolds for tissue engineering [49-52]. Blood vessels develop via two consecutive processes, vasculogenesis and angiogenesis[53]. During vasculogenesis, formation of the earliest vessels is achieved. It is reported that fusion of blood-islands leads to the vasculogenesis of honeycomb-shaped primary capillaries [54]. While angiogenesis, new blood vessels derive from already existing vessels [53]. Angiogenesis involves the proliferation, migration, and remodeling of endothelial cells in the process of tube formation. During angiogenesis, endothelial cells can form honeycomb-like network that simulate tube formation $[55,56]$. The presence of a honeycomb-like vascular structure indicates that vasculogenesis and the initial steps of angiogenesis proceeded normally [57]. Therefore, honeycomb network of endothelial cells is a very important morphogenesis and can be used to indicate both vasculogenesis and angiogenesis.

Previous studies have shown that endothelial cell morphogenesis into capillary-like structures was induced and guided by the geometrical distribution of materials $[14,58]$. One study showed that endothelial cells cultured on substrates micropatterned with $10 \mu \mathrm{m}$-wide lines of fibronectin formed capillary tube-like structures containing a central lumen; cells cultured on wider $(30 \mu \mathrm{m})$ lines did not form tubes [58]. Moon et al. micropatterned PEGDA hydrogels with RGDS in different geometries [14]. As a result, endothelial cells cultured on RGDS patterns reorganized their cell bodies into 
tube-like structures on 50- $\mu \mathrm{m}$-wide stripes, but not on wider stripes. These result suggested that endothelial cells morphogenesis can be regulated by geometrical cues. Development of a well-designed scaffold in which capillary tubes consistently form is an important step toward the fabrication of engineered tissues. In this article, we fabricated a nanofibrous scaffold with a unique honeycomb pattern as a biocompatible template to induce the formation of honeycomb-like vascular network. Honeycomb patterns were obtained by the self-assembly of electrospinning, and cell culture tests were performed using human umbilical vein endothelial cells (HUVECs) monoculture and co-culture with human mesenchymal stromal cells (hMSCs) in order to investigate their ability of angiogenesis on this scaffolds.

\section{Materials and methods}

\section{Fabrication of honeycomb nanofibrous scaffolds}

The electrospinning process used in this study is a homemade electrospinning set-up as mentioned before [59]. Poly(caprolactone) (PCL; $\mathrm{Mn}=\sim 45,000 \mathrm{~g} / \mathrm{mol}$ ) was purchased from Sigma-Aldrich and also used in our previous studies[46]. PCL was dissolved in chloroform-dimethylformamide $\left(\mathrm{CHCl}_{3}: \mathrm{DMF}=4: 1\right)$ at a concentration of $22 \mathrm{wt} \%$ and then stirred overnight at room temperature before electrospinning to ensure good polymer solubilization. The polymer solution was loaded into a $5 \mathrm{~mL} \mathrm{BD}$ syringe and delivered to the stainless steel needle (Unimed S.A.) via a PFTE tube (Sigma-Aldrich). This stainless steel nozzle with an inner diameter of $0.8 \mathrm{~mm}$ was connected to a high voltage power supply to generate the electric field strength during electrospinning. Nanofibers were collected over a flat aluminum foil. Electrospinning conditions were showed as below: high voltage $=15 \mathrm{kV}$; working distance $=15 \mathrm{~cm}$; flow rate $=1 \mathrm{~mL} / \mathrm{h}$; collecting time $=10 \mathrm{~min}$; temperature $=25^{\circ} \mathrm{C}$ and humidity $=$ $35 \%$. 


\section{Characterization of honeycomb structures}

The morphology and topography of the honeycomb-like scaffolds were observed by scanning electron microscopy (Philips XL30 ESEM). Before observation, the scaffolds were coated with gold using a sputter coater 108 Auto set at $30 \mathrm{~mA}$ for 80 seconds. Both the diameter and area of honeycomb were analyzed with Image $\mathrm{J}$ software. The fiber alignment measurement was carried out with the Image $\mathrm{J}$ software plug-in named Orientation $\mathrm{J}$ to calculate the directional coherency coefficient. The 3D optical-profiles and depth of honeycomb were determined by using a confocal laser scanning microscopy (Keyence).

\section{Cell culture and seeding}

HUVECs were purchased from Lonza and cultured in endothelial growth medium (EGM, Lonza) containing $\mathrm{EBM}^{\mathrm{TM}}-2$ basal medium (CC3156) and $\mathrm{EGM}^{\mathrm{TM}}-2$ SingleQuots ${ }^{\mathrm{TM}}$ supplements (CC-4176). For experiments, cells were used between passages 4 and 7 . The tube formation assay was performed as Lonza described in instructions. Briefly, Matrige ${ }^{\circledR}$ (Corning) was used to coat the wells of 48 -well plates $(0.15 \mathrm{ml}$ per well) and was left to incubate at $37{ }^{\circ} \mathrm{C}$ for $30 \mathrm{~min}$. After incubation, HUVECs were seeded on each well at the density of 50,000 cells $/ \mathrm{cm}^{2}$ in EGM. The tube formation of cells was visualized using a light microscope. As showed in Figure 1e-f, HUVECs can form the capillary network after 16h, which is also reported by Lonza.

Prior to seeding cells, all PCL electrospun scaffolds were washed in distilled water overnight to remove the residues from sample preparation, further sterilized by $70 \%$ ethanol solution for $30 \mathrm{~min}$, and dried in a biosafety cabinet. In order to increase cell attachment, the scaffolds were coated using Matrige ${ }^{\circledR}$ (1:150 dilution in EGM) overnight. Cells were seeded on the samples at a density of 20,000 cells $/ \mathrm{cm}^{2}$ in EGM. Then the cells were cultured for 1,3 , and 
5 days in an incubator at $37{ }^{\circ} \mathrm{C}$ with humidity of $95 \%$ and $5 \% \mathrm{CO}_{2}$. The culture medium was refreshed every 2 days.

hMSCs (D8011L, Texas A\&M University) were cultured in basic medium consisting of $\alpha$-MEM (Gibco) with 10\% FBS (Sigma), $0.2 \mathrm{mM}$ ascorbic acid (Sigma), $100 \mathrm{U} / \mathrm{ml}$ penicillin and $100 \mathrm{mg} / \mathrm{ml}$ streptomycin (Gibco). hMSCs and HUVECs were co-cultured at a ratio of $1: 1$ on both scaffolds. The seeding density was 20,000 cells $/ \mathrm{cm}^{2}$. Cells were then co-cultured in a mixed media composed of EGM and basic medium at 1:1 ratio for 5 days.

\section{Live/dead assay}

Cell cytotoxicity was assessed using a live/dead assay kit (Thermo Fisher Scientific) after 1 day of cells cultured on electrospun scaffolds. Briefly, Calcein AM $(1 \mu \mathrm{M})$ and ethidium homodimer-1 (EthD-1, $6 \mu \mathrm{M})$ fluorescent dyes in PBS were added into scaffolds and then incubated for $30 \mathrm{~min}$ at $37^{\circ} \mathrm{C}$. Calcein AM was stained by live cells; EthD-1 stained the nuclei of dead cells respectively. After washing with PBS, the samples were observed using fluorescence microscopy (Nikon Eclipse Ti-S). From the fluorescent images of live/dead assay results, live and dead cells were counted and the percentage of viable cells was calculated from Eq. (Viable cells $\%=$ Live cells/Total cells $\times 100$ ).

\section{Cell viability and proliferation}

The viability of HUVECs on electrospun scaffolds was determined using the PrestoBlue kit (Thermo Fisher Scientific) according to the manufacturer's instructions. The cells were washed with warm PBS and treated with PrestoBlue medium (PrestoBlue: $\mathrm{EGM}=1: 9$ ) for $30 \mathrm{~min}$ at $37{ }^{\circ} \mathrm{C}$. After incubation, the PrestoBlue medium was transferred to a black 96 well-plate with a clear bottom. The fluorescence of each groups was measured by using a microplate reader (CLARIO star, BMG Labtech) at $590 \mathrm{~nm}$.

Next, cell proliferation was evaluated at different time points (1, 3 , and 5 days) with a CyQUANT TM Cell Proliferation Assay Kit (Thermo Fisher Scientific). The 
cell-scaffolds were frozen and thawed for 3 times. $250 \mu$ of Proteinase $\mathrm{K}$ in Tris/EDTA solution was then added to each sample. After overnight incubation at $56^{\circ} \mathrm{C}, 40 \mu \mathrm{l}$ of cell lysate was transferred to a black 96 well plate and the same volume of lysis buffer was added into the well plate for $1 \mathrm{~h}$ incubation. Finally, $80 \mu \mathrm{l}$ of GR dye was added into each well and incubated in dark for $15 \mathrm{~min}$. The fluorescence of the solution was measured with the plate reader (CLARIO star, BMG Labtech) at emission and excitation wavelengths of 480 and $520 \mathrm{~nm}$, respectively.

\section{Immunofluorescence staining}

HUVECs were cultured on the electrospun scaffolds for 5 days and then fixed using $4 \%$ formaldehyde for $30 \mathrm{~min}$ at room temperature. After washing with PBS, cells were permeabilized with $0.1 \%$ Triton-X 100 in PBS for 15 min, then blocked with block solution (0.05\% Tween $20,5 \%$ goat serum, and $1 \%$ BSA in PBS) for $1 \mathrm{~h}$. The samples were incubated with the primary antibodies (antiCD31 or anti-VE-Cadherin antibody, 1:200 dilution in block solution) overnight at $4^{\circ} \mathrm{C}$ after blocking. The cells were then washed with wash buffer (blocking buffer without goat serum) and incubated with the secondary antibody (goatanti mouse; Alexa Fluor 488; 1:200 dilution in wash buffer). After $1 \mathrm{~h}$ of incubation with secondary antibody, the samples were washed with PBS for three times. Cell nuclei were stained with DAPI for $5 \mathrm{~min}$, followed by washing with PBS. Finally cells were imaged with a fluorescence microscope (Nikon Eclipse Ti-S). To quantify angiogenesis, Image $\mathrm{J}$ was used to analyze the length of tube formation.

\section{Cell Morphology and attachment}

SEM images of HUVECs seeded on honeycomb electrospun scaffolds after 5 days was performed. In brief, scaffolds were washed with PBS three times following fixation with $4 \%$ formaldehyde for $30 \mathrm{~min}$ at room temperature. After that, the samples were dehydrated by a standard ethanol series $(30 \%, 50 \%$, $70 \%, 80 \%, 90 \%, 96 \%$ and $100 \%$ ) for at least $15 \mathrm{~min}$. The dehydrated samples 
were immersed in hexamethyl-disilazane (HMDS; Sigma-Aldrich) for $15 \mathrm{~min}$ twice and then dried overnight. After coating with gold, samples were observed by SEM. Cell behavior on the scaffold was also assessed using phalloidin to selectively stain the F-actin. After fixation, nucleus and F-actin of cells were stained with DAPI (Invitrogen, 1:200) and Alexa Fluor 568 phalloidin (Invitrogen, 1:200) according to manufacturer instructions. Cell-scaffolds were then washed with PBS for three times and finally imaged using fluorescence microscopy (Nikon Eclipse Ti-S) and a confocal laser excitation microscope (TCS SP8 STED, Leica).

\section{Statistical analysis}

All data are represented as mean \pm standard deviation. Statistical analysis was carried out using GraphPad Prism 7 software. Unpaired t-test was used to define the significance of the results. In all cases, significance was shown as ${ }^{*} p<0.05,{ }^{* *} p<0.01$ and ${ }^{* * *} p<0.001$.

\section{Results and discussion}

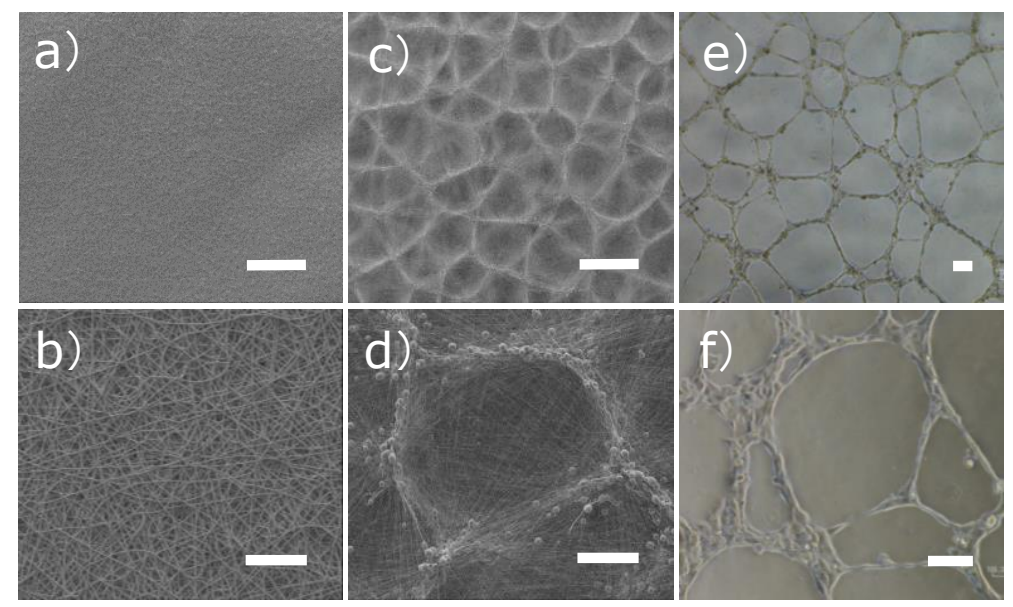

Figure 1. SEM images of random ( $a$ and $b$ ) and honeycomb (c and d) PCL electrospun fibers. Images (e and f) showed the tube formation of HUVECs cultured on Matrigel-coated wellplate

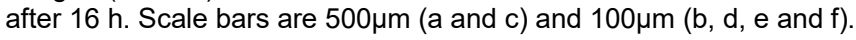


Only a few studies have proved the effect of geometrical control on morphogenesis of ECs into tubular structures by using micropatterned stripes substrates [14, 58]. In the present study, we analyzed the influence of honeycomb patterns on angiogenesis using a self-assembled honeycomb scaffolds. To provide structural guidance for cell response, PCL nanofibrous scaffolds with random and honeycomb morphologies were fabricated.

\section{Morphology of random and honeycomb electrospun scaffolds}

The morphologies of random and honeycomb electrospun scaffolds were examined by scanning electron microscopy (SEM). SEM images clearly showed a difference in morphology between two types of scaffolds. As shown in Figure 1a-b, PCL random fibrous scaffolds were formed with randomly oriented and uniform fibers. The diameter of PCL random fibers was $1.84 \pm 0.14 \mu \mathrm{m}$. From Figure $1 \mathrm{c}-\mathrm{d}$, the self-assembly of nanofibers into a honeycomb pattern was observed in the scaffolds. Honeycomb pattern was well-organized and distributed uniformly in the electrospun scaffolds, which mimics the tube formation of HUVECs (Figure 1e-f). The average diameter and area of honeycombs were $517 \pm 97 \mu \mathrm{m}$ and $1.31 \pm 0.43 \times 10^{5} \mu \mathrm{m}^{2}$, respectively (see the distribution of diameter and area of honeycomb patterns in Figure $2 \mathrm{a}$ and $\mathrm{b}$ ). Due to the competitive actions of surface tension and electrostatic repulsion, the charged nanofibers could self-assemble into the honeycomb structures, which might explain how the patterns were formed[45, 46]. The wall of honeycomb scaffolds were observed by SEM images with higher magnification (Figure S1). Most of the fibers were aligned along the wall of the honeycombs, whereas only few fibers were stretched and suspended in the center of the honeycombs. Moreover, the junctions of the honeycomb patterns tend to form three-branched with an angle approaching $120^{\circ}$ (Figure S1a-b), which is consistent with other electrospun honeycomb studies ${ }^{[44,45]}$. Figure S1c-d clearly showed the beads structure on the wall and the alignment of nanofibers produced by self-organization of the honeycombs. The level of alignment was measured by the coherency coefficients (Figure 
S1e). The coherency coefficient ranges from 0 to 1 , the value of coherency is close to 1 indicating a strongly coherent orientation and greater alignment[60]. Analysis of the fibers showed that the coherency of fibers near the wall of honeycomb was statistically higher $(0.81 \pm 0.03$ vs. $0.20 \pm 0.08$ and $0.21 \pm$ 0.05 ) than that on the central of honeycomb and the random scaffolds, and the fiber randomness at the center of honeycomb is similar to the random scaffolds.

The 3D image and depth of the honeycomb structure was obtained by optical profilometry, as shown in Figure 2c-e. A complete honeycomb was observed in 3D, which showed a similar pattern as what observed by SEM. It can be seen that the wall of honeycombs has a higher depth compared to the central region. The average depth of honeycomb pattern is approximately $82.7 \pm 26.8$ $\mu \mathrm{m}$, whereas a lower depth of random scaffolds (less than $2 \mu \mathrm{m}$ ) was observed in Figure S2. These results showed that the walls of the honeycomb nanofibrous scaffolds display a significant height, providing a 3D surface for cell growth as compared to random scaffolds.

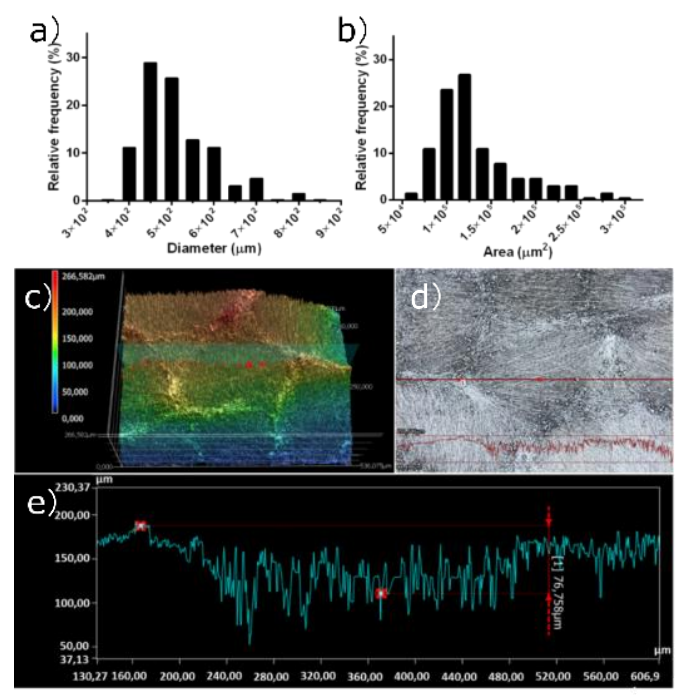

Figure 2. The diameter (a) and area (b) distribution of honeycomb patterns in nanofibrous scaffolds. Images (c and d) are optical profilometer scans of a honeycomb pattern. (e) Profile graph measuring the height of honeycomb structure in the nanofibrous scaffolds. 


\section{HUVECs on random and honeycomb electrospun scaffolds}

Live/dead assays were carried out on random and honeycomb scaffolds after one day of in vitro cell culture. The results can be seen in Figure S3. After one day of culture, cells attached to and survived very well on both scaffolds (green indicates live cells). Only few dead cells were seen on the scaffolds (red indicates dead cells). The percentage of living cells on random and honeycomb scaffolds were $93 \pm 3 \%$ and $95 \pm 2 \%$, respectively, which indicated good biocompatibility for both scaffolds. Cell viability was evaluated by using the PrestoBlue assay at 1, 3 and 5 days as illustrated in Figure 3a. Results showed that cell viability for both groups gradually increases over 5 days, whereas no significant differences were identified between random and honeycomb scaffolds for the same time point. These observations supported the live/dead findings and confirmed low cytotoxicity of both random and honeycomb nanofibrous scaffolds. In addition, cell proliferation was determined using a CyQUANT ${ }^{\mathrm{TM}}$ Cell Proliferation Assay Kit to measure total DNA content. The samples with HUVECs were harvested after 1, 3 and 5 days of culture. The DNA content on honeycomb scaffolds was higher than that on random scaffolds at day 5 (Figure $3 b$ ). There was a statistically significant increase of proliferation on honeycomb scaffolds compared to the random ones. Cell proliferation was also evaluated by Ki67 staining, as it is a marker for proliferation. As shown in Figure S4, at day 5, the intensity of Ki67 fluorescence-positive cells on the honeycomb scaffolds was much higher than that on the random scaffolds. These results suggested that honeycomb patterns in electrospun scaffolds were capable of positively influencing HUVECs growth, ultimately leading to a higher number of cells compared to the random scaffolds. This might be attributed to the 3D structure of honeycomb patterns; indeed, the honeycomb scaffolds have higher depth compared to random scaffolds, which offered increased available surface and large porosity for cell growth. 
a)

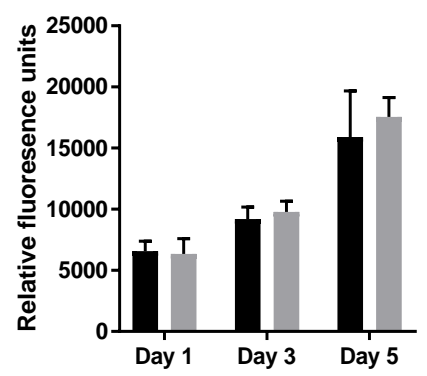

b)

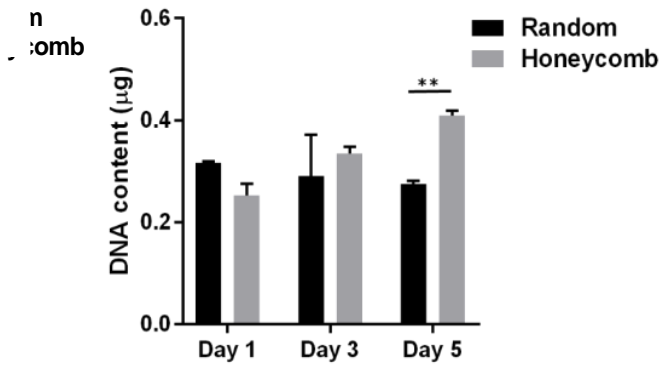

Figure 3. The viability (a) and proliferation (b) of HUVECs cultured for 5 days on PCL random and honeycomb fibrous scaffolds. ${ }^{* *} p<0.01$.

\section{Formation and orientation of tube-like structures}
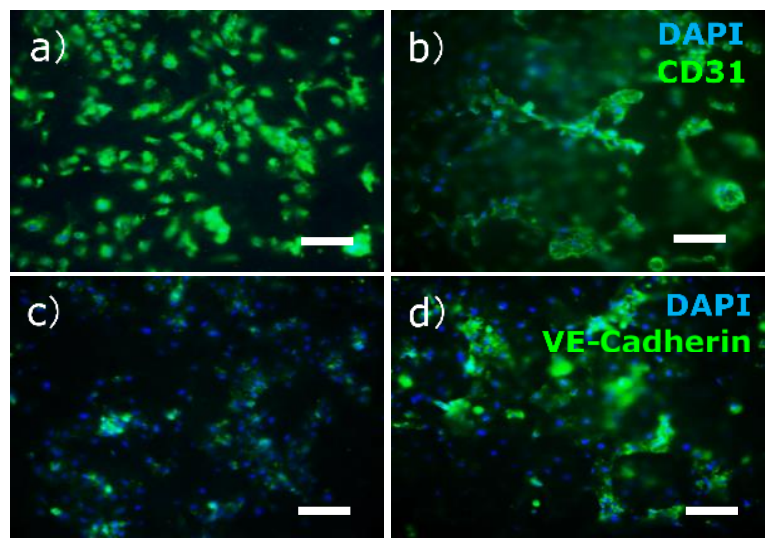

Figure 4. Fluorescence images stained for CD31 (a-b), VE-Cadherin(c-d) and nuclei (DAPI: blue) of HUVECs on the random ( $a$ and $c$ ) and honeycomb ( $b$ and d) fibrous scaffolds after 5 days culture (scale bar: $100 \mu \mathrm{m})$.

In order to test the responses of endothelial cells to honeycomb patterns, cells cultured on random and honeycomb patterns were observed by immunocytochemistry staining and SEM. Immunocytochemistry staining with CD31, VE-Cadherin and DAPI was used to evaluate cell identity and 
morphology on the scaffolds. As shown in Figure 4, the HUVECs cultured on both scaffolds expressed an endothelial cell phenotype showing the positive staining of CD31 and VE-Cadherin. However, the cells responded differently to random and honeycomb nanofibrous scaffolds. Cells on the random scaffolds were well spread and showed a disorganized distribution without any tube formation, as shown in CD31 staining (Figure 4a). In contrast, cells on the honeycomb scaffolds showed the preferential location of the cells along the wall of honeycomb, which is mainly due to the alignment of nanofibers in the honeycomb scaffolds. It has been widely reported that aligned nanofibers could provide contact guidance cues for endothelial cells [61-63]. It also formed cord-like structures organized by HUVECs when cells cultured on honeycomb scaffolds (Figure 4b). This phenomenon resulted in the formation of 3D tube-like structures on honeycomb scaffolds, as also confirmed by 3D confocal images (Figure 5). Confocal images of horizontal and vertical (Figure $5 c-d)$ cross sections confirmed the existence of the central lumen, which appeared as a negatively stained central space extending along multiple cell lengths. Figure S5 also illustrated another negatively labeled lumen and the position of this lumen. We quantified about 30 tubes from multiple CD31 staining images on one scaffolds and the length of tubes was $247.6 \pm 152.5$ $\mu \mathrm{m}$. The junction of HUVECs in the scaffolds was further revealed by VECadherin staining (Figure $4 \mathrm{c}$ and $\mathrm{d}$ ). VE-Cadherin is the basic adhesion junction in endothelial cells, which is important for cell to cell contacts ${ }^{[64]}$. It was interesting to note that more VE-Cadherin (green) was observed when cells were cultured on the honeycomb nanofibrous scaffolds compared to random scaffolds, indicating that cells generated stronger cohesion and organization of cell-cell junctions. Moreover, the honeycomb pattern on electrospun scaffolds could lead to the ability of HUVECs to contact and form a tube-like structure. As proven previously, the formation of cell-cell connections is essential for endothelial cells to maintain cell-cell adhesion and communication, which subsequently directs endothelial cell morphogenesis and guides the early development of vascular networks [65]. The addition of 
micro-/nanotextured topographies to materials could effectively activate angiogenic signaling pathways, which are crucial in the process of endothelial angiogenesis [66,67]. A regular pattern such as the honeycomb guarantees that cells in the entire construct are never further away from the next vessel than half of the long diagonal of a honeycomb cell. The results obtained in the present investigation therefore supported that the geometries of the honeycomb patterns might also activate angiogenic signaling pathways in HUVECs and stimulate reorganization of cell bodies into tube-like structures.

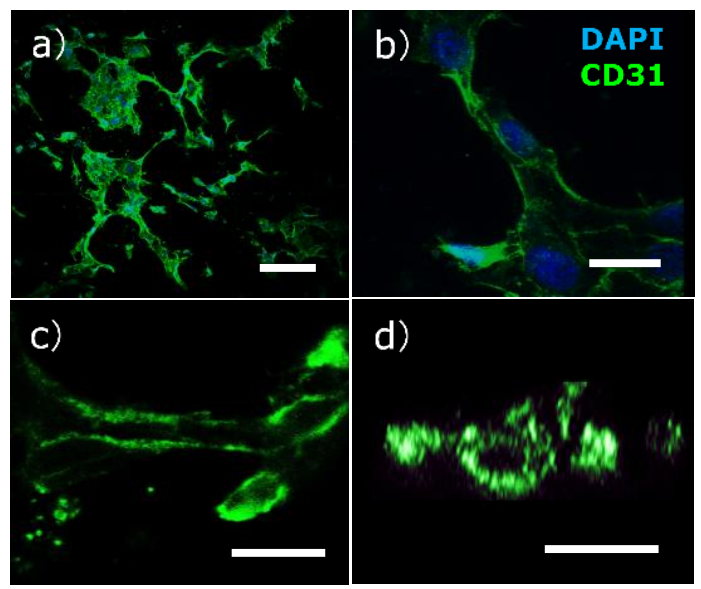

Figure 5. (a-b) 3D confocal images of the HUVECs grow on honeycomb scaffolds showing the capability of cells to generate 3D tube-like structures. (c-d) The lumen cavity appears as a negatively stained central space when viewed in horizontal $(X Y)$ and vertical $(Y Z)$ cross section. Nuclei were labeled with DAPI (blue) and HUVECs were stained with an anti-CD31 antibody (green). Scale bars are $100 \mu \mathrm{m}$ (a), $20 \mu \mathrm{m}$ (b), $10 \mu \mathrm{m}$ (c) and $5 \mu \mathrm{m}$ (d).

The morphology of cells grown on both scaffolds was observed by SEM (Figure 6). HUVECs cultured on random scaffolds were widely spread and showed polygonal shape without a preferential distribution, whereas those on honeycomb scaffolds grew along the wall of the honeycomb and preferred to retain at the wall. This result is consistent with immunostaining. More SEM images of HUVECs on honeycomb scaffolds are shown in Figure S6. We also looked into single cells grown on scaffolds (Figure $6 \mathrm{~b}$ and $\mathrm{d}$ ). It was found that cells on the random scaffolds were more elliptical with less pseudopodia. In contrast, cells on honeycomb scaffolds were more stretched out, and some 
pseudopodia were elongated along the fiber direction. More pseudopodia of cells on honeycomb could firmly attach to the nanofibers and might help cells migrate in three dimensions. Interestingly, with smaller fiber diameter in honeycomb scaffolds the pseudopodia were longer and smaller on attached fibers. This observation was also confirmed by Li et al. [68].
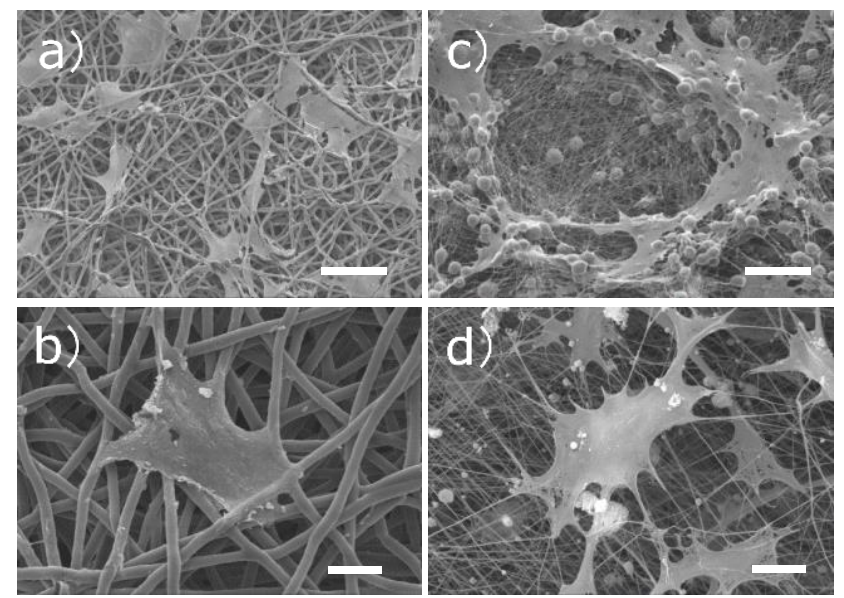

Figure 6. SEM images of HUVECs on random ( $a$ and $b$ ) and honeycomb (c and d) PCL fibers after 5 days culture. Scale bars are $50 \mu \mathrm{m}$ ( $a$ and c) and $10 \mu \mathrm{m}(\mathrm{b}$ and $\mathrm{d}$ )

\section{Co-cultures on honeycomb nanofibrous scaffolds}

Despite ECs being the cell lines that can form the blood vessels in human tissue, perivascular cells, especially pericytes, were shown to have great impact over vascularization. It was previously demonstrated hMSCs can act as pericytes and stabilize the formed vascular structures when co-cultured with ECs in defined conditions. Therefore, co-culturing hMSCs with endothelial cells can be an effective strategy to form vascularization, and to stabilize blood vessels. To determine the topographical influence of honeycomb scaffolds on co-cultured cell behavior, HUVECs and hMSCs were co-cultured up to 5 days. DAPI (blue)/phalloidin (red) staining was performed to observe overall cell distribution and organization. As shown in Figure 7, the honeycomb structure in electrospun scaffolds could guide cell distribution. On random scaffolds, cells exhibited wide spreading of cellular actin filaments and 
were randomly distributed throughout the nanofibers without any preference. While on honeycomb scaffolds, most of cells distributed on the wall of the honeycomb and stretched along the attached nanofibers. It seems that the cells preferred to spread at the top of the honeycomb pattern, growing along the wall. 3D confocal images also proved this observation (Figure S7). The co-culture further corroborated the trend observed in HUVECs monoculture showing that cell behavior can be regulated and guided by honeycomb nanofibrous scaffolds. It was also interesting to note that VE-Cadherin staining was much higher for the HUVECs co-culture with hMSCs on honeycomb scaffolds compared on the random scaffolds, as shown in Figure 8. The results demonstrated that HUVECs/hMSCs co-culture on the honeycomb scaffolds generated strong cohesion and organization of the inter-cellular junctions. However, it was much less on the random scaffolds. This result obtained in the co-culture investigation also supported that the honeycomb scaffolds could facilitate desirable intracellular connection and the following endothelial cell morphogenesis.
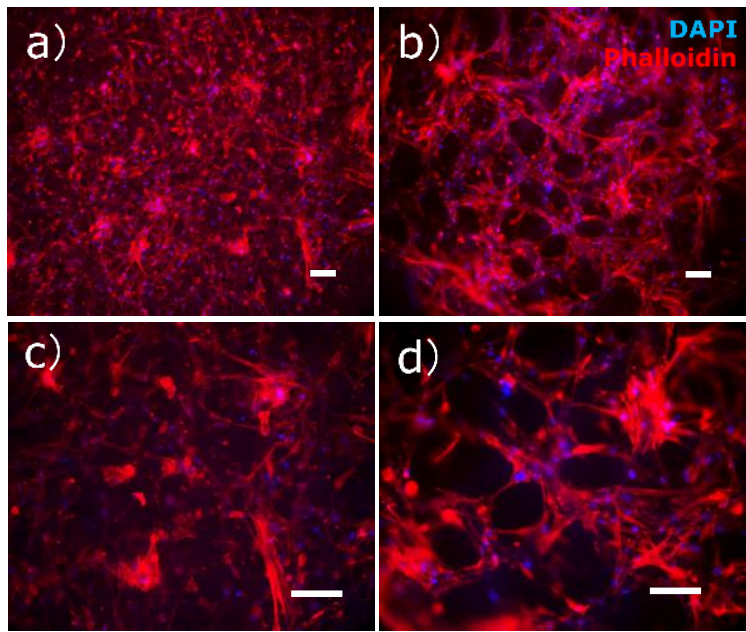

Figure 7. Fluorescence images stained for F-actin (phalloidin: red) and nuclei (DAPI: blue) of hMSCs-HUVECs on random ( $a$ and $c$ ) and honeycomb (b and d) PCL electrospun scaffolds after 5 day of co-culture. Scale bars are $100 \mu \mathrm{m}$. 


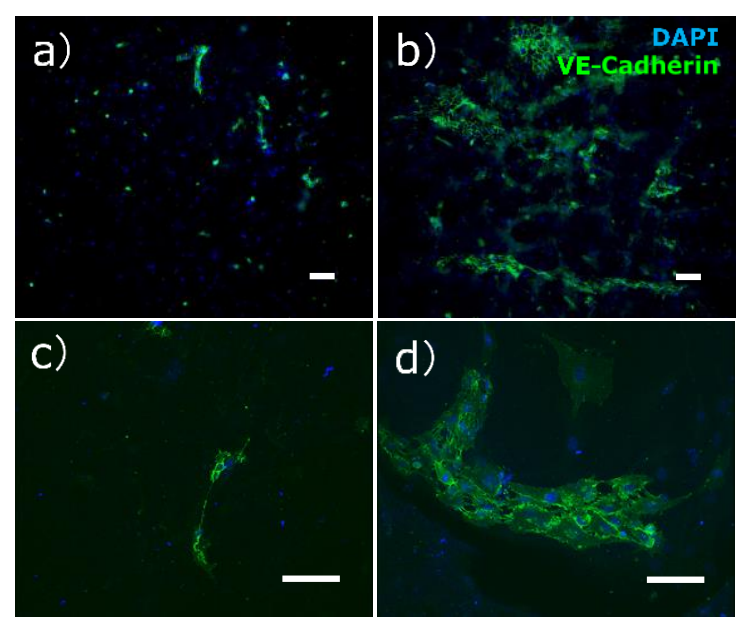

Figure 8. Immunoflourescence staining of VE-Cadherin in HUVECs after co-culture with hMSCs on random ( $a$ and $c$ ) and honeycomb (b and d) scaffolds at day5. Scale bars are $100 \mu \mathrm{m}$.

\section{Conclusion}

In this study, we fabricated honeycomb nanofibrous scaffolds by the selfassembly process of electrospinning. The fabricated honeycomb scaffolds can support endothelial cells adhesion, proliferation, and guide cell migration on the scaffolds. Compared with the random electrospun scaffolds, the honeycomb scaffolds significantly promoted HUVECs proliferation and influenced the distribution of cells. It is interesting that the honeycomb electrospun scaffolds can regulate HUVECs morphogenesis into capillary-like structures with a central lumen. Moreover, higher VE-Cadherin staining was observed when HUVECs were mono-cultured and co-cultured with hMSCs on the honeycomb nanofibrous scaffolds compared to random scaffolds. This study provides evidence that endothelial cells are highly sensitive to their local microenvironment and can respond to geometric cues to form capillary networks. These results show that the better geometric control of endothelial cells during angiogenesis give honeycomb scaffolds more potential for vascular tissue engineering. 


\section{Reference}

[1] S. Chakraborty, T. Ponrasu, S. Chandel, M. Dixit, V. Muthuvijayan, Reduced graphene oxideloaded nanocomposite scaffolds for enhancing angiogenesis in tissue engineering applications, Royal Society open science 5(5) (2018) 172017.

[2] S. Khorshidi, A. Solouk, H. Mirzadeh, S. Mazinani, J.M. Lagaron, S. Sharifi, S. Ramakrishna, A review of key challenges of electrospun scaffolds for tissue-engineering applications, Journal of tissue engineering and regenerative medicine 10(9) (2016) 715-738.

[3] X. Guo, C.G. Elliott, Z. Li, Y. Xu, D.W. Hamilton, J. Guan, Creating 3D angiogenic growth factor gradients in fibrous constructs to guide fast angiogenesis, Biomacromolecules 13(10) (2012) 3262-3271.

[4] S.T. Nillesen, P.J. Geutjes, R. Wismans, J. Schalkwijk, W.F. Daamen, T.H. van Kuppevelt, Increased angiogenesis and blood vessel maturation in acellular collagen-heparin scaffolds containing both FGF2 and VEGF, Biomaterials 28(6) (2007) 1123-1131.

[5] A. Hadjizadeh, F. Ghasemkhah, N. Ghasemzaie, Polymeric scaffold based gene delivery strategies to improve angiogenesis in tissue engineering: a review, Polymer Reviews 57(3) (2017) 505-556.

[6] J. Rouwkema, A. Khademhosseini, Vascularization and angiogenesis in tissue engineering: beyond creating static networks, Trends in biotechnology 34(9) (2016) 733-745.

[7] J. Rouwkema, N.C. Rivron, C.A. van Blitterswijk, Vascularization in tissue engineering, Trends in biotechnology 26(8) (2008) 434-441.

[8] M. Lovett, K. Lee, A. Edwards, D.L. Kaplan, Vascularization strategies for tissue engineering, Tissue Engineering Part B: Reviews 15(3) (2009) 353-370.

[9] C.K. Griffith, C. Miller, R.C. Sainson, J.W. Calvert, N.L. Jeon, C.C. Hughes, S.C. George, Diffusion limits of an in vitro thick prevascularized tissue, Tissue engineering 11(1-2) (2005) 257266.

[10] S. Singh, B.M. Wu, J.C. Dunn, The enhancement of VEGF-mediated angiogenesis by polycaprolactone scaffolds with surface cross-linked heparin, Biomaterials 32(8) (2011) 20592069.

[11] H. Bae, A.S. Puranik, R. Gauvin, F. Edalat, B. Carrillo-Conde, N.A. Peppas, A. Khademhosseini, Building vascular networks, Science translational medicine 4(160) (2012) 160ps23-160ps23.

[12] E. Hunziker, M. Spector, J. Libera, A. Gertzman, S.L.-Y. Woo, A. Ratcliffe, M. Lysaght, A. Coury, D. Kaplan, G. Vunjak-Novakovic, Translation from research to applications, Tissue engineering 12(12) (2006) 3341-3364.

[13] M.W. Laschke, Y. Harder, M. Amon, I. Martin, J. Farhadi, A. Ring, N. Torio-Padron, R. Schramm, M. Rücker, D. Junker, Angiogenesis in tissue engineering: breathing life into constructed tissue substitutes, Tissue engineering 12(8) (2006) 2093-2104.

[14] J.J. Moon, M.S. Hahn, I. Kim, B.A. Nsiah, J.L. West, Micropatterning of poly (ethylene glycol) diacrylate hydrogels with biomolecules to regulate and guide endothelial morphogenesis, Tissue Engineering Part A 15(3) (2008) 579-585.

[15] D. Druecke, S. Langer, E. Lamme, J. Pieper, M. Ugarkovic, H.U. Steinau, H.H. Homann, Neovascularization of poly (ether ester) block - copolymer scaffolds in vivo: Long - term investigations using intravital fluorescent microscopy, Journal of Biomedical Materials Research Part A: An Official Journal of The Society for Biomaterials, The Japanese Society for Biomaterials, and The Australian Society for Biomaterials and the Korean Society for Biomaterials 68(1) (2004) 10-18.

[16] D.W. Hutmacher, Scaffold design and fabrication technologies for engineering tissues - state of the art and future perspectives, Journal of Biomaterials Science, Polymer Edition 12(1) (2001) 107-124.

[17] V. Karageorgiou, D. Kaplan, Porosity of 3D biomaterial scaffolds and osteogenesis, Biomaterials 26(27) (2005) 5474-5491.

[18] S. Yang, K.-F. Leong, Z. Du, C.-K. Chua, The design of scaffolds for use in tissue engineering. Part I. Traditional factors, Tissue engineering 7(6) (2001) 679-689.

[19] K.K. Hirschi, T.C. Skalak, S.M. Peirce, C.D. Little, Vascular assembly in natural and engineered tissues, Annals of the New York Academy of Sciences 961(1) (2002) 223-242.

[20] T.P. Richardson, M.C. Peters, A.B. Ennett, D.J. Mooney, Polymeric system for dual growth factor delivery, Nature biotechnology 19(11) (2001) 1029.

[21] C.S. Choong, D.W. Hutmacher, J.T. Triffitt, Co-culture of bone marrow fibroblasts and endothelial cells on modified polycaprolactone substrates for enhanced potentials in bone tissue engineering, Tissue engineering 12(9) (2006) 2521-2531. 
[22] B.R. Shepherd, D.R. Enis, F. Wang, Y. Suarez, J.S. Pober, J.S. Schechner, B.R. Shepherd, D.R. Enis, F. Wang, Y. Suarez, Vascularization and engraftment of a human skin substitute using circulating progenitor cell-derived endothelial cells, The FASEB journal 20(10) (2006) 1739-1741. [23] R.E. Unger, A. Sartoris, K. Peters, A. Motta, C. Migliaresi, M. Kunkel, U. Bulnheim, J. Rychly, C.J. Kirkpatrick, Tissue-like self-assembly in cocultures of endothelial cells and osteoblasts and the formation of microcapillary-like structures on three-dimensional porous biomaterials, Biomaterials 28(27) (2007) 3965-3976.

[24] D. Grafahrend, K.-H. Heffels, M.V. Beer, P. Gasteier, M. Möller, G. Boehm, P.D. Dalton, J. Groll, Degradable polyester scaffolds with controlled surface chemistry combining minimal protein adsorption with specific bioactivation, Nature materials 10(1) (2011) 67.

[25] Z. Meng, Y. Wang, C. Ma, W. Zheng, L. Li, Y. Zheng, Electrospinning of PLGA/gelatin randomly-oriented and aligned nanofibers as potential scaffold in tissue engineering, Materials Science and Engineering: C 30(8) (2010) 1204-1210.

[26] R.B. Diego, M.P. Olmedilla, Á.S. Aroca, J.G. Ribelles, M.M. Pradas, G.G. Ferrer, M.S. Sánchez, Acrylic scaffolds with interconnected spherical pores and controlled hydrophilicity for tissue engineering, Journal of materials science 40(18) (2005) 4881-4887.

[27] N.J. Amoroso, A. D'Amore, Y. Hong, C.P. Rivera, M.S. Sacks, W.R. Wagner, Microstructural manipulation of electrospun scaffolds for specific bending stiffness for heart valve tissue engineering, Acta biomaterialia 8(12) (2012) 4268-4277.

[28] J.D. Hartgerink, E. Beniash, S.I. Stupp, Self-assembly and mineralization of peptideamphiphile nanofibers, Science 294(5547) (2001) 1684-1688.

[29] J.D. Hartgerink, E. Beniash, S.I. Stupp, Peptide-amphiphile nanofibers: a versatile scaffold for the preparation of self-assembling materials, Proceedings of the National Academy of Sciences 99(8) (2002) 5133-5138.

[30] O.J. Goor, S.I. Hendrikse, P.Y. Dankers, E. Meijer, From supramolecular polymers to multicomponent biomaterials, Chemical Society Reviews 46(21) (2017) 6621-6637.

[31] M.J. Webber, E.A. Appel, E. Meijer, R. Langer, Supramolecular biomaterials, Nature materials 15(1) (2016) 13.

[32] V.J. Chen, P.X. Ma, Nano-fibrous poly (L-lactic acid) scaffolds with interconnected spherical macropores, Biomaterials 25(11) (2004) 2065-2073.

[33] P.X. Ma, R. Zhang, Synthetic nano-scale fibrous extracellular matrix, Journal of Biomedical Materials Research: An Official Journal of The Society for Biomaterials, The Japanese Society for Biomaterials, and The Australian Society for Biomaterials 46(1) (1999) 60-72.

[34] Z.-M. Huang, Y.-Z. Zhang, M. Kotaki, S. Ramakrishna, A review on polymer nanofibers by electrospinning and their applications in nanocomposites, Composites science and technology 63(15) (2003) 2223-2253.

[35] D. Li, Y. Xia, Electrospinning of nanofibers: reinventing the wheel?, Advanced materials 16(14) (2004) 1151-1170.

[36] D.H. Reneker, I. Chun, Nanometre diameter fibres of polymer, produced by electrospinning, Nanotechnology 7(3) (1996) 216.

[37] L. Jiang, Y. Zhao, J. Zhai, A lotus-leaf-like superhydrophobic surface: a porous microsphere/nanofiber composite film prepared by electrohydrodynamics, Angewandte Chemie 116(33) (2004) 4438-4441.

[38] Y. Miyauchi, B. Ding, S. Shiratori, Fabrication of a silver-ragwort-leaf-like super-hydrophobic micro/nanoporous fibrous mat surface by electrospinning, Nanotechnology 17(20) (2006) 5151. [39] E. Bormashenko, Y. Bormashenko, T. Stein, G. Whyman, E. Bormashenko, Why do pigeon feathers repel water? Hydrophobicity of pennae, Cassie-Baxter wetting hypothesis and CassieWenzel capillarity-induced wetting transition, Journal of colloid and interface science 311(1) (2007) 212-216

[40] M. Godinho, J. Canejo, G. Feio, E. Terentjev, Self-winding of helices in plant tendrils and cellulose liquid crystal fibers, Soft Matter 6(23) (2010) 5965-5970.

[41] X. Wang, B. Ding, J. Yu, J. Yang, Large-scale fabrication of two-dimensional spider-web-like gelatin nano-nets via electro-netting, Colloids and Surfaces B: Biointerfaces 86(2) (2011) 345352.

[42] Y. Zhao, X. Cao, L. Jiang, Bio-mimic multichannel microtubes by a facile method, Journal of the American Chemical Society 129(4) (2007) 764-765.

[43] G. Yan, J. Yu, Y. Qiu, X. Yi, J. Lu, X. Zhou, X. Bai, Self-assembly of electrospun polymer nanofibers: a general phenomenon generating honeycomb-patterned nanofibrous structures, Langmuir : the ACS journal of surfaces and colloids 27(8) (2011) 4285-9.

[44] D. Ahirwal, A. Hébraud, R. Kádár, M. Wilhelm, G. Schlatter, From self-assembly of electrospun nanofibers to 3D cm thick hierarchical foams, Soft Matter 9(11) (2013) 3164-3172. 
[45] G. Yan, J. Yu, Y. Qiu, X. Yi, J. Lu, X. Zhou, X. Bai, Self-assembly of electrospun polymer nanofibers: A general phenomenon generating honeycomb-patterned nanofibrous structures, Langmuir 27(8) (2011) 4285-4289.

[46] T. Yao, H. Chen, P. Samal, S. Giselbrecht, M.B. Baker, L. Moroni, Self-assembly of electrospun nanofibers into gradient honeycomb structures, Materials \& Design 168 (2019) 107614.

[47] Y. Fukuhira, E. Kitazono, T. Hayashi, H. Kaneko, M. Tanaka, M. Shimomura, Y. Sumi, Biodegradable honeycomb-patterned film composed of poly (lactic acid) and dioleoylphosphatidylethanolamine, Biomaterials 27(9) (2006) 1797-1802.

[48] H. Sunami, E. Ito, M. Tanaka, S. Yamamoto, M. Shimomura, Effect of honeycomb film on protein adsorption, cell adhesion and proliferation, Colloids and Surfaces A: Physicochemical and Engineering Aspects 284 (2006) 548-551.

[49] Q. Zhang, X. Yang, P. Li, G. Huang, S. Feng, C. Shen, B. Han, X. Zhang, F. Jin, F. Xu, Bioinspired engineering of honeycomb structure-Using nature to inspire human innovation, Progress in Materials Science 74 (2015) 332-400.

[50] H. Itoh, Y. Aso, M. Furuse, Y. Noishiki, T. Miyata, A honeycomb collagen carrier for cell culture as a tissue engineering scaffold, Artificial Organs 25(3) (2001) 213-217.

[51] N. Kakudo, A. Shimotsuma, S. Miyake, S. Kushida, K. Kusumoto, Bone tissue engineering using human adipose-derived stem cells and honeycomb collagen scaffold, Journal of Biomedical Materials Research Part A: An Official Journal of The Society for Biomaterials, The Japanese Society for Biomaterials, and The Australian Society for Biomaterials and the Korean Society for Biomaterials 84(1) (2008) 191-197.

[52] M. Sato, T. Asazuma, M. Ishihara, T. Kikuchi, K. Masuoka, S. Ichimura, M. Kikuchi, A. Kurita, K. Fujikawa, An atelocollagen honeycomb-shaped scaffold with a membrane seal (ACHMS scaffold) for the culture of annulus fibrosus cells from an intervertebral disc, Journal of Biomedical Materials Research Part A: An Official Journal of The Society for Biomaterials, The Japanese Society for Biomaterials, and The Australian Society for Biomaterials and the Korean Society for Biomaterials 64(2) (2003) 248-256.

[53] R. Demir, Y. Seval, B. Huppertz, Vasculogenesis and angiogenesis in the early human placenta, Acta histochemica 109(4) (2007) 257-265.

[54] R.H. Adams, K. Alitalo, Molecular regulation of angiogenesis and lymphangiogenesis, Nature reviews Molecular cell biology 8(6) (2007) 464.

[55] D. Nagata, M. Mogi, K. Walsh, AMP-activated protein kinase (AMPK) signaling in endothelial cells is essential for angiogenesis in response to hypoxic stress, Journal of Biological Chemistry 278(33) (2003) 31000-31006.

[56] H.-J. Park, Y. Zhang, S.P. Georgescu, K.L. Johnson, D. Kong, J.B. Galper, Human umbilical vein endothelial cells and human dermal microvascular endothelial cells offer new insights into the relationship between lipid metabolism and angiogenesis, Stem cell reviews 2(2) (2006) 93 101.

[57] W.J. Yang, D.D. Yang, S. Na, G.E. Sandusky, Q. Zhang, G. Zhao, Dicer is required for embryonic angiogenesis during mouse development, Journal of Biological Chemistry 280(10) (2005) 9330-9335.

[58] L.E. Dike, C.S. Chen, M. Mrksich, J. Tien, G.M. Whitesides, D.E. Ingber, Geometric control of switching between growth, apoptosis, and differentiation during angiogenesis using micropatterned substrates, In Vitro Cellular \& Developmental Biology-Animal 35(8) (1999) 441448.

[59] H. Chen, X. Huang, M. Zhang, F. Damanik, M.B. Baker, A. Leferink, H. Yuan, R. Truckenmüller, C. van Blitterswijk, L. Moroni, Tailoring surface nanoroughness of electrospun scaffolds for skeletal tissue engineering, Acta biomaterialia 59 (2017) 82-93.

[60] E. Fonck, G.G. Feigl, J. Fasel, D. Sage, M. Unser, D.A. Rufenacht, N. Stergiopulos, Effect of aging on elastin functionality in human cerebral arteries, Stroke 40(7) (2009) 2552-2556.

[61] M. Ahmed, T. Ramos, P. Wieringa, C. van Blitterswijk, J. de Boer, L. Moroni, Geometric constraints of endothelial cell migration on electrospun fibres, Scientific reports 8(1) (2018) 6386. [62] D.E. Heath, J.J. Lannutti, S.L. Cooper, Electrospun scaffold topography affects endothelial cell proliferation, metabolic activity, and morphology, Journal of Biomedical Materials Research Part A 94(4) (2010) 1195-1204.

[63] H.G. Sundararaghavan, R.L. Saunders, D.A. Hammer, J.A. Burdick, Fiber alignment directs cell motility over chemotactic gradients, Biotechnology and bioengineering 110(4) (2013) 12491254.

[64] M. Giannotta, M. Trani, E. Dejana, VE-cadherin and endothelial adherens junctions: active guardians of vascular integrity, Developmental cell 26(5) (2013) 441-454.

[65] A.M. Simon, A.R. McWhorter, Vascular abnormalities in mice lacking the endothelial gap junction proteins connexin37 and connexin40, Developmental biology 251(2) (2002) 206-220. 
[66] A.M. Greiner, A. Sales, H. Chen, S.A. Biela, D. Kaufmann, R. Kemkemer, Nano-and microstructured materials for in vitro studies of the physiology of vascular cells, Beilstein journal of nanotechnology 7(1) (2016) 1620-1641.

[67] Y. Lin, Y. Shao, J. Li, W. Zhang, K. Zheng, X. Zheng, X. Huang, Z. Liao, Y. Xie, J. He, The hierarchical micro-/nanotextured topographies promote the proliferation and angiogenesisrelated genes expression in human umbilical vein endothelial cells by initiation of Hedgehog-Gli1 signaling, Artificial cells, nanomedicine, and biotechnology 46(sup3) (2018) S1141-S1151.

[68] M. Li, Y. Guo, Y. Wei, A.G. MacDiarmid, P.I. Lelkes, Electrospinning polyaniline-contained gelatin nanofibers for tissue engineering applications, Biomaterials 27(13) (2006) 2705-2715. 
Fabrication of a Self-assembled Honeycomb Nanofibrous Scaffold to Guide Endothelial Morphogenesis

\section{Supporting Information}
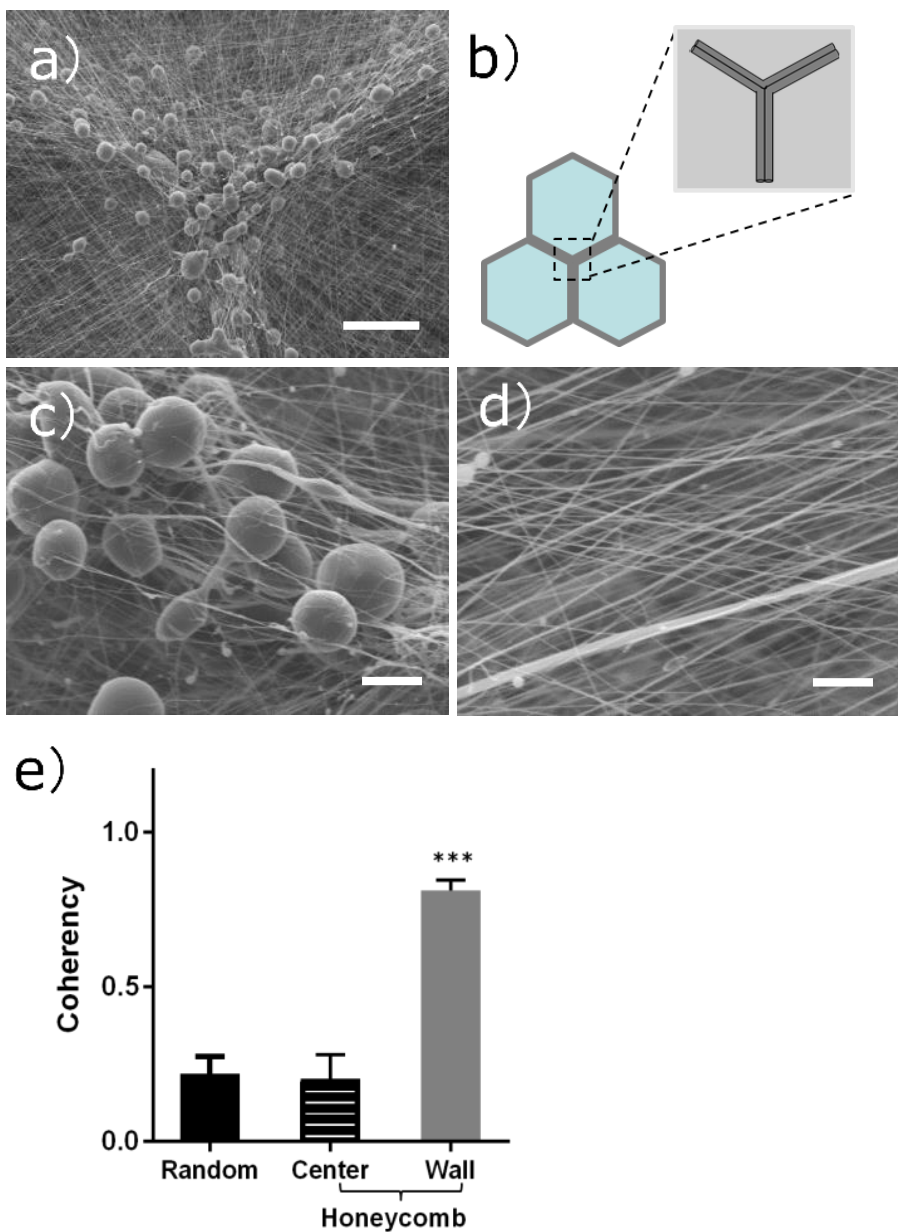

Figure S1. SEM images of the junction corners (a) between three honeycombs. Model (b) of a regular honeycomb structure where contain three-branched corners. SEM images showing the beads (c) and nanofiber (d) structures in honeycomb scaffolds. Alignment coherence (e) of PCL electrospun fibers in random and honeycomb scaffolds. Scale bars are $50 \mu \mathrm{m}$ (a), $10 \mu \mathrm{m}$ (c) and $5 \mu \mathrm{m}(\mathrm{d})\left(^{* * *} \mathrm{p}<0.001\right)$. 


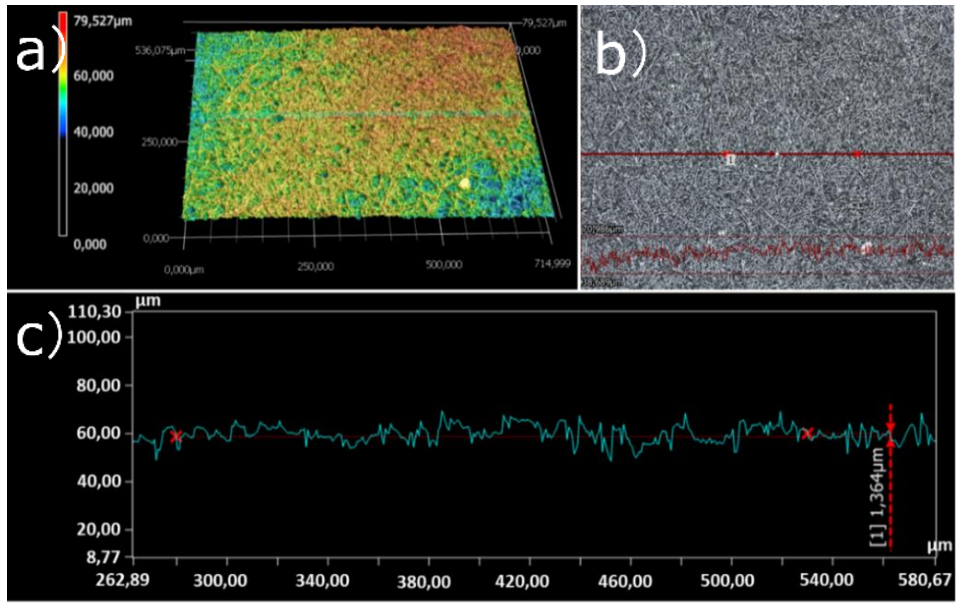

Figure S2. Optical profilometer scans of a random electrospun scaffolds (a and b); (c) Profile graph measuring the height of random scaffolds.
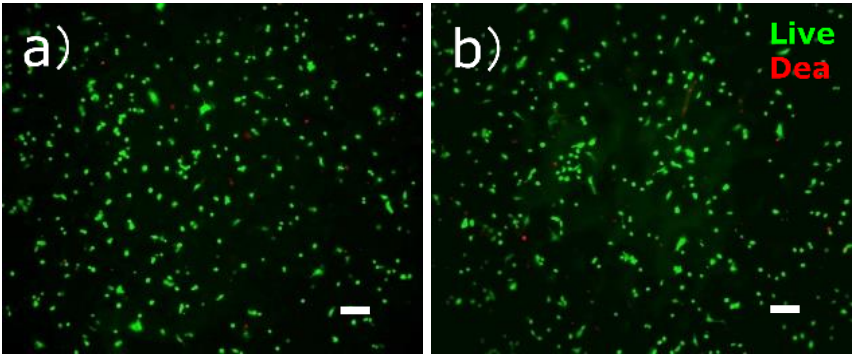

Figure S3. Live (stained green) and dead (stained red) staining of HUVECs cultured for 1 day on random (a) and honeycomb (b) electrospun PCL scaffolds (scale bar: $100 \mu \mathrm{m}$ ). 
Fabrication of a Self-assembled Honeycomb Nanofibrous Scaffold to Guide Endothelial Morphogenesis

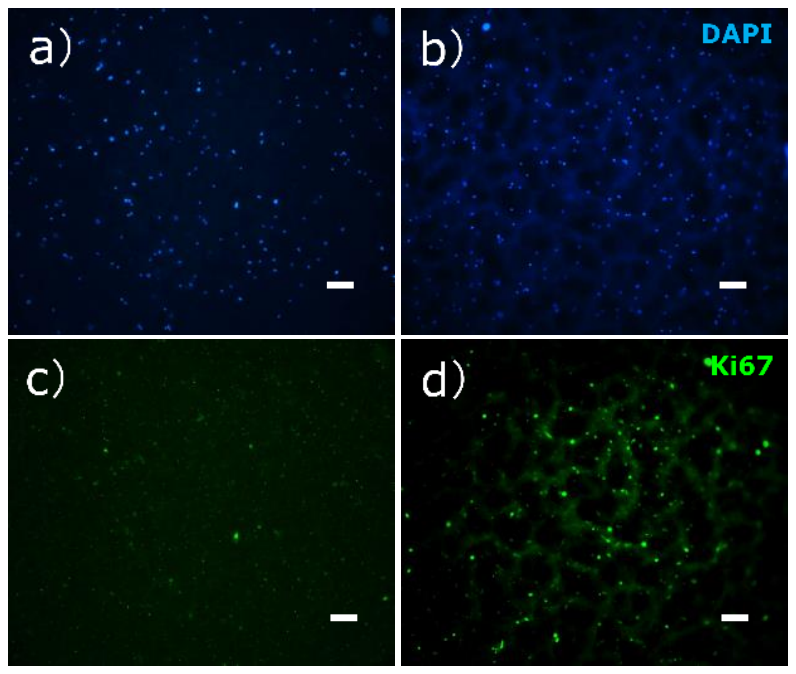

Figure S4. HUVECs on random (a and $c$ ) and honeycomb (b and d) electrospun PCL scaffolds at day 5 stained with Ki67 (green) and nuclear counterstained with DAPI (blue). Scale bars are $100 \mu \mathrm{m}$.
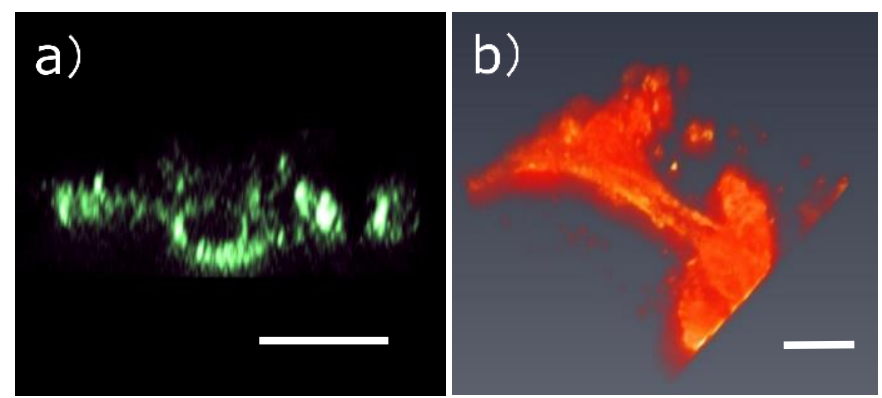

Figure S5. (a) Vertical confocal image cross sections revealed lumen formation by HUVECs on honeycomb scaffolds and (b) the position of lumen corresponding to the left images. Scale bars are $5 \mu \mathrm{m}$. 

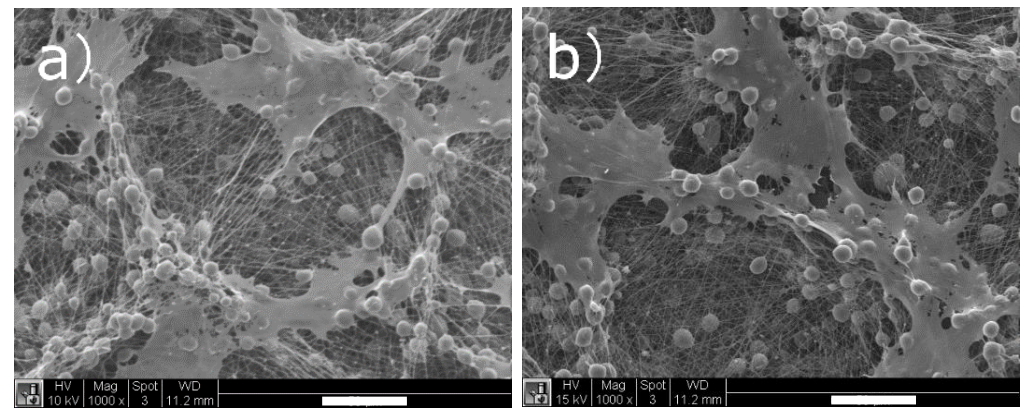

Figure S6. SEM images of HUVECs on honeycomb (a and d) PCL fibers after 5 days culture. Scale bars are $50 \mu \mathrm{m}$.
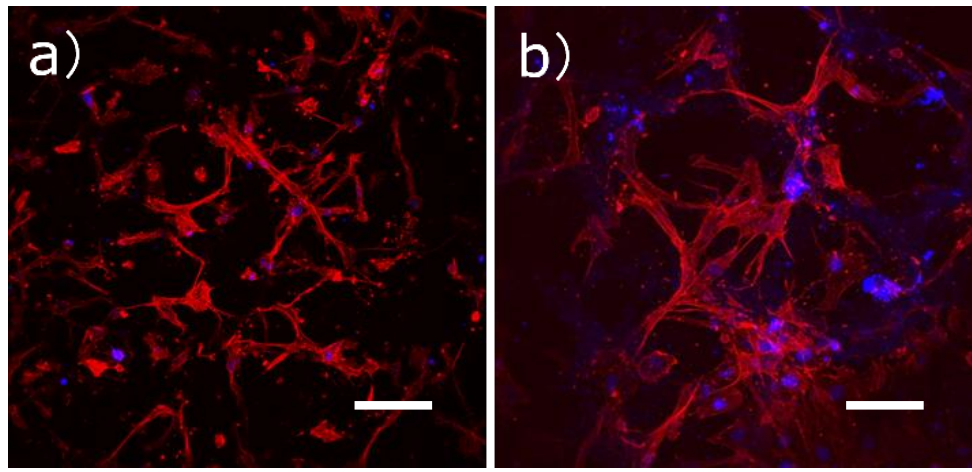

Figure S7. 3D confocal images of co-cultured hMSCs and HUVECs on random (a) and honeycomb scaffolds (b) after 5 days incubation. The actin cytoskeleton and nuclei of cells were stained by Phalloidin(red) and DAPI(blue). Scale bars are $100 \mu \mathrm{m}$. 
Fabrication of a Self-assembled Honeycomb Nanofibrous Scaffold to Guide Endothelial Morphogenesis 


\section{Chapter 5}

\section{Electrospun Fibrous Scaffolds Functionalized with Hydrogen Sulfide Donor Stimulate Angiogenesis}

Tianyu Yao1, Teun van Nunen ${ }^{1}$, Chadwick Powell2, Ryan Carrazzone², Paul Andrew Wieringa ${ }^{1}$, Shahzad Hafeez ${ }^{1}$, Lilian Kessels ${ }^{3}$, Tim G.A.M. Wolfs ${ }^{3}$, John B. Matson², Lorenzo Moroni ${ }^{1}$, Matthew B. Baker ${ }^{1}$

${ }^{1}$ Complex Tissue Regeneration, MERLN Institute for Technology-Inspired Regenerative Medicine, Maastricht University, Maastricht, the Netherlands ${ }^{2}$ Chemistry Department Macromolecules and Innovation Institute, Virginia Tech, Blacksburg VA, United States of America

${ }^{3}$ Department of Pediatrics, Maastricht University, Maastricht, the Netherlands 


\section{Abstract}

Tissue-engineered constructs are currently limited due to the lack of vascularization necessary for the survival and integration of implanted tissues. Hydrogen sulfide $\left(\mathrm{H}_{2} \mathrm{~S}\right)$, a physiological gasotransmitter, has been recently reported to mediate and promote angiogenesis in low concentrations. Yet, sustained delivery remains a challenge. Herein, we have developed angiogenic scaffolds by covalent attachment of an $\mathrm{H}_{2} \mathrm{~S}$ donor to a polycaprolactone (PCL) electrospun scaffold. Via a low-molecular weight azide-PCL, an alkyne N-thiocarboxyanhydrides (NTA, $\mathrm{H}_{2} \mathrm{~S}$ donor) could be attached to electrospun scaffolds by a straightforward click reaction. To evaluate cell compatibility, adhesion, spreading and proliferation, human umbilical vein endothelial cells (HUVECs) were cultured on different NTAfunctionalized scaffolds, as well as on non-functionalized scaffolds for comparison. The NTA functionalized fibrous scaffolds were observed to better support cell proliferation, form confluent endothelial monolayers, and facilitate the formation of tight cell-cell junctions. Moreover, treatment of chicken chorioallantoic membranes (CAM) on NTA-functionalized scaffolds increased vascular growth in vivo. Therefore, we conclude that covalent conjugation of $\mathrm{H}_{2} \mathrm{~S}$ donors to scaffolds not only promotes HUVECs proliferation in vitro, but also increases neovascularization in vivo. NTA-functionalized scaffolds provides local control over the vascularization from a powerful angiogenic agent, which should be further explored to promote angiogenesis in tissue engineering.

Key words: electrospun; N-thiocarboxyanhydrides (NTA); click chemistry; angiogenesis 


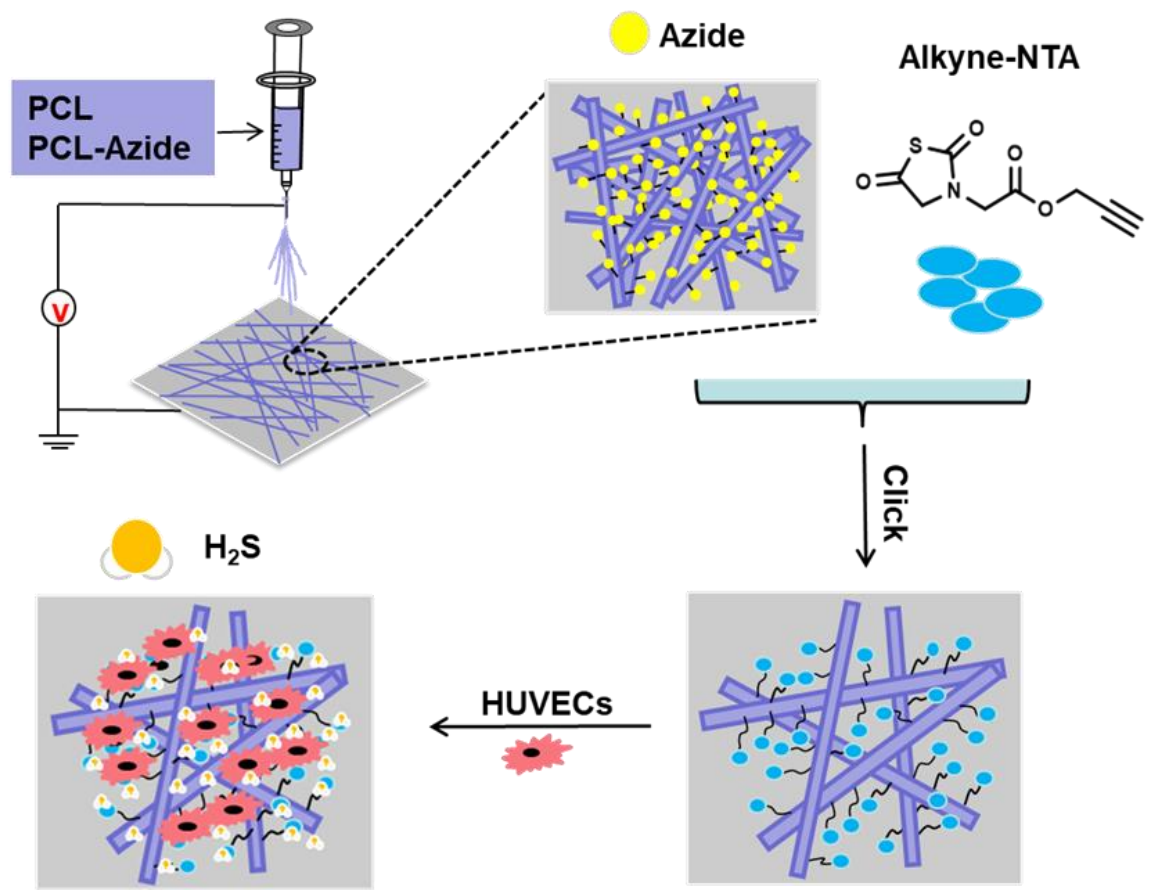




\section{Introduction}

The extra cellular matrix (ECM), a cell's natural environment, consists of various interwoven protein fibers with diameters ranging from tens to hundreds of nanometers [1-3]. The ECM provides structural support and biological communication to guide the maturation and integration of cells to form tissues [4-6]. Tissue engineered scaffolds has been driven by biomimicry-inspired design of ECM to provide a natural network of nanofibers for cell migration, attachment, and proliferation [7, 8]. Therefore, the major challenge in tissue engineering is to design and fabricate a suitable scaffold to mimic the architecture of ECM, which also provides relevant biological cues. Electrospinning has emerged as a simple, cost-effective, and versatile materials-processing method that is used to fabricate continuous, ultrafine fibers from the micro to the nano scale [9-11]. This process utilizes different electrospinning parameters, such as high voltage, flow rate and working distance, to control the morphologies, diameters and pore size of nanofibers $[9,12]$. The large specific surface area, high porosity, and spatial interconnectivity of electrospun nanofibers favors cell adhesion, proliferation, migration, and differentiation [13-15]. Moreover, the electrospun scaffolds can be further functionalized by the incorporation or conjugation with bioactive components (e.g. enzymes [16, 17], DNAs [18, 19], growth factors [20, 21] and small molecules [22-24]) to better control the proliferation and differentiation of cells on the scaffolds [23, 25].

Hydrogen sulfide $\left(\mathrm{H}_{2} \mathrm{~S}\right)$, a unique gasotransmitter, has been recognized as an important physiological and pathological signaling molecule, which can mediate and promote angiogenesis [26, 27]. In endothelial cells (ECs), $\mathrm{H}_{2} \mathrm{~S}$ is generated from cysteine by enzymes such as cystathionine $\beta$-synthase (CBS), cystathionine $\mathrm{Y}$-lyase (CSE), and the combined action of cysteine aminotransferase (CAT) and 3-mercaptopyruvate sulfurtransferase (3-MST) [28-31]. The biological roles of $\mathrm{H}_{2} \mathrm{~S}$ in angiogenesis has been investigated from different aspects. The phenomenon that $\mathrm{H}_{2} \mathrm{~S}$ promotes endothelial cell 
proliferation and migration has been reported by different groups. Papapetropoulos et al. found 60 and $600 \mu \mathrm{M}$ of $\mathrm{H}_{2} \mathrm{~S}$ resulted in a significant proliferation of HUVECs [32]. Cai et al. reported that $\mathrm{NaHS}$ (an $\mathrm{H}_{2} \mathrm{~S}$ donor; 10 and $20 \mu \mathrm{M}$ ) stimulated endothelial cell growth by $12.5 \pm 2.5 \%$ and $11.4 \pm 2.9 \%$, while the treatment with high concentrations (500 and $1000 \mu \mathrm{M}$ ) resulted in a significant decrease in cell proliferation [33]. Therefore, the sustained release of $\mathrm{H}_{2} \mathrm{~S}$ is highly required rather than burst release. In addition, $\mathrm{H}_{2} \mathrm{~S}$ has been reported to stimulate angiogenesis in vitro and in vivo. Papapetropoulos et al. also reported that $\mathrm{H}_{2} \mathrm{~S}$ stimulated capillary morphogenesis of HUVECs on Matrigel [32]. The chicken chorioallantoic membrane (CAM) results showed that $\mathrm{H}_{2} \mathrm{~S}$ induced a potent and concentration-dependent increase in the vessel length [32]. A mouse model has demonstrated that NaHS treatment significantly increased collateral vessel growth, capillary density, and regional tissue blood flow in ischemic hind limb muscles [34]. The most widely and easily used class of $\mathrm{H}_{2} \mathrm{~S}$ donors in biological studies are the sulfide salts, sodium hydrosulfide $(\mathrm{NaSH})$ and sodium sulfide $\left(\mathrm{Na}_{2} \mathrm{~S}\right)$ [35-37]. While sulphide salts are commonly used to evaluate the therapeutic potential of exogenous $\mathrm{H}_{2} \mathrm{~S}$ delivery, there are shortcomings to these $\mathrm{H}_{2} \mathrm{~S}$ donor. Once adding water or medium, these salts generate a large amount of $\mathrm{H}_{2} \mathrm{~S}$ over a short time period [38, 39]. However, angiogenesis takes place over a period of hours or days, sulfide salts often lead to instantaneous release of $\mathrm{H}_{2} \mathrm{~S}$ and does not mimic the slow and continuous process of $\mathrm{H}_{2} \mathrm{~S}$ generation in vivo [40].

Since $\mathrm{H}_{2} \mathrm{~S}$ has been recognized to be beneficial for angiogenesis, many researchers focus on the development of $\mathrm{H}_{2} \mathrm{~S}$ donors, which can release $\mathrm{H}_{2} \mathrm{~S}$ effectively for ECs behavior [39, 41]. The shortcomings of burst release have led to the high demand of $\mathrm{H}_{2} \mathrm{~S}$ release scaffolds that have controllable release rate to mimic biological $\mathrm{H}_{2} \mathrm{~S}$ generation in vivo. A study performed by Powel et al. reported the potential use of $\mathrm{N}$-thiocarboxyanhydrides (NTAs) as Carbonyl sulfide (COS) $/ \mathrm{H}_{2} \mathrm{~S}$ donor for continuous releasing [42]. The ringopening of NTAs to release COS is triggered by primary amine. COS is 
converted into $\mathrm{H}_{2} \mathrm{~S}$ by the enzyme carbonic anhydrase $(C A)$, resulting in more controlled release [43]. The use of NTAs as $\mathrm{H}_{2} \mathrm{~S}$ donors resulted in sustained release with innocuous byproducts.

Motivated by the electrospinning approach for the fabrication of ECM mimicking fibrous scaffolds and the unique properties of NTA in controlled releasing of $\mathrm{H}_{2} \mathrm{~S}$ for angiogenesis, we 1) synthesized PCL-azide (PCL-N $\mathrm{N}_{3}$ ) for further functionalization, 2) electrospun PCL- $\mathrm{N}_{3}$-incorporated $\mathrm{PCL}$ fibrous scaffolds to form "clickable" fibers with high surface content of azide, and 3) coupled alkyne-NTA on PCL- $\mathrm{N}_{3}$ fibrous scaffolds by azide-alkyne click conjugation. The morphology and "clickable azide group" of the different NTAfunctionalized scaffolds were characterized, showing controllable "clickable" scaffolds by changing the PCL- $\mathrm{N}_{3}$ ratios. Our aim was to investigate the effects of different NTA-functionalized scaffolds on ECs behavior, such as cell viability, attachment and proliferation. Cell viability, DNA content, CD31 and VE-cadherin immunostaining were tested to reveal the role of $\mathrm{H}_{2} \mathrm{~S}$-release fibrous scaffolds in vitro. In addition, CAM assay has been performed to assess the effect of functional scaffolds on angiogenesis in vivo. Our goal was to promote angiogenesis by releasing of $\mathrm{H}_{2} \mathrm{~S}$ from NTA functionalized PCL scaffolds.

\section{Materials and methods}

\section{Synthesis}

\section{PCL-azide synthesis}

In the first step, p-toluenesulfonyl-poly( $\varepsilon$-caprolactone) (PCL-OTs) was synthesized, which is an intermediate product to PCL azide. PCL-diol ( $3 \mathrm{~g}$, $0.0015 \mathrm{~mol}$ ) was dissolved in $5 \mathrm{ml}$ of dichloromethane in dried round bottom flask. P-toluenesulfonyl chloride $(0.69 \mathrm{~g}, 0.0036 \mathrm{~mol}, 2.4 \mathrm{eq})$ and triethylamine (1.2g, $0.012 \mathrm{~mol}, 8 \mathrm{eq})$ was dissolved in $7 \mathrm{ml}$ of dichloromethane in a separate flask and added to PCL-diol solution drop by drop. After $24 \mathrm{hrs}$, reaction mixture was washed to remove any insoluble particles and washed with 
dichloromethane. The filtered solution was collected and excessively washed with $0.1 \mathrm{M} \mathrm{HCl}, \mathrm{NaHCO}_{3}, \mathrm{H}_{2} \mathrm{O}$ and $\mathrm{NaCl}, \mathrm{H}_{2} \mathrm{O}$ solution, respectively. The organic phase was vacuum dried and PCL-OTS was obtained (3.3 g, 95\% yield). PCL-OTS $(3.3 \mathrm{~g}, 0.0014 \mathrm{~mol})$ was dissolved in $5 \mathrm{~mL}$ anhydrous dimethylformamide (DMF) under inert environment. Sodium azide $\left(\mathrm{NaN}_{3}\right)$ $(0.55 \mathrm{~g}, 0.008 \mathrm{~mol}, 6 \mathrm{eq})$ was added into the reaction flask and let reaction run for 24 hours at $50^{\circ} \mathrm{C}$ under nitrogen environment. Next, reaction mixture was vacuum dried until minimal DMF was left, precipitated in cold water, and centrifuged at $6000 \mathrm{RCF}$ to obtain product PCL-N $\mathrm{N}_{3}(2.6 \mathrm{~g}, 81 \%$ yield). For cell culture applications, an extra washing step was included. PCL-azide was dissolved in chloroform $\left(\mathrm{CHCl}_{3}\right)$ and washed with excess water using a separatory funnel.

\section{Alkyne-NTA synthesis}

Alkyne-NTA was synthesized by our collaborators, synthetic procedure and characterizations has already been published in the literature [44]. Iminodiacetic acid thiocarbamate TCDA (2.188 g, $9.890 \mathrm{mmol})$ was added into $80 \mathrm{ml} \mathrm{CH}_{2} \mathrm{Cl}_{2}$ and stirred in a roundbottom flask. Pyridine $(0.80 \mathrm{~mL}, 9.9 \mathrm{mmol})$ was added to form pyridinium salt of TCDA in solution. This flask was placed in the ice bath. $\mathrm{EDC} \cdot \mathrm{HCl}(1.896 \mathrm{~g}, 9.890 \mathrm{mmol})$ and $25 \mathrm{ml} \mathrm{CH}_{2} \mathrm{Cl}_{2}$ were added into another roundbottom flask to generate EDC suspension. Allyl alcohol (2.0 $\mathrm{mL}, 30.0 \mathrm{mmol}$ ) was then added to generate clear EDC solution. The TCDA flask was installed with a funnel. EDC solution was dropped to TCDA solution through this funnel in the ice bath. The reaction was detected by Thin layer chromatography (TLC) $\left(5 \% \mathrm{MeOH}\right.$ in $\left.5 \mathrm{CH}_{2} \mathrm{Cl}_{2}\right)$. After the spots of TCDA disappeared, the reaction mixture was washed with $1 \mathrm{~N} \mathrm{HCl}$ and brine, then dried, filtered and concentrated. The product was purified by silica gel chromatography $\left(\mathrm{CH}_{2} \mathrm{Cl}_{2}\right)$ to obtain $\mathbf{i}$.

A two-neck roundbottom flask was flame-dried under vacuum and backfilled with nitrogen. $2 \mathrm{ml}$ dry THF was added to thiocarbamate monoester i ( 0.372 $\mathrm{g}, 1.42 \mathrm{mmol}$ ) to make a clear solution. After dissolved, solution was diluted 
with $3 \mathrm{ml}$ dry THF and transferred to the flask in ice bath. $\mathrm{PBr}_{3}(0.150 \mathrm{~mL}, 1.57$ mmol) was dropped in solution under nitrogen. The mixture solution was stirred in the ice bath for $10 \mathrm{~min}$, followed by placing it to room temperature stirring for $45 \mathrm{~min}$. The flask was put in ice bath again, and $\mathrm{MeOH}$ was dropped to quench excess $\mathrm{PBr}_{3}$. The residue was dissolved in $\mathrm{CH}_{2} \mathrm{Cl}_{2}$ after concentrated by a rotary evaporator. The final mixture was washed with $\mathrm{NaHCO}_{3}$ and brine, dried, filtered, and concentrated. The product was purified via silica gel chromatography $\left(\mathrm{CH}_{2} \mathrm{Cl}_{2}\right)$ to produce alkyne-NTA.
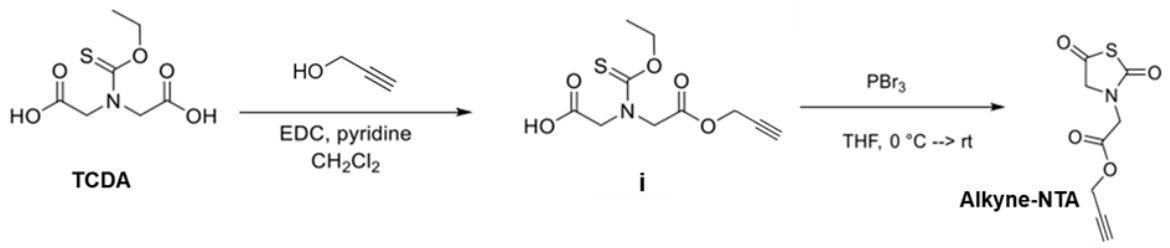

\section{Preparation of PCL- $\mathrm{N}_{3}$ Fibers and Characterization}

A high molecular weight of poly( $\varepsilon$-caprolactone) (PCL-80K) Mn $\approx 80000 \mathrm{~g} / \mathrm{mol}$, a lower molecular weight of PCL-2k and PCL-N $\mathrm{N}_{3}-2 \mathrm{k}$ were mixed in different ratios $\left(1,5\right.$, and $10 w t \%$ of PCL- $\mathrm{N}_{3}$ in final scaffold as described in Table S1) to give a final concentration of $15 \mathrm{wt} \%$ polymer in $\mathrm{CHCl}_{3} / \mathrm{DMF}(4 / 1, \mathrm{v} / \mathrm{v})$ solvent mixture, respectively. The polymer solution was stirred overnight to form a homogeneous solution for electrospinning. The electrospinning setup is a homemade machine for generating nanofibers, as reported before[45]. Briefly, the polymer solution was loaded into a $5 \mathrm{~mL}$ syringe (BD biosciences) equipped with a stainless steel blunt-ended needle. The polymer solution was delivered to the needle via a silicon feed line. The flow rate was controlled by syringe pump (Harvard Apparatus PHD 2000) at $1 \mathrm{~mL} / \mathrm{h}$. An aluminum plate was used as the collector connected to the ground. The distance between the tip and the collecting plate was set as $20 \mathrm{~cm}$, and the electrospinning voltage was kept at $20 \mathrm{kV}$. The temperature was maintained at $25^{\circ} \mathrm{C}$, and the humidity maintained at $35 \%$. The prepared fibrous scaffolds were dried overnight at 
room temperature to remove solvent traces. The morphology of PCL-N $\mathrm{N}_{3}$ fibrous scaffolds were examined by a scanning electron microscopy (SEM; XL30; Philips). The elemental analysis of fibrous scaffolds were determined by energy dispersive X-ray analysis (EDX). Fiber samples were coated with gold for 60 s before image. At least five areas were randomly selected to test the uniformity of the fibers. The diameter of electrospun fibers were quantified from SEM images by using Image J.

\section{Click modification of PCL-N $\mathrm{N}_{3}$ with Alkyne MegaStokes}

To optimize the azide-alkyne functionalization, different PCL-N ${ }_{3}$ scaffolds were treated with the click solution, which contained $0.4 \mathrm{mM} \mathrm{CuSO}_{4} \cdot 5 \mathrm{H}_{2} \mathrm{O}, 2$ $\mathrm{mM} \mathrm{Na-Ascorbate,} \mathrm{and} 0.05 \mathrm{mM}$ Alkyne MegaStokes dye in ethanol at room temperature. Reaction bottles were placed on an orbital shaker for a set time interval. Then, the fibrous scaffolds was washed with absolute ethanol 3 times and dried under nitrogen. Controls were $0 \% \mathrm{PCL}-\mathrm{N}_{3}$ fibrous scaffolds in the click reaction and all other processes were the same. In order to study the effect of time on functionalization, the reaction was set with different time point (15min; 30min; $2 \mathrm{~h}$ and $4 \mathrm{~h}$ ). Finally, samples placed in a glass bottom petri dish (Ibidi) and imaged with a microscope (Nikon Eclipse Ti-S).

\section{Click conjugation of Alkyne-NTA on PCL- $\mathrm{N}_{3}$ electrospun fibers}

Click reaction between PCL-N 3 and Alkyne-NTA was performed on the different PCL-N $\mathrm{N}_{3}$ fibrous scaffolds. Briefly, a mixture of Alkyne-NTA solution including Alkyne-NTA $(0.05 \mathrm{mM}), \mathrm{CuSO}_{4} \cdot 5 \mathrm{H}_{2} \mathrm{O}(0.4 \mathrm{mM})$, Na-Ascorbate (2 $\mathrm{mM}$ ) was dropped on the PCL- $\mathrm{N}_{3}$ scaffolds and the reaction bottles were placed on an orbital shaker for 2 hours. Scaffolds were then washed 3 times with absolute ethanol, followed by 15 min wash with EDTA (0.01 M in milliQ) and 3 washes with absolute ethanol.

After click reaction of the $10 \%$ PCL-N 3 scaffolds with Alkyne-NTA, NTAfunctionalized scaffolds were placed in a new glass reaction bottle wrapped in aluminum foil. The mixture of 6 -aminofluorescence $(0.1 \mathrm{mM})$ and triethylamine 
$(0.2 \mathrm{mM})$ solutions in ethanol was added to the $10 \%$ PCL- $\mathrm{N}_{3} / \mathrm{NTA}$ scaffolds and the reaction bottle was placed on the shaker for $20 \mathrm{~min}$. For the control experiments, $10 \%$ PCL- $\mathrm{N}_{3}$ scaffolds without functionalization was placed in the same fluorescence solution and other processes were the same. Then, samples were washed 3 times in ethanol and placed in a glass bottom petri dish (Ibidi). Finally, samples were imaged with the microscope (Nikon Eclipse Ti-S).

\section{Cell culture}

HUVECs were obtained from Lonza and cultured according to standard procedures of Lonza. Briefly, HUVECs were cultured in endothelial growth medium (EGM, Lonza) containing $\mathrm{EBM}^{\mathrm{TM}}-2$ basal medium (CC-3156) and $E G^{T M}{ }^{T}-2$ SingleQuots ${ }^{T M}$ supplements (CC-4176) according to the manufacturer's protocol (Lonza). Cultures were incubated in a humidified environment with $5 \% \mathrm{CO}_{2}$ at $37^{\circ} \mathrm{C}$. The culture medium was changed every 2 days and cultures were passaged at $80 \%$ confluence to prevent contact inhibition. Passages 4 through 8 were used in this study.

Electrospun scaffolds were punched into round pieces $(15 \mathrm{~mm})$ and washed in water for 3 times. Prior to cell seeding, the scaffolds were sterilized by $70 \%$ ethanol for $30 \mathrm{~min}$, and dried in biosafety cabinet. The sterilized scaffolds were placed on a 24-wellplate and fixed by O-rings. After washing with sterilized water, scaffolds were incubated overnight in Matrigel ${ }^{\circledR}$ (1:150 dilution in EGM) to aid protein adhesion and cell attachment. We also incubated scaffolds with EGM overnight to compare the effect of scaffolds after different coating process. The treated scaffolds was seeded with a density of $2 \times 10^{4} \mathrm{cells} / \mathrm{cm}^{2}$. The culture medium was refreshed every 2 days.

\section{Live/dead assay}

Cell cytotoxicity was assessed using a live/dead assay kit (Invitrogen), which included two components, calcein AM and ethidium homodimer-1 (EthD-1), to simultaneously determine the existence of live and dead cells on electrospun 
scaffolds. Briefly, the scaffolds were washed with PBS, incubated in $1 \mu \mathrm{M}$ calcein AM (staining live cells) and $6 \mu \mathrm{M}$ EthD-1 (staining dead cells) in PBS for $30 \mathrm{~min}$ at $37^{\circ} \mathrm{C}$. The cells were then washed with PBS for three times to remove excess dye. Finally, the samples were observed under a fluorescent microscope. As a result live cells stain green and dead cells are red. The percentage of live cells was assessed by counting the number of calcein AMstained viable cells and EthD-1-stained dead cells.

\section{Cell viability and proliferation}

The cells grew and proliferated on the electrospun scaffolds for 1,3 , and 5 days. Cell viability was analyzed using PrestoBlue ${ }^{\mathrm{TM}}$ assay according to the manufacturer's protocol (Fisher Scientific). 10\% (V/V) of PrestoBlue reagent was mixed with EGM to prepare PrestoBlue medium. $500 \mu \mathrm{l}$ of PrestoBlue medium was added to samples and then incubated at $37^{\circ} \mathrm{C}$ for $30 \mathrm{~min} .100$ $\mu \mathrm{L}$ media samples were transferred from each well into a black 96 -well plate with clear bottom. Fluorescence was measured at 540-570 nm excitation 580$610 \mathrm{~nm}$ emission in a microplate reader (CLARIOstar, BMG Labtech). The readout from the samples was corrected with a control (PrestoBlue medium).

DNA content based on the total amount DNA of each samples was quantitatively determined with CyQUANT ${ }^{\mathrm{TM}}$ Cell Proliferation Assay Kit (Thermo Fisher Scientific) at 1, 3, and 5 days. The cells were first digested overnight with $250 \mu \mathrm{l}$ Proteinase $\mathrm{K}$ in Tris/EDTA solution at $56^{\circ} \mathrm{C}$. CyQUANT $\mathrm{GR}$ dye and lysis buffer were prepared according to the manufacturer's protocol. After freeze-thawing samples for 3 times, $40 \mu \mathrm{L}$ of digested samples was transferred to a black 96-wellplate, then lysed in $40 \mu$ lysis buffer for $1 \mathrm{~h}$ at room temperature. GR dye solution $(80 \mu \mathrm{L})$ was added to each well. After incubating the samples at room temperature for $15 \mathrm{~min}$, the fluorescence intensity of the samples was measured using the microplate reader. 


\section{Immunostaining}

The electrospun scaffolds with HUVECs were fixed with $4 \%$ formaldehyde for $30 \mathrm{~min}$ at room temperature. The samples were permeabilized with PBS containing $0.1 \%$ Triton-X 100 for 15 min. After washing with PBS, samples were blocked with $5 \%$ goat serum in $1 \%$ BSA/0.05\% Tween-PBS solution for $1 \mathrm{~h}$ at room temperature to block nonspecific protein interactions. The samples were then incubated with the primary antibodies (CD31 and VE-Cadherin; 1:200 dilution in blocking solution) overnight at $4{ }^{\circ} \mathrm{C}$. After washing with washing buffer $(0.05 \%$ Tween 20 and $1 \%$ BSA in PBS), the secondary antibody (goat-anti mouse, Alexa Fluor 488, 1:200 dilution in washing buffer) was incubated for $1 \mathrm{~h}$ at room temperature in dark. In addition, the cell cytoskeleton was stained with phalloidin solution for $1 \mathrm{~h}$ at room temperature. DAPI was used to stain the cell nucleus for $5 \mathrm{~min}$ and finally observed with a florescence microscopy (Nikon Eclipse Ti-S).

\section{Chlorioallantoic membrane assay}

The chick embryo chorioallantoic membrane (CAM) assay was performed to assess the ability of NTA functionalized fibrous scaffolds to induce angiogenesis in vivo. Fertilized chicken eggs were purchased from Het Anker B.V., Netherlands. The eggs were incubated at $37^{\circ} \mathrm{C}$ with approximately 50 $55 \%$ humidity (9 eggs for each condition). On day 3 , a window of $1 \times 1.5 \mathrm{~cm}^{2}$ was gently opened with a rotary tool (Dremel) on the wide end of the egg without damaging the embryo. The shell and inner membrane were peeled off with sterile tweezers. About $1-1.5 \mathrm{ml}$ of albumen was aspirated with a syringe in order to detach the developing membrane from the top part of the shell. The windows were closed with transparent tape to prevent dehydration and possible infections before putting back to the incubator. On incubation day 10 , the sterilized scaffolds with diameter of $4 \mathrm{~mm}$ were placed on the egg membrane between branches of the blood vessels. After 4 days of incubation, the scaffolds were imaged with the surrounding vessels under a Leica microscope. The quantification of vessel areas were processed by Image $\mathrm{J}$ 
using an automatic script. Angiogenesis was evaluated by the area of the blood vessels around the scaffolds.

\section{Statistical analysis}

Statistical analysis was carried out using GraphPad Prism 8 software. All data are expressed as mean \pm standard deviation (SD). Data were statistically analyzed by one-way analysis of variance, column values were compared with the control values using the Holm-Sidak multiple-comparisons test. A probability value of less than 0.05 was considered significantly different. Levels of significance were as follows: ${ }^{*} P \leq 0.05$, ${ }^{* *} P \leq 0.005,{ }^{* * *} P \leq 0.0005$, ${ }^{* * * * P} \leq 0.0001$.

\section{Results and Discussion}

\section{Characterization of PCL-azide}

Three polymers characterized by using ${ }^{1} \mathrm{H}$ NMR (Figure S1). Figure S1C shows the spectrum of pure PCL before reaction. The PCL-OTS was used for the chemical transformations of tosyle to azide group. The tosyle peak (i, $\mathrm{g}$ and $h$ ) is observed at $2.42 \mathrm{ppm}$, and 7.34-7.78. Figure S1a showed the final product with clear triplet of $\mathrm{H}(\mathrm{a})$ proton $(\delta=3.3)$ from the end-groups. Synthesis of the PCL-N 3 polymer by using tosylation reaction is an effective approach, which was previously reported [46]. The NMR data was also confirmed with their result.

\section{Fabrication of PCL- $\mathrm{N}_{3}$-Incorporated Electrospun PCL fibers}

To obtain uniform $\mathrm{PCL}$ and $\mathrm{PCL}-\mathrm{N}_{3}$-incorporated $\mathrm{PCL}$ fibers, the concentrations of the total polymer solution was fixed to be $15 \% \mathrm{w} / \mathrm{v}$. The PCL$80 \mathrm{k}$ was mixed with PCL-2k and PCL- $\mathrm{N}_{3}-2 \mathrm{~K}$ in a $\mathrm{DMF} / \mathrm{CHCl}_{3}$ solution as described in the Table S1. The electrospun fibers are referred to as $0 \% \mathrm{PCL}$ $\mathrm{N}_{3}, 1 \% \mathrm{PCL}-\mathrm{N}_{3}, 5 \% \mathrm{PCL}-\mathrm{N}_{3}$ and $10 \% \mathrm{PCL}-\mathrm{N}_{3}$ corresponding to $0,1,5$, and 10 wt\% PCL-N $\mathrm{N}_{3}$ in the final polymer scaffolds, respectively. As shown in Figure 1a-d, all of the fibers were smooth, straight and bead-free. Figure 1e showed 
the average diameter of different PCL- $\mathrm{N}_{3}$ electrospun fibers measured by Image $\mathrm{J}$. The diameter of all different PCL- $\mathrm{N}_{3}$ fibers are in a similar range from 800 to $1200 \mathrm{~nm}$ without significant difference between each group. Although the percentage of PCL- $\mathrm{N}_{3}$ is low, most of the functional azide group is present on the surface of fiber during electrospinning due to the electrostatic attraction forces. The advantage of using this approach is to effectively create functional azide surface for further click functionalization, which has been proved by Lancuški [46]. More than $80 \%$ of azide groups was reported to locate on the fiber surface after electrospinning.

\section{Surface Click of PCL-N $\mathrm{N}_{3}$ electrospun fibers with Alkyne Megastokes}

To confirm the availability of $N_{3}$ on the fiber surface, and optimize the functionalization procedure, we utilized an alkyne-containing fluorescein dye, Alkyne MegaStokes 673 for a test copper (I)-catalyzed azide-alkyne cycloaddition (CuAAC) reaction. Fluorescence images of the fibrous scaffolds confirm that the alkyne dye reacted with the azide groups on the electropun scaffolds (Figure 2a-d). No dye attachment was observed in a control experiment carried out using the $0 \% \mathrm{PCL}-\mathrm{N}_{3}$ (Figure 2a), and an increase in the overall fluorescence intensity of the PCL- $\mathrm{N}_{3}$ fibers with increasing percentage of PCL-N $\mathrm{N}_{3}$ was observed in the fluorescence images. The fluorescent labeling on PCL- $\mathrm{N}_{3}$ electrospun scaffolds confirmed that the amount of small molecule on the fibers could be easily controlled by changing the concentration of PCL- $\mathrm{N}_{3}$. Moreover, the effect of reaction time on click reaction between 5\% PCL- $\mathrm{N}_{3}$ fibrous scaffolds and Alkyne MegaStokes was investigated at $15 \mathrm{~min}, 30 \mathrm{~min}, 2 \mathrm{~h}$ and $4 \mathrm{~h}$, respectively. As shown in Figure $2 \mathrm{e}-$ $\mathrm{h}$, with the increase of the reaction time, the fluorescence intensity increased gradually at first and then reached a maximum fluorescence after $2 \mathrm{~h}$. Therefore, $2 \mathrm{~h}$ was considered to be the optimal time for further investigation. 

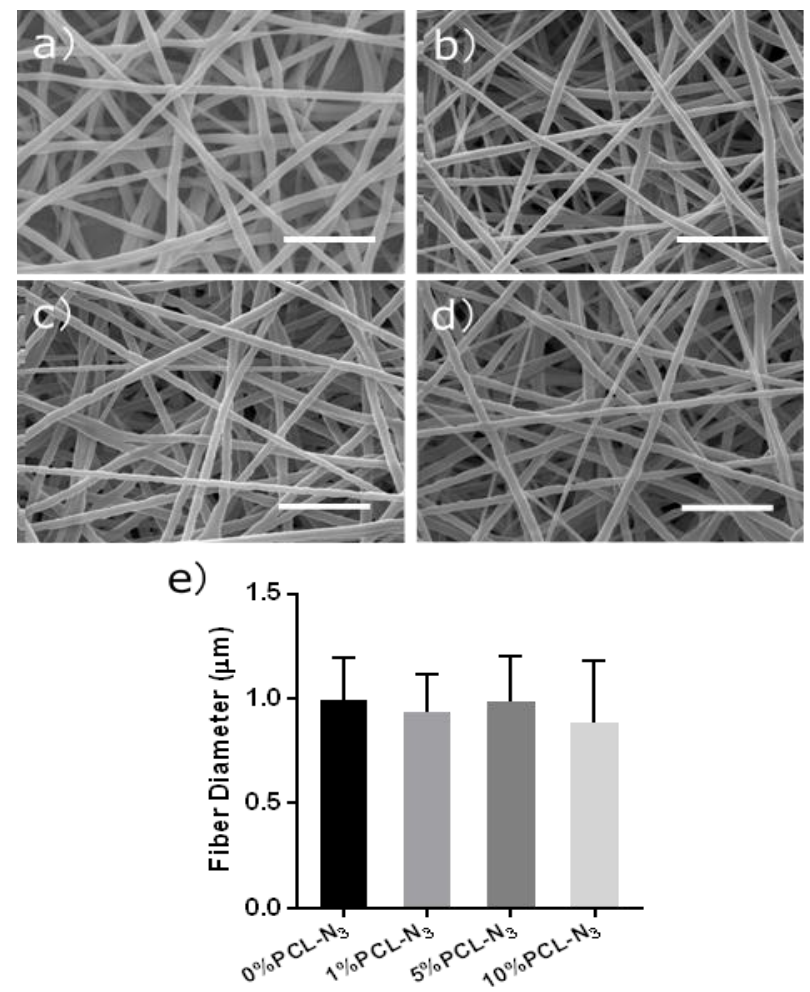

Figure 1. SEM images of (a) $0 \%$ PCL- $\mathrm{N}_{3}$ electrospun scaffolds, (b) $1 \% \mathrm{PCL}-\mathrm{N}_{3}$ electrospun scaffolds, (c) $5 \%$ PCL- $\mathrm{N}_{3}$ electrospun scaffolds and (d) $10 \%$ PCL-N 3 electrospun scaffolds. (e) Fiber diameters of different electrospun scaffolds. Scale bars are $10 \mu \mathrm{m}$.

\section{Detection of NTA on functionalized scaffolds}

NTA is a sulfur mimic of an anhydride group, thus the ring-opening of NTA can be effected with an amine, resulting in amide bond formation. Since NTA can react with amine, 6-aminofluorescein dye was applied to detect the successfully immobilization of Alkyne-NTA on 10\% PCL-N ${ }_{3}$ scaffolds. After being conjugated with Alkyne-NTA, functionalized (10\% PCL- $\mathrm{N}_{3} / \mathrm{NTA}$ ) and non-functionalized (10\% PCL-N 3 ) fibrous scaffolds were immersed into the ethanol solution of 6 -aminofluorescence. Results showed no evident fluorescence exists on the non-functionalized scaffolds due to the lack of NTA on the scaffolds (Figure S2). The scaffolds on which click was performed 
showed a strong fluorescence, indicating the successful click conjugation of alkyne-NTA to the PCL- $\mathrm{N}_{3}$ fibers. This data suggests that the $\mathrm{H}_{2} \mathrm{~S}$ donor, Alkyne-NTA has been successfully coupled onto PCL-N $\mathrm{N}_{3}$ the electrospun fibrous scaffolds. On the other hand, Figure S3 showed the SEM images of different PCL-N $\mathrm{N}_{3}$ fibrous scaffolds after click reaction. The fibers were still uniform and smooth, no significant morphological changes were observed from SEM images. Therefore, it could be concluded that the electrospun fibers maintained its morphology after successful functionalization with alkyne-NTA.
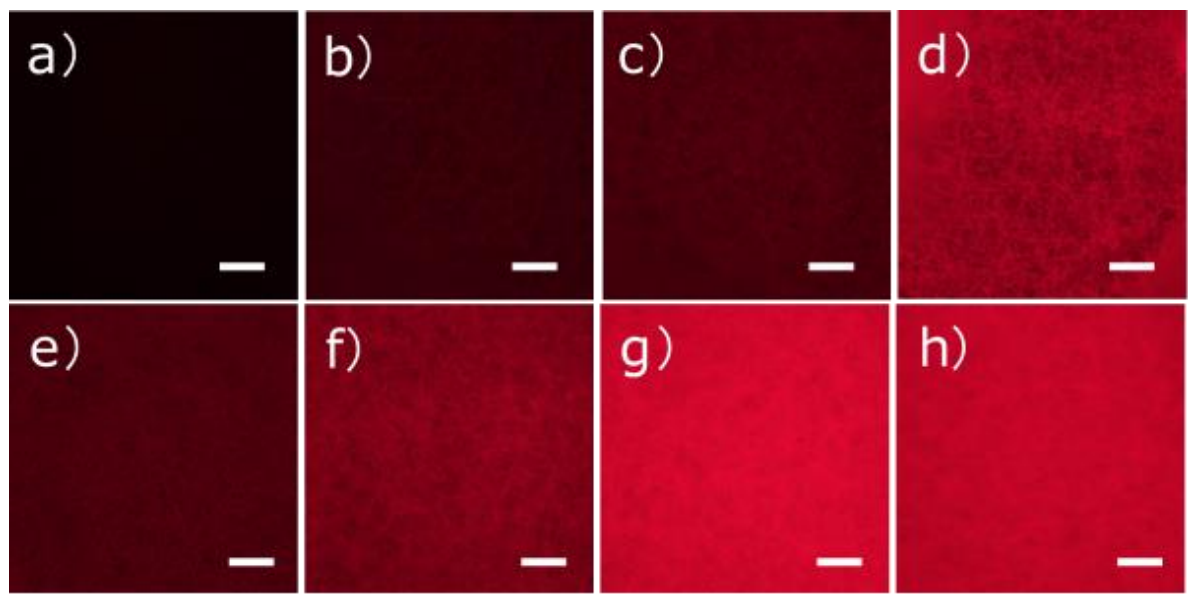

Figure 2. Fluorescence images of different PCL- $\mathrm{N}_{3}$ fibers scaffolds containing: (a) $0 \%$, (b) $1 \%$, (c) $5 \%$ and (d) $10 \%$ PCL- $\mathrm{N}_{3}$ labeled with Alkyne Megastokes after 1 hours. (e-h) showed the effect of click reaction time on the fluorescence intensity of the $5 \% \mathrm{PCL}-\mathrm{N}_{3}$ fibers (e: $15 \mathrm{~min} ; \mathrm{f}: 30 \mathrm{~min}$; $\mathrm{g}: 2 \mathrm{~h}$ and $\mathrm{h}: 4 \mathrm{~h})$. Scale bars are $100 \mu \mathrm{m}$.

\section{Cellular behaviors of HUVECs on different PCL- $\mathrm{N}_{3} / \mathrm{NTA}$ fibrous scaffolds}

To evaluate the biocompatibility of the NTA-functionallized electrospun fibrous scaffolds, HUVECs cultured on scaffolds after day 1 were assessed using the Live/Dead staining. As shown in Figure S4, nearly all the cells remained viable (green staining), and very few dead cells (red staining) were detected. Live cells attached to the surface of the scaffolds and started spreading at day 1 . The percentage of living cells on $0 \% P C L-N_{3}, 1 \% P C L-N_{3} / N T A, 5 \% P C L-$ 
$\mathrm{N}_{3} /$ NTA and 10\%PCL-N $3 /$ NTA scaffolds were $96 \pm 2 \%, 97 \pm 4 \%, 96 \pm 2 \%$ and $98 \pm 1 \%$, respectively. This results suggests that the NTA-functionalized electrospun fibrous scaffolds are non-cytotoxic and suitable for cell culture. The cell viability after 1, 3 and 5 days was evaluated with PrestoBlue assay. Results indicating the cell viability for all conditions showed an increase over 5 days, although substantial differences were noticed already after 3 days of culture (Figure 3a). HUVECs cultured on $5 \% \mathrm{PCL}-\mathrm{N}_{3} / \mathrm{NTA}$ and $10 \% \mathrm{PCL}-$ $\mathrm{N}_{3} /$ NTA fibrous scaffolds showed a statistically significant increase of cell viability at day 3 compared to cells on $0 \% \mathrm{PCL}-\mathrm{N}_{3}$ and $1 \% \mathrm{PCL}-\mathrm{N}_{3} / \mathrm{NTA}$ scaffolds $(P<0.0001)$. However, there was no significant difference of cell viability in different groups at day 5 . The overall increase of cell viability during 5 days confirmed the biocompatibility of the scaffolds. Additionally, high viability of cells on $5 \% \mathrm{PCL}-\mathrm{N}_{3} / \mathrm{NTA}$ and $10 \% \mathrm{PCL}-\mathrm{N}_{3} / \mathrm{NTA}$ fibrous scaffolds showed that higher NTA functionalization has positive effects on endothelial cell viability.

a)

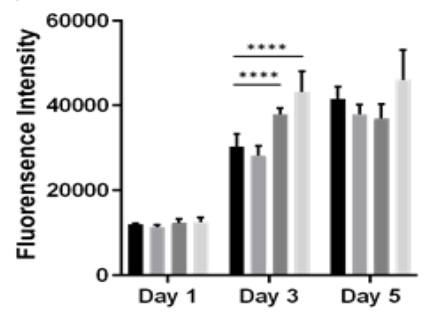

b)

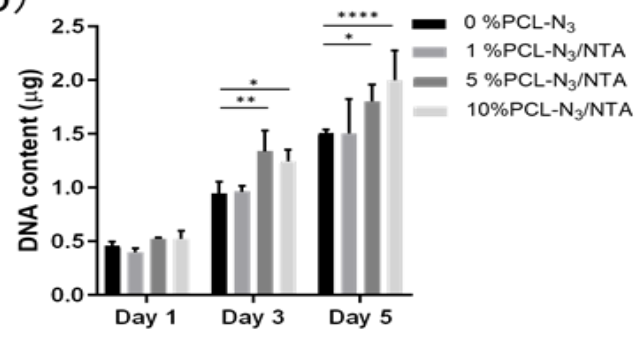

Figure 3. Viability (a) and proliferation (b) of HUVECs cultured for 5 days on different NTA functionalized scaffolds in EGM. ${ }^{*} P \leq 0.05$, ${ }^{* *} P \leq 0.005$, ${ }^{* * *} P \leq 0.0001$.

The effect of NTA scaffolds on cell proliferation was analyzed with total DNA content at day 1, 3 and 5 (Figure 3b). The DNA quantification at day 3 had a similar trend as presented in cell viability, showing a statistically significant increase of proliferation on $5 \% \mathrm{PCL}-\mathrm{N}_{3} / \mathrm{NTA}$ and $10 \% \mathrm{PCL}-\mathrm{N}_{3} / \mathrm{NTA}$ 
functionalized scaffolds compared to $0 \% \mathrm{PCL}-\mathrm{N}_{3}$ and $1 \% \mathrm{PCL}-\mathrm{N}_{3} / \mathrm{NTA}$ scaffolds. A significant increase in cell proliferation on $5 \%$ PCL- $\mathrm{N}_{3} / \mathrm{NTA}$ and $10 \% \mathrm{PCL}-\mathrm{N}_{3} / \mathrm{NTA}$ scaffolds was also observed at day 5 . These results suggest that a high amount of NTA functionalized onto the scaffolds was capable of leading to a higher proliferation of HUVECs compared to the control and lower NTA functionalized scaffolds. Previous studies proved that exposure of endothelial cells with $\mathrm{H}_{2} \mathrm{~S}(60 \mu \mathrm{M})$ led to higher cell proliferation, while lower concentration of $6 \mu \mathrm{M} \mathrm{H}_{2} \mathrm{~S}$ showed no significant effect on the increase of cell number [32]. Therefore, the effect of $\mathrm{H}_{2} \mathrm{~S}$ is a dose-dependent increase in cell proliferation, similar to our findings. Moreover, immunostaining images showed that HUVECs on $5 \% \mathrm{PCL}-\mathrm{N}_{3} / \mathrm{NTA}$ and $10 \% \mathrm{PCL}-\mathrm{N}_{3} / \mathrm{NTA}$ fibrous scaffolds reached about $90 \%$ confluence after 5 days culture (Figure 5 ). It was reported that high confluency of cells over $80 \%$ could result in a drop of cell viability [47]. This observation could explain the reduced increase of cell viability at day 5 , while high DNA content is still measured. As cells proliferate, cell viability increases at the beginning, form a more confluent cell layer, but decreases with increasing the confluence up to $90 \%$. Ki67 staining was performed, as it is a cellular marker for proliferation. As shown in Figure 4, at day 5 , the intensity of Ki67 fluorescence-positive cells in 5\%PCL- $\mathrm{N}_{3} / \mathrm{NTA}$ and $10 \% \mathrm{PCL}-\mathrm{N}_{3} / \mathrm{NTA}$ fibrous scaffolds was much higher than that in $0 \% \mathrm{PCL}-\mathrm{N}_{3}$ and $1 \% \mathrm{PCL}-\mathrm{N}_{3} / \mathrm{NTA}$ scaffolds. The control group (0\%PCL- $\mathrm{N}_{3}$ scaffolds) had the lowest intensity, indicating NTA functionalized scaffolds enhanced the proliferation of HUVECs, therefore showing a higher staining of Ki67. All fibers acted as a scaffold for cell attachment and proliferation, and the NTA could act as $\mathrm{H}_{2} \mathrm{~S}$ releasing donor resulting in faster cell proliferation.

Cell viability and proliferation were also assessed on FBS coated NTA functionalized scaffolds (Figure S5). Although less proliferation was observed on FBS coated scaffolds compared with Matrigel coated scaffolds, higher viability and proliferation of cells was still observed on NTA functionalized scaffolds at day 5 compared with control scaffolds. These results 
demonstrated that NTA functionalized scaffolds have a positive effect on cell growth when coated with a different protein source.

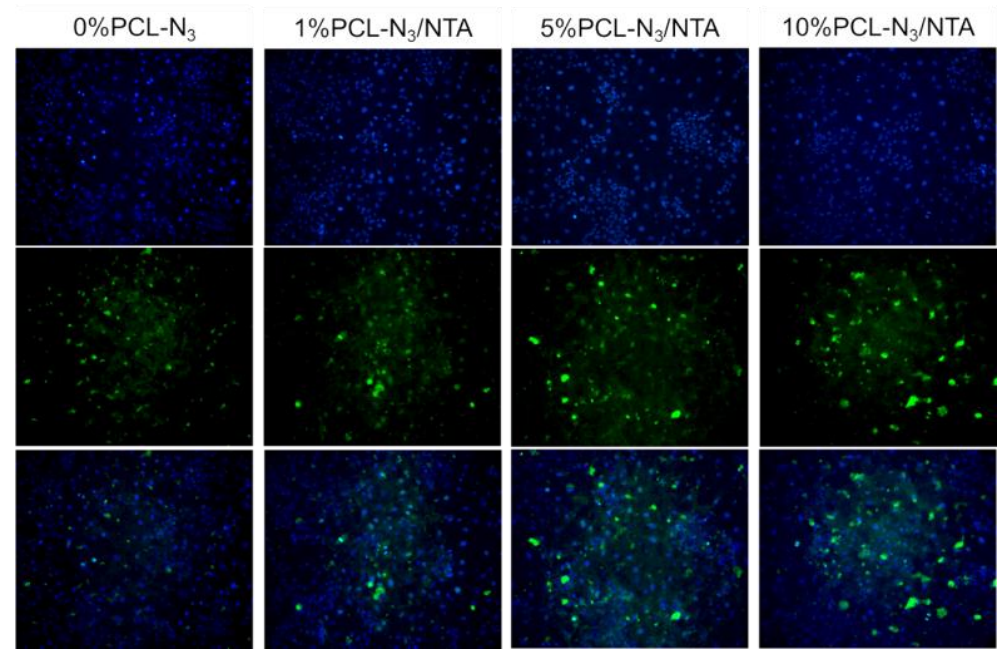

Figure 4. Cell proliferation was visualized by immunofluorescent staining using anti-Ki67 antibody in HUVECs cultured on different fibrous scaffolds after 5 days. Scale bars are $100 \mu \mathrm{m}$.

\section{Morphological analysis of HUVECs grown on different PCL- $\mathrm{N}_{3}$ fibrous scaffolds}

After 5 days of incubation, HUVECs behavior, cytoskeleton development and intercellular junction were investigated on the different PCL- $\mathrm{N}_{3}$ scaffolds by immunochemical staining. To observe cell morphology, we used phalloidin and DAPI to stain the cell cytoskeletons and nuclei, as shown in Figure 5. HUVECs adhered well to all the fibrous scaffolds and distinct cytoskeletal structure was observed. Interestingly, the HUVECs grown on $5 \% \mathrm{PCL}-\mathrm{N}_{3} / \mathrm{NTA}$ and $10 \% \mathrm{PCL}-\mathrm{N}_{3} / \mathrm{NTA}$ fibrous scaffolds rapidly proliferated and showed more confluence in comparison to the HUVECs cultured on $0 \% \mathrm{PCL}-\mathrm{N}_{3}$ and $1 \% \mathrm{PCL}-$ $\mathrm{N}_{3} /$ NTA scaffolds.

In order to study the functional development of HUVECs on the fibers, we analyzed the expression of universal endothelial cell markers: CD31, VECadherin and von Willebrand factor (VWF). CD31 staining was widely 
recognized as an endothelial cell marker to confirm the cellular phenotype for endothelial function. Figure 5 showed positive staining of CD31 in HUVECs, suggesting that HUVECs cultured on different scaffolds expressed an endothelial cell phenotype. Moreover, no changes were observed in HUVECs morphology cultured on the different fibrous scaffolds.

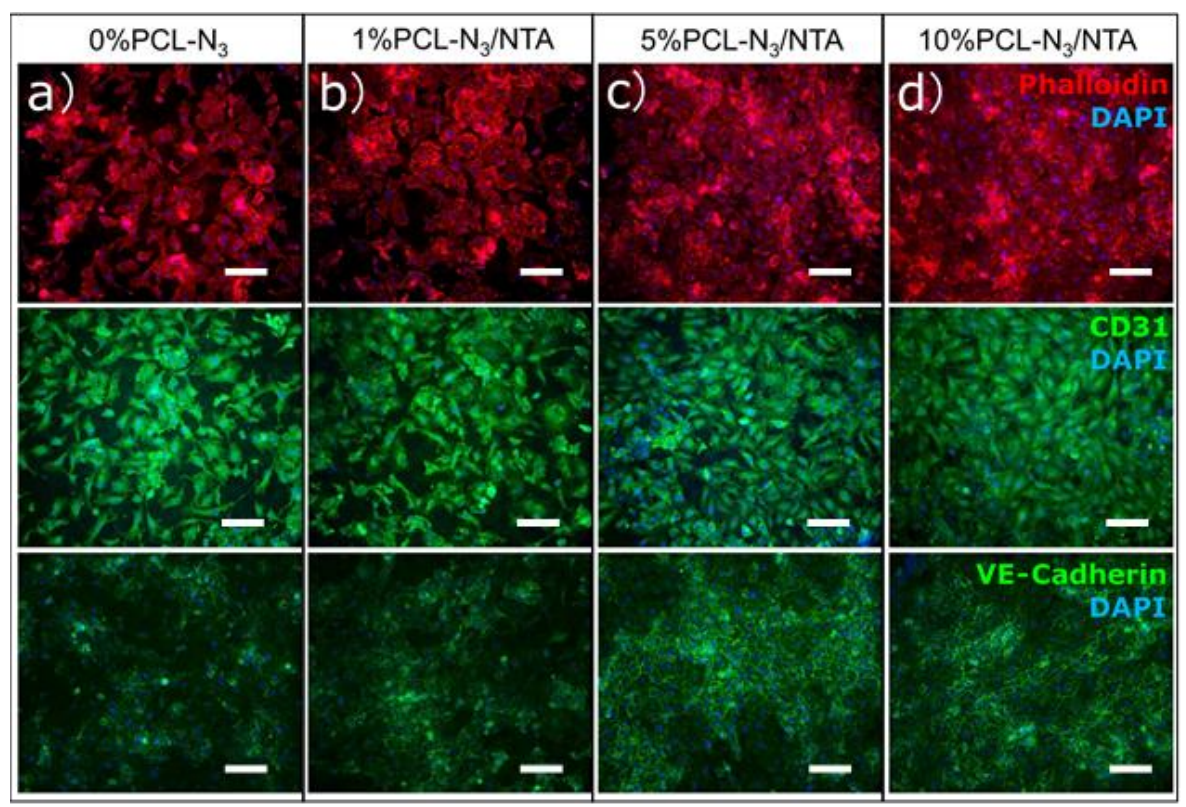

Figure 5. Immunofluorescence staining images showing the nuclei (blue) and the expression of F-actin (red), CD31 (Green) and VE-Cadherin (Green) of HUVECs grown on (a) 0\%PCL-N fibrous scaffolds, (b) $1 \% \mathrm{PCL}-\mathrm{N}_{3} / \mathrm{NTA}$ fibrous scaffolds, (c) $5 \% \mathrm{PCL}-\mathrm{N}_{3} / \mathrm{NTA}$ fibrous scaffolds and (d) $10 \% \mathrm{PCL}-\mathrm{N}_{3} / \mathrm{NTA}$ fibrous scaffolds after 5 days. Scale bars are $100 \mu \mathrm{m}$.

The intercellular junction of HUVECs on the scaffolds was further revealed by VE-Cadherin staining. VE-cadherin is the basic adhesion junction in endothelial cells, which shows cell-cell contacts. As shown in Figure 6, HUVECs on $0 \% \mathrm{PCL}-\mathrm{N}_{3}$ and $1 \% \mathrm{PCL}-\mathrm{N}_{3} / \mathrm{NTA}$ scaffolds were mainly isolated without showing much VE-cadherin staining. However, HUVECs cultured on $5 \% \mathrm{PCL}-\mathrm{N}_{3} / \mathrm{NTA}$ and $10 \% \mathrm{PCL}-\mathrm{N}_{3} / \mathrm{NTA}$ fibrous scaffolds formed a confluent cell monolayer with an increased staining of tight junctions compared with the other two scaffolds groups. The highly expressed VE-cadherin is mainly due 
to faster cell proliferation of HUVECs on these scaffolds. The results demonstrated that firm intercellular junctions were formed on $5 \% \mathrm{PCL}-\mathrm{N}_{3} / \mathrm{NTA}$ and $10 \% \mathrm{PCL}-\mathrm{N}_{3} / \mathrm{NTA}$ fibrous scaffolds, which would be beneficial for generating stabilized confluent endothelial monolayer and the integrity of endothelium. vWF antibody was stained to confirm endothelial cell phenotype. A small, dotted pattern of VWF was clearly observed in Figure S6, which indicate some of HUVECs could produce VWF within the cytoplasm when cultured on different $\mathrm{PCL}-\mathrm{N}_{3}$ fibrous scaffolds. These results demonstrate that HUVECs interact well with PCL-N $\mathrm{N}_{3}$ fibers.

To confirm the morphology and spreading of HUVECs on the different scaffolds, SEM examinations were also performed after 5 day culture. As shown in Figure S7, HUVECs adhered and grew well on these fibrous surfaces. Especially, HUVECs on $5 \% \mathrm{PCL}-\mathrm{N}_{3} / \mathrm{NTA}$ and $10 \% \mathrm{PCL}-\mathrm{N}_{3} / \mathrm{NTA}$ fibrous scaffolds covered about $90 \%$ area at day 5 . These two functionalized scaffolds could be favorable for the cell growth because of high amount of NTA on scaffolds. Moreover, we observed that HUVECs on $10 \% \mathrm{PCL}-\mathrm{N}_{3} / \mathrm{NTA}$ fibrous scaffolds showed lots of dots on cell membrane. The dotted pattern produced by HUVECs can be correlated to VWF dots, which was reported by K. M. Valentijn[48]. Hence, we hypothesize that the dots in SEM images could be the VWF dots secreted by HUVECs.

\section{In vivo CAM assay}

CAM assay was performed to assess whether the NTA functionalized scaffolds could promote angiogenesis in vivo. Figure 6a-d showed the images of blood vessels around $0 \% \mathrm{PCL}-\mathrm{N}_{3}, 1 \% \mathrm{PCL}-\mathrm{N}_{3} / \mathrm{NTA}, 5 \% \mathrm{PCL}-\mathrm{N}_{3} / \mathrm{NTA}$ and 10\%PCL-N $\mathrm{N}_{3} / \mathrm{NTA}$ scaffolds. 5\%PCL-N $\mathrm{N}_{3} / \mathrm{NTA}$ and 10\%PCL-N $\mathrm{N}_{3} / \mathrm{NTA}$ scaffolds implanted on chicken embryo CAM presented an increase of vessels branch surrounding the scaffolds. The capillary vessels grew radially to form a radical like pattern. To quantify the ability of NTA functionalized scaffolds to induce angiogenesis, blood vessel area was counted (Figure 6e). The quantitative 
results indicated that the blood vessels area surrounding the $10 \% \mathrm{PCL}-\mathrm{N}_{3} / \mathrm{NTA}$ scaffolds $(29.8 \pm 1.7 \%)$ was significantly higher than that of the $0 \% \mathrm{PCL}-\mathrm{N}_{3}$ scaffolds $(25.9 \pm 3.2 \%)(P=0.0148)$. This means that implantation with $10 \%$ PCL-N $3 /$ NTA scaffolds lead to 1.15 times the vessel area (about $15.4 \%$ increase) as compared to that on control scaffolds. However, there was no statistical significance of blood vessels area between $0 \% \mathrm{PCL}-\mathrm{N}_{3}, 1 \% \mathrm{PCL}-$ $\mathrm{N}_{3} / \mathrm{NTA}$ and $5 \% \mathrm{PCL}-\mathrm{N}_{3} / \mathrm{NTA}$ scaffolds. This data proved that $10 \% \mathrm{PCL}-$ $\mathrm{N}_{3} /$ NTA scaffolds could induce capillary formation and the introduction of high amount NTA into scaffolds was effectively beneficial to induce angiogenesis in vivo.

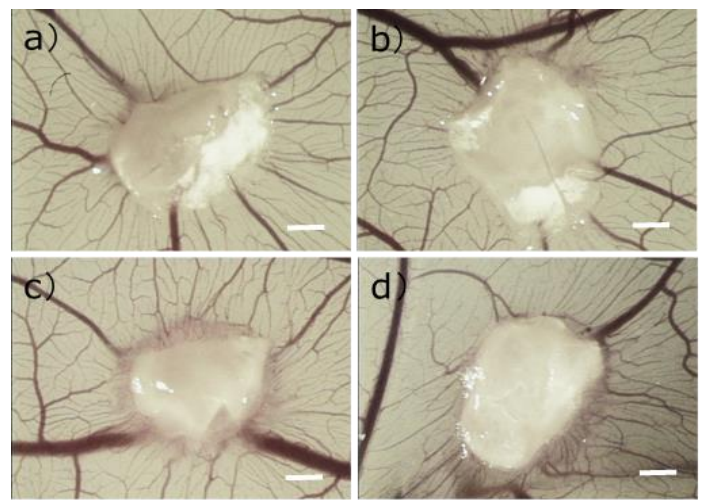

e)

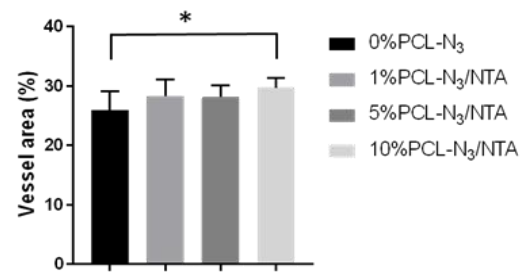

Figure 6. Effects of the different NTA functionalized scaffolds on angiogenesis using a CAM assay. Representative images of the capillary vessels growth surrounding (a) $0 \% \mathrm{PCL}-\mathrm{N}_{3}$, (b) $1 \%$ PCL- $\mathrm{N}_{3} /$ NTA (c) $5 \%$ PCL- $\mathrm{N}_{3} /$ NTA and (d) $10 \%$ PCL- $\mathrm{N}_{3} /$ NTA fibrous scaffolds after 4 days of implantation. (e) Quantification of the vessels area around different fibrous scaffolds. Scale bars are $1 \mathrm{~mm} .{ }^{*} \mathrm{P} \leq 0.05$. 


\section{Conclusion}

In summary, we demonstrated that Alkyne-NTA could be attached into PCL$\mathrm{N}_{3}$ electrospun scaffolds via the click reaction, without impairing fiber morphology of the scaffolds. By adjusting the concentration of PCL-N tunable amounts of alkyne-small molecule functionalization can be achieved. Moreover, we investigated the cell biocompatibility and proliferation on different NTA-functionalized scaffolds. Our data presented HUVECs were spread and proliferated well on functionalized scaffolds, especially $5 \% \mathrm{PCL}$ $\mathrm{N}_{3} / \mathrm{NTA}$ and $10 \%$ PCL-N $\mathrm{N}_{3} / \mathrm{NTA}$ fibrous scaffolds significantly increased cell proliferation and formed tight endothelial monolayer. Firm intercellular junctions were produced on $5 \% \mathrm{PCL}-\mathrm{N}_{3} / \mathrm{NTA}$ and $10 \% \mathrm{PCL}-\mathrm{N}_{3} / \mathrm{NTA}$ fibrous scaffolds. Furthermore, CAM assay have shown that NTA-functionalized scaffolds stimulates angiogenesis blood vessel formation in vivo. Taken together, the NTA-functionalized fibrous scaffolds are promising to promote cell proliferation and form desirable endothelium, which will be a critical step for the success of enhancing angiogenesis in tissue engineering. 


\section{Reference}

[1] V. Estrada, A. Tekinay, H.W. Müller, Neural ECM mimetics, Progress in brain research, Elsevier2014, pp. 391-413.

[2] S. Hinderer, S.L. Layland, K. Schenke-Layland, ECM and ECM-like materials-biomaterials for applications in regenerative medicine and cancer therapy, Advanced drug delivery reviews 97 (2016) 260-269.

[3] J.K. Mouw, G. Ou, V.M. Weaver, Extracellular matrix assembly: a multiscale deconstruction, Nature reviews Molecular cell biology 15(12) (2014) 771-785.

[4] R.O. Hynes, The extracellular matrix: not just pretty fibrils, Science 326(5957) (2009) 1216 1219.

[5] Y. Kim, H. Ko, I.K. Kwon, K. Shin, Extracellular matrix revisited: roles in tissue engineering, International neurourology journal 20(Suppl 1) (2016) S23.

[6] A. Padhi, A.S. Nain, ECM in Differentiation: A Review of Matrix Structure, Composition and Mechanical Properties, Annals of biomedical engineering (2019) 1-19.

[7] B. Chan, K. Leong, Scaffolding in tissue engineering: general approaches and tissue-specific considerations, European spine journal 17(4) (2008) 467-479.

[8] B. Dhandayuthapani, Y. Yoshida, T. Maekawa, D.S. Kumar, Polymeric scaffolds in tissue engineering application: a review, International journal of polymer science 2011 (2011).

[9] N. Bhardwaj, S.C. Kundu, Electrospinning: a fascinating fiber fabrication technique, Biotechnology advances 28(3) (2010) 325-347.

[10] M. Bognitzki, W. Czado, T. Frese, A. Schaper, M. Hellwig, M. Steinhart, A. Greiner, J.H. Wendorff, Nanostructured fibers via electrospinning, Advanced materials 13(1) (2001) 70-72.

[11] D. Li, Y. Xia, Electrospinning of nanofibers: reinventing the wheel?, Advanced materials 16(14) (2004) 1151-1170.

[12] Z.-M. Huang, Y.-Z. Zhang, M. Kotaki, S. Ramakrishna, A review on polymer nanofibers by electrospinning and their applications in nanocomposites, Composites science and technology 63(15) (2003) 2223-2253.

[13] C.H. Kim, M.S. Khil, H.Y. Kim, H.U. Lee, K.Y. Jahng, An improved hydrophilicity via electrospinning for enhanced cell attachment and proliferation, Journal of Biomedical Materials Research Part B: Applied Biomaterials: An Official Journal of The Society for Biomaterials, The Japanese Society for Biomaterials, and The Australian Society for Biomaterials and the Korean Society for Biomaterials 78(2) (2006) 283-290.

[14] W.J. Li, C.T. Laurencin, E.J. Caterson, R.S. Tuan, F.K. Ko, Electrospun nanofibrous structure: a novel scaffold for tissue engineering, Journal of Biomedical Materials Research: An Official Journal of The Society for Biomaterials, The Japanese Society for Biomaterials, and The Australian Society for Biomaterials and the Korean Society for Biomaterials 60(4) (2002) 613-621.

[15] X. Mo, C. Xu, M. Kotaki, S. Ramakrishna, Electrospun P (LLA-CL) nanofiber: a biomimetic extracellular matrix for smooth muscle cell and endothelial cell proliferation, Biomaterials 25(10) (2004) 1883-1890.

[16] W.J. Cloete, C. Adriaanse, P. Swart, B. Klumperman, Facile immobilization of enzymes on electrospun poly (styrene-alt-maleic anhydride) nanofibres, Polymer Chemistry 2(7) (2011) 1479-1481.

[17] Z.-G. Wang, L.-S. Wan, Z.-M. Liu, X.-J. Huang, Z.-K. Xu, Enzyme immobilization on electrospun polymer nanofibers: an overview, Journal of Molecular Catalysis B: Enzymatic 56(4) (2009) 189-195.

[18] Y. Luu, K. Kim, B. Hsiao, B. Chu, M. Hadjiargyrou, Development of a nanostructured DNA delivery scaffold via electrospinning of PLGA and PLA-PEG block copolymers, Journal of controlled release 89 (2) (2003) 341-353.

[19] J. Zhang, Y. Duan, D. Wei, L. Wang, H. Wang, Z. Gu, D. Kong, Co-electrospun fibrous scaffold-adsorbed DNA for substrate-mediated gene delivery, Journal of Biomedical Materials Research Part A 96(1) (2011) 212-220.

[20] C. Li, C. Vepari, H.-J. Jin, H.J. Kim, D.L. Kaplan, Electrospun silk-BMP-2 scaffolds for bone tissue engineering, Biomaterials 27(16) (2006) 3115-3124.

[21] S. Sahoo, L.T. Ang, J.C.H. Goh, S.L. Toh, Growth factor delivery through electrospun nanofibers in scaffolds for tissue engineering applications, Journal of Biomedical Materials Research Part A: An Official Journal of The Society for Biomaterials, The Japanese Society for Biomaterials, and The Australian Society for Biomaterials and the Korean Society for Biomaterials 93(4) (2010) 1539-1550.

[22] C.L. Casper, N. Yamaguchi, K.L. Kiick, J.F. Rabolt, Functionalizing electrospun fibers with biologically relevant macromolecules, Biomacromolecules 6(4) (2005) 1998-2007. 
[23] T.G. Kim, T.G. Park, Surface functionalized electrospun biodegradable nanofibers for immobilization of bioactive molecules, Biotechnology progress 22(4) (2006) 1108-1113.

[24] N.D. Luong, I.-S. Moon, D.S. Lee, Y.-K. Lee, J.-D. Nam, Surface modification of poly (Ilactide) electrospun fibers with nanocrystal hydroxyapatite for engineered scaffold applications, Materials Science and Engineering: C 28(8) (2008) 1242-1249.

[25] X. Wang, B. Ding, B. Li, Biomimetic electrospun nanofibrous structures for tissue engineering, Materials today 16(6) (2013) 229-241.

[26] N.L. Kanagy, C. Szabo, A. Papapetropoulos, Vascular biology of hydrogen sulfide, American Journal of Physiology-Cell Physiology 312(5) (2017) C537-C549.

[27] C. Szabó, A. Papapetropoulos, Hydrogen sulphide and angiogenesis: mechanisms and applications, British journal of pharmacology 164(3) (2011) 853-865.

[28] A.K. Mustafa, M.M. Gadalla, N. Sen, S. Kim, W. Mu, S.K. Gazi, R.K. Barrow, G. Yang, R. Wang, S.H. Snyder, H2S signals through protein S-sulfhydration, Sci. Signal. 2(96) (2009) ra72ra72.

[29] N. Shibuya, Y. Mikami, Y. Kimura, N. Nagahara, H. Kimura, Vascular endothelium expresses 3-mercaptopyruvate sulfurtransferase and produces hydrogen sulfide, The journal of biochemistry 146(5) (2009) 623-626.

[30] C. Szabó, Hydrogen sulphide and its therapeutic potential, Nature reviews Drug discovery 6(11) (2007) 917.

[31] R. Wang, The gasotransmitter role of hydrogen sulfide, Antioxidants and Redox Signaling 5(4) (2003) 493-501.

[32] A. Papapetropoulos, A. Pyriochou, Z. Altaany, G. Yang, A. Marazioti, Z. Zhou, M.G. Jeschke, L.K. Branski, D.N. Herndon, R. Wang, Hydrogen sulfide is an endogenous stimulator of angiogenesis, Proceedings of the National Academy of Sciences 106(51) (2009) 21972-21977.

[33] W.-J. Cai, M.-J. Wang, P.K. Moore, H.-M. Jin, T. Yao, Y.-C. Zhu, The novel proangiogenic effect of hydrogen sulfide is dependent on Akt phosphorylation, Cardiovascular research 76(1) (2007) 29-40.

[34] M.-J. Wang, W.-J. Cai, N. Li, Y.-J. Ding, Y. Chen, Y.-C. Zhu, The hydrogen sulfide donor NaHS promotes angiogenesis in a rat model of hind limb ischemia, Antioxidants \& redox signaling 12(9) (2010) 1065-1077.

[35] T. Li, B. Zhao, C. Wang, H. Wang, Z. Liu, W. Li, H. Jin, C. Tang, J. Du, Regulatory effects of hydrogen sulfide on IL-6, IL-8 and IL-10 levels in the plasma and pulmonary tissue of rats with acute lung injury, Experimental biology and medicine 233(9) (2008) 1081-1087.

[36] L. Liu, H. Liu, D. Sun, W. Qiao, Y. Qi, H. Sun, C. Yan, Effects of H2S on myogenic responses in rat cerebral arterioles, Circulation Journal 76(4) (2012) 1012-1019.

[37] W. Zhao, J. Zhang, Y. Lu, R. Wang, The vasorelaxant effect of $\mathrm{H} 2 \mathrm{~S}$ as a novel endogenous gaseous KATP channel opener, The EMBO journal 20(21) (2001) 6008-6016.

[38] Z.W. Lee, J. Zhou, C.-S. Chen, Y. Zhao, C.-H. Tan, L. Li, P.K. Moore, L.-W. Deng, The slowreleasing hydrogen sulfide donor, GYY4137, exhibits novel anti-cancer effects in vitro and in vivo, Plos one 6(6) (2011) e21077.

[39] C.R. Powell, K.M. Dillon, J.B. Matson, A review of hydrogen sulfide (H2S) donors: Chemistry and potential therapeutic applications, Biochemical pharmacology 149 (2018) 110-123.

[40] M.M. Gadalla, S.H. Snyder, Hydrogen sulfide as a gasotransmitter, Journal of neurochemistry 113(1) (2010) 14-26.

[41] Z.J. Song, M.Y. Ng, Z.-W. Lee, W. Dai, T. Hagen, P.K. Moore, D. Huang, L.-W. Deng, C.-H. Tan, Hydrogen sulfide donors in research and drug development, MedChemComm 5(5) (2014) 557-570.

[42] C.R. Powell, J.C. Foster, B. Okyere, M.H. Theus, J.B. Matson, Therapeutic Delivery of H(2)S via COS: Small Molecule and Polymeric Donors with Benign Byproducts, Journal of the American Chemical Society 138(41) (2016) 13477-13480.

[43] E. Corner, I. Geis, D. Goodsell, Carbonic Anhydrase.

[44] C.R. Powell, K. Kaur, K.M. Dillon, M. Zhou, M. Alaboalirat, J.B. Matson, Functional NSubstituted N-Thiocarboxyanhydrides as Modular Tools for Constructing H2S Donor Conjugates, ACS chemical biology (2019).

[45] H. Chen, X. Huang, M. Zhang, F. Damanik, M.B. Baker, A. Leferink, H. Yuan, R. Truckenmüller, C. van Blitterswijk, L. Moroni, Tailoring surface nanoroughness of electrospun scaffolds for skeletal tissue engineering, Acta biomaterialia 59 (2017) 82-93.

[46] A. Lancuški, S.b. Fort, F.d.r. Bossard, Electrospun azido-PCL nanofibers for enhanced surface functionalization by click chemistry, ACS applied materials \& interfaces 4(12) (2012) 6499-6504. [47] F.A. Abo-Aziza, A. Zaki, The impact of confluence on bone marrow mesenchymal stem (bmmsc) proliferation and osteogenic differentiation, International journal of hematologyoncology and stem cell research 11(2) (2017) 121. 
[48] K.M. Valentijn, L.F. van Driel, M.J. Mourik, G.-J. Hendriks, T.J. Arends, A.J. Koster, J.A. Valentijn, Multigranular exocytosis of Weibel-Palade bodies in vascular endothelial cells, Blood 116(10) (2010) 1807-1816. 


\section{Supporting Information}

Table S1. Electrospinning parameters for PCL-80K and azide-functionalized fibers: $0 \% \mathrm{PCL}-\mathrm{N}_{3}$, $1 \%$ PCL- $\mathrm{N}_{3}, 5 \% \mathrm{PCL}-\mathrm{N}_{3}$ and $10 \% \mathrm{PCL}-\mathrm{N}_{3}$

\begin{tabular}{|c|c|c|c|c|c|c|c|}
\hline $\begin{array}{l}\text { Electrospun } \\
\text { fibers }\end{array}$ & $\begin{array}{l}\text { Total } \\
\text { polymer } \\
\text { (wt } \% \text { ) }\end{array}$ & PCL-80k: & PCL-2k: & $\begin{array}{l}\mathrm{PCL}-\mathrm{N}_{3}- \\
2 \mathrm{k}\end{array}$ & $\begin{array}{l}\text { Voltage } \\
\text { (kV) }\end{array}$ & $\begin{array}{l}\text { Flow rate } \\
(\mathrm{mL} / \mathrm{h})\end{array}$ & $\begin{array}{l}\text { Working } \\
\text { Distance } \\
\text { (cm) }\end{array}$ \\
\hline $0 \% \mathrm{PCL}-\mathrm{N}_{3}$ & 15 & 90 & 10 & 0 & 23 & 1 & 20 \\
\hline $1 \% \mathrm{PCL}-\mathrm{N}_{3}$ & 15 & 90 & 9 & 1 & 20 & 1 & 20 \\
\hline $5 \%$ PCL- $\mathrm{N}_{3}$ & 15 & 90 & 5 & 5 & 20 & 1 & 20 \\
\hline $10 \%$ PCL-N ${ }_{3}$ & 15 & 90 & 0 & 10 & 20 & 1 & 20 \\
\hline
\end{tabular}

a)

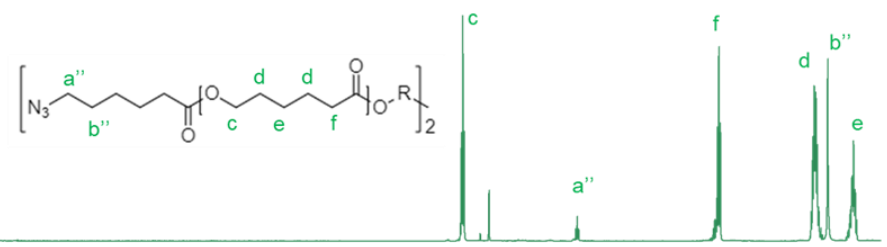

b)

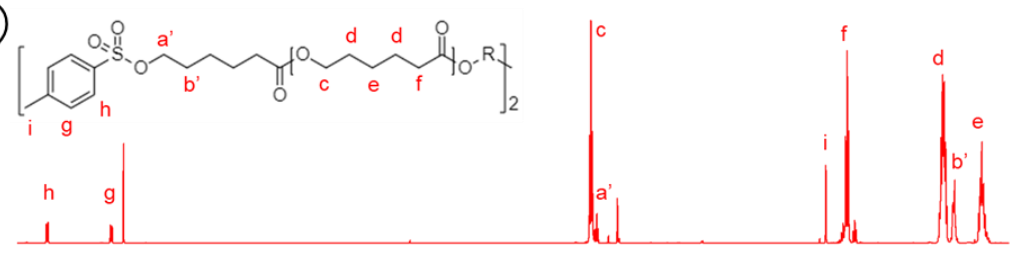

c)
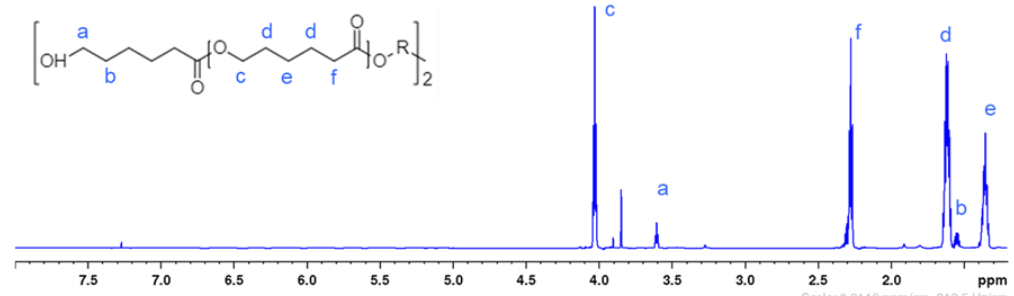

Figure S1. ${ }^{1} \mathrm{H}$ NMR $\left(700 \mathrm{MHz}\right.$ ) spectra of the (a) PCL- $\mathrm{N}_{3}$, (b) PCL-OTS, and (c) PCL polymers in $\mathrm{CDCl}_{3}$. 

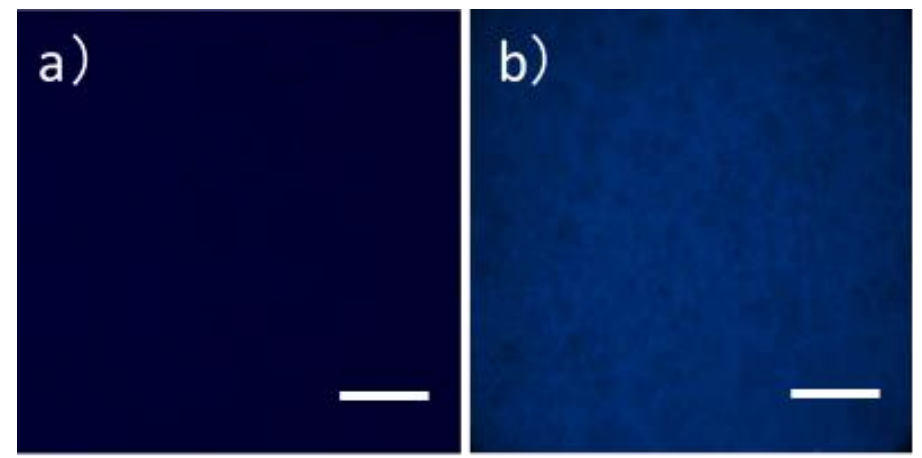

Figure S2. Fluorescence images of a) $10 \%$ PCL- $\mathrm{N}_{3}$ electrospun scaffolds after immersion in the 6-Aminofluorescence solution, b) $10 \%$ PCL- $\mathrm{N}_{3}$ electrospun scaffolds functionalized with AlkyneNTA and then labelled with 6-Aminofluorescence. Scale bars are $100 \mu \mathrm{m}$.
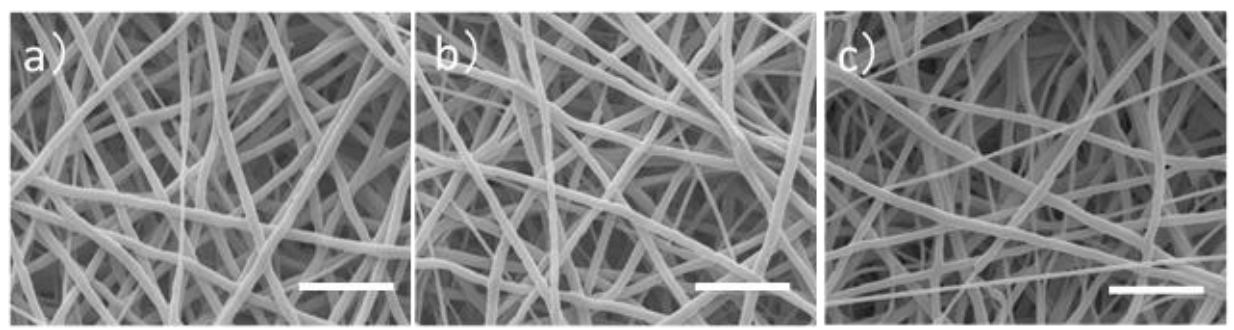

Figure S3. SEM images of (a) $1 \%$ PCL- $\mathrm{N}_{3}$, (b) $5 \%$ PCL- $\mathrm{N}_{3}$ and (c) $10 \%$ PCL- $\mathrm{N}_{3}$ nanofibrous scaffolds after clicked with alkyne-NTA. Scale bars are $10 \mu \mathrm{m}$. 

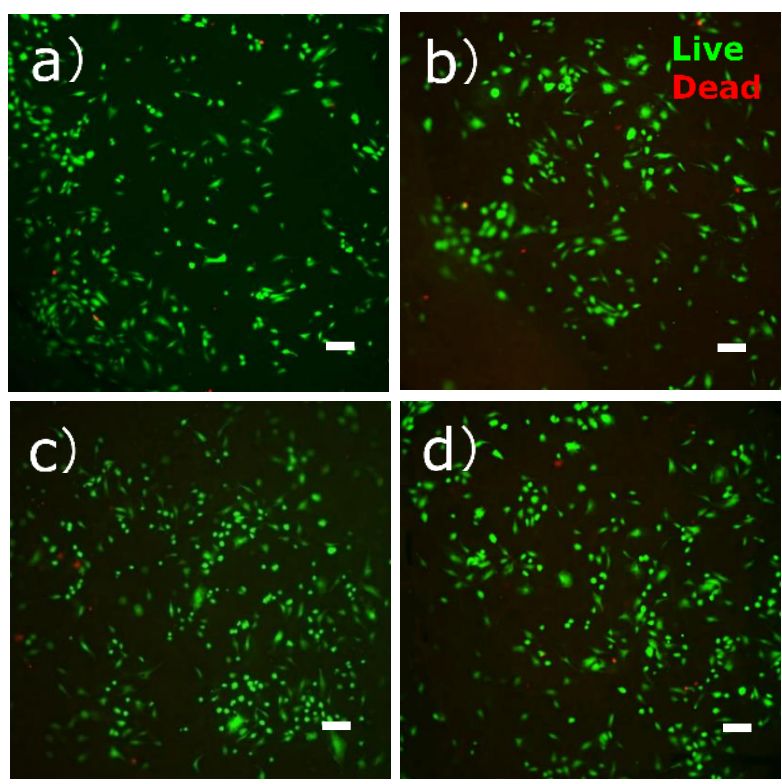

Figure S4. Live/dead staining images of HUVECs cultured on (a) $0 \% \mathrm{PCL}-\mathrm{N}_{3}$ fibrous scaffolds, (b) $1 \%$ PCL-N 3 /NTA fibrous scaffolds, (c) $5 \%$ PCL- $\mathrm{N}_{3} /$ NTA fibrous scaffolds and (d) $10 \%$ PCL-N $\mathrm{N}_{3} / \mathrm{NTA}$ fibrous scaffolds. Scale bars are $100 \mu \mathrm{m}$.

a)

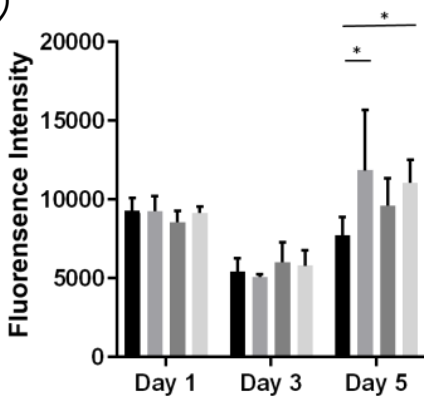

b)

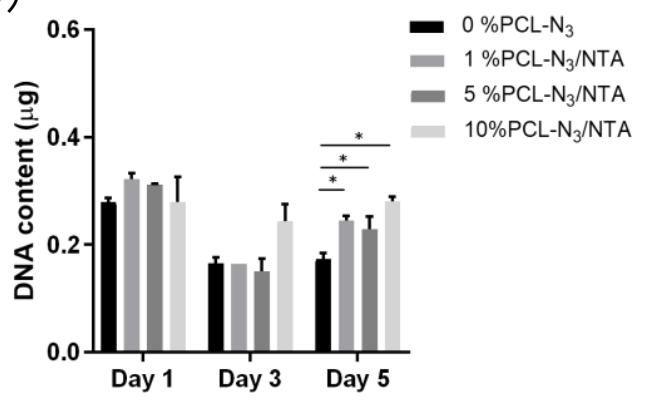

Figure S5. Viability (a) and proliferation (b) of HUVECs cultured for 5 days on different NTA functionalized scaffolds (with FBS pre-coating). ${ }^{*} \mathrm{P} \leq 0.05$. 


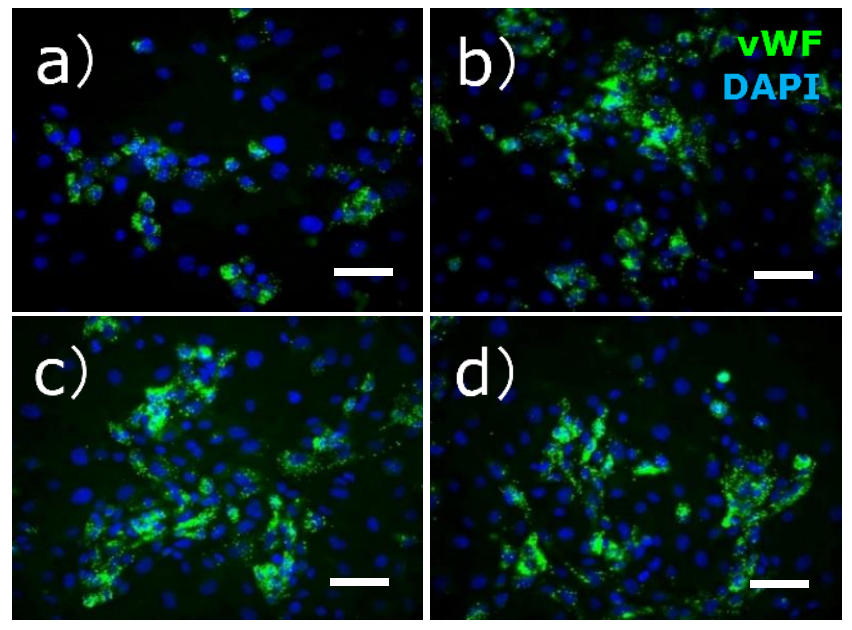

Figure S6. Expression of VWF on HUVECs grown on on (a) $0 \% \mathrm{PCL}-\mathrm{N}_{3}$ fibrous scaffolds, (b) $1 \% \mathrm{PCL}-\mathrm{N}_{3} / \mathrm{NTA}$ fibrous scaffolds, (c) $5 \% \mathrm{PCL}-\mathrm{N}_{3} / \mathrm{NTA}$ fibrous scaffolds, and (d) $10 \% \mathrm{PCL}-\mathrm{N}_{3} / \mathrm{NTA}$ fibrous scaffolds after 5 days culture. Scale bars are $50 \mu \mathrm{m}$.

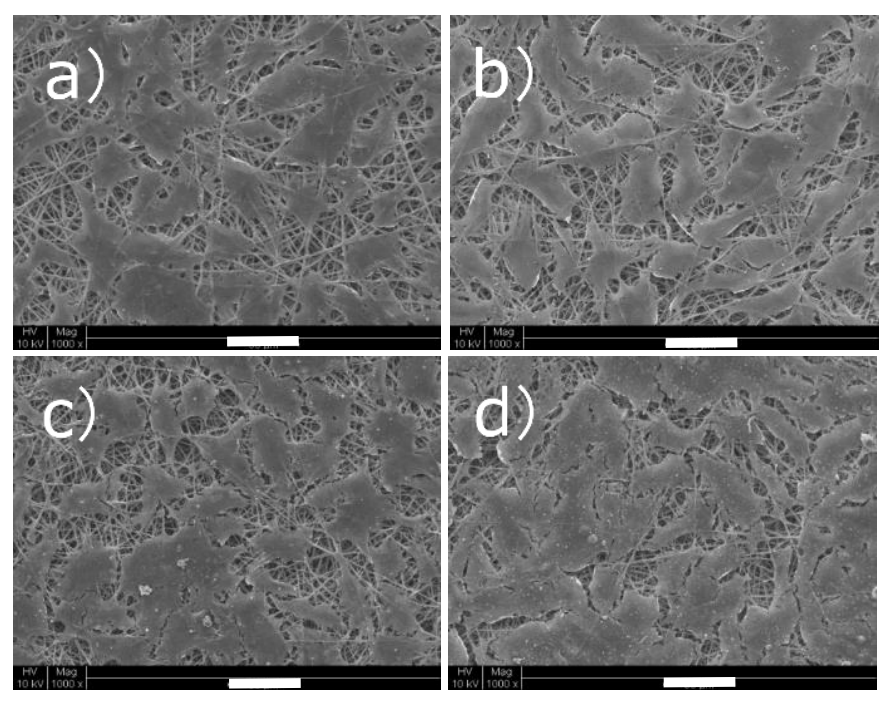

Figure S7. SEM images of HUVECs on (a) $0 \% \mathrm{PCL}-\mathrm{N}_{3}$ fibrous scaffolds, (b) $1 \% \mathrm{PCL}-\mathrm{N}_{3} / \mathrm{NTA}$ fibrous scaffolds, (c) $5 \%$ PCL- $\mathrm{N}_{3} /$ NTA fibrous scaffolds and (d) $10 \%$ PCL- $\mathrm{N}_{3} / \mathrm{NTA}$ fibrous scaffolds after 5 days culture. Scale bars are $50 \mu \mathrm{m}$. 


\section{Chapter 6}

\section{Thiol-ene Click Conjugation of VEGF Peptide to Electrospun Scaffolds as Potential Application for Angiogenesis}

Tianyu Yao ${ }^{1}$, Rong Wang ${ }^{1}$, Rebeca Rivero ${ }^{1}$, Lilian Kessels ${ }^{2}$, Tim G.A.M. Wolfs $^{2}$, Matthew B Baker ${ }^{1}$, Lorenzo Moroni ${ }^{*}$

1. Complex Tissue Regeneration Department, MERLN Institute for Technology Inspired Regenerative Medicine Maastricht University, Maastricht, 6229 ER, the Netherlands

${ }^{2}$ Laboratory of Pediatrics, Maastricht University, 6229 ER, the Netherlands 


\section{Abstract}

Vascular endothelial growth factor (VEGF) plays a vital role to promote the attachment and proliferation of endothelial cells, and induce angiogenesis. In recent years, much research has been conducted for the functionalization of tissue engineering scaffolds with VEGF or VEGF-mimetic peptide to promote angiogenesis. However, most chemical reactions are nonspecific and require organic solvents, which can compromise VEGF peptide activity. Recent advances in the fabrication of functionalizable 'clickable' electrospun fibers are reported, which showed potentially to solve these problems. In this study, we used thiol-ene click chemistry for the conjugation of VEGF peptide to the surface of poly ( $\varepsilon$-caprolactone) (PCL) fibrous scaffolds. PCL $(\mathrm{Mn} \approx 80 \mathrm{~K})$ and $\mathrm{PCL}$-diacrylates (PCL-DA) with lower molecular weight $(\mathrm{Mn} \approx 2 \mathrm{~K})$ were mixed together for electrospinning. A VEGF-mimetic peptide was then immobilized on PCL-DA fibrous scaffolds by thiol-ene click reaction. 7-Mercapto-4methylcoumarin was used to validate the thiol-ene click reaction with fibrous scaffolds. Fluorescence labeling of PCL-DA scaffolds after the click reaction indicated the success of the surface coupling. In particular, patterned structures were clearly observed after using a photomask on the fibrous film. Moreover, in vitro studies indicated that scaffolds functionalized with VEGF peptide are able to maintain higher HUVECs survival compared with unfunctionalized scaffolds. Proliferation and immunofluorescent staining analysis showed that cells could attach, spread and proliferated well on scaffolds, expressing several specific endothelial markers. A CAM assay further indicated that the VEGF peptide functionalized scaffolds are able to promote angiogenesis in vivo. Together, these results suggest that the functionalized VEGF peptide-scaffolds have potential for vascular tissue regeneration.

Key words: electrospun; fibrous scaffolds; thiol-ene click; VEGF peptide 


\section{Introduction}

Angiogenesis plays a pivotal role in tissue engineering and regenerative medicine for the successful survival of critical sized biological constructs [1-3]. During tissue regeneration, blood vessels can supply oxygen and nutrients to sustain cell viability [4, 5]. Cells located away from blood vessel suffer from hypoxia and apoptosis [6, 7]. In the absence of blood vessels, the removal of cell waste products is limited, resulting in their local accumulation which trigger inflammatory responses $[6,8]$. A highly organized vascular network is required for engineered tissues. To promote the formation of vascular network, many strategies have been developed. One of the most promising approaches is the immobilization of growth factors or peptides on scaffolds to stimulate neovascularization [9]. Among those growth factors, vascular endothelial growth factor (VEGF) has been the most potential angiogenic promoter [10], stimulating endothelial cell recruitment [11], proliferation [12, 13], and differentiation [14], and the formation of blood vessels [15]. However, VEGF was not applied widely because of its high costs, difficulties of manufacturing and the possibility of an immune response $[16,17]$. An alternative approach has been to use VEGF-mimetic peptides [18-20]. To this end, D'Andrea et al. [21] designed a VEGF-mimetic peptide, QK (domain: KLTWQELYQLKYKGI), reproducing the helix region 17-25 of VEGF, and showed the ability to activate VEGF receptors and similar bioactivity to VEGF. QK peptides provided many advantages including smaller molecular weight, possible to use in chemical reactions, low immunogenic potential, and cost-effectiveness by synthesis [17, 19-22]. This peptide promoted the attachment and proliferation of endothelial cells, and most importantly, induced capillary network formation [21, 23]. Leslie-Barbick et al. also reported that QK peptide is easier to conjugate or immobilize into poly(ethylene glycol) hydrogels than VEGF because it could diffuse faster and thoroughly into the scaffolds [20].

Scaffolds should be biodegradable, biocompatible and have native-like mechanical properties and a fibrillary structure that can mimic the structural 
and functional properties of the natural extracellular matrix (ECM) [8, 24]. Significant progress has been made in the development of ECM-mimicking scaffolds for tissue engineering, primarily focusing on improving micro- and nano-fabrication techniques [25]. Among many scaffolds fabrication methodologies, electrospinning has received much attention, due to the fact that it is a simple and cost-effective polymer processing technique widely used to produce micro and nanostructured fiber materials with a large surface to volume ratio [26-28]. By controlling the parameter of electrospinning process, such as high voltage, flow rate and working distance, the morphologies, diameters and pore size of nanofibers can be successfully controlled [29, 30]. It has been reported that the fibrillar structure of fibrous scaffolds with micro or nano diameter mimics the morphological features of ECM, provides a viable environment for cell adhesion, proliferation, migration, and differentiation [31, 32].

Motivated by the versatile electrospinning approach for ECM mimicking micro/nano fibrous scaffolds fabrication and the unique contributions of VEGFmimetic peptide in angiogenesis, we prepared electrospun VEGF peptidefunctionalized PCL nanofibrous scaffolds to form bioactive scaffolds for vascular tissue engineering. Several methods can be found in literature describing the immobilization of a peptide to a targeted surface or scaffold, such as covalent conjugation chemistry [33-35] or the use of a crosslinker and binding tags [36, 37]. However, these chemical reactions are nonspecific, possess limited efficiency and often require organic solvents that can compromise VEGF activity or the mechanical stability of the scaffolds [22, 38]. "Click" chemistry is an attractive alternative because of the simple reaction conditions, high reaction rate, high yields and functional group tolerance [3941]. Several "click" methods including radical thiol-ene [42], copper-catalyzed azide alkyne cycloaddition (CuAAC) [43, 44], strain-promoted azide-alkyne cycloaddition (SPAAC) [45, 46], Diels-Alder addition [47] and Michael additions [48] have been employed for nanofiber modifications [49]. The thiolene reactions provide an attractive and effective method for functionalization 
because the reaction involves thermal or photochemical generation of freeradicals. The UV-initiated thiol-ene click was found to preserve the emissive color integrity of poly(fluorene) films and allowed for facile photopatterning of the active polymer layer [42]. Here, we used thiol-ene click chemistry to introduce the VEGF-mimetic peptide on electrospun scaffolds. In the present work, we 1) synthesized "ene"-containing polymer with low molecular weight (PCL-diacrylates; PCL-DA; $\mathrm{Mn} \approx 2000 \mathrm{~g} / \mathrm{mol}$ ), blend it with a high-molecularweight PCL $(\mathrm{Mn} \approx 80000 \mathrm{~g} / \mathrm{mol})$ for the fabrication of the "clickable" electrospun fibers; 2 ) designed VEGF peptides with a thiol group by coupling with a cysteine; 3) and finally applied the radical thiol-ene reaction to immobilize the VEGF-mimetic peptide on the fibrous scaffolds. In addition, human umbilical vein endothelial cells (HUVECs) were seeded on functionalized scaffolds and cultured under starving medium and endothelial growth medium in order to determine the VEGF-peptide signaling capacity of the scaffolds.

\section{Materials and methods}

Poly( $\varepsilon$-caprolactone) (PCL, Mn $\approx 80000 \mathrm{~g} / \mathrm{mol})$, Poly( $\varepsilon$-caprolactone) (PCL$2 \mathrm{k}, \mathrm{Mn} \approx 2000 \mathrm{~g} / \mathrm{mol}$ ), trimethylamine, acryloyl chloride, 7-Mercapto-4methylcoumarin and all organic solvents were purchased from Sigma Aldrich and used without further purification.

\section{Synthesis of PCL-diacrylates (PCL-DA)}

$4.0 \mathrm{~g}$ of PCL-2k diol was dissolved in $40 \mathrm{~mL}$ of benzene and then reacted with $0.63 \mathrm{~mL}$ of trimethylamine and $0.37 \mathrm{~mL}$ of acryloyl chloride. The mixture was electro-stirred at $80^{\circ} \mathrm{C}$ for $3 \mathrm{~h}$ in a $250 \mathrm{~mL}$ three-necked flask, after which the triethylamine hydrochloride was removed by filtration. Finally, the mixture were precipitated in $\mathrm{n}$-hexane and dried in a vacuum at $40^{\circ} \mathrm{C}$ under reduced pressure for $24 \mathrm{~h}$ to produce the powdered form of PCL-DA. The final product was characterized by ${ }^{1} \mathrm{HNMR}$ and stored at $-20^{\circ} \mathrm{C}$ until use. 


\section{Preparation of electrospun PCL-DA fibers}

A high molecular weight of PCL and a lower molecular weight of PCL-DA were blended in different ratios $(10,30$, and 50 wt \% of PCL-DA as described in Table S1) to give a final concentration of $20 \mathrm{wt} \%$ polymer in a solvent mixture, respectively. All polymer solutions were prepared in chloroformdimethylformamide $\left(\mathrm{CHCl}_{3}: \mathrm{DMF}=4: 1\right)$. After mixing for at least $10 \mathrm{~h}$, the solution was loaded into a $5 \mathrm{~mL} B D$ plastic syringe equipped with a stainless steel blunt-ended needle. The polymer solution was delivered to the needle via a silicon feed line with a constant flow rate of $1 \mathrm{ml} / \mathrm{h}$ using a syringe pump (Harvard Apparatus PHD 2000). The working distance between the needle and conductive aluminum collector was fixed at $20 \mathrm{~cm}$. The high-voltage power was set at $20 \mathrm{kV}$. The environmental parameters were held constant and were similar for all of the experiments $\left(T \approx 25^{\circ} \mathrm{C}, \mathrm{H} \approx 35 \%\right)$.

\section{Fluorescent dye immobilization on fibers using thiol-ene reaction}

7-Mercapto-4-methylcoumarin was used to validate thiol-ene click reaction with $30 \%$ PCL-DA fibrous scaffolds. Fibrous mesh were covered with $1 \mathrm{~mL}$ of ethanol-water (1:1) solution containing 7-Mercapto-4-methylcoumarin (2 $\mathrm{mg} / \mathrm{mL}$ ) in a petri dish. The petri dish were exposed to UV light for $10 \mathrm{~min}$ (365 $\mathrm{nm}$, intensity $10 \mathrm{~mW} / \mathrm{cm}^{2}$ ). The control group was treated in dark for the same time. After the reaction, the sample was washed with excess ethanol-water (1:1) solution to remove the unbound dye. Fluorescence was observed with a fluorescent microscope (Nikon Eclipse Ti-S) and then quantified by UV-Vis spectrophotometer (UV-Vis Cary60; Agilent). Each of the absorption bands were monitored by Fourier-transform infrared spectroscopy (ATR-FTIR; Bruker). The variation in molecular weight of $30 \% \mathrm{PCL}-\mathrm{DA}$ was determined from gel permeation chromatography (GPC).

Patterning solutions consisted of $2 \mathrm{mg} / \mathrm{mL}$ 7-Mercapto-4-methylcoumarin in an ethanol-water (1:1) solution. 30\%PCL-DA fibrous scaffolds containing the desired solution were covered with different photomasks and irradiated for 
10min. Patterned fibrous mesh were placed in ethanol-water (1:1) solution and washed 3 times to remove the excess dye. Fluorescence pattern was detected by a UV lamp.

\section{Functionalization of PCL-DA fibrous scaffolds with VEGF peptide}

VEGF peptide (Ac-CGGKLTWQELYQLKYKGI-NH ${ }_{2}$ ) (MW: 2090.35; ChinaPeptides) was dissolved in ethanol-water (1:1) solution at a concentration of $2 \mathrm{mg} / \mathrm{ml}$. The $30 \% \mathrm{PCL}-\mathrm{DA}$ fibrous scaffolds was placed in the peptide solution along with a photoinitiator (Irgacure 2959, $0.5 \mathrm{w} / \mathrm{v} \%$ ) at room temperature. This fibrous scaffold was then exposed to $10 \mathrm{~mW} / \mathrm{cm}^{2} \mathrm{UV}$ for $10 \mathrm{~min}$. The active form of the peptide bonded onto PCL-DA fibers is termed as " $30 \%$ PCL-DA/VEGF pep" fibrous scaffolds.

\section{Characterization of electrospun fibers}

The morphology and diameter of the PCL-DA electrospun fibers was observed by scanning electron microscopy (SEM; XL30; Philips). The diameter of electrospun fibers were determined by Image $\mathrm{J}$. The morphological change of the fibers after binding with click reaction was also examined.

\section{Cell culture}

HUVECs were purchased from Lonza and cultured in endothelial growth medium (EGM, Lonza) containing EBM $^{\mathrm{TM}}-2$ basal medium (CC-3156) and $E^{E G M}{ }^{T M}-2$ SingleQuots ${ }^{T M}$ supplements (CC-4176), according to the manufacturer's protocol. HUVECs between four and eight passages were used in this study. The culture medium was refreshed every 2 days and the cells were cultured at $37^{\circ} \mathrm{C}$ in a humidified $5 \% \mathrm{CO}_{2}$.

The electrospun scaffolds (diameter: $15 \mathrm{~mm}$ ) were sterilized by $70 \%$ ethanol for 30min and then dried under a biosafety flow hood. The sterilized scaffolds were placed on a 24-wellplate and fixed by O-rings (ERIKS). After washing with sterilized water, the scaffolds were coated using Matrigel ${ }^{\circledR}$ (1:150 dilution 
in EBM) overnight in order to increase cell attachment. HUVECs $\left(2 \times 10^{4}\right)$ were then seeded on the scaffolds, and incubated with $5 \% \mathrm{CO}_{2}$ at $37{ }^{\circ} \mathrm{C}$.

\section{Cell survival and proliferation assays}

To evaluate cell survival on 30\%PCL-DA and 30\%PCL-DA/VEGF pep fibrous scaffolds, endothelial basal media (EBM) without growth factors was used to induce a starvation condition. After seeding on scaffolds, cells were cultured in a growth-factor-free setting for cell viability and DNA assays. Cell viability was tested by the PrestoBlue ${ }^{\mathrm{TM}}$ reagent (Fisher Scientific). Briefly, at 1, 3, and 5 days after cell seeding, $500 \mu \mathrm{l}$ of PrestoBlue medium at a dilution of 1:10 with EBM media were added to each sample and incubated at $37^{\circ} \mathrm{C}$ with $5 \%$ $\mathrm{CO}_{2}$. $30 \mathrm{~min}$ later, $100 \mu \mathrm{L}$ of media were transferred to 96 -well plate to measure absorption value at a wavelength of $590 \mathrm{~nm}$ using a microplate reader (CLARIOstar, BMG Labtech). Cell proliferation on cell-scaffolds was evaluated with CyQUANTTM Cell Proliferation Assay Kit (Thermo Fisher Scientific) according to the manufacturer's protocol. Briefly, the cells harvested after 1,3 , and 5 days were washed with PBS and digested overnight with $250 \mu \mathrm{l}$ Proteinase $\mathrm{K}$ in Tris/EDTA solution at $56{ }^{\circ} \mathrm{C}$. After freezethawing samples for 3 times, the digested solutions were then transferred into a black 96 -well plate. A $40 \mu$ of lysis buffer was added into each well and incubated for $1 \mathrm{~h}$. Finally, the cell lysate were stained with $80 \mu \mathrm{l} \mathrm{GR}$ dye for $15 \mathrm{~min}$ at room temperature. Fluorescent intensity was measured at an excitation/emission of $450 / 520 \mathrm{~nm}$ using microplate reader. A standard curve of DNA content was obtained using serially diluted $\lambda$ DNA with the concentration ranging from 0 to $1 \mu \mathrm{g} / \mathrm{ml}$.

The cell proliferation on 30\%PCL-DA and 30\%PCL-DA/VEGF pep fibrous scaffolds was evaluated by using endothelial growth media without VEGF (EGM-VEGF) to assess the specific effect of VEGF peptide. Cell viability and proliferation was tested by the PrestoBlue ${ }^{\mathrm{TM}}$ reagent and CyQUANT ${ }^{\mathrm{TM}}$ Cell Proliferation Assay Kit as described above. 


\section{VEGFR1 and VEGFR2 phosphorylation ELISA assays}

The concentrations of phosphorylated VEGF receptor 1 (VEGFR1) and VEGF receptor 2 (VEGFR2) were assayed by using Human Phospho-VEGFR1 and Human Phospho-VEGFR2 DuoSet IC ELISA kits (R\&D Systems). First, HUVECs were seeded on 30\%PCL-DA and 30\%PCL-DA/VEGF pep fibrous scaffolds, then cultured in EBM without any serum or growth factor. After incubating $5 \mathrm{~h}$ and $24 \mathrm{~h}$, cells were washed with PBS twice. Cells were solubilized in lysis buffer following the recommended protocol from R\&D. $100 \mu \mathrm{L}$ of sample and controls were added to the pretreated 96-well plates and incubated for $2 \mathrm{~h}$ at room temperature. After washing with wash buffer, $100 \mu \mathrm{L}$ of detection antibody conjugates were added and placed under dark for $2 \mathrm{~h}$. The well plate was carefully aspirated and washed by wash buffer. A $100 \mu \mathrm{L}$ of substrate solution was added to each well and incubated for $20 \mathrm{~min}$ in the dark. The reaction was stopped by the addition of $2 \mathrm{~N} \mathrm{H}_{2} \mathrm{SO}_{4}$. A plate reader was used to determine the optical density in each well at a wavelength of $450 \mathrm{~nm}$.

\section{Immunostaining}

After 5 days culture, HUVECs on scaffolds were fixed using $4 \%$ formaldehyde for $30 \mathrm{~min}$ at room temperature. Subsequently, cells were stained with Alexa Fluor ${ }^{\circledR} 568$ phalloidin and endothelial markers (anti-CD31, anti-vWF and antieNOS). The samples were permeabilized in PBS containing $0.1 \%$ Triton-X 100 for 15 min and then washed with PBS for 3 times. After blocking with 5\% goat serum for $1 \mathrm{~h}$, the samples were incubated with the primary antibodies (1:200 dilution in blocking solution) overnight at $4^{\circ} \mathrm{C}$. The samples were washed by washing buffer (contain $0.05 \%$ Tween 20 and 1\% BSA in PBS) for 3 times, then secondary antibodies (goat-anti mouse, Alexa Fluor 488, 1:200 dilution in washing buffer) were added and incubated for $1 \mathrm{~h}$ in dark. Finally, the samples were stained with DAPI and imaged with a fluorescence microscope (Nikon Eclipse Ti-S) after washing with PBS. 


\section{Chick Chlorioallantoic membrane assay}

To assess the bioactivity and angiogenesis of functionalized scaffolds in vivo, the chick embryo chorioallantoic membrane (CAM) assay has been performed. In brief, fertilized chicken eggs (provided by Het Anker B.V., Netherlands) were placed in an incubator as soon as embryogenesis started and kept under $50-55 \%$ humidity at $37^{\circ} \mathrm{C}$. After 3 days of incubation, a square window of 1 $x 1.5 \mathrm{~cm}^{2}$ was opened with a rotary tool (Dremel) on the shell and then sealed with adhesive tape. On day 10, VEGF peptide functionalized scaffolds with diameter of $4 \mathrm{~mm}$ were placed on the surface of the egg membrane (10 eggs for each group). After 4 days, the vessels surrounding the scaffold was visualized under a Leica microscope. A change in vessel number and vessel area around fibrous scaffolds was quantified by using Image J. This change in vascularization implies an effect of functionalized scaffolds on angiogenesis in vivo.

\section{Statistical analysis}

Statistical analysis was carried out using GraphPad Prism 8 software. All data are expressed as mean \pm standard deviation (SD). Data were statistically analyzed by one-way analysis of variance, column values were compared with the control values using Student's t-test. A probability value of less than 0.05 was considered significantly different. Levels of significance were as follows: ${ }^{*} \mathrm{P} \leq 0.05,{ }^{* *} \mathrm{P} \leq 0.005,{ }^{* * *} \mathrm{P} \leq 0.0005$.

\section{Results and Discussion}

\section{Characterization of PCL-diacrylates (PCL-DA)}

The formation of PCL-diacrylates was confirmed through ${ }^{1} \mathrm{H}-\mathrm{NMR}$ spectrometer. As shown in ${ }^{1} \mathrm{H}$-NMR spectrum (Figure S1), the $\mathrm{CH}_{2}=\mathrm{CH}$ signals of the PCL-diacrylates was present in the $\delta 5.80-6.45 \mathrm{ppm}$ range, which is consistent with other literature [50-52]. The detail of vinyl groups is shown below: ${ }^{1} \mathrm{H}$ NMR $\left(700 \mathrm{MHz}, \mathrm{CDCl}_{3}\right) \delta 6.41(\mathrm{dd}, \mathrm{J}=17.4,1.1 \mathrm{~Hz}, 1 \mathrm{H})$, 
$6.13(\mathrm{dd}, \mathrm{J}=17.3,10.4 \mathrm{~Hz}, 1 \mathrm{H}), 5.83(\mathrm{dd}, \mathrm{J}=10.5,1.1 \mathrm{~Hz}, 1 \mathrm{H})$. From the ${ }^{1 \mathrm{H}-}$ NMR results, the hydroxyl groups in PCL were successfully converted to vinyl groups of PCL-DA after reacting with acryloyl chloride.
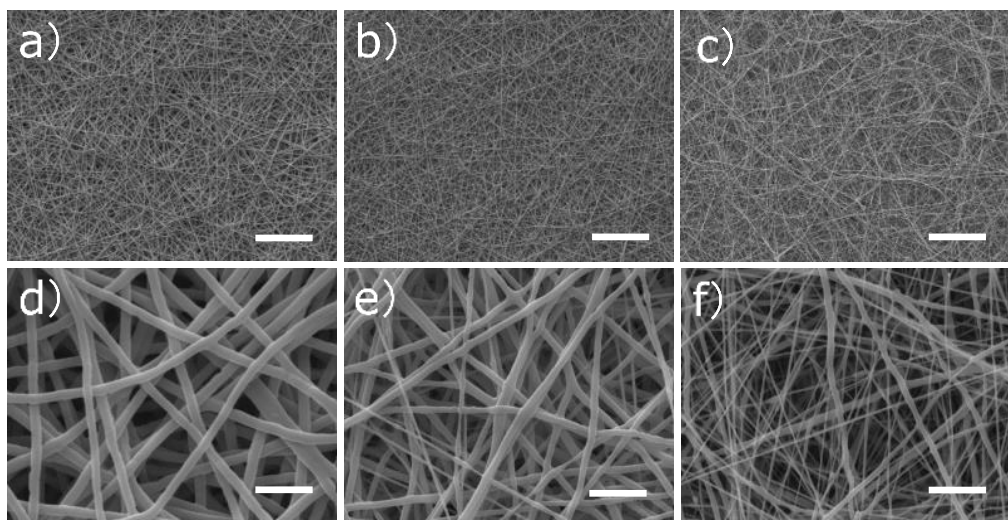

Figure 1. Micro- or nano- structure of electrospun fibrous scaffolds; (a and d) 10\%PCL-DA, (b and e) $30 \%$ PCL-DA, and (c and f) 50\%PCL-DA at low (top) and high (bottom) magnifications. Scale bars are $100 \mu \mathrm{m}(\mathrm{a}-\mathrm{c})$ and $10 \mu \mathrm{m}(\mathrm{b}-\mathrm{d})$.

\section{Fabrication of PCL-DA-Incorporated electrospun PCL fibers}

To investigate the effect of PCL-DA $(M w=2 K)$ on fiber morphology, different percentages of PCL-DA were incorporated into PCL solution and the concentrations of the total polymer solution was fixed to be in $20 \%$ (Table S1). The morphology of the formed fibrous scaffolds was observed by SEM (Figure 1). It is clear that with higher percentage of PCL-DA, the fibrous scaffolds displayed smaller fibers. After more PCL-DA was added, the average dimeter of PCL fibers decreased from $1.71 \pm 0.18$ to $0.49 \pm 0.23 \mu \mathrm{m}$, suggesting that the diameter of $P C L$ fibers decreased after mixing with lower molecular weight PCL-DA (Figure S2a). Moreover, 10\% PCL-DA and 30\% PCL-DA fibrous scaffolds showed more uniform fiber morphology compared to $50 \%$ PCL-DA scaffolds. Our finding that fiber diameter decreases with the decline of molecular weight was also studied in literature. Tao et al. reported that at a fixed concentration, the polyvinylalcohol (PVA) fiber diameter decreased as the molecular weight was decreased [53]. When the molecular weight 
decreased, the solution viscosity decreased significantly. During the electrospinning process, the low surface tension produced by the low viscosity of the polymer solution could results in smaller fibers.

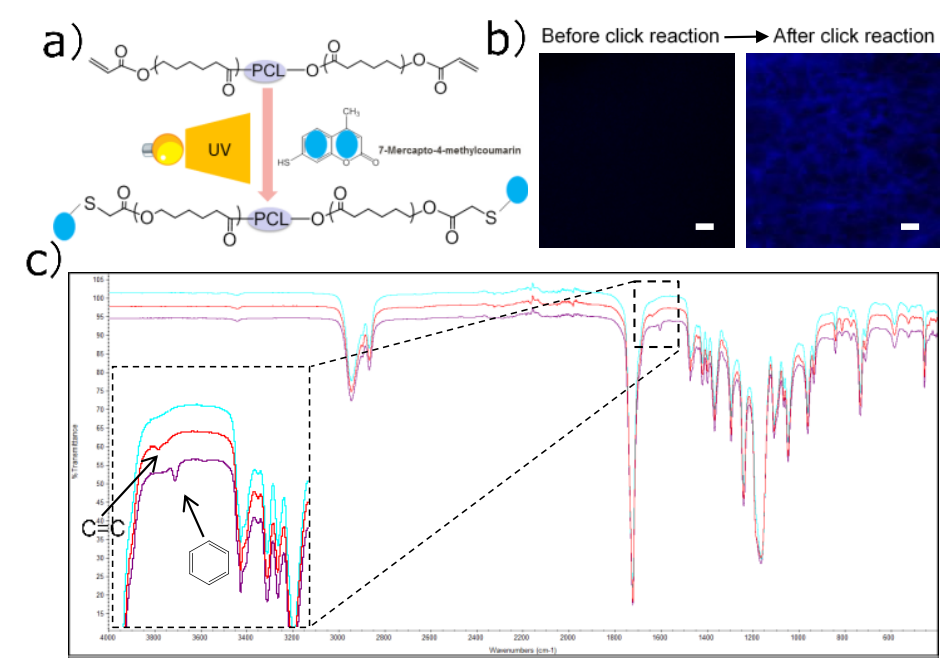

Figure 2. (a) Thiol-ene click reaction between 7-Mercapto-4-methylcoumarin and PCL-DA. (b) Fluorescence images and (c) FTIR spectra of fibrous scaffolds before and after click reaction. Scale bars are $100 \mu \mathrm{m}$.

\section{Surface modification of PCL-DA fibers}

The availability of "clickable" groups on the fiber surfaces was demonstrated using a thiol-containing fluorescent dye. Figure 2a illustrated how 7-mercapto4-methylcoumarin was labeled onto PCL-DA fibrous scaffolds by the radical thiol-ene reaction. Fluorescence images were captured from the $30 \%$ PCLDA fibers after thiol-ene reaction in the solution of 7-mercapto-4methylcoumarin. Compared to the reaction groups, the fluorescence in the controls was much weaker. The results demonstrated successful modification with 7-mercapto-4-methylcoumarin onto PCL-DA fibrous scaffolds (Figure 2b). Fluorescence labeling of $30 \% \mathrm{PCL}-\mathrm{DA}$ fibers with thiol dye proved that the ene groups are surface-localized as well as available for click-chemistry coupling. After thiol-ene click modification, SEM images showed that the PCLDA fibers maintained their fiber morphology (Figure S2b-c). This observation 
proved the click reaction worked quite well on PCL-DA scaffolds without changing fiber morphology.

The success of fluorescence dye coupling was furthered verified via FTIR spectroscopy. The " $\mathrm{C}=\mathrm{C}$ " stretch peak is not visible after reaction (Figure $2 \mathrm{C}$ purple line), while much stronger signals of benzene were found for the latter, indicating the complete conversion of the -ene groups within the limits of FTIR detection. This clearly corresponds to a successful click event where a C-S-C linkage is formed between PCL-DA and 7-mercapto-4-methylcoumarin. Conjugation of fluorescence dye to PCL-DA fibrous scaffolds was also confirmed via GPC (Figure S3), which demonstrated that the low-molecular weight peak of PCL-DA have the strong absorbance of 7-mercapto-4methylcoumarin at $358 \mathrm{~nm}$. In addition, the molecular weight of PCL-DA showed a small increase after reaction with 7-mercapto-4-methylcoumarin. The click chemistry results with a fluorescence dye proved that "clickable" groups on the fiber surface are also available for further click functionalization. Unlike many functionalization methods, this blend and click approach do not need specific solvents which may destroy the morphology of fibers. Therefore, this surface functionalization approach provides an opportunity to couple VEGF mimicking peptides, among other biological factors, on the surface of PCL-DA fibers without interfering with the fiber morphology.

\section{The effect of time and PCL-DA concentration on click reaction}

As shown in Figure 3a, with increasing of the reaction time, the fluorescence intensity increased rapidly at first until $10 \mathrm{~min}$ and then further increased gradually reaching a relative high point after $30 \mathrm{~min}$. Therefore, $10 \mathrm{~min}$ was chosen as the effective reaction time for further investigation. Without the UV exposure, the control group showed no specific absorbance under fluorescence dye, indicating that the PCL-DA were intact during this process and no obvious physical absorption was found in $30 \mathrm{~min}$.

Figure S4a showed the fluorescence spectra at different concentrations of 7mercapto-4-methylcoumarin. The corresponding regression equation was 
shown in Figure S4b. Quantification of double bonds available at the surface of different PCL-DA fibrous scaffolds was calculated from the calibration curve. In Figure 3b, it can be seen that the amount of 7-mercapto-4-methylcoumarin immobilized on the surface increased with increased blend ratio of PCL-DA. Obviously, the higher blend ratio of PCL-DA resulted in the greater amount of surface -ene, providing more functional group for fluorescence dye or peptide coupling on the surface. This result showed the possibility to precisely control the reaction by changing the percentage of PCL-DA. Although the $50 \% \mathrm{PCL}-$ DA fibrous scaffolds contained the highest clickable group, the obtained fiber diameter were quite small and less uniform compared with $30 \% \mathrm{PCL}-\mathrm{DA}$ scaffolds. Finally, 30\% PCL-DA fibrous scaffolds were chosen for later in vitro and in vivo studies.

a)

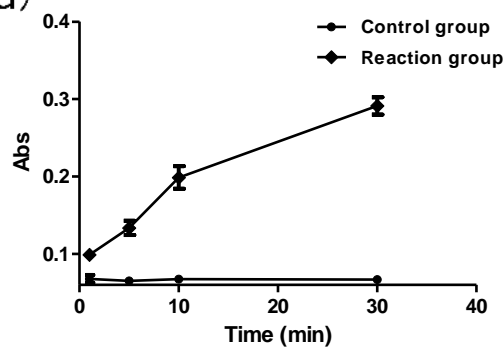

b)

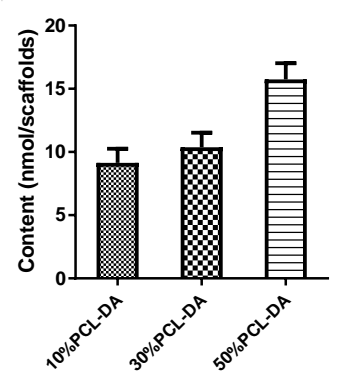

Figure 3. (a) The effect of reaction time on the fluorescence increase of $30 \%$ PCL-DA fibrous scaffolds. The control group is the reaction group without UV treatment. Excitation wavelength: $335 \mathrm{~nm}$. (b) Quantification of 7-Mercapto-4-methylcoumarin reacted with per 10,30 and $50 \%$ of the PCL-DA electrospun scaffolds, respectively.

\section{Photopatterning of PCL-DA fibrous scaffolds}

To demonstrate UV-regulated the process of fiber functionalization, we performed photopatterning experiments to generate fluorescence patterns using photo masks (Figure 4a). This photopatterning strategy is based on the advantage of using the photochemically promoted radical thiol-ene click, so that conjugation of 7-mercapto-4-methylcoumarin under UV exposure through a photomask was probed. Figure 4b showed the resulting fluorescent pattern 
after thiol-ene click on $30 \%$ PCL-DA fibrous scaffolds, where the bright-blue regions are areas of clicked polymer fluorescing under UV light. Dark regions were masked during reaction, and the unbound dye was washed off with ethanol. As a demonstration, various patterns were achieved on the $30 \% \mathrm{PCL}$ DA fibrous scaffolds by UV illumination through different photomasks (Figure 4c). The photopattern approach based on thiol-ene click was also reported by other researchers [42]. However, this study did not show the possibility of performing photopatterning on fibrous scaffolds. Our study successfully proved that this simple and effective approach could be used on PCL-DA fibrous scaffolds. The ability to use thiol-ene chemistry creating any spatial functionalization of PCL-DA fibrous films is a significant advantage, which could be used for the partial functionalization of bioactive molecules on fibrous scaffolds.

a)

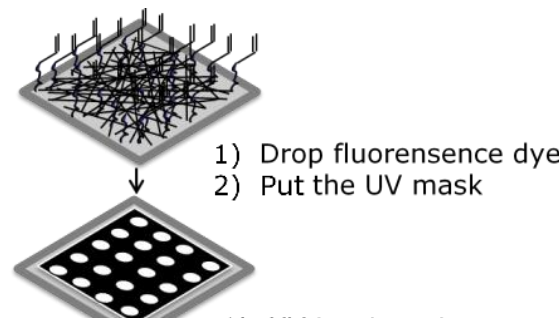

1) UV treatment

2) Take off the mask

3) Wash

C)

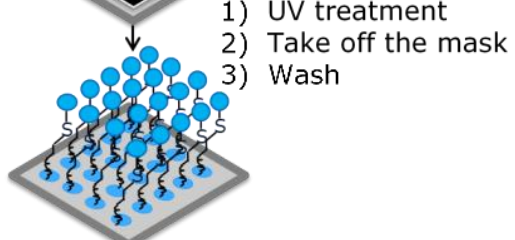

b)
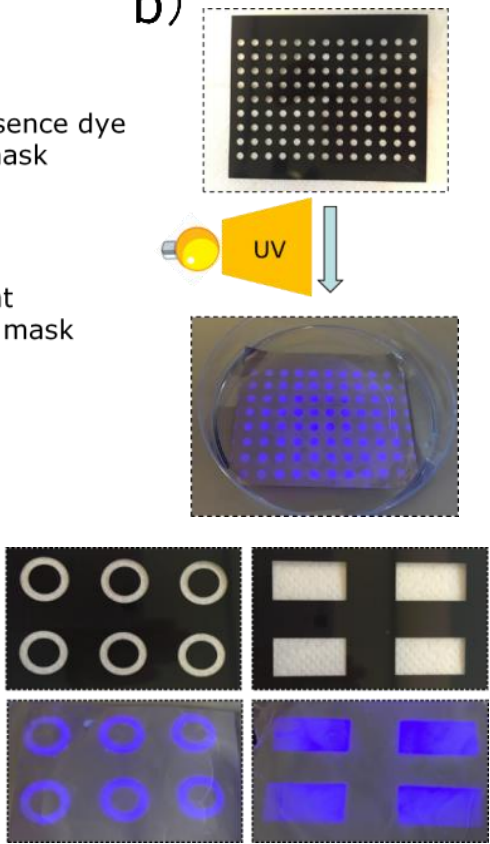

Figure 4. (a) Photopatterning steps of $30 \%$ PCL-DA fibrous scaffolds with 7-Mercapto-4methylcoumarin. (b) Images of mask and photopatterned fibrous scaffolds and (c) different mask and photopatterned fibrous scaffolds. 
a)

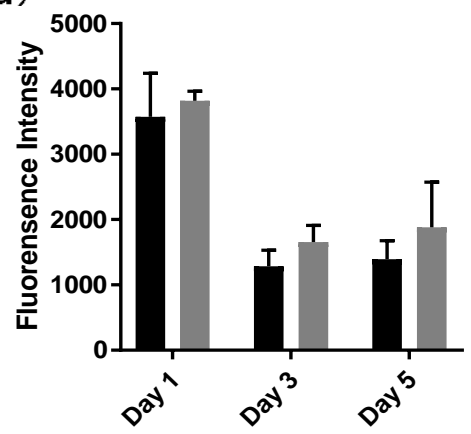

b)

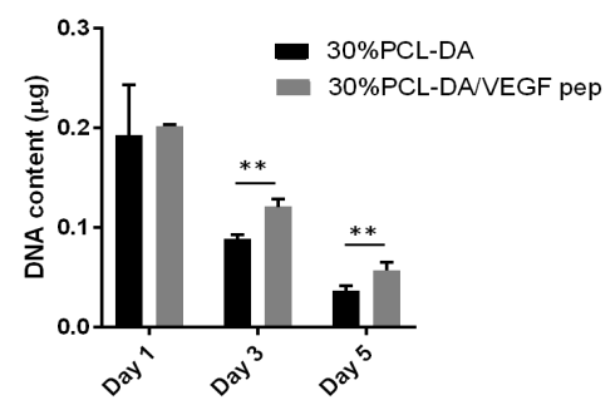

Figure 5. Effect of VEGF peptide immobilizing on HUVECs survival under nutrient starvation conditions. Viability (a) and DNA content (b) of HUVECs cultured for 5 days on $30 \%$ PCL-DA and $30 \%$ PCL-DA/VEGF pep fibrous scaffolds. ( $\left.{ }^{* *} \mathrm{P} \leq 0.005\right)$

\section{HUVECs survival on $30 \%$ PCL-DA/VEGF pep scaffolds under starvation conditions}

HUVECs were cultured on the 30\% PCL-DA and 30\% PCL-DA/VEGF pep scaffolds under nutrient starvation conditions to evaluate the effect of VEGF peptide on cell survival. Cell viability was evaluated by using the PrestoBlue assay at 1,3 and 5 days. Figure 5 a demonstrates that cell viability on both scaffolds was similar after 1 day of culture. Cell viability for both scaffolds decreased after 3 days' incubation under starvation conditions, whereas no significant decrease was identified at day 5 . In addition, cell survival was determined using a CyQUANT ${ }^{\mathrm{TM}}$ Cell Proliferation Assay Kit to measure total DNA content. Results showed that DNA content for both groups gradually decreased over 5 days (Figure $5 b$ ). The DNA content of both scaffolds was the same at day 1 . After 3 days' incubation under nutrient starvation conditions, both scaffolds experienced extensive cell death. The DNA content at day 5 on the $30 \%$ PCL-DA scaffolds was $24.4 \%$ of its day 1 value, while it was $29.6 \%$ for the $30 \%$ PCL-DA/VEGF pep scaffolds. The DNA content on VEGF peptide functionalized scaffold was significantly higher than that on the control scaffold at day 3 and day 5 , indicating that VEGF peptide on scaffolds increased HUVECs survival. These observations also supported that VEGF peptide was 
successfully immobilized onto the scaffolds. During implantation of engineered tissue, cell survival may be limited if the implantation site is not well vascularized or angiogenesis is not timely formed. Poor cell survival is directly related to the nutrient starvation environment. Efforts employing prosurvival growth factors or peptide functionalized scaffolds have been tried to improve cell survival. We hypothesize that using prosurvival VEGF peptide scaffolds to maintain endothelial cell survival until forming angiogenesis may be a strategy to solve this problem.

Tris(2-carboxyethyl)phosphine (TCEP) is a commercially reducing agent to break Cys-Cys bridge, and used as co-reactant for the thiol-ene click of $30 \%$ PCL-DA fibrous scaffolds with VEGF peptide. However, we compared cell survival on VEGF peptide functionalized scaffolds with and without TCEP catalyst. No differences were observed (data not shown). Therefore, TCEP was not added into reaction solution in the following experiment.

\section{VEGFR1 and VEGFR2 phosphorylation assay on the scaffolds}

In order to further detect biological signaling of VEGF peptide from the functionalized scaffolds, HUVECs were cultured on 30\% PCL-DA and 30\% PCL-DA/VEGF pep scaffolds, and then stimulated to produce phosphorylated VEGF receptor 1 (ph-VEGFR1) or phosphorylated VEGF receptor 2 (phVEGFR2). Quantification of phosphorylated VEGFR1 and VEGFR2 (Figure S5) showed that HUVECs on $30 \%$ PCL-DA scaffolds after 5 h produced a small amount of phosphorylated VEGFR1; HUVECs on the $30 \%$ PCLDA/VEGF pep scaffolds had a slightly higher level of phosphorylated VEGFR1 than that on unfunctionalized scaffolds. However, such difference disappeared on phosphorylated VEGFR1 after 24h and no difference were noticed phosphorylated VEGFR2 after $5 \mathrm{~h}$ and $24 \mathrm{~h}$. These data indicated that VEGF peptide from the $30 \%$ PCL-DA/VEGF pep scaffolds have a slight effect on VEGFR1 phosphorylation at $5 \mathrm{~h}$, while no significant effect on VEGFR2 phosphorylation. These results were also confirmed by immunostaining of phVEGFR1 and ph-VEGFR2 (Figure S5a-d). HUVECs cultured on both scaffolds 
could express ph-VEGFR1 and ph-VEGFR2. Ph-VEGFR1 staining showed slightly higher fluorescence on VEGF-pep functionalized scaffolds. According to these results, the functionalized VEGF-pep fibrous scaffolds demonstrated no significant effect on VEGFR1 and VEGFR2 phosphorylation at $5 \mathrm{~h}$ and $24 \mathrm{~h}$. Webber et al. reported that the effect of VEGF peptide amphiphile on VEGFR1 and VEGFR2 phosphorylation only increased in the first $10 \mathrm{~min}$, followed by a decrease of stimulation until $60 \mathrm{~min}[54]$. Maybe this study could explain the reason why we could not find significant effect on VEGFR1 and VEGFR2 phosphorylation. In our experiment, the VEGF peptide is coupled on fibrous scaffolds. After scaffold seeding, the cells were quickly exposed to the VEGF peptide environment, but they also need more than 60 min to attach on scaffolds. Therefore, it is hard to detect the time-dependent stimulation of VEGF-pep scaffolds on VEGFR1 and VEGFR2 phosphorylation in the first hour of the seeding procedure.

\section{HUVECs proliferation on $30 \%$ PCL-DA/VEGF pep scaffolds}

HUVECs were seeded on 30\% PCL-DA and 30\% PCL-DA/VEGF pep scaffolds and allowed to proliferate in EGM without VEGF (EGM-VEGF) medium. After 1, 3 and 5 days of culture, cell viability and proliferation were evaluated. As shown in Figure S6, we consistently noticed an increase in cell viability and DNA content on both scaffolds during culture time. However, no significant difference between 30\% PCL-DA and 30\% PCL-DA/VEGF pep scaffolds could be observed. Except VEGF, endothelial growth medium contain other growth factors, such as hFGF-B, R3-IGF-1 and hEGF, which are well known to influence endothelial cell proliferation. The results illustrated that the introduction of VEGF peptide on the fibrous electrosupn PCL scaffolds did not influence the proliferation of HUVECs when culture in EGM-VEGF medium, which is probably due to the positive effect of the other growth factors on HUVECs proliferation, as explained above, thus covering the effect of VEGF peptide. 
Overall, the high relative increase of cell viability and DNA content during 5 days culture indicated that both scaffolds were biocompatible, non-cytotoxic, and could be used as tissue engineering scaffolds for in vivo study.

\section{Cell morphology and expression of endothelial functional proteins on scaffolds}

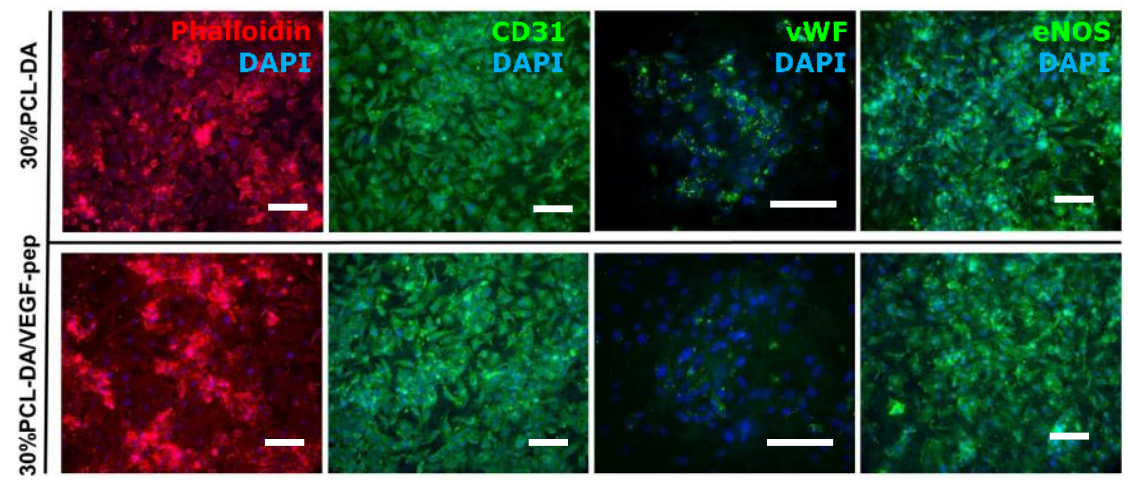

Figure 6. Immunofluorescence staining images showing the nuclei (blue) and the expression of F-actin (red), CD31 (Green), vWF (Green) and eNOS (Green) of HUVECs grown on 30\%PCLDA fibrous scaffolds and 30\%PCL-DA/VEGF pep fibrous scaffolds after 5 days. Scale bars are $100 \mu \mathrm{m}$.

In order to observe cell morphology on the scaffolds, DAPI and Phalloidin stained cell nucleus and actin filaments was performed after 5 days culture. Results clearly showed that all cells spread and adhered to both scaffolds. The functional development of HUVECs on scaffolds was analyzed by immunostaining of the endothelial proteins, CD31, vWF and eNOS. As seen in Figure 6, positive CD31 staining was clearly detected on all HUVECs on scaffolds. A vWF dot pattern was observed in small amounts of HUVECs, which demonstrated vWF was produced within the cytoplasm of HUVECs cultured on both scaffolds. eNOS is a marker for nitric oxide production in endothelial cells. All HUVECs stained positive for eNOS, indicating a functional cellular phenotype. Taken together, HUVECs on $30 \%$ PCLDA/VEGF pep scaffolds did not show any considerable visible difference from 
these immunostaining results as compared to cells seeded on 30\% PCL-DA scaffolds. However, cells positively stained with endothelial markers (CD31, vWF and eNOS) confirmed that HUVECs maintained the endothelial phenotype and kept endothelial function when cultured on both scaffolds.

\section{In vivo CAM assay}
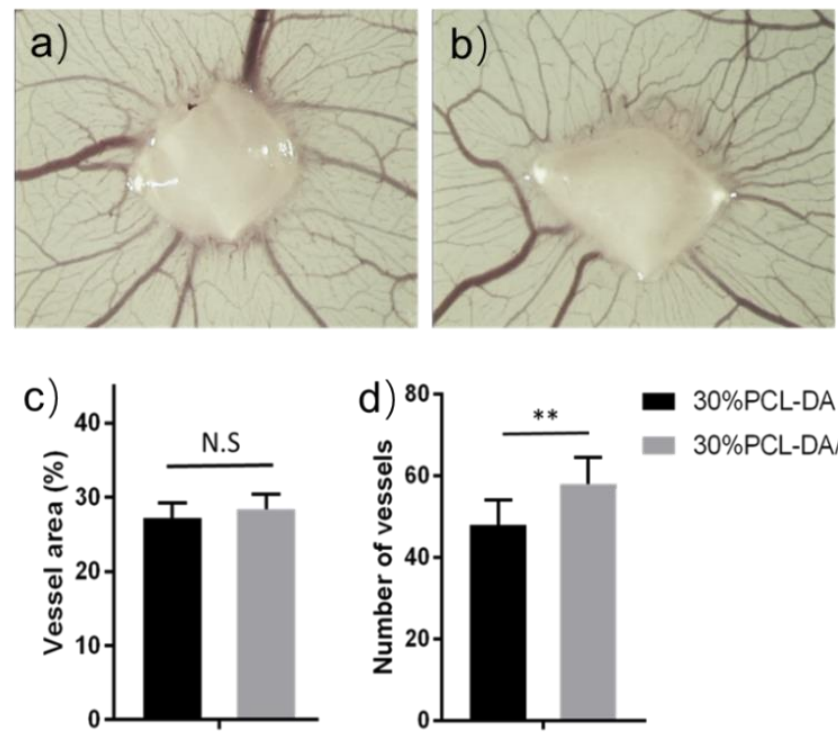

$30 \%$ PCL-DA

$30 \%$ PCL-DA/VEGF pep

Figure 7. Representative images of (a) 30\%PCL-DA and (b) 30\%PCL-DA/VEGF pep fibrous scaffolds implanted on the CAM after 4 days. The quantification of (c) vessel area in the images and (d) number of vessels around implanted scaffolds. ( $\left.{ }^{\star *} P \leqslant 0.005\right)$

A CAM model was used to evaluate whether the VEGF peptide functionalized scaffolds could promote angiogenesis in vivo. After fibrous scaffolds were implanted on the CAM for 4 days, we saw many vessels growing around electrospun scaffolds as shown in Figure 7a-b. For comparison, the total vessels area and vessels number were quantified (Figure $7 \mathrm{c}-d$ ). 30\%PCLDA/VEGF pep fibrous scaffolds displayed a slightly higher (1.2\%) amount of vessels area around scaffolds. However, no significant statistically difference compared with $30 \%$ PCL-DA fibrous scaffolds was shown $(n=10)$. The quantitative results of vessels number indicated that the number of blood 
vessels surrounding the $30 \% \mathrm{PCL}-\mathrm{DA} / \mathrm{VEGF}$ pep fibrous scaffolds $(57.9 \pm 6.7)$ was significantly higher than that of the $30 \% \mathrm{PCL}-\mathrm{DA}$ fibrous scaffolds (48.0 \pm 6.0) $(P=0.003)$. This means that implantation with $30 \% P C L-D A / V E G F$ pep fibrous scaffolds led to more small vessel growth surrounding the scaffolds compared with control. The result suggests a positive angiogenic response from the VEGF peptide functionalized scaffolds in vivo.

\section{Conclusion}

In conclusion, we reported a new approach for the fabrication of VEGFpeptide functionalized electrospun scaffolds by using UV-initiated thiol-ene click chemistry. Spatial control of the fiber functionalization, an exclusive advantage of using the photochemically promoted thiol-ene based conjugation strategy, was successfully proved. This functionalization approach under mild conditions could maintain fiber morphology and mechanical properties of scaffolds. Moreover, cell studies showed that VEGF peptide functionalized scaffolds significantly enhanced cell survival compared with unfunctionalized scaffolds. However, VEGF peptide functionalization did not show significant enhancement on cell proliferation. Immunostaining images demonstrated that HUVECs could spread, grow and proliferate well, especially maintaining endothelial function on fibrous scaffolds. VEGF peptide functionalized scaffolds enhanced angiogenesis in vivo as shown in a CAM assay. The advantages of VEGF peptide-factionalized fibrous scaffolds, especially including the capacity of photopatterning, make them attractive for vascular tissue engineering. 


\section{Reference}

[1] L.S. Gambino, N.G. Wreford, J.F. Bertram, P. Dockery, F. Lederman, P.A. Rogers, Angiogenesis occurs by vessel elongation in proliferative phase human endometrium, Human Reproduction 17(5) (2002) 1199-1206.

[2] R. Munoz-Chapuli, A. Quesada, M.A. Medina, Angiogenesis and signal transduction in endothelial cells, Cellular and Molecular Life Sciences CMLS 61(17) (2004) 2224-2243.

[3] W. Risau, Mechanisms of angiogenesis, nature 386(6626) (1997) 671.

[4] M.W. Laschke, Y. Harder, M. Amon, I. Martin, J. Farhadi, A. Ring, N. Torio-Padron, R. Schramm, M. Rücker, D. Junker, Angiogenesis in tissue engineering: breathing life into constructed tissue substitutes, Tissue engineering 12(8) (2006) 2093-2104.

[5] M. Lovett, K. Lee, A. Edwards, D.L. Kaplan, Vascularization strategies for tissue engineering, Tissue Engineering Part B: Reviews 15(3) (2009) 353-370.

[6] N. Goonoo, Vascularization and angiogenesis in electrospun tissue engineered constructs: towards the creation of long-term functional networks, Biomedical Physics \& Engineering Express 4(3) (2018) 032001.

[7] J.M. Stenman, J. Rajagopal, T.J. Carroll, M. Ishibashi, J. McMahon, A.P. McMahon, Canonical Wnt signaling regulates organ-specific assembly and differentiation of CNS vasculature, Science 322(5905) (2008) 1247-1250.

[8] D.W. Hutmacher, Scaffolds in tissue engineering bone and cartilage, The Biomaterials: Silver Jubilee Compendium, Elsevier2000, pp. 175-189.

[9] T.P. Richardson, M.C. Peters, A.B. Ennett, D.J. Mooney, Polymeric system for dual growth factor delivery, Nature biotechnology 19(11) (2001) 1029.

[10] L. Coultas, K. Chawengsaksophak, J. Rossant, Endothelial cells and VEGF in vascular development, Nature 438(7070) (2005) 937.

[11] M. Grunewald, I. Avraham, Y. Dor, E. Bachar-Lustig, A. Itin, S. Yung, S. Chimenti, L. Landsman, R. Abramovitch, E. Keshet, VEGF-induced adult neovascularization: recruitment, retention, and role of accessory cells, Cell 124(1) (2006) 175-189.

[12] W.J. Lamoreaux, M.E. Fitzgerald, A. Reiner, K.A. Hasty, S.T. Charles, Vascular endothelial growth factor increases release of gelatinase $A$ and decreases release of tissue inhibitor of metalloproteinases by microvascular endothelial cellsin vitro, Microvascular research 55(1) (1998) 29-42.

[13] A. Sahni, C.W. Francis, Vascular endothelial growth factor binds to fibrinogen and fibrin and stimulates endothelial cell proliferation, Blood 96(12) (2000) 3772-3778.

[14] J. Oswald, S. Boxberger, B. Jørgensen, S. Feldmann, G. Ehninger, M. Bornhäuser, C. Werner, Mesenchymal stem cells can be differentiated into endothelial cells in vitro, Stem cells 22(3) (2004) 377-384.

[15] N. Ferrara, Molecular and biological properties of vascular endothelial growth factor, Journal of molecular medicine 77(7) (1999) 527-543.

[16] P. Chames, M. Van Regenmortel, E. Weiss, D. Baty, Therapeutic antibodies: successes, limitations and hopes for the future, British journal of pharmacology 157(2) (2009) 220-233.

[17] F. Zhou, X. Jia, Y. Yang, Q. Yang, C. Gao, Y. Zhao, Y. Fan, X. Yuan, Peptide-modified PELCL electrospun membranes for regulation of vascular endothelial cells, Materials Science and Engineering: C 68 (2016) 623-631.

[18] L. Cai, C.B. Dinh, S.C. Heilshorn, One-pot synthesis of elastin-like polypeptide hydrogels with grafted VEGF-mimetic peptides, Biomaterials science 2(5) (2014) 757-765.

[19] F. Finetti, A. Basile, D. Capasso, S. Di Gaetano, R. Di Stasi, M. Pascale, C.M. Turco, M. Ziche, L. Morbidelli, L.D. D'Andrea, Functional and pharmacological characterization of a VEGF mimetic peptide on reparative angiogenesis, Biochemical pharmacology 84(3) (2012) 303-311.

[20] J.E. Leslie-Barbick, J.E. Saik, D.J. Gould, M.E. Dickinson, J.L. West, The promotion of microvasculature formation in poly (ethylene glycol) diacrylate hydrogels by an immobilized VEGF-mimetic peptide, Biomaterials 32(25) (2011) 5782-5789.

[21] L.D. D'Andrea, G. Iaccarino, R. Fattorusso, D. Sorriento, C. Carannante, D. Capasso, B. Trimarco, C. Pedone, Targeting angiogenesis: structural characterization and biological properties of a de novo engineered VEGF mimicking peptide, Proceedings of the National Academy of Sciences 102(40) (2005) 14215-14220.

[22] T.R. Chan, P.J. Stahl, S.M. Yu, Matrix-bound vegf mimetic peptides: design and endothelialcell activation in collagen scaffolds, Advanced functional materials 21(22) (2011) 4252-4262.

[23] X. Wang, A. Horii, S. Zhang, Designer functionalized self-assembling peptide nanofiber scaffolds for growth, migration, and tubulogenesis of human umbilical vein endothelial cells, Soft Matter 4(12) (2008) 2388-2395. 
[24] A. Cheng, Z. Schwartz, A. Kahn, X. Li, Z. Shao, M. Sun, Y. Ao, B.D. Boyan, H. Chen, Advances in porous scaffold Design for Bone and Cartilage Tissue Engineering and regeneration, Tissue Engineering Part B: Reviews 25(1) (2019) 14-29.

[25] J.D. Kretlow, A.G. Mikos, From material to tissue: Biomaterial development, scaffold fabrication, and tissue engineering, AIChE Journal 54(12) (2008) 3048-3067.

[26] S. Ramakrishna, K. Fujihara, W.-E. Teo, T. Yong, Z. Ma, R. Ramaseshan, Electrospun nanofibers: solving global issues, Materials today 9(3) (2006) 40-50.

[27] W.J. Li, C.T. Laurencin, E.J. Caterson, R.S. Tuan, F.K. Ko, Electrospun nanofibrous structure: a novel scaffold for tissue engineering, Journal of Biomedical Materials Research: An Official Journal of The Society for Biomaterials, The Japanese Society for Biomaterials, and The Australian Society for Biomaterials and the Korean Society for Biomaterials 60(4) (2002) 613-621.

[28] J. Kucinska-Lipka, I. Gubanska, H. Janik, M. Sienkiewicz, Fabrication of polyurethane and polyurethane based composite fibres by the electrospinning technique for soft tissue engineering of cardiovascular system, Materials Science and Engineering: C 46 (2015) 166-176.

[29] Z.-M. Huang, Y.-Z. Zhang, M. Kotaki, S. Ramakrishna, A review on polymer nanofibers by electrospinning and their applications in nanocomposites, Composites science and technology 63(15) (2003) 2223-2253.

[30] N. Bhardwaj, S.C. Kundu, Electrospinning: a fascinating fiber fabrication technique, Biotechnology advances 28(3) (2010) 325-347.

[31] R. Murugan, S. Ramakrishna, Nano-featured scaffolds for tissue engineering: a review of spinning methodologies, Tissue engineering 12(3) (2006) 435-447.

[32] Q.P. Pham, U. Sharma, A.G. Mikos, Electrospinning of polymeric nanofibers for tissue engineering applications: a review, Tissue engineering 12(5) (2006) 1197-1211.

[33] F. Costa, I.F. Carvalho, R.C. Montelaro, P. Gomes, M.C.L. Martins, Covalent immobilization of antimicrobial peptides (AMPs) onto biomaterial surfaces, Acta biomaterialia 7(4) (2011) 1431 1440 .

[34] S.G. Lévesque, M.S. Shoichet, Synthesis of cell-adhesive dextran hydrogels and macroporous scaffolds, Biomaterials 27(30) (2006) 5277-5285.

[35] S. Xiao, M. Textor, N. D SPENCER, M. Wieland, B. Keller, H. Sigrist, Immobilization of the cell-adhesive peptide Arg-Gly-Asp-Cys (RGDC) on titanium surfaces by covalent chemical attachment, Journal of materials science: Materials in Medicine 8(12) (1997) 867-872.

[36] X. Duan, C. McLaughlin, M. Griffith, H. Sheardown, Biofunctionalization of collagen for improved biological response: scaffolds for corneal tissue engineering, Biomaterials 28(1) (2007) 78-88.

[37] A.S. Sarvestani, X. He, E. Jabbari, Effect of osteonectin-derived peptide on the viscoelasticity of hydrogel/apatite nanocomposite scaffolds, Biopolymers: Original Research on Biomolecules 85(4) (2007) 370-378.

[38] O.I. Kalaoglu-Altan, B. Verbraeken, K. Lava, T.N. Gevrek, R. Sanyal, T. Dargaville, K. De Clerck, R. Hoogenboom, A. Sanyal, Multireactive poly (2-oxazoline) nanofibers through electrospinning with crosslinking on the fly, ACS Macro Letters 5(6) (2016) 676-681.

[39] W.H. Binder, R. Sachsenhofer, 'Click'chemistry in polymer and materials science, Macromolecular Rapid Communications 28(1) (2007) 15-54.

[40] A. Celebioglu, S. Demirci, T. Uyar, Cyclodextrin-grafted electrospun cellulose acetate nanofibers via "Click" reaction for removal of phenanthrene, Applied Surface Science 305 (2014) 581-588.

[41] J.E. Moses, A.D. Moorhouse, The growing applications of click chemistry, Chemical Society Reviews 36(8) (2007) 1249-1262.

[42] A.R. Davis, J.A. Maegerlein, K.R. Carter, Electroluminescent networks via photo "click" chemistry, Journal of the American Chemical Society 133(50) (2011) 20546-20551.

[43] A. Lancuški, S.b. Fort, F.d.r. Bossard, Electrospun azido-PCL nanofibers for enhanced surface functionalization by click chemistry, ACS applied materials \& interfaces 4(12) (2012) 6499-6504. [44] Q. Shi, X. Chen, T. Lu, X. Jing, The immobilization of proteins on biodegradable polymer fibers via click chemistry, Biomaterials 29(8) (2008) 1118-1126.

[45] L.A.S. Callahan, S. Xie, I.A. Barker, J. Zheng, D.H. Reneker, A.P. Dove, M.L. Becker, Directed differentiation and neurite extension of mouse embryonic stem cell on aligned poly (lactide) nanofibers functionalized with YIGSR peptide, Biomaterials 34(36) (2013) 9089-9095.

[46] J. Zheng, K. Liu, D.H. Reneker, M.L. Becker, Post-assembly derivatization of electrospun nanofibers via strain-promoted azide alkyne cycloaddition, Journal of the American Chemical Society 134(41) (2012) 17274-17277.

[47] O.I. Kalaoglu-Altan, R. Sanyal, A. Sanyal, "Clickable" Polymeric Nanofibers through Hydrophilic-Hydrophobic Balance: Fabrication of Robust Biomolecular Immobilization Platforms, Biomacromolecules 16(5) (2015) 1590-1597. 
[48] H. Yang, Q. Zhang, B. Lin, G. Fu, X. Zhang, L. Guo, Thermo-sensitive electrospun fibers prepared by a sequential thiol-ene click chemistry approach, Journal of Polymer Science Part A: Polymer Chemistry 50(20) (2012) 4182-4190.

[49] O.I. Kalaoglu-Altan, R. Sanyal, A. Sanyal, Reactive and 'clickable'electrospun polymeric nanofibers, Polymer Chemistry 6(18) (2015) 3372-3381.

[50] L. Cai, S. Wang, Poly ( $\varepsilon$-caprolactone) acrylates synthesized using a facile method for fabricating networks to achieve controllable physicochemical properties and tunable cell responses, Polymer 51(1) (2010) 164-177.

[51] Y.-L. Cheng, F. Chen, Preparation and characterization of photocured poly ( $\varepsilon$-caprolactone) diacrylate/poly (ethylene glycol) diacrylate/chitosan for photopolymerization-type 3D printing tissue engineering scaffold application, Materials Science and Engineering: C 81 (2017) 66-73.

[52] H. Kweon, M.K. Yoo, I.K. Park, T.H. Kim, H.C. Lee, H.-S. Lee, J.-S. Oh, T. Akaike, C.-S. Cho, A novel degradable polycaprolactone networks for tissue engineering, Biomaterials 24(5) (2003) 801-808.

[53] J. Tao, S. Shivkumar, Molecular weight dependent structural regimes during the electrospinning of PVA, Materials letters 61(11-12) (2007) 2325-2328.

[54] M.J. Webber, J. Tongers, C.J. Newcomb, K.-T. Marquardt, J. Bauersachs, D.W. Losordo, S.I. Stupp, Supramolecular nanostructures that mimic VEGF as a strategy for ischemic tissue repair, Proceedings of the National Academy of Sciences 108(33) (2011) 13438-13443. 


\section{Supplementary Information}

Table S1. Electrospinning parameters of different PCL-DA fibers: 10\%PCL-DA, 30\%PCL-DA and $50 \%$ PCL-DA.

\begin{tabular}{l|c|cc|crr}
$\begin{array}{l}\text { Electrospun } \\
\text { fibers }\end{array}$ & $\begin{array}{l}\text { Total PCL } \\
\text { (wt\%) }\end{array}$ & PCL-80k: & $\begin{array}{l}\text { PCL-DA- } \\
\mathbf{2 k}\end{array}$ & $\begin{array}{l}\text { Voltage } \\
\mathbf{( k V )}\end{array}$ & $\begin{array}{l}\text { Flow rate } \\
\text { (mL/h) }\end{array}$ & $\begin{array}{l}\text { Working } \\
\text { Distance } \\
\text { (cm) }\end{array}$ \\
\hline $10 \%$ PCL-DA & 20 & 90 & 10 & 20 & 1 & 20 \\
$30 \% P C L-D A$ & 20 & 70 & 30 & 20 & 1 & 20 \\
$50 \% P C L-D A$ & 20 & 50 & 50 & 20 & 1 & 20
\end{tabular}

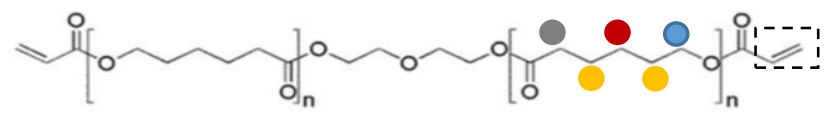

PCL-DA

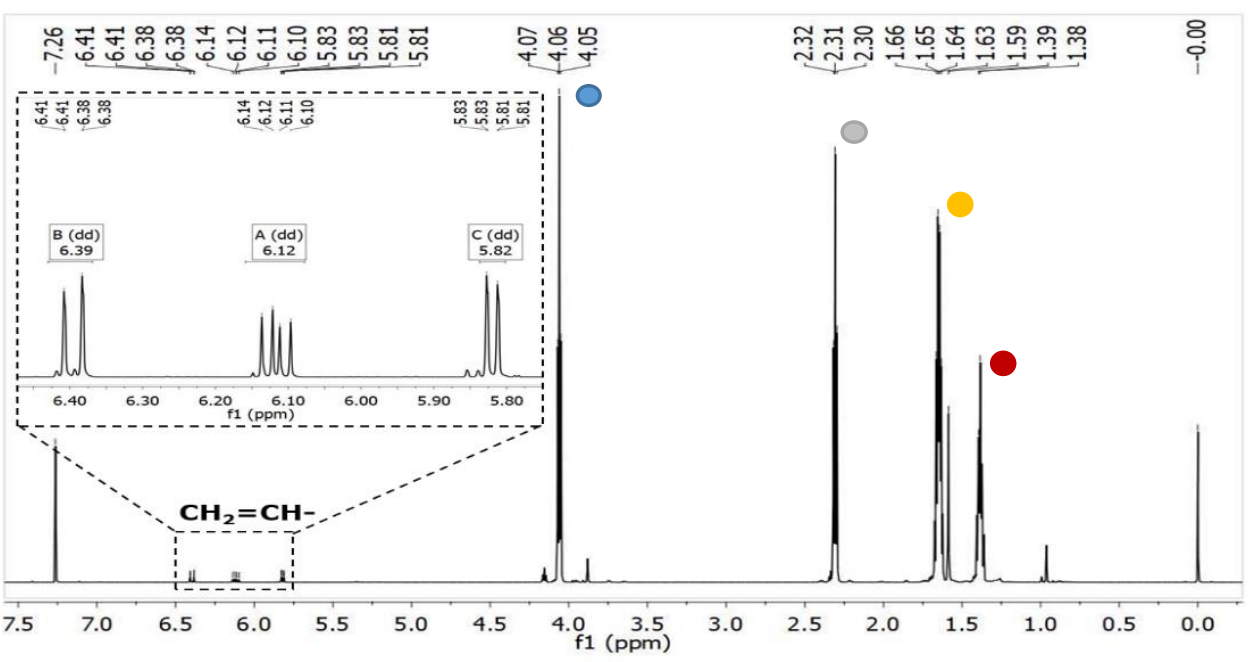

Figure S1. ${ }^{1} \mathrm{H}$ NMR $(700 \mathrm{MHz})$ spectrum of PCL-diacrylates (PCL-DA) in $\mathrm{CDCl}_{3}$. 
a)
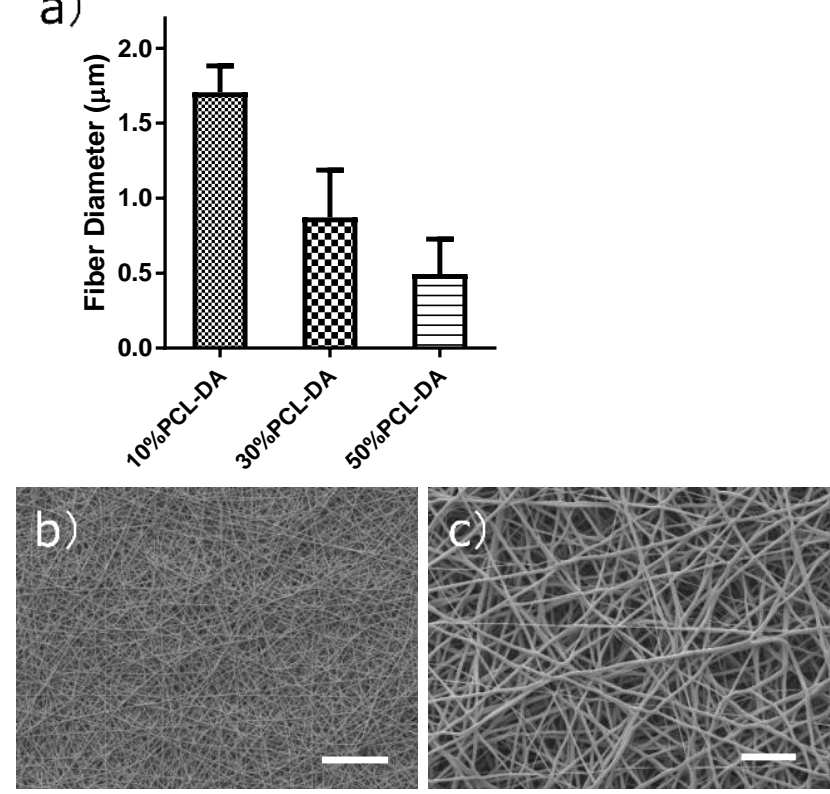

Figure S2. (a) Fiber diameters of $10 \%, 30 \%$ and $50 \%$ PCL-DA electrospun scaffolds. SEM images ( $b$ and $c$ ) of $30 \%$ PCL-DA fibers after click conjugation with 7-Mercapto-4-methylcoumarin. Scale bars are $100 \mu \mathrm{m}$ (b) and $20 \mu \mathrm{m}$ (c).
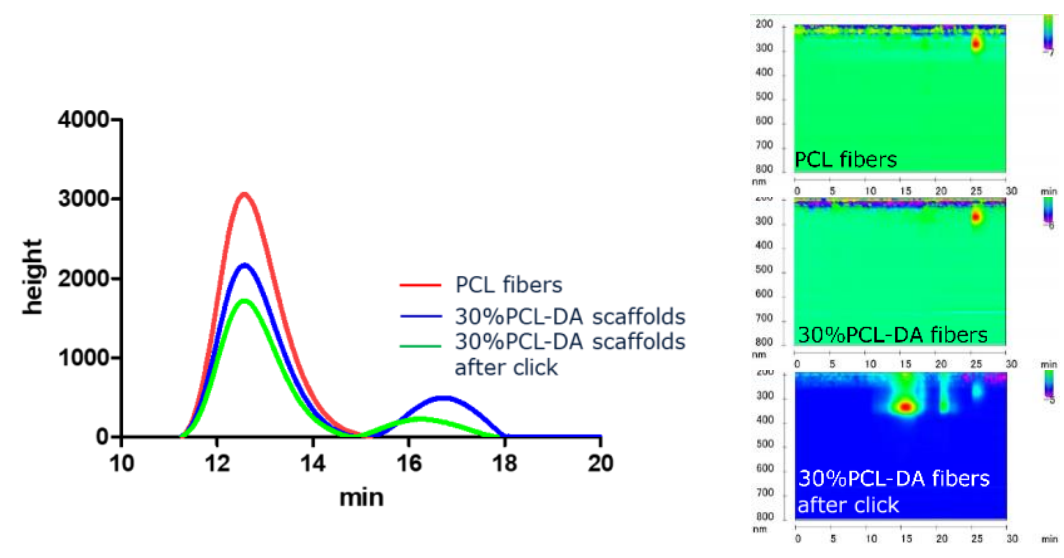

Figure S3. GPC trace of PCL, 30\%PCL-DA electrpspun fibers and 30\%PCL-DA fibers after bonding with 7-Mercapto-4-methylcoumarin. 
a)

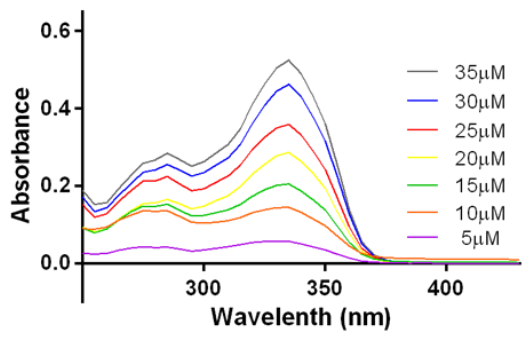

b) Standard curve $(335 \mathrm{~nm})$

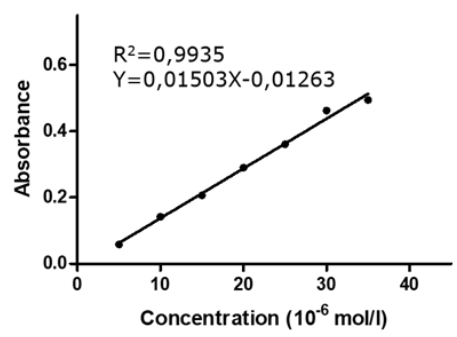

Figure S4. (a) UV-Visible spectra and (b) calibration curve as a correlation between absorbance to concentration of 7-Mercapto-4-methylcoumarin, dissolved in 1 $\mathrm{ml} \mathrm{1,} \mathrm{4-dioxane} \mathrm{and} \mathrm{absorbance}$ at $335 \mathrm{~nm}$.
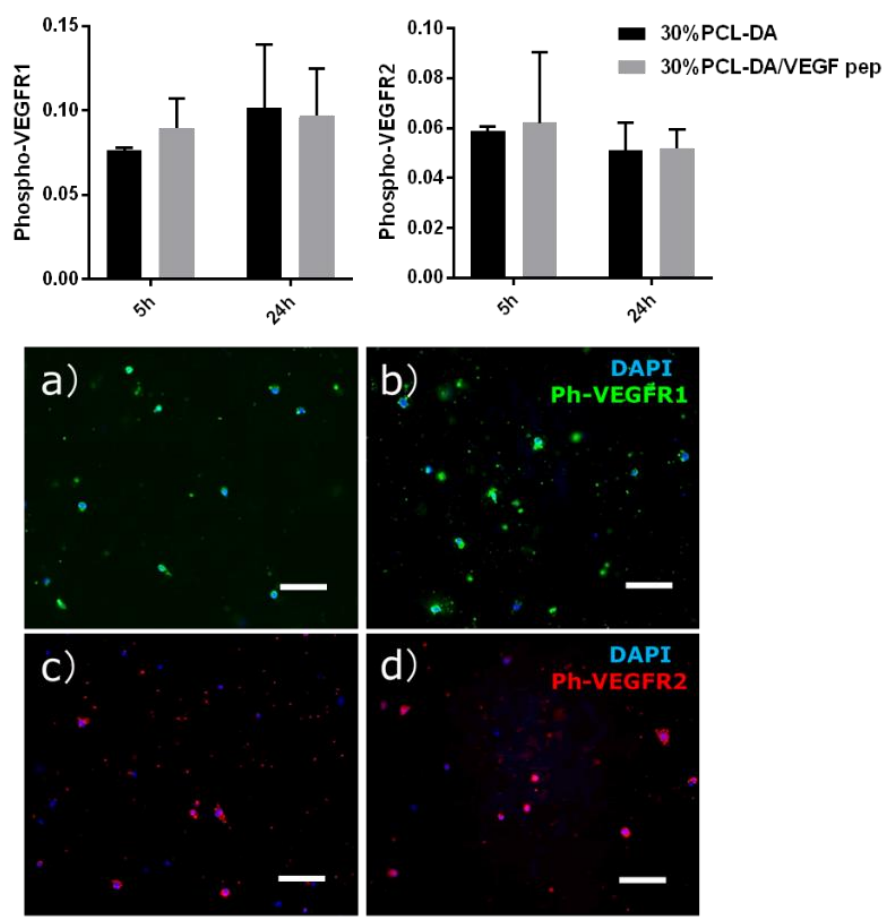

Figure S5. ELISA assay showing that HUVECs cultured on 30\%PCL-DA and 30\%PCL-DA/VEGF pep fibrous scaffolds induced VEGFR1 and VEGFR2 phosphorylation after 5 hours and 24 hours. Fluorescence images stained for Phospho-VEGF Receptor 1/2 and nuclei (DAPI: blue) of HUVECs on 30\%PCL-DB (a, c) and 30\%PCL-DB/VEGF pep scaffolds (b, d) after 1 days culture (scale bar: $100 \mu \mathrm{m}$ ). 
a)

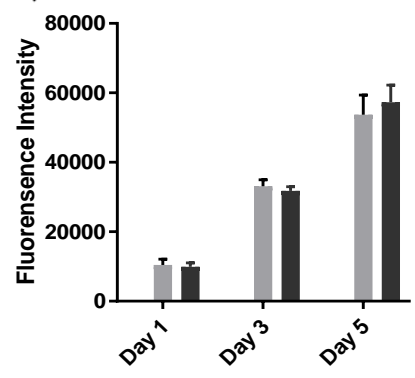

b)

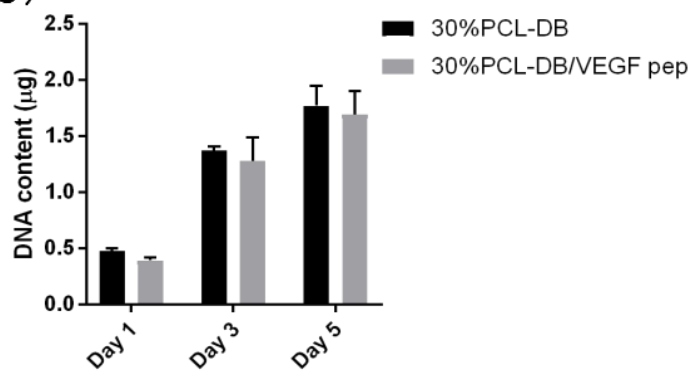

Figure S6. The viability (a) and proliferation (b) of HUVECs on 30\%PCL-DA and 30\%PCLDA/VEGF pep fibrous scaffolds in EGM medium without VEGF during 5 days of culture. 


\section{Chapter 7}

\section{General Discussion}


Scaffolds for tissue engineering have become more and more important in regenerative medicine, which is crucial for the development of advanced clinical therapy for those critical tissue damages that do not heal correctly by themselves. The key factors for tissue engineering include cells, biological factors and scaffolds, which are used alone or in combination to promote and guide cell proliferation and differentiation, and consequently tissue regeneration. In recent years, many researches have focused on the development of novel combinatorial approaches to design bioactive scaffolds for tissue regeneration. An ideal scaffold should not only provide an appropriate physical environment, which mimics the mechanical and structural properties of the target tissue, but also provide growth factor or other bioactive molecules to guide cellular behavior. To reach these goals, electrospinning is often used, since it is a simple and promising technique for the fabrication of biomimetic scaffolds that are capable of mimicking the physical properties and structure of natural extracellular matrix (ECM). The properties of electrospun nanofiber scaffolds, especially topographical features, can be easily controlled by adjusting electrospinning parameters. In chapter 2-4, we designed fibrous scaffolds with aligned and honeycomb patterns to investigate their effect on endothelial cell activity and organization. In addition, as electrospun fibrous scaffolds functionalized with bioactive components have been widely used to promote cell repair and tissue regeneration, in chapter 5-6 we functionalized fibrous scaffolds with VEGF peptide and N-thiocarboxyanhydride (NTA). We then investigated the effect of functionalized scaffolds on endothelial cells behavior. Overall, the aim of this thesis was to design different fabrication strategies to improve the instructiveness of scaffolds based on physical or chemical modifications, which could be used to enhance angiogenesis and tissue vascularization.

\section{Changing structure features of electrospun fibrous scaffolds}

In the bone matrix, collagen fibers are arranged in a specific direction (parallel to the direction of bone); their parallel-arranged structures are important to 
provide strength in tension and resistance in bending [1-3]. Many researchers attempted to mimic the parallel-orientation of collagen fibers by using aligned nanofibers [4, 5]. It was already reported that fiber alignment promotes osteogenic differentiation and upregulates the expression of osteogenic genes [4]. Moreover, calcium deposition was significantly higher on aligned nanofibers compared to that on random fibers [6]. These parallel nanofibrous scaffolds showed to support bone regeneration. However, the lack of vascularization in scaffolds is still a primary challenge to support long-term functions of the regenerated bone [7, 8]. Vascularization is a critical process during bone regeneration. The shortage of vascular formation results in insufficient supply of oxygen and nutrition, which reduce the survival of the tissue-engineered bone. One strategy for improving the survival and osteogenesis of tissue-engineered bone involves the co-culture of endothelial cells (ECs) with mesenchymal stromal cells (MSCs). In chapter 2, we fabricated polycaprolactone (PCL) electrospun fibers with aligned and random morphology, co-cultured human MSCs with human umbilical ECs (HUVECs), and finally investigated how these two factors modulate the osteogenic differentiation of hMSCs. After optimizing cell ratio, a hMSCs/HUVECs 90:10 ratio was considered to be the best combination for osteogenic differentiation. Co-culture results showed that the alignment of fibrous scaffolds strongly influenced the morphology and orientation of hMSCs and HUVECs; however, fiber alignment was observed to not affect alkaline phosphate activity (ALP) or mineralization of hMSCs compared to random scaffolds. More importantly, co-cultured cells on both random and aligned scaffolds had significantly higher ALP activities than monoculture groups, which indicated co-culture with HUVECs provided a larger relative contribution to the osteogenesis of hMSCs compared to fiber alignment. Previous studies only investigated the effect of aligned topography of nanofibers on hMSCs osteogenic differentiation. For example, MSCs on the aligned microfibers exhibited relatively higher expression of osteogenic makers (osteocalcin, runx2, osteopontin and osteonectin) compared to that on random fiber [9]. Aligned electrospun fibers 
provide geometrical cues, which promoted calcium deposition of MSCs compared to random fibers[6]. Another study however reported that fiber alignment guided the orientation of adherent cells, but did not influence osteogenic differentiation of hMSCs [10]. Adding the co-culture of HUVECs, our results are consistent with observations that the alignment of fibers only guide the orientation of tissue, but do not significantly affect osteogenic differentiation. Bone regeneration is a complex process, which requires highly vascularized bone tissues and distinctive aligned features. However, there is no study to look into how these two factors (co-culture with HUVECs and fiber alignment) modulate the osteogenic differentiation of hMSCs at same time. Our results successfully showed the ability to grow oriented tissue engineered co-cultures with significant increases in osteogenesis over monoculture conditions.

Interface tissues display unique gradients in organization, which gradually vary from one side to another $[11,12]$. Structural gradients can be found mainly in interface tissues [13,14], such as bone-cartilage interfaces [15], dentino-enamel junctions [16], tendon-bone [17] and ligament-bone tissues [18]. Gradient scaffolds have been developed and applied to mimic complex gradients found in native tissues [19, 20]. Gradient scaffolds could provide cues similar to the native environment and may guide stem cells to migrate [21] or differentiate toward the targeted tissue to be regenerated [13, 17, 22]. Most of the conventional scaffolds reported in tissue engineering have uniform composition and pore sizes, which lack the structural complexity to regenerate specific tissue [12]. Gradient scaffolds are generally more difficult to fabricate than uniform or homogenous biomaterials [23]. Some studies have investigated the fabrication of uniform honeycomb fibrous meshes by electrospinning [24], yet honeycomb fibrous meshes with gradients in pore sizes have not been reported. Many researchers created electrospun honeycomb meshes by using templates. In a previous study, Zhang et al. reported the fabrication of electrospun mats with controllable architectures and patterns by using electroconductive templates [25]. Electrospun 
nanofibers could be organized into honeycomb-like pattern, which is strictly controlled by the honeycomb collectors. Another study demonstrated that the generation of nanofibrous patterns by self-deposition of electrospun nanofibers onto a honeycomb pattern was possible [26]. This phenomenon is attributed to large electrical fields, which produce more electrostatic repulsion and drive fiber clusters to form the honeycomb pattern. All these studies used for selective deposition only produced a well-formed honeycomb pattern with different size. Honeycomb fibrous meshes with gradients in pore sizes have not been fabricated. In chapter $\mathbf{3}$, we show a simple, versatile and effective approach to generate gradient honeycomb patterns in nanofibrous meshes. Using this self-assembly approach, we can readily fabricate nanofibrous meshes with gradient honeycomb patterns, which have never been previously reported. Different honeycomb patterns were successfully fabricated by controlling the electrospinning conditions. The working distance was found to be the most important factor for the formation of gradient honeycomb structures. At a smaller working distance of $12 \mathrm{~cm}$, gradients honeycomb patterns were successfully fabricated in nanofibrous scaffolds. The decrease of working distance largely leads to increase the electrostatic force, consequently generating gradients in electric field. After the gradient in electric field formed on the collecting plate, we found that the honeycomb size varied radially with the largest pores in the central area and the smaller pores at the boundary of the collected meshes. The pore diameter of the obtained gradient honeycomb structures spanned a range from $800 \mu \mathrm{m}$ to $300 \mu \mathrm{m}$. The average depth of gradient honeycombs was $123 \pm 56 \mu \mathrm{m}$. Our approach fabricating honeycomb nanofibrous meshes with controllable diameter and 3D structure should be adaptable for tissue regeneration. Their gradient porosity makes them particularly attractive for the regeneration of interface tissue.

Blood vessels are generated by two consecutive processes, vasculogenesis and angiogenesis [27]. It is reported that fusion of blood-islands leads to the vasculogenesis of honeycomb-shaped primary capillaries [28]. During angiogenesis, endothelial cells can form honeycomb-like network that 
simulate tube formation $[29,30]$. The presence of a honeycomb-like vascular structure indicates that vasculogenesis and the initial steps of angiogenesis proceeded normally [31]. Therefore, honeycomb network of ECs is a very important morphogenetic step in vascular development and can be used to indicate both vasculogenesis and angiogenesis. Previous studies have shown that ECs assemble into tube-like morphology, which was regulated by the geometrical distribution of materials [32, 33]. Although those studies have proved the effect of geometrical control on ECs tubular formation [32-36], these works were only performed on micropatterned stripes substrates to guide single tube formation without interconnection between each tubes, and often introduced biological factors (growth factor or peptide) on the surface of substrates. Inspired by the capillary network formation of ECs, in chapter 4 we show a simple, versatile and effective self-assembly approach to generate honeycomb patterns in nanofibrous scaffolds. We successfully fabricated nanofibrous scaffolds with honeycomb structures by this approach and then investigated cell behavior on the scaffolds. Our results showed that honeycomb nanofibrous scaffolds promoted cell proliferation and regulate HUVECs morphogenesis into capillary-like structures. Honeycomb pattern is an additional topography to electrospun nanofibrous meshes, which could afford specific cues for endothelial cells. The addition of micro-/nanotextured topographies to materials could effectively activate angiogenic signaling pathways, which are crucial in the process of endothelial angiogenesis [37, 38]. The results obtained in the present investigation, therefore, supported that the geometries of the honeycomb patterns might also activate angiogenic signaling pathways in HUVECs in response to geometric cues, thus helping in the formation of capillary networks. The guided organization via honeycomb nanofibrous scaffolds could be utilized for tissue engineering that demand the formation of capillary networks.

\section{Chemical functionalization of electrospun fibrous scaffolds}

Hydrogen sulfide $\left(\mathrm{H}_{2} \mathrm{~S}\right)$, a unique gasotransmitter, has been considered as a significant physiological and pathological signaling gas, which can promote 
and modulate angiogenesis [39, 40]. Sulfide salts, such as sodium hydrosulfide $(\mathrm{NaSH})$ and sodium sulfide $\left(\mathrm{Na}_{2} \mathrm{~S}\right)$, are the most widely used class of $\mathrm{H}_{2} \mathrm{~S}$ donors in biological studies [41-43]. Normally, angiogenesis is a process that last for more than few hours or days; however, sulfide salts only result in the burst release of $\mathrm{H}_{2} \mathrm{~S}$ and could not produce $\mathrm{H}_{2} \mathrm{~S}$ in a slow and continuous way like in vivo [44-46]. The group of Matson reported the use of $\mathrm{N}$-thiocarboxyanhydrides (NTAs) as Carbonyl sulfide (COS) $/ \mathrm{H}_{2} \mathrm{~S}$ donor [47]. NTAs release COS in the presence of primary amines and the ubiquitous enzyme carbonic anhydrase (CA) catalyzes the hydrolysis of the released COS into $\mathrm{H}_{2} \mathrm{~S}$, resulting in a certain degree of controlled release. Such an approach could be appealing when combined with surface functionalization, so to modulate the release of $\mathrm{H}_{2} \mathrm{~S}$ in time, compared to other conventional $\mathrm{H}_{2} \mathrm{~S}$ donors approaches present in literature [48-50]. In chapter 5, we prepared electrospun PCL-N $\mathrm{N}_{3}$-incorporated PCL fibrous scaffolds to form clickable scaffolds and then bond alkyne-NTA on scaffolds by azide-alkyne click conjugation. To evaluate cell compatibility, adhesion, spreading and proliferation, human umbilical vein endothelial cells (HUVECs) were cultured on different NTA-functionalized scaffolds, as well as on non-functionalized scaffolds for comparison. The $5 \% \mathrm{PCL}-\mathrm{N}_{3} / \mathrm{NTA}$ and $10 \% \mathrm{PCL}-\mathrm{N}_{3} / \mathrm{NTA}$ fibrous scaffolds were observed to better support cell proliferation and form confluent endothelial monolayer. Moreover, VE-Cadherin staining demonstrated that firm intercellular junctions were formed on $5 \% \mathrm{PCL}-\mathrm{N}_{3} / \mathrm{NTA}$ and $10 \% \mathrm{PCL}-$ $\mathrm{N}_{3} /$ NTA fibrous scaffolds, which would be beneficial for generating a stabilized confluent endothelial monolayer and the integrity of the endothelium. A chicken chorioallantoic membrane (CAM) assay on NTA-functionalized scaffolds showed an increase in vascular growth in vivo. Therefore, we conclude that our NTA-functionalized scaffolds could be potentially used to promote angiogenesis in tissue engineering. NTA as an $\mathrm{H}_{2} \mathrm{~S}$ donor could continuously release $\mathrm{H}_{2} \mathrm{~S}$ under biologically relevant conditions with innocuous peptide byproducts. In pervious literature, the slow release of $\mathrm{H}_{2} \mathrm{~S}$ from NTA was verified [51]. Cell studies were subsequently performed by 
adding NTA in cell culture medium. BrdU staining showed NTA at $100 \mu \mathrm{M}$ significantly increased endothelial cell proliferation. This result is similar to our Ki67 staining observations. The positive effect of $\mathrm{H}_{2} \mathrm{~S}$ on endothelial cell proliferation was also reported by Papapetropoulos et al. [52]. They also investigated the possibility of $\mathrm{H}_{2} \mathrm{~S}$ to promote angiogenesis in vivo. CAM results showed that $\mathrm{H}_{2} \mathrm{~S}$ increased the length of the blood vessels in a dosedependent manner. They hypothesized that $\mathrm{H}_{2} \mathrm{~S}$ stimulate endothelial cells through KATP channels that in turn induce the activation of MAPK pathways, finally resulting in new vessel formation.

After having investigated the effect of gaseotransmitter on angiogenesis, we also looked into the effect of vascular endothelial growth factor (VEGF) as an endogenous angiogenic agent. VEGF has been widely reported to be the most potential angiogenic promoter [53], stimulating EC recruitment [54], proliferation [55, 56], and differentiation [57], and the formation of blood vessels [58]. VEGF peptides are more promising, because they can be easily conjugated or immobilized to surface and scaffolds for tissue engineering. A VEGF-mimetic peptide, QK (domain: KLTWQELYQLKYKGI), mimicking the helix region 17-25 of VEGF, showed the ability to activate VEGF receptors and similar bioactivity of VEGF. QK peptides provided many advantages, including their small size, possibility to use in chemical reactions, low immunogenic potential, and cost-effectiveness of their synthesis [59-63]. This peptide promoted the attachment and proliferation of ECs, and most importantly, induced capillary network formation [60, 64]. In chapter 6, we used thiol-ene click chemistry for the conjugation of the QK VEGF-mimetic peptide to the surface of PCL fibrous scaffolds. PCL $(\mathrm{Mn} \approx 80 \mathrm{~K})$ and PCLdiacrylates (PCL-DA) with lower molecular weight $(\mathrm{Mn} \approx 2 \mathrm{~K})$ were mixed together for electrospinning. The VEGF peptide was then immobilized on PCL-DA fibrous scaffolds by thiol-ene click chemistry. 7-Mercapto-4methylcoumarin was used to validate thiol-ene click reaction with fibrous scaffolds. Fluorescence labeling of PCL-DA scaffolds after the click reaction indicated the success of the surface coupling. In particular, patterned 
structures were clearly observed after using a photomask on the fibrous film, thus showing also the potential of this method to control spatially the presentation of the VEGF-mimetic cues. Moreover, in vitro studies indicated that the VEGF peptide was on PCL fibrous scaffolds and affected cell survival over 5 days. Scaffolds functionalized with VEGF peptide were able to maintain higher HUVECs survival compared with unfunctionalized scaffolds in nutrient deprivation conditions. The effect of VEGF peptide on HUVECs survival was also reported by Webber et al. [65]. In the presence of VEGF peptide, serumstarved HUVECs showed higher cell survival (23\% death) compared to the control group (31.7\% death). There are two studies, which have immobilized same sequence of VEGF peptide as we used on our scaffolds. Parthiban et al. covalently bonded a very similar VEGF peptide on gelatin methacrylate (GeIMA) and cultured HUVECs as a cell model to test the effect on vascularization [66]. Results demonstrated that VEGF peptide functionalized GelMA upregulated vascular maker genes (KDR, CD34, Ang2, and vWF), leading to promote vascularization. Another study immobilized the same VEGF peptide on collagen-gelatin substrates as angiogenic scaffolds for endothelial cells [67]. HUVECs organized capillary network on VEGF peptide immobilized substrates, while cells only maintained their cobblestone-like morphology on control substrates. The VEGF peptide used in this study proved to support network formation of HUVECs, which is promising for angiogenesis. Moreover, HUVECs cultured on both scaffolds could activate VEGFR1 and VEGFR2 phosphorylation. CAM assay indicated that the VEGF peptide functionalized scaffolds promoted the growth of blood vessels in vivo.

\section{Future perspective}

Electrospun scaffolds were widely used in tissue engineering and regenerative medicine due to their ability to mimic the extra cellular matrix (ECM) of living tissues. However, there are still some drawbacks remaining for electrospun scaffolds. First, most of tissue regeneration, such as, bone, muscle and cartilage, necessitate 3D scaffolds, but nanofibrous scaffolds with 
high thickness are difficult to obtain by electrospinning. Second, it is hard to drive nanofibers to form highly ordered pattern due to electrostatic repulsion between nanofibers during electrospinning. Electrospinning normally produces $2 \mathrm{D}$ random nanofibrous scaffolds with high porosity in the height of few microns. In our work, honeycomb scaffolds were fabricated with higher depth reaching to $130 \mu \mathrm{m}$, which is still at the microscale range. Therefore, there is high demand to explore more microfabrication approaches combined with electrospinning to increase the thickness of nanofibrous scaffolds. Combining electrospinning with melt electrospinning or additive manufacturing might be a possible approach to generate electrospun fibers with higher thickness. 3D filaments could act as a template layer, which increase the depth of nanofibrous meshes and also create high porosity. Porous nanofibrous scaffolds with higher depth provide a common and versatile $3 \mathrm{D}$ environment for cell migration and infiltration, which could be an important progress in the field of electrospun scaffolds for tissue regeneration applications.

Except ECM mimicking, the high surface area of the electrospun scaffolds is favorable for bioactive molecules loading and releasing. In chapter 6, we developed a novel approach to do photopatterning on electrospinning PCL fibrous scaffolds. This approach is validated by simple, proof-of-concept experiments by using different photomasks. In the future, it could be possible to partially functionalize nanofibrous scaffolds with peptides or other bioactive molecules by this approach, thus creating biological patterns within a 3D scaffold. After spatial functionalization, nanofibrous substrates could become partial bonded with bioactive components and then have a more direct effect to guide cell behavior. For example, we could partially bond some cell adhesion factors on nanofibrous mesh to form stripe pattern functionalized scaffolds, then control cell distribution on this functionalized scaffolds, finally may be used for guiding tube formation. Moreover, other bioactive components, such as growth factors, peptides, drugs, enzymes and DNAs, could be functionalized on the scaffolds. This photopatterning approach is 
active and interesting; it is expected to be a promising platform for vascularized tissue engineering applications. After functional vascular network is sufficient, hMSCs could be introduced to regenerate complex organs such as bone.

This thesis only designed different improved scaffolds based on physical or chemical modifications to enhance angiogenesis and the vascularization of tissues. However, we haven't combined two modifications together. In the future, a combination of physical and chemical modifications, such as combining honeycomb patterns with functionalization of a VEGF mimetic peptide on nanofibrous scaffolds, may have a synergistic impact in directing cell organization towards tissues engineering of functional vascular networks. 


\section{References}

[1] G.E. Fantner, H. Birkedal, J.H. Kindt, T. Hassenkam, J.C. Weaver, J.A. Cutroni, B.L. Bosma, L. Bawazer, M.M. Finch, G.A. Cidade, Influence of the degradation of the organic matrix on the microscopic fracture behavior of trabecular bone, Bone 35(5) (2004) 1013-1022.

[2] J. Ramasamy, O. Akkus, Local variations in the micromechanical properties of mouse femur: the involvement of collagen fiber orientation and mineralization, Journal of biomechanics $40(4)$ (2007) 910-918.

[3] M.C. Summitt, K.D. Reisinger, Characterization of the mechanical properties of demineralized bone, Journal of Biomedical Materials Research Part A: An Official Journal of The Society for Biomaterials, The Japanese Society for Biomaterials, and The Australian Society for Biomaterials and the Korean Society for Biomaterials 67(3) (2003) 742-750.

[4] Z. Guo, J. Xu, S. Ding, H. Li, C. Zhou, L. Li, In vitro evaluation of random and aligned polycaprolactone/gelatin fibers via electrospinning for bone tissue engineering, Journal of Biomaterials Science, Polymer Edition 26(15) (2015) 989-1001.

[5] J. Xie, X. Li, J. Lipner, C.N. Manning, A.G. Schwartz, S. Thomopoulos, Y. Xia, "Aligned-torandom" nanofiber scaffolds for mimicking the structure of the tendon-to-bone insertion site, Nanoscale 2(6) (2010) 923-926.

[6] J. Ma, X. He, E. Jabbari, Osteogenic differentiation of marrow stromal cells on random and aligned electrospun poly (L-lactide) nanofibers, Annals of biomedical engineering 39(1) (2011) 14-25.

[7] Y. Naito, T. Shinoka, D. Duncan, N. Hibino, D. Solomon, M. Cleary, A. Rathore, C. Fein, S. Church, C. Breuer, Vascular tissue engineering: towards the next generation vascular grafts, Advanced drug delivery reviews 63(4-5) (2011) 312-323.

[8] Y. Liu, J.K. Chan, S.H. Teoh, Review of vascularised bone tissue-engineering strategies with a focus on co-culture systems, Journal of tissue engineering and regenerative medicine $9(2)$ (2015) 85-105.

[9] Y. Wang, R. Gao, P.-P. Wang, J. Jian, X.-L. Jiang, C. Yan, X. Lin, L. Wu, G.-Q. Chen, Q. Wu, The differential effects of aligned electrospun $\mathrm{PHBHHx}$ fibers on adipogenic and osteogenic potential of MSCs through the regulation of PPARY signaling, Biomaterials 33(2) (2012) 485-493. [10] S.K. Madhurakkat Perikamana, J. Lee, T. Ahmad, Y. Jeong, D.-G. Kim, K. Kim, H. Shin, Effects of immobilized BMP-2 and nanofiber morphology on in vitro osteogenic differentiation of hMSCs and in vivo collagen assembly of regenerated bone, ACS applied materials \& interfaces 7(16) (2015) 8798-8808.

[11] J. Guo, C. Li, S. Ling, W. Huang, Y. Chen, D.L. Kaplan, Multiscale design and synthesis of biomimetic gradient protein/biosilica composites for interfacial tissue engineering, Biomaterials 145 (2017) 44-55.

[12] A. Seidi, M. Ramalingam, I. Elloumi-Hannachi, S. Ostrovidov, A. Khademhosseini, Gradient biomaterials for soft-to-hard interface tissue engineering, Acta biomaterialia 7(4) (2011) 14411451.

[13] A. Di Luca, B. Ostrowska, I. Lorenzo-Moldero, A. Lepedda, W. Swieszkowski, C. Van Blitterswijk, L. Moroni, Gradients in pore size enhance the osteogenic differentiation of human mesenchymal stromal cells in three-dimensional scaffolds, Scientific reports 6 (2016) 22898.

[14] S. Sant, M.J. Hancock, J.P. Donnelly, D. Iyer, A. Khademhosseini, Biomimetic gradient hydrogels for tissue engineering, The Canadian journal of chemical engineering $88(6)(2010)$ 899-911.

[15] A. Miserez, T. Schneberk, C. Sun, F.W. Zok, J.H. Waite, The transition from stiff to compliant materials in squid beaks, Science 319(5871) (2008) 1816-1819.

[16] P.J. Yang, J.S. Temenoff, Engineering orthopedic tissue interfaces, Tissue Engineering Part B: Reviews 15(2) (2009) 127-141.

[17] R.I. Sharma, J.G. Snedeker, Biochemical and biomechanical gradients for directed bone marrow stromal cell differentiation toward tendon and bone, Biomaterials 31(30) (2010) 76957704.

[18] L. Lohmander, A. Östenberg, M. Englund, H. Roos, High prevalence of knee osteoarthritis, pain, and functional limitations in female soccer players twelve years after anterior cruciate ligament injury, Arthritis \& Rheumatism: Official Journal of the American College of Rheumatology 50(10) (2004) 3145-3152.

[19] H. Liu, L. Yang, E. Zhang, R. Zhang, D. Cai, S. Zhu, J. Ran, V. Bunpetch, Y. Cai, B.C. Heng, Biomimetic tendon extracellular matrix composite gradient scaffold enhances ligament-to-bone junction reconstruction, Acta biomaterialia 56 (2017) 129-140. 
[20] L. Diaz-Gomez, B.T. Smith, P.D. Kontoyiannis, S.M. Bittner, A.J. Melchiorri, A.G. Mikos, Multimaterial segmented fiber printing for gradient tissue engineering, Tissue Engineering Part C: Methods (2018).

[21] J. Wu, Z. Mao, H. Tan, L. Han, T. Ren, C. Gao, Gradient biomaterials and their influences on cell migration, Interface focus 2(3) (2012) 337-355.

[22] P.Y. Wang, L.R. Clements, H. Thissen, A. Jane, W.B. Tsai, N.H. Voelcker, Screening mesenchymal stem cell attachment and differentiation on porous silicon gradients, Advanced Functional Materials 22(16) (2012) 3414-3423.

[23] X. Miao, D. Sun, Graded/gradient porous biomaterials, Materials 3(1) (2009) 26-47.

[24] G. Yan, J. Yu, Y. Qiu, X. Yi, J. Lu, X. Zhou, X. Bai, Self-assembly of electrospun polymer nanofibers: a general phenomenon generating honeycomb-patterned nanofibrous structures, Langmuir : the ACS journal of surfaces and colloids 27(8) (2011) 4285-9.

[25] D. Zhang, J. Chang, Patterning of electrospun fibers using electroconductive templates, Advanced Materials 19(21) (2007) 3664-3667.

[26] G. Yan, J. Yu, Y. Qiu, X. Yi, J. Lu, X. Zhou, X. Bai, Self-assembly of electrospun polymer nanofibers: A general phenomenon generating honeycomb-patterned nanofibrous structures, Langmuir 27(8) (2011) 4285-4289.

[27] R. Demir, Y. Seval, B. Huppertz, Vasculogenesis and angiogenesis in the early human placenta, Acta histochemica 109(4) (2007) 257-265.

[28] R.H. Adams, K. Alitalo, Molecular regulation of angiogenesis and lymphangiogenesis, Nature reviews Molecular cell biology 8(6) (2007) 464.

[29] D. Nagata, M. Mogi, K. Walsh, AMP-activated protein kinase (AMPK) signaling in endothelial cells is essential for angiogenesis in response to hypoxic stress, Journal of Biological Chemistry 278(33) (2003) 31000-31006.

[30] H.-J. Park, Y. Zhang, S.P. Georgescu, K.L. Johnson, D. Kong, J.B. Galper, Human umbilical vein endothelial cells and human dermal microvascular endothelial cells offer new insights into the relationship between lipid metabolism and angiogenesis, Stem cell reviews 2(2) (2006) 93101.

[31] W.J. Yang, D.D. Yang, S. Na, G.E. Sandusky, Q. Zhang, G. Zhao, Dicer is required for embryonic angiogenesis during mouse development, Journal of Biological Chemistry 280(10) (2005) 9330-9335.

[32] L.E. Dike, C.S. Chen, M. Mrksich, J. Tien, G.M. Whitesides, D.E. Ingber, Geometric control of switching between growth, apoptosis, and differentiation during angiogenesis using micropatterned substrates, In Vitro Cellular \& Developmental Biology-Animal 35(8) (1999) 441448.

[33] J.J. Moon, M.S. Hahn, I. Kim, B.A. Nsiah, J.L. West, Micropatterning of poly (ethylene glycol) diacrylate hydrogels with biomolecules to regulate and guide endothelial morphogenesis, Tissue Engineering Part A 15(3) (2008) 579-585.

[34] Y. Lei, O.F. Zouani, M. Rémy, C. Ayela, M.-C. Durrieu, Geometrical microfeature cues for directing tubulogenesis of endothelial cells, PloS one 7(7) (2012) e41163.

[35] J.E. Leslie-Barbick, C. Shen, C. Chen, J.L. West, Micron-scale spatially patterned, covalently immobilized vascular endothelial growth factor on hydrogels accelerates endothelial tubulogenesis and increases cellular angiogenic responses, Tissue Engineering Part A 17(1-2) (2010) 221-229.

[36] M. Nikkhah, N. Eshak, P. Zorlutuna, N. Annabi, M. Castello, K. Kim, A. Dolatshahi-Pirouz, F. Edalat, H. Bae, Y. Yang, Directed endothelial cell morphogenesis in micropatterned gelatin methacrylate hydrogels, Biomaterials 33(35) (2012) 9009-9018.

[37] A.M. Greiner, A. Sales, H. Chen, S.A. Biela, D. Kaufmann, R. Kemkemer, Nano-and microstructured materials for in vitro studies of the physiology of vascular cells, Beilstein journal of nanotechnology $7(1)$ (2016) 1620-1641.

[38] Y. Lin, Y. Shao, J. Li, W. Zhang, K. Zheng, X. Zheng, X. Huang, Z. Liao, Y. Xie, J. He, The hierarchical micro-/nanotextured topographies promote the proliferation and angiogenesisrelated genes expression in human umbilical vein endothelial cells by initiation of Hedgehog-Gli1 signaling, Artificial cells, nanomedicine, and biotechnology 46(sup3) (2018) S1141-S1151.

[39] N.L. Kanagy, C. Szabo, A. Papapetropoulos, Vascular biology of hydrogen sulfide, American Journal of Physiology-Cell Physiology 312(5) (2017) C537-C549.

[40] C. Szabó, A. Papapetropoulos, Hydrogen sulphide and angiogenesis: mechanisms and applications, British journal of pharmacology 164(3) (2011) 853-865.

[41] T. Li, B. Zhao, C. Wang, H. Wang, Z. Liu, W. Li, H. Jin, C. Tang, J. Du, Regulatory effects of hydrogen sulfide on IL-6, IL-8 and IL-10 levels in the plasma and pulmonary tissue of rats with acute lung injury, Experimental biology and medicine 233(9) (2008) 1081-1087.

[42] L. Liu, H. Liu, D. Sun, W. Qiao, Y. Qi, H. Sun, C. Yan, Effects of H2S on myogenic responses in rat cerebral arterioles, Circulation Journal 76(4) (2012) 1012-1019. 
[43] W. Zhao, J. Zhang, Y. Lu, R. Wang, The vasorelaxant effect of $\mathrm{H} 2 \mathrm{~S}$ as a novel endogenous gaseous KATP channel opener, The EMBO journal 20(21) (2001) 6008-6016.

[44] M.M. Gadalla, S.H. Snyder, Hydrogen sulfide as a gasotransmitter, Journal of neurochemistry 113(1) (2010) 14-26.

[45] L. Li, P. Moore, Putative biological roles of hydrogen sulfide in health and disease: a breath of not so fresh air?, Trends in pharmacological sciences 29(2) (2008) 84-90.

[46] C. Szabó, Hydrogen sulphide and its therapeutic potential, Nature reviews Drug discovery 6(11) (2007) 917.

[47] C.R. Powell, J.C. Foster, B. Okyere, M.H. Theus, J.B. Matson, Therapeutic Delivery of H(2)S via COS: Small Molecule and Polymeric Donors with Benign Byproducts, Journal of the American Chemical Society 138(41) (2016) 13477-13480.

[48] L. Li, M. Whiteman, Y.Y. Guan, K.L. Neo, Y. Cheng, S.W. Lee, Y. Zhao, R. Baskar, C.-H. Tan, P.K. Moore, Characterization of a novel, water-soluble hydrogen sulfide-releasing molecule (GYY4137), Circulation 117(18) (2008) 2351-2360.

[49] L. Nicolau, R. Silva, S. Damasceno, N. Carvalho, N. Costa, K. Aragão, A. Barbosa, P. Soares, M. Souza, J. Medeiros, The hydrogen sulfide donor, Lawesson's reagent, prevents alendronateinduced gastric damage in rats, Brazilian Journal of Medical and Biological Research 46(8) (2013) 708-714.

[50] C.-M. Park, Y. Zhao, Z. Zhu, A. Pacheco, B. Peng, N.O. Devarie-Baez, P. Bagdon, H. Zhang, M. Xian, Synthesis and evaluation of phosphorodithioate-based hydrogen sulfide donors, Molecular BioSystems 9(10) (2013) 2430-2434.

[51] C.R. Powell, K. Kaur, K.M. Dillon, M. Zhou, M. Alaboalirat, J.B. Matson, Functional NSubstituted N-Thiocarboxyanhydrides as Modular Tools for Constructing H2S Donor Conjugates, ACS chemical biology (2019).

[52] A. Papapetropoulos, A. Pyriochou, Z. Altaany, G. Yang, A. Marazioti, Z. Zhou, M.G. Jeschke, L.K. Branski, D.N. Herndon, R. Wang, Hydrogen sulfide is an endogenous stimulator of angiogenesis, Proceedings of the National Academy of Sciences 106(51) (2009) 21972-21977.

[53] L. Coultas, K. Chawengsaksophak, J. Rossant, Endothelial cells and VEGF in vascular development, Nature 438(7070) (2005) 937.

[54] M. Grunewald, I. Avraham, Y. Dor, E. Bachar-Lustig, A. Itin, S. Yung, S. Chimenti, L. Landsman, R. Abramovitch, E. Keshet, VEGF-induced adult neovascularization: recruitment, retention, and role of accessory cells, Cell 124(1) (2006) 175-189.

[55] W.J. Lamoreaux, M.E. Fitzgerald, A. Reiner, K.A. Hasty, S.T. Charles, Vascular endothelial growth factor increases release of gelatinase $A$ and decreases release of tissue inhibitor of metalloproteinases by microvascular endothelial cellsin vitro, Microvascular research 55(1) (1998) 29-42.

[56] A. Sahni, C.W. Francis, Vascular endothelial growth factor binds to fibrinogen and fibrin and stimulates endothelial cell proliferation, Blood 96(12) (2000) 3772-3778.

[57] J. Oswald, S. Boxberger, B. Jørgensen, S. Feldmann, G. Ehninger, M. Bornhäuser, C. Werner, Mesenchymal stem cells can be differentiated into endothelial cells in vitro, Stem cells 22(3) (2004) 377-384.

[58] N. Ferrara, Molecular and biological properties of vascular endothelial growth factor, Journal of molecular medicine 77(7) (1999) 527-543.

[59] T.R. Chan, P.J. Stahl, S.M. Yu, Matrix-bound vegf mimetic peptides: design and endothelialcell activation in collagen scaffolds, Advanced functional materials 21(22) (2011) 4252-4262.

[60] L.D. D'Andrea, G. Iaccarino, R. Fattorusso, D. Sorriento, C. Carannante, D. Capasso, B. Trimarco, C. Pedone, Targeting angiogenesis: structural characterization and biological properties of a de novo engineered VEGF mimicking peptide, Proceedings of the National Academy of Sciences 102(40) (2005) 14215-14220.

[61] F. Finetti, A. Basile, D. Capasso, S. Di Gaetano, R. Di Stasi, M. Pascale, C.M. Turco, M. Ziche, L. Morbidelli, L.D. D'Andrea, Functional and pharmacological characterization of a VEGF mimetic peptide on reparative angiogenesis, Biochemical pharmacology 84(3) (2012) 303-311.

[62] F. Zhou, X. Jia, Y. Yang, Q. Yang, C. Gao, Y. Zhao, Y. Fan, X. Yuan, Peptide-modified PELCL electrospun membranes for regulation of vascular endothelial cells, Materials Science and Engineering: C 68 (2016) 623-631.

[63] J.E. Leslie-Barbick, J.E. Saik, D.J. Gould, M.E. Dickinson, J.L. West, The promotion of microvasculature formation in poly (ethylene glycol) diacrylate hydrogels by an immobilized VEGF-mimetic peptide, Biomaterials 32(25) (2011) 5782-5789.

[64] X. Wang, A. Horii, S. Zhang, Designer functionalized self-assembling peptide nanofiber scaffolds for growth, migration, and tubulogenesis of human umbilical vein endothelial cells, Soft Matter 4(12) (2008) 2388-2395. 
[65] M.J. Webber, J. Tongers, C.J. Newcomb, K.-T. Marquardt, J. Bauersachs, D.W. Losordo, S.I. Stupp, Supramolecular nanostructures that mimic VEGF as a strategy for ischemic tissue repair, Proceedings of the National Academy of Sciences 108(33) (2011) 13438-13443.

[66] S.P. Parthiban, D. Rana, E. Jabbari, N. Benkirane-Jessel, M. Ramalingam, Covalently immobilized VEGF-mimicking peptide with gelatin methacrylate enhances microvascularization of endothelial cells, Acta biomaterialia 51 (2017) 330-340.

[67] T.R. Chan, P.J. Stahl, Y. Li, S.M. Yu, Collagen-gelatin mixtures as wound model, and substrates for VEGF-mimetic peptide binding and endothelial cell activation, Acta biomaterialia 15 (2015) 164-172. 


\section{Valorisation}


In this chapter, an attempt is made to discuss the clinical and commercial value of our findings and how they can be translated into the clinic in the field of tissue engineering and regenerative medicine. The final goal of our scientific output is to transfer the research findings into practice, via which they can contribute to clinical and commercial application. The application to generate value in this process is called "valorisation". The development of tissue engineering scaffolds are likely to bring clinical and commercial benefits to the society. Our study on fabrication of self-assembled honeycomb scaffolds to induce angiogenesis in Chapter 4 showed high potential for valorisation.

\section{Clinical and commercial relevance}

The biomedical research has risen rapidly because people could benefit from it. The life expectancy of young generation is increasing and the chronic disability of old people is decreasing, these trends is mainly due to the fast development of biomedical technologies [1]. Our society emphasizes the importance of biomedical development and has spent lots of money in biomedical research. For example, the estimated yearly cost of pharmaceutical, biotechnology, and medical companies on biomedical research is more than $\$ 60$ billion worldwide [2]. Despite some biomedical products have shown initial successes in translating from the lab to the clinic, the ability to regenerate complex tissue/organ is still one of the great challenges for clinical use [3]. In tissue engineering, cells from patients are seeded into an appropriate 3D scaffold to generate the tissue construct. However, the lack of adequate and fast vascularization often lead to cell death after seeding [4]. The formation of new tissue constructs needs blood vessels to continuously supply oxygen and nutrition [5]. Insufficient blood supply limits the size of tissue-engineered constructs and results in failure of translation [6]. In order to solve this problem, we developed a self-assembled honeycomb scaffold that could afford biophysical cues to induce initial blood vessel formation. 
Honeycomb nanofibrous scaffolds created by the self-assembly of electrospun fibers could mimic the capillary network of endothelial cells (Figure 1). Some studies reported that the honeycomb-like network of endothelial cells is a very important morphogenetic feature that could simulate tube formation during angiogenesis [7, 8]. The wall of honeycomb scaffolds contains connected fiber clusters and beads, therefore allowing cells to adhere on the wall and possibly guide cell migration. In chapter 4, we showed that the fabricated honeycomb scaffolds significantly promoted HUVECs proliferation and influenced the distribution of cells. Especially, honeycomb electrospun scaffolds could regulate HUVECs morphogenesis into capillarylike structures with a central lumen.
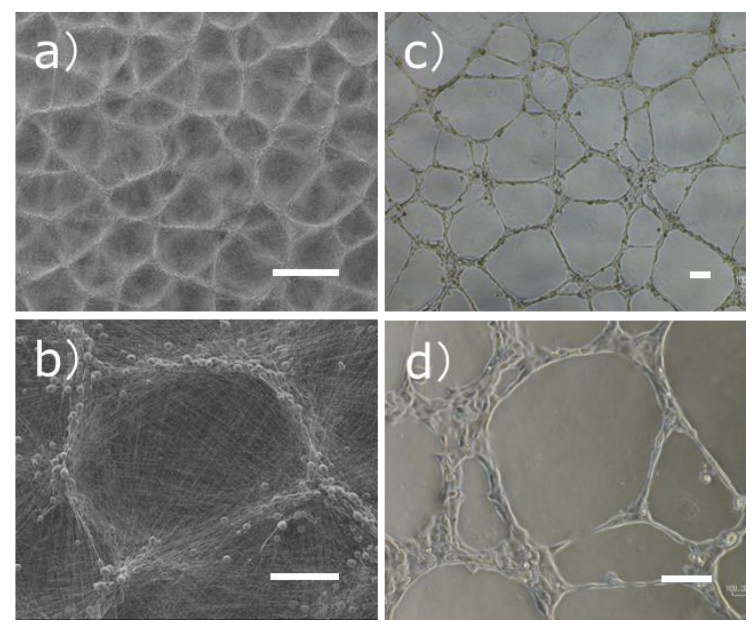

Figure 1. SEM images of honeycomb (a) PCL electrospun nanofibers. Images (c and d) showed the tube formation of HUVECs cultured on Matrigel-coated wellplate after $16 \mathrm{~h}$. Scale bars are $500 \mu \mathrm{m}(\mathrm{a})$ and $100 \mu \mathrm{m}$ (b, c and d).

\section{Target group}

Our findings on the development of honeycomb nanofibrous scaffolds for vascular tissue engineering can benefit other researchers. For example, many studies reported how geometrical cues affect endothelial cell tube formation by using micropatterned stripes. To the best of our knowledge, no study was performed so far on the influence of honeycomb patterns on tube formation. 
Here, we focused on the effect of honeycomb patterns on vessel formation. Investigating the effect of honeycomb pattern on angiogenesis will pave the way towards the fabrication of advanced angiogenic scaffolds that hold to be more promising for clinical applications. Beyond the preliminary studies that we have here reported, the efficacy and safety of honeycomb scaffolds have to be tested by further in vitro and in vivo assays, before finally being translated in patients [9]. After getting approval for clinical trials, the final products could attract the attention of investors, making it possible to enter into the market.

\section{Innovation and implementation}

Chapter 4 investigated the positive role of honeycomb patterns in promoting angiogenesis. The novelty of this study is 1) using a self-assembled electrospinning approach to fabricate a honeycomb pattern, and 2) guiding endothelial cells morphogenesis into capillary network through the honeycomb scaffolds, finally promoting tube formation. This honeycomb scaffold in principle could be used for some applications where prevascularization is highly needed to rapidly generate vascular network before implantation. Serval studies have reported the addition of endothelial cells sheets for vascularized bone regeneration [10, 11]. During prevascularization, human mesenchymal stromal cells (hMSCs) are seeded on honeycomb scaffolds and human umbilical vein endothelial cells (HUVECs) are seeded on the top of hMSCs in order to generate vascularized tissue constructs. The geometric cues of honeycomb scaffolds could accelerate the initial vascular network formation. This could shorten the time during which tissue construct suffers from hypoxia and lack of nutrition.

The honeycomb scaffolds are made from poly(caprolactone), which has been approved by Food and Drug Administration (FDA) and already used in patients as drug delivery devices and sutures. Furthermore, to fabricate thermal-triggered cells sheets, honeycomb patterns could be produced from electrospinning of thermosresponsive polymers (e.g. pNIPAAm). After using 
such honeycomb thermal scaffolds, cultured endothelial layers or mixtures of endothelial cells with other cell types could be easily harvested by changing temperature. This improvement could be more promising for tissue implantation.

Our findings has only been proved by in vitro studies, so that the application of honeycomb scaffolds in vivo should be further investigated. The next step is to perform animal tests to confirm the efficacy and safety of honeycomb scaffolds on angiogenesis. If our results were confirmed in larger animal tests, these honeycomb scaffolds would then be eligible for further clinical experimentation, after having passed regulatory and medical ethical approval. Clinical testing without significant side effects or safety issues would provide these scaffolds a chance to secure further investment for introduction into the market. Another potential value of our findings is that researchers may also consider the role of geometric cues when designing biomaterials for vascular regeneration. Especially, highly vascularized tissues may require the fast formation of blood vessels to support regeneration. 


\section{References}

[1] D.M. Cutler, A.B. Rosen, S. Vijan, The value of medical spending in the United States, 19602000, New England journal of medicine 355(9) (2006) 920-927.

[2] E.R. Dorsey, J. De Roulet, J.P. Thompson, J.I. Reminick, A. Thai, Z. White-Stellato, C.A. Beck, B.P. George, H. Moses, Funding of US biomedical research, 2003-2008, Jama 303(2) (2010) 137143.

[3] P.S. Briquez, L.E. Clegg, M.M. Martino, F. Mac Gabhann, J.A. Hubbell, Design principles for therapeutic angiogenic materials, Nature Reviews Materials 1(1) (2016) 15006.

[4] X. Guo, C.G. Elliott, Z. Li, Y. Xu, D.W. Hamilton, J. Guan, Creating 3D angiogenic growth factor gradients in fibrous constructs to guide fast angiogenesis, Biomacromolecules 13(10) (2012) 3262-3271.

[5] J. Rouwkema, A. Khademhosseini, Vascularization and angiogenesis in tissue engineering: beyond creating static networks, Trends in biotechnology 34(9) (2016) 733-745.

[6] M. Lovett, K. Lee, A. Edwards, D.L. Kaplan, Vascularization strategies for tissue engineering, Tissue Engineering Part B: Reviews 15(3) (2009) 353-370.

[7] D. Nagata, M. Mogi, K. Walsh, AMP-activated protein kinase (AMPK) signaling in endothelial cells is essential for angiogenesis in response to hypoxic stress, Journal of Biological Chemistry 278(33) (2003) 31000-31006.

[8] H.-J. Park, Y. Zhang, S.P. Georgescu, K.L. Johnson, D. Kong, J.B. Galper, Human umbilical vein endothelial cells and human dermal microvascular endothelial cells offer new insights into the relationship between lipid metabolism and angiogenesis, Stem cell reviews 2(2) (2006) 93101.

[9] E.T. Pashuck, M.M. Stevens, Designing regenerative biomaterial therapies for the clinic, Science translational medicine 4(160) (2012) 160sr4-160sr4.

[10] R.P. Pirraco, T. Iwata, T. Yoshida, A.P. Marques, M. Yamato, R.L. Reis, T. Okano, Endothelial cells enhance the in vivo bone-forming ability of osteogenic cell sheets, Laboratory Investigation 94(6) (2014) 663-673.

[11] T. Sasagawa, T. Shimizu, S. Sekiya, M. Yamato, T. Okano, Comparison of angiogenic potential between prevascular and non-prevascular layered adipose-derived stem cell-sheets in early post-transplanted period, Journal of Biomedical Materials Research Part A: An Official Journal of The Society for Biomaterials, The Japanese Society for Biomaterials, and The Australian Society for Biomaterials and the Korean Society for Biomaterials 102(2) (2014) 358-365. 


\section{Summary}

The use of tissue-engineered scaffolds has found widespread applications in the field of regenerative medicine for the treatment of injured tissues. In my thesis, I focus on the fabrication of scaffolds for vascularized tissue regeneration. Chapter 1 describes recent literature review on advanced nanofibrous scaffolds, which are widely used in tissue engineering. Especially, electrospun scaffolds for promoting vascular tissue regeneration has been introduced in more details. According to the review we described in chapter 1, many requirements should be considered for designing angiogenic scaffolds. First, an ideal scaffold should be biomimetic to the native targeted tissue. Second, the scaffolds should deliver angiogenic factors. Therefore, in chapter 2-6 we investigated a few different design options to create biomimetic nanofibrous scaffolds and immobilize angiogenic factors on them.

Chapter 2 describes the investigation of polycaprolactone (PCL) aligned fibers and co-culture with human umbilical endothelial cells (HUVECs) on the osteogenic differentiation of mesenchymal stromal cells (hMSCs). The main results demonstrated that aligned structure strongly influenced the morphology and orientation of cells, yet without interfering with the osteogenic differentiation of hMSCs. Moreover, co-culture with endothelial cells showed a positive influence to the osteogenesis of hMSCs.

Chapter 3 presents a simple and effective method to fabricate honeycomb nanofibrous meshes. This self-assembly method could produce honeycomb nanofibrous meshes with controllable diameter by adjusting electrospinning processing parameters. Gradients honeycomb meshes ranging from $800 \mu \mathrm{m}$ to $300 \mu \mathrm{m}$ were successfully fabricated. Structural gradients can be found mainly in interface tissues. The concept of gradient scaffolds has been applied to mimic complex gradients found in native interface tissues, such as bonecartilage interfaces. Gradient honeycomb scaffolds may provide structural 
cues to guide cells to migrate or differentiate, which may be beneficial for interface tissue regeneration.

In chapter 4 , the influence of a honeycomb pattern on endothelial cell morphogenesis is discussed. Honeycomb nanofibrous scaffolds proved to promote cell proliferation and regulate HUVECs morphogenesis into capillarylike structures. HUVECs generated stronger cohesion and cell-cell junctions when cultured on honeycomb scaffolds. Therefore, this scaffold is promising for those tissue engineering applications demanding the formation of capillary networks.

Hydrogen sulfide $\left(\mathrm{H}_{2} \mathrm{~S}\right)$, a unique gasotransmitter, has been considered as a signaling molecule to modulate angiogenesis. In chapter $\mathbf{5}$, we demonstrated a method for bonding NTAs (N-thiocarboxyanhydrides, an $\mathrm{H}_{2} \mathrm{~S}$ donor) on fibrous scaffolds by azide-alkyne click conjugation. These experiments showed a new strategy to fabricate $\mathrm{H}_{2} \mathrm{~S}$ releasing fibrous scaffolds by conjugating NTAs, as other strategies providing $\mathrm{H}_{2} \mathrm{~S}$ in culture focused on traditional $\mathrm{H}_{2} \mathrm{~S}$ donors (e.g. sulfide salts, $\mathrm{NaSH}$ and $\mathrm{Na}_{2} \mathrm{~S}$ ), which are hard to control and often cause burst release. The use of NTAs as $\mathrm{H}_{2} \mathrm{~S}$ donors could result in controlled and sustained release. The NTA functionalized scaffolds supported better cell proliferation and formed more rapidly a confluent endothelial monolayer than non-functionalized scaffolds. A chicken chorioallantoic membrane (CAM) assay indicated a significant increase in vascular growth on NTA scaffolds in vivo. The NTA-functionalized scaffolds could, therefore, offer a biochemical route towards promoting angiogenesis for vascularized tissue regeneration.

Vascular endothelial growth factor (VEGF) has been widely reported to stimulate endothelial cell proliferation and tube formation. VEGF-mimetic peptides have the ability to activate VEGF receptors, therefore possessing similar bioactivity of VEGF. In chapter 6 , we prepared VEGF peptide functionalized fibrous scaffolds by thiol-ene click chemistry. In vitro studies proved that the VEGF peptide functionalized fibrous scaffolds significantly 
maintained higher HUVECs survival compared with non-functionalized scaffolds in starving conditions. HUVECs cultured on both VEGF peptide functionalized scaffolds and unfunctionalized scaffolds activated VEGFR1 and VEGFR2 phosphorylation. Moreover, spatial control of the fibrous scaffolds functionalization is another advantage of using the photochemically promoted radical thiol-ene conjugation. Photopatterning experiments showed the potential of using photomasks to spatially control the presentation of the VEGF-mimetic peptide used in these studies.

A general discussion of our results and future perspectives are introduced in chapter 7. The valorization potential along with future applications of this research is described in chapter 8. 
206 


\section{Acknowledgements}

I would like to acknowledge the contribution of "China Scholarship Council (CSC)". Without their support and funding, I could not have this opportunity to study abroad.

Foremost, I would like to express my sincere gratitude to my supervisors, Prof. Lorenzo Moroni and Dr. Matthew B. Baker, for the continuous support of my PhD study and research. Prof. Lorenzo Moroni, much appreciated for giving me an opportunity to study in your group. You teach me a lot, from basic experiment to data analysis. Thank you for your patient. Especially when encountering problems during my experiments, I always feel very disappointed, but you are always optimism and tell me "not so bad". Your continuous encouragement have been a great motivation to me. Dr. Matthew B. Baker, thank you very much for having me in your synthesis group. Although I did not do that that much chemical synthesis, I learned a lot of chemistry knowledge from group meeting. You always teach us to analyze NMR data. That is quite useful for me. I was very impressed that you could always catch some big mistake (polymer structure, unit....) in my manuscript that I could not notice. Thank you for your constant support and all your feedback on my work.

Besides my supervisors, I would also like to thank the members of my thesis evaluation committee: Prof. Dr. Tilman M. Hackeng (Chairman), Prof. Dr. Mark Post, Prof. Dr. Leon Schurgers, Prof. Dr. Carlijn Bouten, and Dr. Fang Yang. Thank you so much for spending time and effort to read my thesis, and thank you for all comments and suggestions.

My sincere thanks also goes to our collaborators. Dr. John B. Matson, Ryan Carrazzone, Chadwick Powell, for offering me the $\mathrm{H}_{2} \mathrm{~S}$ donor and helping the measurements of $\mathrm{H}_{2} \mathrm{~S}$ release. Thanks to Prof. Tim G.A.M. Wolfs and Lilian Kessels for giving me an opportunity to perform CAM assay on my scaffolds and leading me working on in vivo experiments. 
Next, many thanks also goes to my dear colleagues: Maria, my paranymph, also my best friend. I feel so lucky to meet you during my PhD. We always have lunch together. I can talk about anything with you. Thanks for your listening. haha. You are so kind and always offer help to me. It is great to have you around in MERLN. I still could remember we went to join Zumba together at the beginning of our PhD. You always drive me home after Zumba class. It makes me feel not alone here. You always share and introduce delicious food with me when you back from Spain. Thanks for all the happiness you bring to me. You are always hard working and well-prepared for everything, so I am sure you will have a happy life and successful career in the future. Clarrisa, thanks for being another paranymph in my defense. You always bring lots of fun to me, that is why I really like to talk with you. Enjoy your time in MERLN, and good luck with your PhD journey.

Rabeil, I was impressed that you were quite smart when we were in Japan. Thanks for finding the way for us in Japan. I still could remember nice time we spent there. You are so kind and considerate of others. I really enjoy the time staying with you. Pinak, my neighbor, I still could remember everyday we went home together with Honglin. It is so nice to have you to be my neighbor. Thanks for explaining me all the letters from rental company. Thanks for your help with honeycomb measurements. Afonso, you are so kind-hearted, thank you for always helping me with my experiments, especially helping me to prove tubular structure from images. Paul, my Image $\mathrm{J}$ teacher, always help me with Image J, from updating software to writing a script. Thanks for all your help. Carlos, thank you for giving me suggestions in my experiments. Ravi, you always kindly remind me "how is the blood vessels growing on the scaffolds?". Finally, it form vessels. I really like to discuss with you about my experiments. Your suggestions help me a lot. Sandra, you are a smart person with a lot of research experience. I could ask you any questions, from cell study to chemistry functionalization, even animal study. Seems you did all the experiments I could think of. Thanks for guiding me with my experiments. Tobias, I still could remember we did electrospinning together. Although there 
is no good results, we had a lot of fun, with electrospun films flying around. Thanks for bring me funny time. Shahzad, thanks for offering me PCL-N $\mathrm{N}_{3}$, your chemistry support make my experiment much easier. I also would like to thank my master student, Teun. Thanks for helping me on $\mathrm{H}_{2} \mathrm{~S}$ chapter. David, thanks for introducing Dil-Ac-LDL dye, it is really useful to my coculture study. In addition, my thanks are extended to all my other colleagues and friends in MERLN: Jip, Kenny, Tristan, Rebecca, Ivo, Floor, Francis, Tony, Amit, Shevish, Vahid, Andrea, Mirco, Adrián, and other MERLNers.... I deeply appreciate the time spent with all of you, and thanks to all of you for giving me such a beautiful memory, one that I will cherish for a lifetime.

Last but not the least, I would like to use my native language to thank my Chinese friends, teacher and my family. 首先要感谢我硕士时的导师, 王进义 教授，感谢王老师帮我写推荐信，让我有机会能出国读博。王老师认真的科研 态度也是我一直的学习榜样, 感谢王老师的培养。洪林师兄, 唯一一个亲师兄, 你是我来 MERLN 之前联系的最多的人, 我们同一个导师, 有着相似的经历。感谢你 给我的所有帮助，从最开始的融入，到课题的设计，毕业，再到找工作。我不管遇到 什么问题，总想告诉你，先听听你的意见，而你总是很耐心的解答我所有问题。你的 科研实力很强, 我却常常望尘莫及。每次看到你发的文章, 心中也很是敬佩。同时你 的优秀也一直激励着我, 让我不断学习。祝你科研顺利, 和敏敏师姐一直幸福下去。 冰涛, 你是我来马城第一个见到的“亲人”。我们相识于本科, 虽然不同专业, 但是因为 一起跳健美操逐渐熟悉。并且大家都顺利读研，再到最后一起出国读博，又到同一所 大学, 这些轨迹都是不谋而合。我们总是能聊很多, 过去, 现在, 未来.......你一直那 么贴心, 让我觉得很温暖。特别是在我刚来马城的时候, 总是叫我去你家吃饭, 做很 多好吃的给我, 让我觉得无比感动。你和张超的爱情长跑也让人羡慕, 最终你们一起 进入山大工作，祝你们事业顺利，家庭美满。

练慈，张明，辛莹。我们四年来一直相互陪伴，相互鼓励，让我们在国外的生活不再 孤单, 并且有满满的正能量一起前行。练慈, 我们第一次见面是在北京, 记得你很贴 心的帮我订好酒店, 随后我们一起飞荷兰，坐火车去马城，一路上幸好有彼此的陪伴。 就算是坐错车, 走错路, 也互相调㑆着我们的“马圆”旅程。我已经不记得刚来的时候有 多么不容易, 只记得我们那时的欢声笑语。即使随后你转去了乌特, 我们的友谊也从 
未改变。虽然你是重庆妹儿, 但却内心细淢, 十分文艺。你喜欢看书, 喜欢文学作品, 诗集。我们也会彼此推荐自己喜欢的书, 看完还相互讨论, 吐槽, 每次聊完都会感觉 收获满满。你有很多优点, 只有相处时间长了才会发现。希望你早点遇到能读懂你的 那个他。小明, 第一次见你是在学校, 那也是你第一天到马城, 记得一见面你就给我 了个大大的拥抱。你活泼开朗, 乐于助人, 幽默风趣, 总是能给我们带来好多欢乐。 每次遇到问题, 我也喜欢向你倾诉, 听听你的意见。你总是能抓住重点, 给出有效的 意见。现在你和你老公彦兵已经开始了你们在荷兰婚后新生活, 祝你们工作顺利, 爱 情甜蜜。还要同样感谢彦兵, 厨艺真好, 每次去你们家都是在改善伙食, 给你点赞。 小莹, 我的邻居。我已经记不得第一次见你是什么时候, 只记得在我搬来你对门后, 你给我做的第一顿早餐, 那时觉得幸福满满。之后我们约着一起上下班, 一起做饭, 一起加班, 一起逛街, 一起旅游, 真的是形影不离。谢谢你让我在国外的生活不孤单。 你是那么贴心, 温柔善良, 又那么包容, 善解人意, 让我觉得我是多么幸运能遇到这 么好的邻居。现在你和高芳生活也已经步入正轨, 祝你们早点结束异地, 生活幸福美 满。

李老师, 在 MERLN 您像是老师, 又是朋友。实验上遇到问题时, 你总能给我们很多意 见, 提供很多帮助。假期来临, 又总会告诉我们荷兰哪儿好玩, 给我们推荐旅游景点。 很感谢李老师在我四年来给与的所有帮助。也祝你工作顺利, 事事顺心。荣师姐, 第 一次见师姐是你来组里做 presentation, 当时就觉得师姐很优秀, 英语流利, 报告思路 清晰, 思维活跃。随后你顺利来到组里做博后, 是你建立了我们的“小圈子”, 带我去参 加小圈子的各种活动。我们一起做实验, 讨论实验, 科研上你也给我了很大帮助, 给 我了很多建议。师姐在荷兰也有了自己的公司, 在我心里就是令人羡慕的女强人。祝 EGGXPERT 蓬勃发展。永刚, 你很安静, 工作总是那么勤奋认真。祝你实验顺利, 多 发 paper! 还有东琴, 幸真, 晶晶, 天然, 你们来的时候我差不多即将毕业, 也祝你们 在 MERLN 科研顺利，天天开心。

徐青师姐, 宗盛华师兄, 很高兴能认识你们。你们比我高一级, 所以不管是工作还是 生活, 总是能给我很多帮助, 让我感觉像家人一样温暖。感谢你们给我的所有帮助。 祝你们工作顺利, 小玉米健康快乐。萍姐, 谢谢你的热心款待, 谢谢开美的画, 祝你 们永远开心快乐。乔奇, 你乐观的态度, 还有你对工作带的认真勤奋, 让我相信你一 定能收获你想要的。在我博士最后阶段, 你总是鼓励我, 给我信心, 让我非常感动, 
感谢遇到你。雯婕, 记得以前我们一起游泳 Zumba 旅游, 很多人在一起玩的很开心, 印象深刻的是你的欢笑, 谢谢你带来的所有快乐。还有很多的人要感谢, 安宁, 张硕 师兄，蜀金，荣辉，龚英，笑迪，顺金金 谢谢你们给与我的所有帮助, 祝你们科 研顺利，开心快乐。

最后我要感谢的家人。妈咪，谢谢你多年来对我的照顾和关心。从我决定出国，我就 知道你心里的所有顾虑, 你担心我在国外会孤单, 你担心我一个人在国外会不安全, 而我总是向你积极展现出坚强勇敢的那一面, 说服你同意我的决定。出国后无论是学 习上的困扰，还是感情上的问题，我总是会向你诉说，你也会耐心倾听，给我建议。 你总是默默支持，鼓励着我，也指导着我，你对我的爱也是我不断向前的动力，让我 遇到什么困难都不会退缩。谢谢你让我深刻体会到了伟大的母爱。老爸, 你言语很少, 每次打电话都只是简单问候，但是简短的几句话，也能让我在国外备感温暖。你工作 认真, 勤劳善良, 默默为家里奉献着, 任劳任怨, 这些简单淳朴的品质也是我学习的 榜样。你总是那么信任我，相信并支持我的所有决定。父爱如山，你的父爱是深沉严 肃的，谢谢你给与了我深沉的父爱。爸妈，作为父母，你们总是想给我最好的，其实 你们已经给与我太多, 健康快乐, 关心陪伴, 温暖的家就是你们给我的最大财富。我 时常觉得自己真的是太幸运，遇到这么好的父母，教会我很多，还给我了一个温暖有 爱的幸福家庭, 想想就觉得很幸福, 很知足。最后, 我想感谢那个坚强勇敢的自己, 是自己的坚强勇敢支撑着我不断前行, 努力成为更好的自己。(-) 
212 


\section{Scientific output}

\section{List of publications}

- Yao, T., Chen, H., Baker, M. B., \& Moroni, L. (2020). Effects of Fiber Alignment and Coculture with Endothelial Cells on Osteogenic Differentiation of Mesenchymal Stromal Cells. Tissue Engineering Part C: Methods, 26(1), 11-22.

- Yao, T., Chen, H., Samal, P., Giselbrecht, S., Baker, M. B., \& Moroni, L. (2019). Self-assembly of electrospun nanofibers into gradient honeycomb structures. Materials \& Design, 168, 107614.

- Yao, T., Baker, M. B., \& Moroni, L. (2020) Strategies to Improve Nanofibrous Scaffolds for Vascular Tissue Regeneration. Nanomaterials (major revision).

- Yao, T., Wieringa P. A., Chen, H., Samal, P., Giselbrecht, S., Baker, M. B., \& Moroni, L. (2020) Fabrication of a Self-assembled Honeycomb Nanofibrous Scaffold to Guide Endothelial Morphogenesis. Biofabrication (under review).

- Yao, T., Nunen, Powell, C., Carrazzone, R., Wieringa P. A., Hafeez, S., Kessels, L., Wolfs, T. G.A.M., Matson J. B., Moroni, L., \& Baker, M. B. (2020) Electrospun fibrous Scaffolds Functionalized with Hydrogen Sulfide Donor Stimulate Angiogenesis (In preparation).

- Yao, T., Wang, R., Rivero, R., Kessels, L., Wolfs, T. G.A.M., Baker, M. B., \& Moroni, L. (2020) Thiol-ene Click Conjugation of VEGF Peptide to Electrospun Scaffolds as Potential Application for Angiogenesis (In preparation). 


\section{Conferences}

- 7th China-Europe Symposium on Biomaterials in Regenerative Medicine (2019 CESB, Guangzhou, China), Oral Presentation

- The 5th TERMIS World Congress (2018 TERMIS-WC, Kyoto, Japan), Poster Presentation

- The 29th conference of the European Society for Biomaterials (2018 ESB, Maastrictht, Netherlands), Poster Presentation.

- Chemistry As Innovating Science (2017 CHAINS, Eindhoven, Netherlands), Poster Presentation. 


\section{Curriculum vitae}

Tianyu Yao was born on the 15th of August 1987 in Hanyin, a beautiful town in Shaanxi province of China. Tianyu started her study Pharmacy Engineering at Northwest A\&F University in 2007 and received her bachelor degree in June, 2011. After that, she continued her Master education in the major of chemical biology at Northwest A\&F University. Her Master thesis was entitled " $\mathrm{SiO}_{2}$ nanoparticles and diphenylcarbazide doped polymethylmethacrylate electrospun fibrous film for $\mathrm{Cd}^{2+}$ colorimetric detection", under supervision of Prof. Jinyi Wang. In September 2015, she started her PhD research at the MERLN institute in Maastricht University under supervision of Prof. Lorenzo Moroni and Prof. Matthew B. Baker. Her research was focused on the fabrication of advanced nanofibrous scaffolds for vascularized tissue regeneration and the result are described in this thesis.

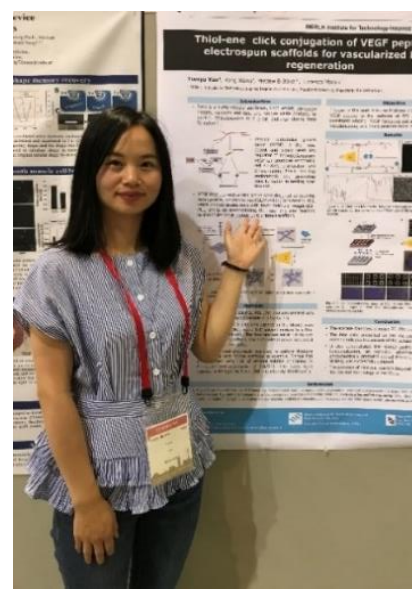


216 